\title{
WestVirginiaUniversity
}

THE RESEARCH REPOSITORY @ WVU

Graduate Theses, Dissertations, and Problem Reports

1999

\section{Aging and design of concrete members reinforced with GFRP bars}

P. V. Vijay

West Virginia University

Follow this and additional works at: https://researchrepository.wvu.edu/etd

\section{Recommended Citation}

Vijay, P. V., "Aging and design of concrete members reinforced with GFRP bars" (1999). Graduate Theses, Dissertations, and Problem Reports. 3138.

https://researchrepository.wvu.edu/etd/3138

This Dissertation is protected by copyright and/or related rights. It has been brought to you by the The Research Repository @ WVU with permission from the rights-holder(s). You are free to use this Dissertation in any way that is permitted by the copyright and related rights legislation that applies to your use. For other uses you must obtain permission from the rights-holder(s) directly, unless additional rights are indicated by a Creative Commons license in the record and/ or on the work itself. This Dissertation has been accepted for inclusion in WVU Graduate Theses, Dissertations, and Problem Reports collection by an authorized administrator of The Research Repository @ WVU.

For more information, please contact researchrepository@mail.wvu.edu. 


\title{
AGING AND DESIGN OF CONCRETE MEMBERS \\ REINFORCED WITH GFRP BARS
}

\author{
By \\ P.V. Vijay
}

\section{DISSERTATION}

\author{
Submitted to the \\ College of Engineering and Mineral Resources \\ at West Virginia University \\ in partial fulfillment of the requirements \\ for the degree of
}

\section{Doctor of Philosophy \\ in \\ Civil Engineering}
Hota V.S. GangaRao, Ph.D., CEE, Chair. Larry Luttrell, Ph.D., CEE.
Rakesh Gupta, Ph.D., Ch.E.
Roger Chen, Ph.D., CEE.
Timothy Norman, Ph.D., MAE.
Department of Civil Engineering
West Virginia University
Morgantown, West Virginia
1999

Keywords: Aging, Concrete, GFRP, Creep, Bending, Knock-down factor.

Copyright 1999 P.V. Vijay 


\section{ABSTRACT \\ AGING AND DESIGN OF CONCRETE MEMBERS \\ REINFORCED WITH GFRP BARS}

\section{By P.V.Vijay}

Strength and stiffness properties of GFRP bars and moisture transport phenomenon into the bars was investigated in this research for various conditioning schemes with and without the application of sustained loads. Low viscosity urethane modified vinylester resin is identified as the most suitable resin, from the durability viewpoint.

Based on accelerated test results calibrated with respect to naturally aged results it is safely concluded that the service life of the FRP bars with durable resin is about 60 years as a minimum with $20 \%$ sustained stress on the bar. Concrete cover protection on the GFRP bars enhanced the service life up to an additional 60 years. Bond strengths between concrete and GFRP did not decrease under salt and tap water immersion of pull-out specimens subjected to freeze-thaw variations. Compression failure philosophy has been developed for moment resistance and serviceability limit states were established based on curvature limit of $0.005 / \mathrm{d}$, which unifies other limit states such as crack-width and deflection. Average bond strain of $0.006 \mathrm{in}$./in. for GFRP stirrups provides good theoretical correlation with experimental results on shear capacity from this research as well as those of others.

From this research it is evident that despite reduction in the properties of GFRP bars over time in the concrete environment, moment capacities of the beams were not affected provided compression failure philosophy is used. Advantages of compression failure over tension failures was systematically investigated for GFRP reinforced concrete beams under both static and fatigue loads. Reduction in the moment capacity of GFRP reinforced concrete beam designed for tension failure and vulnerability against fatigue loads was clearly demonstrated. Maximum concrete strains at working loads should be preferably well below $750 \times 10^{-6}\left(25 \%\right.$ of $\left.\varepsilon_{\mathrm{cu}}\right)$ for GFRP reinforced concrete beams designed for compression failure due to fatigue considerations. In addition, conservative reduction factor of 0.75 is proposed for the time dependent factor $\xi$, used by ACI Eqn. 9-10 for the purpose of approximately estimating long-term deflections resulting from creep and shrinkage. Many findings in this investigation lead to the approval of design guidelines for FRP reinforced concrete structures through ACI 440-H. 


\section{ACKNOWLEDGEMENTS}

I wish to thank my advisor Dr. Hota V.S. GangaRao for his valuable guidance, discussions, encouragement and support during my academic program at WVU. I also wish to thank my committee members Dr. Larry Luttrell, Dr. Rakesh Gupta, Dr. Roger Chen and Dr. Timothy Norman for their valuable contribution.

I also wish to thank Mr. Rajesh Kalluri, Mr.John Bargo, Ms.Vimala Shekhar and Mr. Srinivas Aluri for their help during different stages of the experimental work. Thanks are also due to Mr. Paul Frum, Mr. Dana Humberson and Mr. Dave Turner for their laboratory help. Ms. Sharon Santos, Ms. Eleanor Neveara and Ms. Sharon Chadderton of the Constructed Facilities Center also deserve a special mention for their co-operation during this research. Monetary support from FHWA and WVDOT for this project is also acknowledged. Comments on this research work from Dr. Narendra Taly, California State University, are appreciated.

Finally, thanks are due to my beloved wife Sucharitha and daughter Aishwarya for their love, understanding and patience. My parents VenkataRayappa, B.S, and Anjana, and in-laws Bachanna and Rajeswari are thanked for their ideals, guidance, wisdom and love. My gradparents Beguru Bayyamma, late Lakshmamma and Narayanappa, C., are thanked for their abundant love and inspiration. My wonderful brothers Drs. Ravindra, P.V., Harish, P.V., and Aravind, P.V. and brothers-in-law Srinivas, B., and Swamy, B.L.N., are thanked for their unconditional love. 


\section{EXECUTIVE SUMMARY}

The aim of this research is to identify durable resin for manufacturing Glass Fiber Reinforced Polymer (GFRP) reinforcement for concrete structures and evaluating the long-term durability of GFRP bars and GFRP reinforced concrete members under different moisture (consisting of $\mathrm{pH}$ variations), temperature and stress conditions. Accelerated aging tests have been conducted on both GFRP bars and GFRP reinforced concrete beams and the results are calibrated with respect to natural weathering.

The aim and scope of this research have been described in Chapter 1. Literature on the mechanical properties of GFRP bars and behavior of concrete members reinforced with GFRP bars is reviewed in Chapter 2. In this research, low viscosity urethane modified vinylester resin was experimentally found to be having superior durability for GFRP bars among unsaturated polyesters, isocyanurate vinylesters and urethane modified vinlylesters as explained in Chapter 3. Six different conditioning schemes and seven different resin constructions were considered in this study. Sand coated bars and bars with deformed surface texture (C-Bars) were used in this study.

Moisture absorption tests on about 200 GFRP bars were conducted up to 543 days, which indicated an increase in moisture content (a maximum of $0.6 \%$ by weight) under alkaline exposure for room and freeze-thaw conditioning. Increase in moisture content under alkaline conditioning was twice those of salt or tap water immersion as explained in Chapter 4. Scanning Electron Microscopy studies are being carried out to develop moisture diffusion equations of GFRP bars in the future.

Short-term and long-term strength and stiffness properties of GFRP bars subjected to harsh combinations of environmental conditions are evaluated. Different simulated environmental conditions include: $\mathrm{pH}$ variations representing salt and alkaline solution $(3<\mathrm{pH}<13)$, freeze-thaw temperature-fluctuations $\left(-10^{0} \mathrm{~F}\right.$ to $\left.150^{\circ} \mathrm{F}\right)$ and sustained loading (none, $20 \%$ and $50 \%$ of the ultimate) that would represent in-service condition of GFRP reinforced concrete structures were evaluated as described in Chapters 4 and 5. Over 250 GFRP bars in tension (including bars extracted from aged beams) and over 100 bars in compression were tested under different conditioning schemes. Tensile strength reduction of $55 \%$ of ultimate strength was noted in 30 months due to accelerated aging under alkaline conditioning and freeze-thaw variations. These reductions were calibrated (based on Proctor's field data), and found to be approximately equivalent to a lower-bound service life of 59 years in "real life" weathering with $20 \%$ sustained 
stress. Reductions in compressive strength of bars were similar to those of tension specimens. On an average, stiffness variation was within $5 \%$ for all types of conditioning schemes in sand coated as well as C-bars.

Short-term and long-term bond or pull-out strength properties of GFRP bars in concrete cylinders under solutions of different $\mathrm{pH}$ and varying temperatures were evaluated as described in Chapter 6. In addition, bond properties of bundled GFRP bars were also evaluated. More than 60 cylinder specimens were tested as a part of this evaluation. GFRP bars were found to have better bond strength (above 2000 psi) with concrete than steel bars. No reduction in bond strength was observed under tap water or salt water conditioning at room temperature or freeze-thaw conditioning. Bond strength of bundled bars was found to be proportional to their perimeter ratios. Mathematical formulation for bond strength development is presented in this Chapter.

Short-term and/or long-term bending and shear behavior of concrete beams reinforced with GFRP bars and stirrups with or without environmental conditioning is described in Chapters 7, 8 and 9. Bending design philosophy has been based on compression failure, because of better energy absorption in compression failures for GFRP reinforced concrete members (the findings of this research on failure philosophy were adopted by ACI 440-H committee, 1999). Based on deflection and deformability limits and adequate energy absorption, unified limit state has been found to be $(0.005 / \mathrm{d}) \mathrm{rad} . / \mathrm{inch}$, where, $\mathrm{d}$ is the depth of the member. Fifty-four beams (10 ft. and $5 \mathrm{ft}$. long) were tested as a part of this study. Additional 70 beams tests by other researchers were theoretically evaluated before arriving at the above curvature to depth limit states. Mathematical formulations are provided for delineating tension and compression failure modes.

Creep and fatigue behavior of concrete beams reinforced with GFRP bars are described in Chapter 10. GFRP reinforced concrete beams under sustained loads over 500 to 800 days provided comparable creep coefficients as those in steel reinforced concrete beams. Fatigue tests for 2 million cycles (maximum concrete and FRP strain of 1250 and $4050 \mu$ in./in., respectively) indicated minimal stiffness losses when the maximum concrete strain and strain range restrictions (specification) were maintained. In addition, fatigue loading indicated catastrophic nature of failure for GFRP reinforced concrete beams designed under tension failure.

Finally, appropriate knock-down factors, which can be used in the design of concrete structures accounting for environmental conditions are suggested in individual Chapters and summarized in conclusions. 


\section{TABLE OF CONTENTS}

ACKNOWLEDGEMENTS

EXECUTIVE SUMMARY iv

TABLE OF CONTENTS Vi vi vis

LIST OF TABLES $\quad$ xvii

$\begin{array}{ll}\text { LIST OF FIGURES } & \text { xx }\end{array}$

NOTATIONS $\quad$ xxvi

$\begin{array}{ll}\text { CHAPTER } 1 & 1\end{array}$

INTRODUCTION 1

1.1 INTRODUCTION 1

1.2 OVERVIEW 2

$1.3 \quad$ OBJECTIVES AND SCOPES 3

1.3.1 Screening of Resins and Selection of Durable Resin 4

1.3.2 Moisture Absorption Tests of GFRP Bars 5

1.3.3 Strength and Stiffness Degradation of GFRP Bars 6

1.3.4 Accelerated Stress Corrosion of GFRP Bars 7

1.3.5 Bond Strength Degradation of GFRP Bars with Concrete
and Bond Strength of Bundled Bars

1.3.6 Bending Behavior of GFRP Reinforced Concrete Beam 9

1.3.7 Shear behavior of GFRP Reinforced Concrete Beams with GFRP Stirrups 
1.3.8 Concrete Beam Degradation 11

1.3.9 Concrete Beam Creep and Fatigue Study 12

1.4 NEED FOR ACCELERATED AGING RESEARCH 12

$\begin{array}{lll}1.5 & \text { SUMMARY } & 14\end{array}$

$\begin{array}{lr}\text { CHAPTER 2 } & 17\end{array}$

LITERATURE REVIEW 17

\begin{tabular}{lll}
\hline $2.1 \quad$ INTRODUCTION & 17
\end{tabular}

\begin{tabular}{lll}
\hline $2.2 \quad$ GLASS FIBERS & 18
\end{tabular}

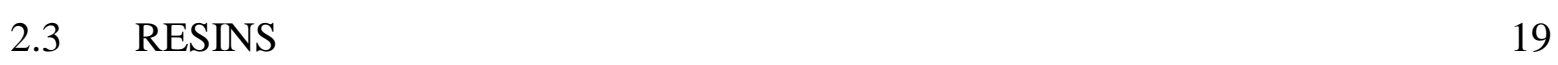

2.3.1 Thermoplastic Resins 19

2.3.2 Thermoset Resins 20

$\begin{array}{ll}\text { 2.3.2.1 Polyester Resins } & 20\end{array}$

2.3.2.2 Vinylester Resins 21

$\begin{array}{ll}\text { 2.3.2.3 Epoxy Resins } & 21\end{array}$

$\begin{array}{ll}\text { 2.3.2.4 Polyurethanes } & 21\end{array}$

2.3.2.5 Phenolic Resins 22

\begin{tabular}{lll}
\hline 2.4 & GFRP BARS & 22
\end{tabular}

$2.5 \quad$ RESEARCH ON GFRP REINFORCED CONCRETE ELEMENTS 24

$\begin{array}{lll}2.5 .1 & \text { Bending } & 24\end{array}$

2.5.2 Deflection and Crackwidth 25

$\begin{array}{lll}2.5 .3 & \text { Bond } 26\end{array}$ 
2.5.4 Shear Predictions 26

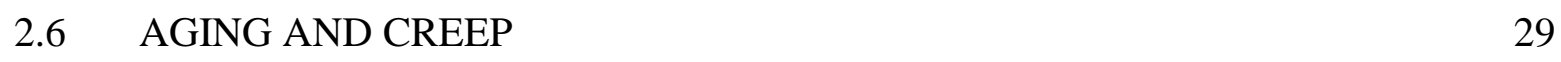

2.6.1 Time Temperature-Stress Superposition Principle 30

2.6.2 Fiber-Resin Interface 31

2.6.3 Moisture Ingress and Temperature Variations 31

2.6.4 Reaction of Composites with Chemicals 32

$\begin{array}{lll}2.6 .5 & \text { Creep } & 33\end{array}$

\begin{tabular}{|lll}
\hline 2.7 & CONCLUSIONS & 34
\end{tabular}

$\begin{array}{lll}\text { 2.7.1 GFRP Bars } & 34\end{array}$

2.7.2 GFRP Reinforced Concrete Beams 35

\begin{tabular}{|l|l}
\hline CHAPTER 3 & 37
\end{tabular}

SCREENING TESTS FOR SELECTION OF DURABLE THERMOSET RESIN 37

\begin{tabular}{lll}
\hline $3.1 \quad$ INTRODUCTION & 37
\end{tabular}

\begin{tabular}{lll}
\hline $3.2 \quad$ OBJECTIVE & 37
\end{tabular}

$3.3 \quad$ RESIN SYSTEMS AND CONDITIONING ENVIRONMENTS 38

3.3.1 Resin Systems $\quad 38$

3.3.2 Conditioning Environment and Duration $\quad 40$

$3.4 \quad$ CONDITIONING METHODS AND TESTING PROCEDURES 41

3.4.1 Unconditioned Test 41

3.4.2 Salt Test 41

3.4.3 Freeze-Thaw and Salt Test 41

3.4.4 Alkaline Test 42 
3.4.5 Freeze-Thaw and Alkaline Test 42

3.4.6 Stressed Alkaline Test 42

\begin{tabular}{lll}
\hline 3.5 & TEST PROCEDURES & 43
\end{tabular}

\begin{tabular}{|lll}
\hline 3.6 & TEST RESULTS AND DISCUSSION & 43
\end{tabular}

3.6.1 Unconditioned Test 43

3.6.2 Salt Test 45

3.6.3 Freeze-Thaw Salt Test 46

3.6.4 Alkaline Test 46

3.6.5 Freeze-Thaw and Alkaline Test 47

3.6.6 Stressed Alkaline Test $\quad 48$

\begin{tabular}{lll}
\hline $3.7 \quad$ MICROSCOPY & 53
\end{tabular}

\begin{tabular}{lll}
\hline $3.8 \quad$ CONCLUSIONS & 53
\end{tabular}

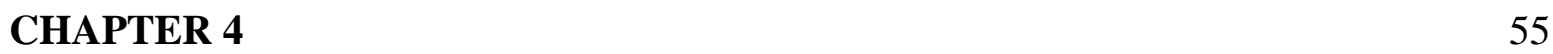

HYGROTHERMAL RESPONSE OF GFRP BARS UNDER DIFFERENT CONDITIONING SCHEMES

$\begin{array}{lll}4.1 & \text { INTRODUCTION } & 55\end{array}$

$\begin{array}{lll}4.2 & \text { OBJECTIVES } & 55\end{array}$

4.3 OVERVIEW 56

4.3.1 Fickian Diffusion 56

$\begin{array}{lll}\text { 4.3.2 } & \text { Moisture Content (M) } & 58\end{array}$

4.3.3 Diffusion Coefficient $\left(\mathrm{D}_{\mathrm{c}}\right) \quad 59$ 
\begin{tabular}{lll}
\hline $4.4 \quad$ TEST PROCEDURE & 59
\end{tabular}

4.4.1 Moisture Absorption $\quad 59$

4.4.2 Moisture and Dimension Measurements $\quad 60$

\begin{tabular}{|lll}
\hline 4.5 & TEST RESULTS AND DISCUSSION & 61
\end{tabular}

\begin{tabular}{|lll}
\hline 4.6 & CONCLUSIONS & 68
\end{tabular}

\begin{tabular}{|r|}
\hline CHAPTER 5 \\
\hline
\end{tabular}

ACCELARATED AND NATURAL WEATHERING OF GFRP BARS 69

\begin{tabular}{lll}
\hline $5.1 \quad$ INTRODUCTION & 69
\end{tabular}

\begin{tabular}{lll}
\hline 5.2 & OVERVIEW & 70
\end{tabular}

$\begin{array}{ll}\text { 5.2.1 Glass Composition } & 70\end{array}$

$\begin{array}{lll}\text { 5.2.2 Glass Corrosion } & 70\end{array}$

$\begin{array}{ll}\text { 5.2.2.1 Alkaline attack } & 70\end{array}$

$\begin{array}{ll}\text { 5.2.2.2 Acid attack } & 71\end{array}$

$\begin{array}{ll}\text { 5.2.2.3 Neutral } \mathrm{pH} \text { solution attack } & 72\end{array}$

\begin{tabular}{|ll|}
\hline 5.3 & CONDITIONING METHODS AND TESTING PROCEDURES FOR \\
& GFRP BARS
\end{tabular}

5.3.1 Salt Conditioning and Freeze-Thaw Temperature 73

5.3.2 Alkaline Conditioning at Room and Freeze-Thaw Temperatures 75

5.3.3 Stressed-Salt and Stressed-Alkaline Conditioning at Room/Freeze$\begin{array}{ll}\text { Thaw Temperatures } & 75\end{array}$

\begin{tabular}{lll}
\hline 5.4 & TENSION TEST PROCEDURES & 77
\end{tabular}

$\begin{array}{lll}5.5 & \text { TENSION TEST RESULTS AND DISCUSSIONS } & 78\end{array}$ 
$\begin{array}{lll}\text { 5.5.1 Unconditioned Test } & 78\end{array}$

5.5.2 Salt and alkaline Conditioning $\quad 82$

5.5.3 Salt and Alkaline Conditioning with Stress 82

5.5.4 Stress Corrosion at High Temperature $\quad 89$

5.6 TENSILE STIFFNESS OF GFRP BARS UNDER ACCELERATED AGING 90

$\begin{array}{lll}5.7 & \text { FAILURE MODES IN BARS UNDER TENSION } & 92\end{array}$

5.8 COMPRESSIVE STRENGTH OF AGED GFRP BARS 94

5.8.1 Compressive Strength of Aged GFRP Bars 95

5.8.2 Failure Modes in Bars under Compression 96

5.9 CORRELATION OF ACCELERATED AND NATURAL WEATHERING 97

$5.10 \quad$ LIMITATION OF LITHERLAND'S METHOD 106

\begin{tabular}{lll}
\hline 5.11 & SUMMARY & 106
\end{tabular}

5.11.1 Accelerated Aging Results on Tension Bars 106

5.11.2 Accelerated Aging Results on Compression Bars 107

5.11.3 Calibration of Accelerated and Natural Weathering 108

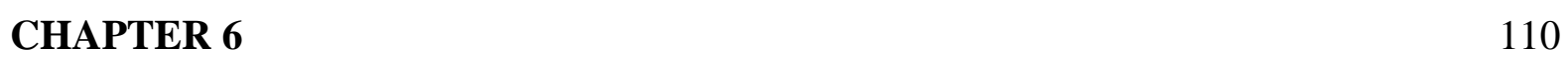

BOND BEHAVIOR OF GFRP BARS UNDER ACCELERATED AGING 110

\begin{tabular}{lll}
\hline $6.1 \quad$ INTRODUCTION & 110
\end{tabular}

\begin{tabular}{lll}
\hline 6.2 & OVERVIEW & 110
\end{tabular}

6.3 TEST SPECIMENS, INSTRUMENATION AND TEST PROCEDURES 111

6.4 TEST RESULTS AND DISCUSSION 112 
6.5 COMPARISON OF BOND STRENGTHS OF GFRP AND STEEL BARS

$7.1 \quad$ INTRODUCTION

7.2 OVERVIEW

7.3 OBJECTIVES

\begin{tabular}{lll}
\hline $7.4 \quad$ BENDING TESTS & 120
\end{tabular}

\begin{tabular}{lll}
\hline 7.5 & TEST RESULTS AND DISCUSSIONS & 121
\end{tabular}

$\begin{array}{lll}\text { 7.5.1 Failure Modes } & 121\end{array}$

$\begin{array}{ll}\text { 7.5.2 Deformability and Ductility } & 124\end{array}$

7.6 UNIFIED SERVICEABILITY CRITERIA FOR DEFORMABILITY

7.7 $\quad$ EFFECT OF COMPRESSION BARS ON MOMENT CAPACITY AND DEFORMABILITY FACTOR 128

$\begin{array}{lll}7.8 & \text { DESIGN CONSIDERATIONS } & 130\end{array}$

$\begin{array}{lll}\text { 7.8.1 Failure under Bending } & 130\end{array}$

$\begin{array}{lll}\text { 7.8.2 Balanced Failure } & 131\end{array}$

$\begin{array}{ll}\text { 7.8.2.1 Percentage reinforcement }(\rho) \text { approach } & 131\end{array}$ 
7.8.2.2 Ratio of neutral axis depth to effective depth (c/d) approach

7.8.3 Tension Failure

7.8.4 Compression Failure

7.8.5 Comparison of Moments in Tension and Compression Failure

7.8.6 Theoretical Correlation of Bending Results

7.8.7 Deflection Control

7.8.8 Crack-Width Control for GFRP Reinforced Concrete

$7.9 \quad$ CONCLUSIONS

\begin{tabular}{ll}
\hline CHAPTER 8 & 139
\end{tabular}

SHEAR BEHAVIOR OF CONCRETE BEAMS WITH GFRP STIRRUPS

$\begin{array}{lll}8.1 \quad \text { INTRODUCTION } & 139\end{array}$

$\begin{array}{lll}8.2 & \text { OVERVIEW } & 139\end{array}$

\begin{tabular}{lll}
\hline 8.3 & OBJECTIVES & 140
\end{tabular}

$8.4 \quad$ TEST SPECIMENS, INSTRUMENTATION AND TEST PROCEDURES $\quad 140$

$\begin{array}{lll}\text { 8.4.1 Test Specimens } & 140\end{array}$

8.4.2 Instrumentation and Test Procedures 141

8.5 DISCUSSION OF TEST RESULTS AND THEORETICAL ANALYSIS 143

\begin{tabular}{lll}
\hline 8.6 & CONCLUSIONS & 145
\end{tabular} 


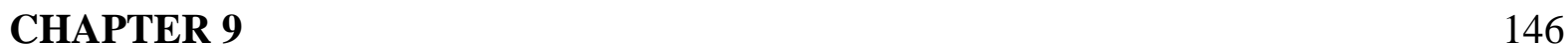

ACCELERATED AGING BEHAVIOR OF GFRP REINFORCED

\begin{tabular}{lll}
\hline $9.1 \quad$ INTRODUCTION & 146
\end{tabular}

\begin{tabular}{lll}
\hline 9.2 OBJECTIVES & 146
\end{tabular}

9.3 SPECIMENS, EQUIPMENT AND TEST PROCEDURES 147

$9.4 \quad$ FREEZE-THAW AND SALT CONDITION ING $\quad 148$

$9.5 \quad$ FREEZE-THAW AND ALKALINE CONDITIONING 151

$\begin{array}{lll}9.6 & \text { THEORETICAL COMPARISONS } & 154\end{array}$

\begin{tabular}{|l|l|}
\hline 9.7 & COMPARISON OF AGING OF GFRP BARS IN BEAMS \\
AND DIRECT GFRP BAR AGING & 154
\end{tabular}

\begin{tabular}{lll}
\hline 9.8 & CONCLUSIONS & 156
\end{tabular}

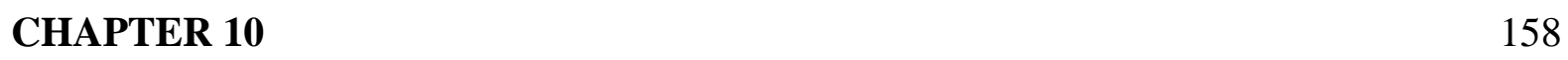

\begin{tabular}{l} 
CREEP AND FATIGUE BEHAVIOR OF CONCRETE BEAMS \\
WITH GFRP BARS \\
\hline
\end{tabular}

\begin{tabular}{lll}
\hline 10.1 & INTRODUCTION & 158
\end{tabular}

\begin{tabular}{lll}
10.2 & CREEP STUDY & 158 \\
\hline
\end{tabular}

$\begin{array}{ll}\text { 10.2.1 Overview } & 158\end{array}$

$\begin{array}{ll}\text { 10.2.2 Objectives } & 159\end{array}$

$\begin{array}{ll}\text { 10.2.3 Test Specimens } & 160\end{array}$

10.2.4 Sustained Load Application $\quad 161$

10.2.5 Results and Discussion on Creep Study 163 
10.2.5.2 Deflections

$\begin{array}{ll}\text { 10.4.1 Fatigue of Beam T1CR } & 170\end{array}$

10.4.2 Fatigue of Beams F1M and F2M 171

10.4.3 Fatigue of Beams F3IG 172

10.5 COMPARISON OF AGING OF GFRP BARS IN BEAMS AND DIRECT GFRP BAR AGING

\begin{tabular}{lll}
\hline 10.6 & CONCLUSIONS ON FATIGUE STUDY & 175
\end{tabular}

\begin{tabular}{lr}
\hline CHAPTER 11 & 176
\end{tabular}

$\begin{array}{ll}\text { SUMMARY AND CONCLUSIONS } & 176\end{array}$

$\begin{array}{lll}11.1 & \text { SUMMARY } & 176\end{array}$

11.1.1 Screening Tests For Selection of Durable Thermoset Resin 176

11.1.2 Hygrothermal Response of GFRP Bars under Different Conditioning Schemes

11.1.3 Accelerated and Natural Weathering of GFRP Bars 177

11.1.3.1 Accelerated Aging Results in Tension 177

11.1.3.2 Accelerated Aging Results in Compression $\quad 179$ 
11.1.4 Bond Behavior of GFRP Bars under Accelerated Aging

11.1.5 Bending Behavior of Concrete Beams Reinforced with GFRP

11.1.6 Shear Behavior of Concrete Beams with GFRP Stirrups

11.1.7 Accelerated Aging Behavior of GFRP Reinforced Concrete Beams

11.1.8 Creep and Fatigue Behavior of GFRP Reinforced Concrete Beams

$\begin{array}{lll}11.3 & \text { KNOCK-DOWN FACTORS } & 186\end{array}$

\begin{tabular}{lr}
\hline REFERENCES & 188
\end{tabular}

\begin{tabular}{|c|c|}
\hline \multirow[t]{2}{*}{ APPENDIX-A } & THEORETICAL COMPARISON OF BENDING \\
\hline & MOMENT CAPACITIES AND FAILURE MODES \\
\hline
\end{tabular}




\section{LIST OF TABLES}

Table 1.1 Conditioning and Testing Schemes 4

Table 1.2 Moisture Absorption Test Matrix 5

Table 1.3 Strength and Stiffness Degradation Matrix for Tension Tests 6

Table 1.4 Strength Degradation Matrix for Compression Bars $\quad 7$

$\begin{array}{lll}\text { Table } 1.5 & \text { Accelerated Stress Corrosion Test Matrix } & 8\end{array}$

Table 1.6 Bond Degradation Test Matrix 9

Table $1.7 \quad$ Bond Strength of Bundled Bars 9

$\begin{array}{lll}\text { Table } 1.8 & \text { Beam Bending Test Matrix } & 10\end{array}$

$\begin{array}{lll}\text { Table } 1.9 & \text { Beam Shear Test Matrix } & 10\end{array}$

Table $1.10 \quad$ Beam Bending Degradation Test Matrix 11

$\begin{array}{lll}\text { Table } 1.11 & \text { Beam Creep and Fatigue Study } & 12\end{array}$

Table $3.1 \quad$ Bar Identification and Resin 38

Table 3.2 Bar Identification and Formula for Production 39

$\begin{array}{lll}\text { Table } 3.3 \quad \text { Conditioning and Testing Schemes } & 40\end{array}$

Table 3.4 Observed Strength and Stiffness in Unconditioned Bars 44

Table 3.5 Strength and Stiffness Loss in Salt Conditioned Bars 45

Table 3.6 Strength and Stiffness Loss in Freeze-Thaw and Salt Conditioned Bars 46

Table $3.7 \quad$ Strength and Stiffness Loss in Alkaline Conditioned Bars 47

Table 3.8 Strength and Stiffness Loss in Freeze-Thaw and Alkaline

Conditioned Bars $\quad 47$

Table 3.9 Strength and Stiffness Loss in Stressed and Alkaline Conditioned Bars 48 
Table 4.1 Sample Conditioning Scheme for Different Containers

Table 4.2 Comparison of Moisture Content (\% by weight)

of Marshall Bars (M1) for Different Conditioning Schemes

Table 4.3 Comparison of Moisture Content (\% by weight)

of Marshall Bars (M2) for Different Conditioning Schemes

Table 4.4 Comparison of Moisture Content (\% by weight)

of IG Bars for Different Conditioning Schemes

Table 4.5 Maximum Moisture Content (\% by weight) for Different GFRP Bars

Table 5.1 Chemical Composition of E-Glass Fibers

Table 5.2 Thermotron Chamber Temperature and Humidity

Table 5.3 Unconditioned strength and stiffness of bars

Table 5.4 Salt Stress Factor (S.S.F) for IG (IG1) and

Marshall (M1) Bars

Table 5.5 Alkaline Stress Factor (A.S.F) for IG (IG1) and Marshall (M1) Bars

Table 5.6 Comparison of Compressive and Tensile Strength of Unconditioned \#4 GFRP Bars

Table 6.1 Bond Strength of GFRP Bars after Conditioning

Table 6.2 Geometric Properties of Normally Spaced Bars,

Bundled Bars and Equivalent Single Bar (Nawy, 1990)

Table 6.3 Pull-out Cylinder Test Results of Bundled Bars

(Marshall M1 Type) and Comparison with Two Bar Bundle

Table 7.1 Beams Tested with GFRP Reinforcement under Four-Point Bending

Table 7.2 Flexural Test Results on GFRP Reinforced Beams

under Four-Point Bending

Table 7.3 Effect of Reinforcement on Moment Capacity and Failure Mode

Table 7. 4 Serviceability Based Approach for Deformability 
Table 7.5 Effect of Compression Reinforcement on Moment Capacity and Deformability in a Compression Failure

Table 7.6 Flexural Strength Range in Tension and Compression Failure Modes

Table 7.7 Flexural Strength in Tension and Compression Failure Modes

Table 7.8 Comparison of Bending Test Results in Concrete Beams with GFRP Bars

Table $8.1 \quad$ Details of the Shear Test Specimens

Table 8.2 Test Results-Shear Resistance of Concrete

Table 8.3 Test Results-Shear Strength of Concrete Beams

Table 8.4 Comparison of Experimental Shear Strength

Table 9.1 Flexural Strength of Salt Conditioned Beams under Freeze-Thaw Conditions

Table 9.2 Flexural Strength of Alkaline Conditioned Beams under Freeze-Thaw Conditions

Table 9.3 Theoretical Comparison of Salt, and Alkaline Conditioned Beams

Table 10.1 Details of the Test Specimens

Table 10.2 Static Testing of Beams under Creep

Table 10.3 Beams Tested under 3-Point Bending Fatigue

Table 10.4 Details of Fatigue Testing 


\section{LIST OF FIGURES}

Fig. 3.1 Tensile Strength of \#4 GFRP Bars

Fig. $3.2 \quad$ Stiffness of \#4 GFRP Bars

Fig. 3.3 Tensile Strength of \#6 GFRP Bars

Fig. $3.4 \quad$ Stiffness of \#6 GFRP Bars

Fig. 3.5 Variation of Tensile Strength in Conditioned \#4 GFRP Bars

Fig. 3.6 Variation of Stiffness in Conditioned \#4 GFRP Bars

Fig. 3.7 Variation of Tensile Strength in Conditioned\#6 GFRP Bars

Fig. 3.8 Variation of Stiffness in Conditioned \#6 GFRP Bars

Fig.3.9 Sample Preparation and Micrography of an Alkaline Conditioned GFRP Rebar

Fig. 4.1 FRP Sample Conditioning in the Thermotron Chamber

Fig. 4.2 Moisture Content of GFRP Bars Immersed in

Tap Water at Room Temperature (Each Data Point is Average of 6 Specimens)

Fig. 4.3 Moisture Content of GFRP Bars Immersed in

Salt Water at Room Temperature (Each Data

Point is Average of 6 Specimens)

Fig. 4.4 Moisture Content of GFRP Bars Immersed in Alkaline Water at Room Temperature (Each data point is average of 6 specimens)

Fig.4.5 Moisture Content of GFRP Bars Immersed in Tap Water under Freeze-thaw Conditioning (Each Data Point is Average of 6 Specimens)

Fig.4.6 Moisture Content of GFRP Bars Immersed in Salt Water under Freeze-thaw Conditioning (Each Data Point is Average of 6 Specimens) 
Fig.4.7 Moisture Content of GFRP Bars Immersed in Alkaline Water under Freeze-thaw Conditioning (Each Data Point is Average of 6 Specimens)

Fig.4.8 Moisture Content of GFRP Bars Immersed in Alkaline Water under $120^{\circ} \mathrm{F}$ Conditioning

(Each Data Point is Average of 3 Specimens)

Fig.4.9 Moisture Content of GFRP Bars Immersed in Alkaline Water under $150^{\circ} \mathrm{F}$ (Each Data Point is Average of 3 Specimens)

Fig. 5.1 Schematic Representation of Etching Process (Adams, 1984) $\quad 71$

Fig. 5.2 Schematic Representation of Leaching Process (Adams, 1984) 72

$\begin{array}{lll}\text { Fig. 5.3 Thermotron Environmental Chamber } & 75\end{array}$

Fig. 5.4 Monitoring Stress Relaxation and Stress Loss for Sand Coated and C- Bars in a Multiple Cell Frame

Fig. 5.5 Bars with and without Stress being Conditioned in Salt and Alkaline Solution at Room Temperature

Fig. 5.6 Tension Testing of GFRP Bars in Baldwin Machine

Fig. 5.7 Linear Stress-Strain Relation of a Salt and Freeze-Thaw Conditioned C-Bar (M2)

Fig. 5.8 Tensile Stress Variation in Sand-Coated Bars under Different Conditioning Schemes (Each Value is an Average of two or more Samples)

Fig. 5.9 Tensile Stress Variation in C-Bars under Salt and Alkaline Conditioning at Room Temperature (Each Value is an Average of two or more Samples)

Fig. 5.10 Tensile Stress Variation in C-bars under Salt and Alkaline Conditioning at Freeze-Thaw and $150^{\circ} \mathrm{F}$ Temperatures (Each Value is an Average of two or more Samples) 
Fig. 5.11 Bars Taken out from the Frames after

Conditioning Duration and Stress Removal

Fig. 5.12 Tensile Stress Variation in Sand-Coated bars under Different

Conditioning Schemes (Each value is an average

of Minimum Three Samples and in few cases only two)

Fig. 5.13 Stress Variation in Sand-Coated Bars under

Different Conditioning Schemes with Sustained

Stress Application (Each Value is an Average of

two or more Samples)

Fig. 5.14 Bar Failures in Alkaline Solution with

Stress and Freeze-Thaw Temperatures

Fig. 5.15 Tensile Stress Variation in C-bars under Salt and Alkaline

Conditioning at Room Temperature with Sustained

Stress Application (Each Value is an Average

of two or more Samples)

Fig. 5.16 Variation of Stiffness in IG Bars under Accelerated Aging

Fig. 5.17 Variation of Stiffness in Marshall Bars (M1)

under Accelerated Aging

Fig. 5.18 Variation of Stiffness in Marshall Bars (M2)

under Accelerated Aging

92

Fig. 5.19 Sand-coated Bars (a) Freeze-Thaw Conditioned

(b) Alkaline Conditioned (15 months, room temp.)

(c) Extracted from a Beam Alkaline and Freeze-Thaw

Conditioned for 12 Months

93

Fig. 5.20 Ribbed C-Bars Tested at 3 Months (a) Salt and Freeze-Thaw Conditioned (b)Alkaline and Freeze-Thaw Conditioned

(c) Alkaline and Room Temperature Conditioned

Fig 5.21 Compressive Failure Strength of IG Bars Subjected to Accelerated Aging

Fig. 5.22 Compressive Failure Strength of Marshall Bars (M1)

Subjected to Accelerated Aging 
Fig. 5.23 Compression Testing of GFRP Bars Subjected

to Accelerated Aging and Different Failure Modes

Fig. 5.24 SIC (Glass Strand in Cement) Strength Retention

in Water at DifferentTemperatures (Litherland et al., 1981) 98

$\begin{array}{lll}\text { Fig. 5.25 Arrhenius Plot (Litherland et al, 1981) } & 98\end{array}$

Fig. 5.26 Normalized Arrhenius Plot (Litherland et al., 1981) 100

Fig. 5.27 Normalized Arrhenius Plot Including Weathering Data 101

(Litherland et al., 1981)

Fig. 5.28 Calibration of WVU Data on Accelerated

Weathering and Data by Litherland et al. (1981)

102

Fig. 5.29 (a) Bars Extracted from Tension side of Concrete Beams after 3 months of Salt and Alkaline Conditioning and Freeze-Thaw Fluctuations (b) Beams, Bars and Bond Specimens under Natural Weathering (c) Bar Extraction from a Concrete Beam (d) Extracted bars with Grips ready for Testing

Fig 5.30 Chart for Converting Accelerated Weathering to Natural Weathering

Fig. 6.1 Bond Specimens Placed in Containers with Salt and Alkaline Solutions at Room Temperature

Fig. 6.2 Testing of Bond Specimens in Up-Right and Inverted Positions

Fig. 6.3 Variation of Bond Strength of IG Bars under Accelerated Aging

Fig. 6.4 Bond-Stress and Slip Relation for an Unconditioned GFRP Bar Pull-Out Specimen

Fig. 6.5 Comparison of Bond Strength between Steel and GFRP (M1 and IG1) Bars

Fig 6.6 Curing of Cylinder Pull-out Specimens with Bundled Bars

Fig. 7.1 Four-point Bending Test Set-up with Data Acquisition System 
Fig. 7.2 Testing of Beam M2 for Compression Failure in Several Cycles

Fig. 7.3 Testing of Beam T3 for Tension Failure in Several Cycles

Fig. 7.4 Testing of Beam M1 for Compression Failure in Several Cycles

Fig. 7.5 Testing of Beams with 4 Different Compression GFRP Reinforcement Configurations a)Zero; b)1; c)2; and d)3 Compression Bars

Fig. 8.1 Shear Test Set-Up and Different Shear Failures under Four-Point Loads

Fig. 9.1 Concrete Beams Tested after 8 months of Salt (left)

and Alkaline (right) Conditioning under Freeze-Thaw Fluctuations

Fig. 9.2 Variation of Deformability Factor in Salt and Freeze-Thaw Conditioned GFRP Reinforced Beams

Fig. 9.3 Load-Deflection of Beam SB2 Immersed in Salt Solution under Freeze-Thaw Fluctuation for 3 Months

Fig. 9.4 Moment-Curvature of Beam SB5 Immersed in Salt Solution under Freeze-Thaw Fluctuation for 12 Months

Fig. 9.5 Tested Concrete Beams after Conditioning for 3

Months in Salt (at bottom) and Alkaline (at top) Solution

Fig. 9.6 Variation of Deformability Factor in Alkaline and Freeze-Thaw Conditioned (3,8 and 12 months) GFRP Reinforced Beams

Fig. 9.7 Moment-Curvature Curves for Beams (AB1 on right and AB2 on left) Immersed for 3 Months in Alkaline Solution under Freeze-Thaw Fluctuation

Fig. 9.8 Load-Deflection for Beam AB5 Immersed for 12 Months in Alkaline Solution under Freeze-Thaw Fluctuation

Fig. 9.9 Tension Test Results of Bars Extracted from Beams Subjected to Accelerated Aging 
Fig. 10.1 Longitudinal and Side Views of Concrete Beam

Reinforced with GFRP Bars under Sustained Load

and a Schematic Representation

Fig. 10.2 Concrete Creep Strains in Beam (C1CR) Reinforced

With GFRP Bars

Fig. 10.3 Creep Deflections in Beam (T2CR)

Reinforced with GFRP Bars

Fig. 10.4 Creep Deflections in Beam (C1CR) Reinforced with GFRP Bars

Fig. 10.5 Static Load-Deflection Test of Beam T2CR subjected

to 27 months of Creep at $50 \%$ of the Sustained Load

Fig. 10.6 Beam T2CR under Static Test Exhibiting close to

Perfect Balanced Failure

Fig. $10.7 \quad$ Fatigue of Beam T1CR

Fig. 10.8 Fatigue of Beams F1M and F2M

Fig. 10.9 Deflections in the beam F3IG subjected to fatigue loading

Fig. 10.10 Static Testing of Beam F3IG after 2.25 $\times 10^{6}$ Cycles

Fig. 10. 11 Tensile Strength of Bars Extracted from Concrete 


\section{NOTATIONS}

A $=$ effective tension area of concrete surrounding the flexural tension reinforcement and having the same centroid as that reinforcement, divided by the number of bars or wires, in. ${ }^{2}$ When the flexural reinforcement consists of different bar or wire sizes the number of bars or wires shall be computed as the total area of reinforcement divided by the area of the largest bar or wire used

$\mathrm{A}_{\mathrm{f}}=$ total area of longitudinal FRP reinforcement

$\mathrm{A}_{\mathrm{f}} \quad=\quad$ total area of longitudinal FRP reinforcement

$\mathrm{A}_{\mathrm{f}, \min }=\quad$ total minimum area of longitudinal FRP reinforcement

$\mathrm{c}=$ distance from extreme compression fiber to neutral axis

$\mathrm{d}=$ distance from extreme compression fiber to centroid of tension reinforcement

$\mathrm{d}^{\prime} \quad=\quad$ cover to tension FRP bars

d" $\quad=\quad$ distance to centroid of compression FRP reinforcement

$\mathrm{d}_{\mathrm{c}}=$ thickness of concrete cover measured from extreme fiber to center of bar or wire

$\mathrm{E}_{\mathrm{f}}=$ modulus of elasticity of FRP reinforcement

$\mathrm{f}_{\mathrm{f}}=$ nominal strength of FRP reinforcement

$\mathrm{f}_{\mathrm{f}, \mathrm{s}}=$ calculated stress at service load in FRP reinforcement

$\mathrm{f}_{\mathrm{f}, \mathrm{s}}=\quad$ stress in FRP reinforcement under service loads $=\mathrm{E}_{\mathrm{f}} \mathrm{x} \varepsilon_{\mathrm{f}, \mathrm{s}}$

$\mathrm{f}_{\mathrm{f}, \mathrm{u}}=$ ultimate failure stress of FRP reinforcement

$\mathrm{I}_{\mathrm{m}} \quad=\quad$ modified moment of inertia for computation of post-cracking deflection

$\mathrm{m} \quad=\quad$ slope of the curve 


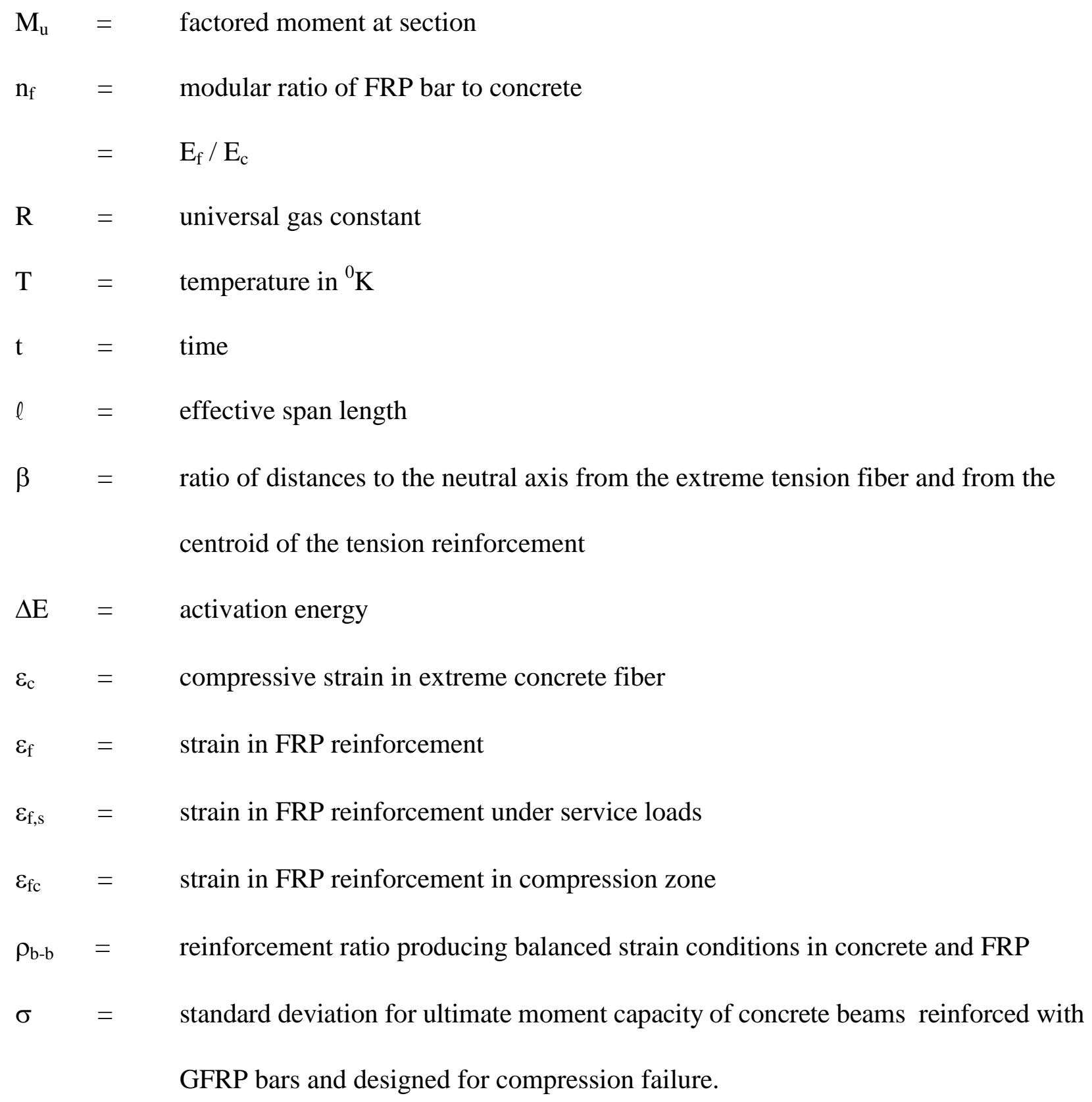




\section{CHAPTER 1}

\section{INTRODUCTION}

\subsection{INTRODUCTION}

Glass fiber reinforced polymer (GFRP) composites with thermoset resins have been used in a wide range of applications in transportation, aerospace, marine, military and civil structures (Rostasy, 1996). These structural applications have been mainly driven by design flexibility, ease of fabrication, high strength to weight ratio, low cost, corrosion resistance, magnetic transparency and many other factors. Some examples of GFRP application include: (1) non-magnetic structures (MRI units, radar equipment calibrations), (2) structures under extremely corrosive environments (salt domes or chemical processing facilities and tanks) where steel bars in concrete corrode rapidly, and (3) structural applications with deicing chemical exposure, e.g., highway bridges, and marine structures.

Reduction in properties of GFRP bars may occur under harsh environments and under physical aging, compromising structural safety and effectiveness of composite systems (GangaRao et al., 1995). The extent of degradation may be accelerated under high $\mathrm{pH}$ environment of concrete, sustained stress, and exposure to freeze-thaw conditions. Hence, understanding the durability of GFRP bars as a function of glass fibers and polymeric resin is essential to design GFRP reinforced concrete members and to guarantee the typical infrastructure service life ( 75 years), and safety. 


\subsection{OVERVIEW}

Despite high demand and successful applications of FRP in the aerospace industry, some of the material characteristics under environmental variations have not been understood completely. Environmental effects on FRP are significant and should be accounted for in design (Springer 1988). High humidity and temperature conditions are often unavoidable in infrastructural systems, and affect the material properties in various ways, including changes in lattice structure of the material, intermolecular bond strength, adhesive strength between FRP bars and concrete, and chemical composition (Pandey 1991). These material property changes can lead to strength and stiffness variations in constituent materials (fibers and matrix), resulting in a decrease in the performance of GFRP bars. In addition, major concerns are expressed by engineering community (ACI, $440 \mathrm{H})$ regarding the susceptibility of glass fibers to alkaline environment caused preliminarily by portland cement, i.e., use of FRP bars in concrete as reinforcement. In order to understand structural response and long-term durability of FRP bars, including physical and chemical aging, research on environmental exposure of FRP bars is needed.

GFRP composites are currently enjoying a high rate of applications in transportation/highway industry because of their cost effectiveness as compared with other advanced materials (boron/epoxy, graphite/epoxy, etc.). However, structural design flexibility is limited in the absence of long-term design data on strength, stiffness and performance of GFRP materials.

To assure long-term durability of GFRP bars, fundamental understanding of strength, stiffness, and bond degradation is essential. Long-term response of FRP bars can be obtained by evaluating individual and combined effects under sustained stresses, alkaline and other chemical 
(salt) reactions, and hygrothermal exposure, and also by evaluating concrete beams reinforced with FRP bars. Accelerated testing and evaluation program are needed to evaluate the anticipated service performance of individual FRP bars, as well as concrete beams reinforced with FRP bars. In addition, calibration of the accelerated test results with natural weathering data of in-service structures is needed to establish safe service life expectancy.

\subsection{OBJECTIVES AND SCOPES}

Overall objectives of this research are:

- To screen resin systems having better durability for GFRP bar usage as reinforcement in concrete structures (section 1.3.1 and Chapter 3).

- To evaluate short-term and long-term strength and stiffness properties of GFRP bars subjected to combination of $\mathrm{pH}$ variation, temperature-fluctuation and sustained loading representing in-service condition of GFRP reinforced concrete structures (sections 1.3.2, 1.3.3, 1.3.4, and Chapters 4 and 5).

- To evaluate short-term and long-term bond properties between concrete and single as well as bundled GFRP bars under varying $\mathrm{pH}$ concentrations and temperatures (section 1.3 .5 and Chapter 6).

- To study short-term and long-term bending and shear behavior of concrete beams reinforced with GFRP bars and stirrups, with and without environmental conditioning (sections 1.3.6, 1.3.7, 1.3.8 and Chapters 7, 8 and 9).

- To study the creep and fatigue behavior of concrete beams reinforced with GFRP bars (sections 1.3.9 and Chapter 10). 
- To recommend a design philosophy of concrete beams reinforced with FRP bars for a service life of about 75 years by including long term strength and stiffness of GFRP bars; bending, bond and shear behavior of concrete beams including failure modes; creep coefficients and knock-down factors (mechanical property reduction factors).

Scope of this study, including the interaction between research results is described in sections 1.3.1 through 1.3.9.

\subsubsection{Screening of Resins and Selection of Durable Resin}

Objective of this study is to screen and evaluate generic resins or their combination for identifying durable resin system that would provide adequate protection to glass fibers under alkaline, salt and hygrothermal exposure over their service life ( 75 years). Durable resins identified in this program are used for extensive evaluation as described in sections 1.3.2 to 1.3.9.

Table 1.1 Conditioning and Testing Schemes

\begin{tabular}{|c|c|c|c|}
\hline \multirow[t]{2}{*}{ No. } & \multicolumn{2}{|c|}{ Details of Conditioning } & \multirow[t]{2}{*}{ Types of Resins } \\
\hline & Conditioning & $\begin{array}{l}\text { Testing Type and } \\
\text { Duration }\end{array}$ & \\
\hline 1 & Unconditioned & tested as received & \multirow{6}{*}{$\begin{array}{ll}\text { - } & \text { Medium reactivity isophthalic } \\
\text { unsaturated polyester (UPE) } \\
\text { - } & \text { High reactivity UPE } \\
\text { - } & \text { High reactivity, corrosion grade } \\
\text { hybrid UPE } \\
\text { - } \\
\text { High reactivity, isocyanurate } \\
\text { vinyl ester (IVE) } \\
\text { - IVE with (C glass) corrosion } \\
\text { resistant glass fiber veil } \\
\text { - IVE with P.E.T. fiber overwrap } \\
\text { - Low viscosity, urethane } \\
\text { modified vinyl ester }\end{array}$} \\
\hline 2 & Salt ( pH 7) & 203 days & \\
\hline 3 & Freeze-Thaw and Salt & 141 cycles & \\
\hline 4 & Alkaline ( pH 13) & 203 days & \\
\hline 5 & $\begin{array}{l}\text { Freeze-Thaw and } \\
\text { Alkaline }\left(0 \text { to } 70^{0} \mathrm{~F}\right)\end{array}$ & 141 cycles & \\
\hline 6 & Stressed Alkaline & $\begin{array}{l}25-30 \% \text { of ultimate } \\
\text { tensile load for } 102 \\
\text { days }\end{array}$ & \\
\hline
\end{tabular}




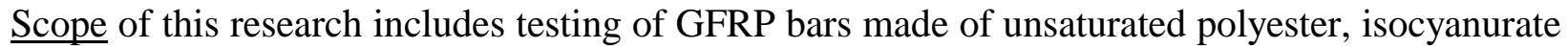
vinylester, and low viscosity urethane modified vinylester resins, under salt and alkaline solutions,

with and without stress at room temperature and freeze-thaw conditions. Since this is a screening study, limited number of bars with different resins are conditioned under different $\mathrm{pH}$, temperature and stress application. Experimental program for the screening study is shown in Table 1.1.

\subsubsection{Moisture Absorption Tests of GFRP Bars}

Objective of this study is to understand the liquid transport characteristics of GFRP bars under salt, alkaline, and tap water solutions at different temperatures. Moisture gains obtained in this study are combined with mechanical properties of bars under accelerated aging subjected to similar conditioning to understand the variation in strength and stiffness as explained in section

\subsection{3.}

Table 1.2 Moisture Absorption Test Matrix

\begin{tabular}{|l|c|}
\hline \multicolumn{1}{|c|}{ Test Parameter } & Number of Variables \\
\hline Rebar size (1/2 " Diameter with 2" length) & 1 \\
\hline Bar types (C-Bar M1 and M2, and Sand coated) & 3 \\
\hline Fiber type (E-glass) & 1 \\
\hline $\begin{array}{l}\text { Environmental conditioning } \\
\text { (Salt Solution, Alkaline Solution, Tap Water) }\end{array}$ & 3 \\
\hline $\begin{array}{l}\text { Temperature variation } \\
\text { (Room, 150 F, and Freeze-Thaw Temperature) }\end{array}$ & 3 \\
\hline Samples per condition & 6 \\
\hline Total number of samples & $\mathbf{1 6 2}$ \\
\hline
\end{tabular}




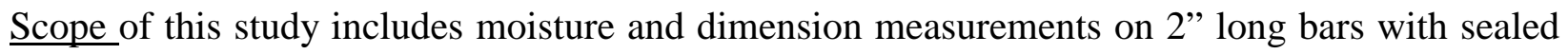
ends. A total of 162 samples were used for this research as shown in Table 1.2. Additional samples were also investigated for moisture absorption at $90^{\circ} \mathrm{F}$ and $120^{\circ} \mathrm{F}$.

\subsubsection{Strength and Stiffness Degradation of GFRP Bars}

Objective of this research is to establish the rate of degradation in tensile strength and stiffness of GFRP bars subjected to salt, alkaline, stress and freeze-thaw temperature conditions. Based on the accelerated aging results, master chart is constructed by accounting for the applied sustained stress on bars. In addition, compression tests are conducted on $1.25 "$ long \#4 bars on aged and unaged samples. The focus is mainly on the strength variations.

Scope of this research includes testing of 144 tension bars. However, including the unconditioned bars and bars extracted from concrete beams, over 200 bars are tested (Tables 1.3. and 1.4).

Table 1.3 Strength and Stiffness Degradation Matrix for Tension Tests

\begin{tabular}{|l|c|}
\hline \multicolumn{1}{|c|}{ Test Parameter } & \multicolumn{1}{|c|}{$\begin{array}{c}\text { Number of } \\
\text { Variables }\end{array}$} \\
\hline Rebar size (1/2 " diameter) & 1 \\
\hline $\begin{array}{l}\text { Bar type } \\
\text { (sand coated and c-bar) }\end{array}$ & 2 \\
\hline Fiber type (E-glass) & 1 \\
\hline $\begin{array}{l}\text { Environmental conditioning } \\
\text { (salt solution, alkaline solution) }\end{array}$ & 2 \\
\hline $\begin{array}{l}\text { Stress conditions } \\
(0,20 \%, \text { and 40\% of ultimate strength) }\end{array}$ & 2 \\
\hline $\begin{array}{l}\text { Temperature variation } \\
\text { (room, and freeze-thaw ) }\end{array}$ & 6 \\
\hline $\begin{array}{l}\text { Samples per condition } \\
\text { (samples to be tested at about 3, 8, and 15 months) }\end{array}$ & $\mathbf{1 4 4}$ \\
\hline \hline Total number of samples & 3 \\
\hline
\end{tabular}


Table 1.4 Strength Degradation Matrix for Compression Bars

\begin{tabular}{|l|c|}
\hline \multicolumn{1}{|c|}{ Test Parameter } & $\begin{array}{c}\text { Number of } \\
\text { Variables }\end{array}$ \\
\hline Rebar size (1/2 " diameter) & 1 \\
\hline $\begin{array}{l}\text { Bar type } \\
\text { (sand coated and c-bar) }\end{array}$ & 2 \\
\hline Fiber type (E-glass) & 1 \\
\hline $\begin{array}{l}\text { Environmental conditioning } \\
\text { (salt solution, alkaline solution) }\end{array}$ & 2 \\
\hline $\begin{array}{l}\text { Stress conditions* } \\
(0,20 \%, \text { and 40\% of ultimate strength) }\end{array}$ & 3 \\
\hline $\begin{array}{l}\text { Temperature variation } \\
\text { (room, and freeze-thaw ) }\end{array}$ & 2 \\
\hline $\begin{array}{l}\text { Samples per condition } \\
\text { (samples to be tested at about 3,8, and 15 months) }\end{array}$ & 6 \\
\hline Total number of samples & $\mathbf{1 4 4}$ \\
\hline
\end{tabular}

Note: * Sustained stress on these bars was tensile.

\subsubsection{Accelerated Stress Corrosion of GFRP Bars}

Objective of this research is to find the rate of degradation of GFRP bars under accelerated aging by increasing the temperature surrounding the test samples immersed in alkaline solution.

Scope of this research includes testing of 9 bars at intervals of 2, 4 and 6 months from alkaline conditioning with elevated temperature of $150^{\circ} \mathrm{F}$ with $35 \%$ stress (Table 1.5).

Results of accelerated stress corrosion are combined with those in section 1.3.3 to understand the effect of temperature and stress on the mechanical properties of GFRP bars. 
Table 1.5 Accelerated Stress Corrosion Test Matrix

\begin{tabular}{|l|c|}
\hline \multicolumn{1}{|c|}{ TEST PARAMETER } & $\begin{array}{c}\text { NUMBER OF } \\
\text { VARIABLES }\end{array}$ \\
\hline Rebar size (1/2 " diameter) & 1 \\
\hline Resin type & 1 \\
\hline Rebar type (c-bar, sand coated) & 2 \\
\hline $\begin{array}{l}\text { Environmental conditioning } \\
\text { (alkaline solution) }\end{array}$ & 1 \\
\hline $\begin{array}{l}\text { Stress conditions } \\
(0,35 \% \text { of ultimate strength) }\end{array}$ & 2 \\
\hline $\begin{array}{l}\text { Temperature variation } \\
\left(150^{0} \mathrm{~F}\right)\end{array}$ & 1 \\
\hline $\begin{array}{l}\text { Samples per condition } \\
(2 \text { samples to be tested at } 2,4, \text { and } 6 \text { months })\end{array}$ & 6 \\
\hline \hline Total number of samples & 24 \\
\hline
\end{tabular}

\subsubsection{Bond Strength Degradation of GFRP Bars with Concrete and Bond Strength of Bundled Bars}

Objective of this research is to establish GFRP-concrete bond degradation rates under salt water, tap water, and freeze-thaw conditions through cylinder pull-out tests. Additional objective is to establish the bond strength capability of bundled GFRP bars.

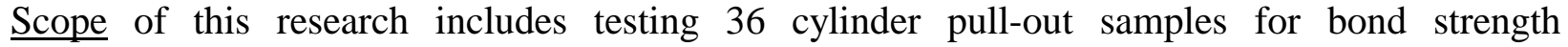
degradation. Additional tests are conducted to establish bond strength of 2, 3 and 4 bar bundles through cylinder pull-out tests (Tables 1.6 and 1.7). 


\section{Table 1.6 Bond Degradation Test Matrix}

\begin{tabular}{|l|c|}
\hline \multicolumn{1}{|c|}{ Test Parameter } & Number of Variables \\
\hline Rebar size (1/2 " diameter) & 1 \\
\hline Type of bars & 1 \\
\hline Fiber type (E-glass) & 1 \\
\hline $\begin{array}{l}\text { Environmental conditioning } \\
\text { (salt solution, tap water) }\end{array}$ & 2 \\
\hline $\begin{array}{l}\text { Temperature variation } \\
\text { (room, and freeze-thaw) }\end{array}$ & 2 \\
\hline $\begin{array}{l}\text { Samples per condition } \\
\text { (3 samples to be tested at 3,11 and 15 months) }\end{array}$ & 9 \\
\hline Total number of samples & 36 \\
\hline
\end{tabular}

Table 1.7 Bond Strength of Bundled Bars

\begin{tabular}{|l|c|}
\hline \multicolumn{1}{|c|}{ Test Parameter } & Number of Variables \\
\hline Rebar size (1/2 " diameter) & 1 \\
\hline Type of bars & 2 \\
\hline Fiber type (E-glass) & 1 \\
\hline Type of bundle (none, two, three and four) & 4 \\
\hline Samples per bundle & 3 \\
\hline \hline Total number of samples & 24 \\
\hline
\end{tabular}

\subsubsection{Bending Behavior of GFRP Reinforced Concrete Beams}

Objective of this study is to develop mathematical tools for predicting bending behavior of concrete beams reinforced with GFRP bars similar to the ACI 318-95 guidelines and obtain unified serviceability limit states of deflection and crack width. Additional beams are tested to understand the effect of compression reinforcement in a beam designed for compression failure with respect to flexural strength and deformability factor. Deformability factor is defined as the ratio of the total energy absorbed by a structure up to its ultimate to the energy absorbed up to a reference curvature. 


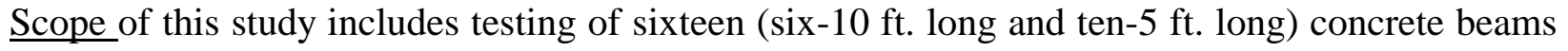
under tension and compression failure modes, and to validate the results against published literature with respect to bending capacity and failure modes (Table 1.8).

Table 1.8 Beam Bending Test Matrix

\begin{tabular}{|l|c|}
\hline \multicolumn{1}{|c|}{ Test parameter } & Number of variables \\
\hline Resin type & 1 \\
\hline Fiber type (E-glass) & 1 \\
\hline Reinforcement type (Sand Coated and Deformed) & 2 \\
\hline Dimensions (Depth and Length) & 2 \\
\hline Reinforcement ratio & 3 \\
\hline \hline Total number of beams & $\mathbf{1 2 + 4} * \mathbf{1 6}$ \\
\hline
\end{tabular}

Note: * Additional 4 beams were tested to evaluate the effect of compression reinforcement in a beam designed for compression failure with respect to flexural strength and deformability factor.

\subsubsection{Shear behavior of GFRP Reinforced Concrete Beams with GFRP Stirrups}

Objective of this study is to develop mathematical tools for predicting shear behavior of concrete beams reinforced with GFRP bars and stirrups similar to the ACI 318-95 guidelines.

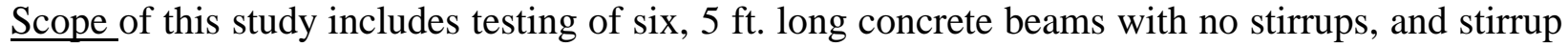
spacing of 4" and 6" (Table 1.9).

Table 1.9 Beam Shear Test Matrix

\begin{tabular}{|l|c|}
\hline \multicolumn{1}{|c|}{ Test Parameter } & Number of Variables \\
\hline Resin type & 1 \\
\hline Fiber type (e-glass) & 1 \\
\hline $\begin{array}{l}\text { Main reinforcement type (sand coated, } \\
\text { deformed) }\end{array}$ & 2 \\
\hline Stirrup type (sand coated) & 1 \\
\hline Stirrup spacing (4", 6" and no stirrups) & 3 \\
\hline \hline Total number of beams & $\mathbf{6}$ \\
\hline
\end{tabular}




\subsubsection{Concrete Beam Degradation}

Objective of this research is to establish the behavior of GFRP reinforced and pre-cracked concrete beam specimens, immersed in salt and alkaline solutions and subjected to freeze-thaw temperatures. Parameters of interest include degradation rates in ultimate flexural strength, deflection, cracking, ductility/deformability and changes in mode of failure.

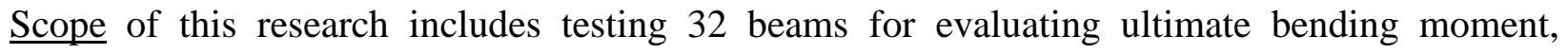
deflection, cracking, deformability, and modes of failure for two different reinforcement configurations. After testing, bars are extracted from the beams for calibration of accelerated aging with natural weathering (Table 1.10).

\section{Table 1.10 Beam Bending Degradation Test Matrix}

\begin{tabular}{|c|c|}
\hline Test Parameter & Number of Variables \\
\hline Rebar size (1/2 " diameter) & 1 \\
\hline Resin type & 1 \\
\hline Fiber type (E-glass) & 1 \\
\hline Reinforcement configuration & 2 \\
\hline $\begin{array}{l}\text { Environmental conditioning } \\
\text { (salt solution, alkaline solution) }\end{array}$ & 2 \\
\hline Temperature variation (freeze-thaw) & 1 \\
\hline $\begin{array}{l}\text { Samples per condition } \\
2 \text { beam samples to be tested at } 3,8 \text {, and } 12 \text { months }\end{array}$ & 6 \\
\hline Total number of samples & $24+8 *=32$ \\
\hline
\end{tabular}

Note: * Eight beams were tested as reference beams for reinforcement and environmental conditions with two replications. 


\subsubsection{Concrete Beam Creep and Fatigue Study}

- Objective of this study is to evaluate and compare concrete creep strain rate, and creep deflection and crack width of concrete beams reinforced with GFRP bars under different levels of sustained bending loads. Objective of the fatigue study is to evaluate the relationship between failure modes and strain levels due to fatigue loads in GFRP reinforced concrete beams.

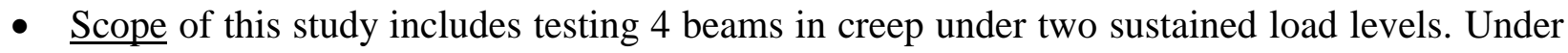
fatigue study, beams designed for tension and compression failure modes are fatigue-tested under different strain ranges (Table 1.11).

Table 1.11 Beam Creep and Fatigue Study

\begin{tabular}{|l|c|}
\hline \multicolumn{1}{|c|}{ Test Parameter } & Number of Variables \\
\hline Rebar size (1/2 " diameter) & 1 \\
\hline $\begin{array}{l}\text { Resin type } \\
\text { (best screened resin, refer chapter3) }\end{array}$ & 1 \\
\hline Fiber type (E-glass) & 1 \\
\hline Reinforcement configuration & 2 \\
\hline Type of tests (Creep and fatigue) & 2 \\
\hline Load (stress/strain) levels in each type of tests & 2 \\
\hline \hline Total number of samples & $\mathbf{8}$ \\
\hline
\end{tabular}

\subsection{NEED FOR ACCELERATED AGING RESEARCH}

In any design, basic conditions to be satisfied are ultimate limit states and serviceability limit states. In terms of ultimate limit state checks, the internal forces/stresses and deformations/rotations developed in a structure need to be analyzed. For a successful design, these ultimate forces/stresses and deformations/rotations must be less than the design resistance (limit state) values. Hence, as a minimum, a structure reinforced with GFRP must satisfy the 
intended function, i.e., tension, compression, bending, shear/torsion, buckling/dimensional/thermal stability, and a combination of the above five. In addition, the structure must satisfy the serviceability limit states, i.e., deformability, crackwidth, human response and aging constraints. Depending on the function of a structure, the design of a FRP composite member should include effects of creep, fatigue, impact, blast, fire and chemicals. These effects must include factors affecting their magnitude, quantification of stresses or strains, member deformations, and finally, the design methodologies.

Nominal strength (resistance) and stiffness values for design are obtained by multiplying the base values with applicable modification factors (known as knock-down factors, which are <1) to account for actual field and environmental conditions in accordance with Eqs. 1.1 and 1.2 (viz., Eqs. 8.4.4.1-1 and 8.4.4.1-2, Section 8, Wood Structures, AASHTO LRFD Bridge Design Specifications):

$$
\begin{aligned}
& \mathrm{F}= \mathrm{F}_{\mathrm{o}} \mathrm{C}_{\mathrm{f}} \mathrm{C}_{\mathrm{m}} \mathrm{C}_{\mathrm{c}} \mathrm{C}_{\mathrm{a}} \mathrm{C}_{\mathrm{st}} \\
& \mathrm{E}=\mathrm{E}_{\mathrm{o}} \mathrm{C}_{\mathrm{m}} \\
& \mathrm{F}=\quad \text { Nominal resistance in bending (b), or torsion }(\mathrm{t}), \text { or compression }(\mathrm{c}), \text { or shear }(\mathrm{v}) \\
& \mathrm{F}_{\mathrm{o}}=\quad \text { Base resistance of } \mathrm{b}, \mathrm{t}, \mathrm{c}, \text { or } \mathrm{v} \\
& \mathrm{E}=\quad \text { Nominal modulus for } \mathrm{b}, \mathrm{t}, \mathrm{c} \text { or } \mathrm{v} \\
& \mathrm{E}_{\mathrm{o}}=\quad \text { Base modulus for } \mathrm{b}, \mathrm{t}, \mathrm{c} \text { or } \mathrm{v} \\
& \mathrm{C}_{\mathrm{f}}=\quad \text { Size effect factor for dimensions of width, depth, span etc. } \\
& \mathrm{C}_{\mathrm{m}}=\quad \text { Moisture content factor and/or humidity factor with pH variation } \\
& \mathrm{C}_{\mathrm{c}}=\quad \text { Environmental factor, which varies with the FRP material exposure to different } \\
& \mathrm{C}_{\mathrm{a}}=\quad \text { Physical aging factor that varies with number of years of service }
\end{aligned}
$$




\section{$\mathrm{C}_{\mathrm{st}}=$ Sustained load factor}

The knock-down factors or modification factors, need to be established through different tests and field evaluations of structures with long service life. Necessary refinements have to be made to these factors. This research establishes some of those factors.

\subsection{SUMMARY}

Based on review of published literature and the test results of this research, following parameters and guidelines for the design of GFRP reinforced concrete beams are formulated.

- Durable resins are identified for manufacturing GFRP bars used as reinforcing element in major concrete structures such as bridges and buildings exposed to harsh environments.

- The rate of moisture pick-up is established in small scale GFRP bars immersed in tap water, salt water, and alkaline water under different temperatures. This information is used to understand the mechanical property variations of GFRP bars subjected to similar immersions under varying sustained stresses.

- It is known that GFRP bars exposed to alkaline concrete environment undergo reduction in their mechanical properties (CDCC-98 Proceedings). Accelerated aging tests are conducted under different $\mathrm{pH}$ conditions, temperature and sustained stress conditions on GFRP bars manufactured using durable resins selected through screening tests. Through accelerated aging, tensile strength and stiffness reductions are established for the GFRP bars, and a methodology is developed for correlating accelerated weathering to natural weathering of GFRP bars in concrete environment under sustained loads. In addition, compressive strength reductions are established. Contribution of GFRP compression reinforcement to flexural strength of concrete beams is investigated. 
- Bond degradation factors to be accounted for in the design of GFRP reinforced concrete are established, through cylinder pull-out tests. Slender member configurations and dimensional restrictions warrant closer spacing of bars in reinforced concrete; hence, the bond strength of bundled bars is investigated.

- Designers and researchers are beginning to consider unconventional failure modes for GFRP reinforced concrete beams (other than conventional flexural tension failure modes) in light of the fact that both flexural tension and flexural compression failure involve two brittle materials, viz., concrete and GFRP. Energy absorbing capabilities either in the form of ductility or deformability of these two failure modes for GFRP reinforced concrete beams are evaluated with respect to serviceability requirements (deflection and crack-width) in order to avoid catastrophic failures. Lack of durability data on GFRPs has led to the use of unsubstantiated safety factors, and may lead to catastrophic structural failures. Interaction between failure modes such as flexural tension or flexural compression of the structural system with the strength, serviceability, energy absorbing capability, and safety are addressed in this research. Mathematical models similar to ACI 318-95 are developed, which are validated by comparing results of other researchers.

- Most tests conducted on concrete beams with GFRP bars have so far focussed primarily on flexural behavior in comparison to shear behavior. Through this research, shear capacity of concrete beams reinforced with GFRP stirrups are evaluated, and design equations developed.

- Research data on accelerated aging of GFRP reinforced concrete beams that are pre-cracked is required to understand changes in failure modes and serviceability parameters (deflections and crack-widths). Data from these tests provide the needed perspective to the accelerated 
aging results obtained through direct exposure of GFRP bars to varying $\mathrm{pH}$ or temperature levels. Results of these tests are used to calibrate naturally weathered samples exposed to actual field conditions.

- Limited data are available on creep characteristics of concrete structural elements reinforced with GFRP bars, particularly for small scale beams, though such data are extensively available for beams reinforced with steel bars. Creep data on full-scale specimens from these tests are used in establishing creep coefficients for GFRP reinforced concrete members. Limited fatigue tests in this research program are designed to study the effect of fatigue load on tension and compression failure modes, and to suggest safe operating strain ranges on GFRP reinforced concrete members.

- Develop and propose knock-down factors for design of GFRP reinforced concrete members.

A comprehensive literature review is provided in Chapter 2 on the use of GFRP bars for infrastructure applications, including the design of concrete members reinforced with GFRP. 


\section{CHAPTER 2}

\section{LITERATURE REVIEW}

\subsection{INTRODUCTION}

In the last decade, increase in the use of Glass Fiber Reinforced Polymer (GFRP) composite bars in lieu of steel bars is noted to overcome corrosion related degradation of steel reinforced concrete structures (Benmokrane and Masmoudi, 1996). The advantages of using FRP reinforcement over steel are: (1) excellent corrosion resistance, (2) high strength-to-weight ratio, (3) high stiffness-to-weight ratio and (4) magnetic transparency. Bridges, buildings, off-shore structures, mining operations, chemical plants, highway pavements, geotechnical applications, structural or nonstructural elements are being reinforced, rehabilitated or stabilized with glass FRP in the form of bars, fabrics and grids (Rostasy, 1996, Seible and Karbhari, 1996).

Several types of FRP products (carbon, glass and aramid) are now available for field applications. For large-scale infrastructure applications, glass appears to be the most economical reinforcing material. However, long-term safety, serviceability, and durability of structures reinforced with FRP need to be established. Durability of FRP depends on the chemical, mechanical and thermal properties of their constituents, viz., resins and fibers. In the following section, properties of GFRP bars, behavior of GFRP reinforced concrete beams under bending and shear, long term durability, and design issues are reviewed. Emphasis is placed on the stateof-the-art knowledge on durability, and utilization of new resins. In addition, knock down factors (generally, mechanical property modification factors <1) representing the durability of GFRP are being developed to incorporate in design using composites (Litherland et al., 1981). 


\subsection{GLASS FIBERS}

Glass fibers are the most commonly used fibers in FRP composites. Glass fibers are made from molten glass spun from an electrically heated platinum-rhodium alloy bushings (or furnace) at a speed of $200 \mathrm{mph}$ (Mallick, 1993). These filaments cool from a temperature of $2192{ }^{0} \mathrm{~F}$ to room temperature within $10^{-5}$ seconds. Glass fibers have a diameter ranging from 0.000090 " to 0.00035". Two hundred and four filaments are grouped together with a lubricant into "strands" during a process called sizing. Strands are combined to form thicker bundles than rovings (CISPI, 1992). The size is a mixture of lubricants (which prevent abrasion between filaments), antistatic agents (which reduce static friction between the filaments), and a binder (which packs the filaments together into a strand (Mallick, 1993).

There are five types of glass fibers currently available (CISPI, 1992):E-glass, Z-glass, Aglass, C-glass, S- or R-glass. Chemical structure of E- and S-glass fibers indicates silica $\left(\mathrm{SiO}_{2}\right)$ as the principal ingredient. Oxides such as $\mathrm{B}_{2} \mathrm{O}_{3}$ and $\mathrm{Al}_{2} \mathrm{O}_{3}$ are added to modify the network structure of $\mathrm{SiO}_{2}$ and improve workability. The $\mathrm{Na}_{2} \mathrm{O}$ and $\mathrm{K}_{2} \mathrm{O}$ content are low to give E- and $\mathrm{S}$ glass fibers a better corrosion resistance against water and a higher surface receptivity.

The advantages of glass fibers are: low cost, high tensile strength, high corrosion resistance, and excellent insulating properties. The limitations of glass fibers are (Mallick, 1993): low tensile modulus, sensitivity to abrasion during handling, and high hardness (Mallick, 1993). Since the type of glass fiber controls overall cost of GFRP bar (glass is about $75 \%$ by weight of the bar), E-glass, the most economical fiber, has been selected as the reinforcement. Significant research has been done on the E-glass fiber and reported in literature (proceedings of CDCC'98, FRPRCS-3'97, ICCI'96 and FRPRCS-2'95). 


\subsection{RESINS}

Since resins play a major role in the durability of FRP bars, proper selection of durable resin is essential. Accordingly, the literature survey is focused on resin types, their advantages and suitability.

Resins (matrix) by themselves do not provide much strength to a composite, since most of the load is taken by the fibers. When a load is applied on a composite, the resin helps in distributing the load between glass fibers. In addition it also protects the fibers partially against environmental attack and mechanical abrasion. There are two main types of polymers: thermoset and thermoplastic; a variety of resins are commercially available in both types. Choosing resin as a binder is important because of its influence on the interlaminar and in-plane shear properties of the final composite product. The selection of proper resin is also important when designing damage-tolerant structures because of the role played by fiber-matrix interaction (Mallick, 1993).

\subsubsection{Thermoplastic Resins}

Thermoplastic resins consist of linear molecules that are not interconnected by chemical random cross linking. Instead, they are connected by secondary weak bonds (intermolecular forces), such as vander Waals bonds and hydrogen bonds (Mallick, 1993). With heat and pressure, these molecules can be moved into a new position and will freeze when cooled at their new position. This enables the resin to be reshaped when heated. This process can be repeated, but the material becomes more brittle with each additional thermal cycle (CISPI, 1992). Some of the most common thermoplastic resins are: acrylonitrite butadiene styrene (ABS), acetal, acrylics, fluoropolymers, liquid crystal polymers, polycarbonate, polyethylene, polypropylene, polysulfone, and polyether ether ketone (PEEK). 


\subsubsection{Thermoset Resins}

Thermoset resins commonly used in pultrusion, have cross-links between the linear molecules, and once the cross-links are formed the resin cannot be reheated or reshaped. They are formed of low molecular weight liquid chemicals with very low viscosity. The main reasons for using thermoset resins in products such as GFRP bars are (CISPI, 1992): better bonding between glass fibers and the matrix, excellent creep resistance, and lower initial costs. Some of the thermoset resins are described in sections 2.3.2.1 to 2.3.2.5. Selection of durable resins for GFRP bars in concrete based on screening tests is described in detail in Chapter 3.

2.3.2.1 Polyester Resins: The advantages of polyester resins are: low viscosity, fast cure time, low cost. Unsaturated polyester resins are the most widely used resins, due to their relatively low costs. They represent approximately $75 \%$ of the total thermoset resins used in the composite market. Generally, polyester resins are supplied with medium to low viscosity (similar to maple syrup or heavy motor oil) (CISPI, 1992 Although the strength and modulus properties of polyester resins are lower than epoxy resins, they have a variety of properties ranging from hard and brittle to soft and flexible. The major disadvantage of polyester resins is its high volumetric shrinkage $(5 \%-12 \%)$, which can leave sink marks (uneven depression) in the finished product. These defects can be reduced by partly combining a low-shrinkage polyester resin that contains a thermoplastic component (Mallick, 1993).

Common commercial types of unsaturated polyester resins are (ACI, 1995):

Orthophthalic Polyester (OP), Isophthalic Resin (Iso Polyester), Bisphenol A Furmerates (BPA), Chlorendics. 
2.3.2.2 Vinylester Resins: Vinylester resins offer excellent corrosion resistance and higher fracture toughness than epoxy resins without the difficulties encountered with epoxy resins during processing, handling, or special shape fabricating practices (CISPI, 1992). Vinylester resins have low viscosity, and fast curing time like polyester resins. Disadvantage of vinylester resins is their high volume shrinkage of 5\% - 10\%. They have moderate adhesive strength when compared to epoxy resins. Vinylester resins combined with heat-resistant epoxy resins can improve the heat deflection temperature and thermal stability (Mallick, 1993).

2.3.2.3 Epoxy Resins: Epoxies are used in high-performance composites to achieve superior mechanical properties and resistance to corrosive liquids and atmosphere. Epoxies are more expensive than other polyester resins and have a much higher viscosity than most polyester resins. The higher viscosity renders epoxies more difficult to use (CISPI, 1992). The advantages of epoxies over other types of resins are: wide range of properties, which allow a greater choice of selection, absence of volatile matters and, low shrinkage during curing, excellent resistance to chemicals and solvents, excellent adhesion to a wide variety of fillers, fibers, and other substrates. The major disadvantages of epoxies are their higher cost and longer cure time (Mallick, 1993) than other polyesters.

2.3.2.4 Polyurethanes: Polyurethane is available in both types of thermosetting and thermoplastic polymers. In thermosetting, the primary ingredients used to make polyurethane are polyisocyanate and polyol by a process called "Reaction Injection Molding" (RIM). This polymer can vary in properties depending on the ingredients used, and the final product can be flexible to rigid (CISPI, 1992). 
2.3.2.5 Phenolic Resins: These resins are based upon phenol (carbolic acid) and formaldehyde. During the cure stage, these resins produce water which should be removed because the glass fibers will not absorb water. The water formation can be handled by compression molding by releasing the steam generated during the molding cycle by "bumping" the press. New compression molding techniques such as SMC are opening the doors for these resins (CISPI, 1992).

\subsection{GFRP BARS}

Several types of FRP bars are commercially produced, and each has distinct strength and durability properties depending on the type of resin matrix and fibers used. Fibers in the bars may be made of glass, aramid, carbon, and/or a combination thereof. Surface of the bars may be smooth, sand-coated, deformed, helically wrapped, ribbed and/or sand coated. The ribbed surface texture is similar to that of a steel bar.

The properties and behavior of FRP bars can vary significantly based on the type of fibers and resins, fiber volume fraction, fiber orientation, and quality control during manufacturing. Tension, compression, bending, and torsion tests were conducted on GFRP bars at the Constructed Facilities Center (CFC) to characterize the strength and stiffness properties ( $\mathrm{Wu}$, 1990). Different failure modes were observed for bars in tension depending on the type of bar. Smooth bars had fiber breakage, whereas, wrapped or ribbed bars exhibited matrix cracking before the fiber breakage, accompanied by the failure of outer fibers and peeling off before total failure (Wu, 1990). The ultimate strength and stiffness of bars depends upon the bar diameter, type of fibers, fiber volume fraction, quality control in manufacturing, and matrix system. The 
strength and stiffness of GFPR bars in compression were found to be lower than those in tension; and their shear strength is also low.

$\mathrm{Wu}(1990)$ conducted compression testing of GFRP bars. Length of the specimen was 2.5 times the diameter. Bar diameters tested were \#7 and \#8. The failure mode of bars in compression was either buckling of fibers or a splitting failure between fibers and matrix. The compressive moduli of smooth bars were found to be close to those in tension. However, compression modulus of ribbed specimens was found to be about $72 \%$ of their mean tensile modulus (Wu, 1990).

Torsion tests were conducted on 11 inch long GFRP bars using a Reihle machine on \#4 and \#7 bars. Failure of specimens was initiated by shear (Wu, 1990). The ribbed specimens had a combination of rib breakage and matrix fracture, whereas the smooth specimens failed due to fiber/matrix debonding which was initiated by excessive shear strain at the surface. Final failure was in shear, because the fiber/matrix debonding is believed to be induced from transverse tensile stresses developed around failed fibers (Wu, 1990). Larger diameter bars exhibited lower torsional strength.

Bending tests have been conducted on GFRP bars under 3-point bending using \#7 and \#8 bars. The dominant failure mode for smooth and ribbed specimens was fiber/matrix debonding, whereas some ribbed specimens reportedly had a fracture in ribs. The failures were initiated on compression side (Wu, 1990).

GFRP bars also exhibit shear lag phenomenon, which is due to higher stresses carried by outer fibers as compared to the core fibers. As the bar size increases, ultimate failure stress decreases. For example, \#9 bars have about $70 \mathrm{ksi}$ mean tensile strength as compared to $130 \mathrm{ksi}$ mean tensile strength of \#3 bars. This is due to more uniform stress distribution between the 
outer and inner fibers in lower diameter bars as compared to larger diameter bars (GangaRao, $1995^{1}$ ). Similar research results on FRP bars consistent with those by GangaRao are available in the literature.

\subsection{RESEARCH ON GFRP REINFORCED CONCRETE ELEMENTS}

\subsubsection{Bending}

Available test results on the flexural behavior of concrete beams reinforced with FRP bars and the ongoing research (CDCC-1998, FRPRCS-3-1998, ICCI-1996, ACMBS-II-1996) suggest that search is still on for refining existing mathematical models. Research in early 1990 suggested the conservative estimation of flexural strength using modified working stress equations, and limiting the concrete compressive strength (Roll, 1991). This uncertainty bothered many researchers due to lack of validation of the mathematical models against the test results and the conventionally unacceptable compression failure modes. To obtain tension failures as specified in the ACI guidelines of steel reinforced concrete beams, researchers had to either use beams with large depths or with lower reinforcement ratios. Still, the results were received with apprehension, due to the fact that, traditional yielding similar to that of steel reinforcement was missing from the mathematical model, and conclusions were drawn about the ductility of the whole structural member by considering just one component, i.e., failure of either FRP bar or concrete.

Several tests have been conducted by Benmokrane et al. (1996), Saadamanesh and Malik (1998), Hosny et al (1996), Abdallah et al., (1996), Matthys and Taerwe (1996), Nanni (1996), Razaqpur and Ali, (1996) and Faza and GangaRao (1992) on the bending behavior of concrete 
beams reinforced with GFRP bars. Flexural strength of a concrete beam failing in tension is evaluated using Eq. 2.1:

$$
M_{n}=A_{f} f_{f}(d-a / 2)
$$

Although, tension failures are predicted reasonably well, compression failure predictions are not conservative and vary by $30 \%$ or more (Sonobe, et al., 1997).

\subsubsection{Deflection and Crackwidth}

Deflection equations of concrete beams with GFRP bars reflect the low stiffness of GFRP bars (5000 to $6000 \mathrm{ksi}$ ) and higher cracking in Eq. 2.2 given by ACI for steel reinforced concrete beams (GangaRao and Faza, 1992, Almusallam et al., 1996, Abdalla et al., 1996, Arockiasamy et al, 1996).

$$
I_{e f f}=I_{c r}+\left(I_{g r}-I_{c r}\right)\left(\frac{M_{c r}}{M_{a}}\right)^{3}
$$

Benmokrane et al. (1996) used a modification factor in the calculation of $\mathrm{I}_{\text {eff, }}$ so that a smaller value of the effective moment of inertia of the concrete section can be obtained. Brown et al. (1996), used the power coefficient to be 5 instead of 3 in the ACI equation for estimating $I_{\text {eff }}$. Faza and GangaRao (1992) have suggested modified moment of inertia $\left(I_{m}\right)$, where, the central section was considered as highly cracked in comparison to the end sections of the beam:

$$
I_{m}=\frac{240 I_{c r} I_{e}}{39 I_{c r}+241 I_{e}}
$$


Crack width predictions similar to the ACI guidelines are given by many researchers to account for the increase in crack widths (Masmoudi et al., 1996, Benmokrane et al., 1996). Eq. 2.4 has been suggested by GangaRao (1995), wherein, crack-width values are increased by a factor of $\left(\mathrm{E}_{\mathrm{s}} / \mathrm{E}_{\mathrm{f}}\right)$, the ratio of the modulus of elasticity of steel to that of FRP.

$$
w_{\text {max }}=0.076 \beta \frac{E_{s}}{E_{f}} f_{f} \sqrt[3]{d_{c} A} 10^{-3}
$$

\subsubsection{Bond}

Many researchers have suggested bond development lengths for GFRP bars by modifying the ACI formula (Tepfers, 1998, Freimanis et al., 1998, Tighiourt et al., 1998, Dulaijan et al., 1996, Lundy and Kachlakev, 1996, Saadatmanesh and Tao, 1996, Mustafa and Barakaypt, 1996). Eq. 2.5 by GangaRao, 1995, conservatively predicts the bond length for GFRP bars to be $50 \%$ higher than those given for steel reinforcing bars.

$$
\mathrm{l}_{\mathrm{db}}=0.06 \frac{A_{b}\left(f_{f}\right)}{\sqrt{f_{c}^{\prime}}}
$$

\subsubsection{Shear Predictions}

Attempts to use the conventional ACI-318 shear Eqs. 2.6 to 2.8 for concrete beams with GFRP stirrups are reported in the literature (Sheheta, 1998, Al-Mosallam et al., 1996, Maruyama and Zhao, 1996, Umezu et al.,1997, Tawre et al., 1997). 


$$
\begin{aligned}
& V_{c}=2 \sqrt{f_{c}^{\prime}} b_{w} d \\
& V_{c}=\left(1.9 \sqrt{f_{c}^{\prime}}+2500 \rho \frac{V_{u} d}{M_{u}}\right) b_{w} d \quad \text { (ACI 11.3.1.1) } \\
& V_{s}=\frac{A_{v} f_{v} d}{s}
\end{aligned}
$$

Al-Salloum et al. (1996) have suggested truss and tie model for predicting the shear strength of beams with FRP longitudinal bars and steel stirrups as given by Eq. 2.9. Four different combinations of longitudinal bars and stirrup materials showed the ratios of theoretical (truss and tie) to test shear strengths to vary between 0.38 and 1.08. In comparison, the conventional ACI model provided a ratio between 1.07 and 1.83. Based on these tests, it is concluded that FRP stirrups can carry maximum shear force of $0.67 f_{u}$, where $f_{u}$ is the ultimate tensile strength of the FRP bar. This model is validated against two beam test results. Clearly, truss and tie model, to a large extent ignores the contribution of concrete shear capability.

$$
V_{n}=\frac{1}{6} \sqrt{f_{c}^{\prime}} b d+\frac{A_{v} f_{y} d}{s}
$$

$$
\text { where } \mathrm{f}_{\mathrm{y}}=0.67 \mathrm{f}_{\mathrm{u}} \text { of GFRP. }
$$

Maruyama and Zhao (1996) have proposed a truss model for prdicting shear strength of concrete beams with CFRP longitudinal grid and GFRP stirrups. Their approach essentially uses modified Japanese Code provisions (Sonobe et al., 1997) for shear strength of concrete beams 
without stirrups. The modification involves multiplying the longitudinal reinforcement ratio $\left(P_{t}\right)$ by the ration $E_{f} / E_{s}$, where $E_{f}$ and $E_{s}$ are, respectively, modulus of elasticity of CFRP and steel (Eqs. 2.10 and 2.11). Contribution of stirrups $\left(\mathrm{V}_{\mathrm{s}}\right)$ to shear strength is estimated by Eq. 2.12.

$$
\begin{aligned}
& V_{u}=V_{c}+V_{s} \\
& V_{c}=0.2\left(f_{c}^{\prime}\right)^{1 / 3}\left(P_{t} E_{f} / E_{s}\right)^{1 / 3}(d / 1000)^{1 / 4}\{0.75+1.4 d / a\} b_{w} d, \mathrm{kN} \\
& V_{s}=A_{w} E_{f} \varepsilon_{f}(z / s), \mathrm{kN}
\end{aligned}
$$

where,

$$
\begin{aligned}
& \mathrm{f}_{\mathrm{c}}{ }^{\prime}=\text { compressive strength of concrete, Mpa. } \\
& \mathrm{P}_{\mathrm{t}}=100 \mathrm{~A}_{\mathrm{f}} / \mathrm{b}_{\mathrm{w}} \mathrm{d} \\
& \mathrm{A}_{\mathrm{w}}=\text { cross sectional area of CFRP bar, } \mathrm{mm}^{2} \\
& \mathrm{~b}_{\mathrm{w}}=\text { web width, } \mathrm{mm} \\
& \mathrm{d}=\text { effective depth, mm } \\
& \varepsilon_{\mathrm{f}}=\text { strain of CFRP stirrup at ultimate. } \\
& \mathrm{z}=\text { lever arm, mm } \\
& \mathrm{s}=\text { stirrup spacing, mm. }
\end{aligned}
$$

Literature review indicates that conflicting views are presented on the dowel contribution, shear contribution of concrete to total shear strength, when concrete beams are reinforced with GFRP stirrups. Some of these reports also suggest that dowel contribution and 
concrete/aggregate interlocking forces are lower in FRP stirrup reinforced beams than steel reinforced and may be conservatively neglected.

\subsection{AGING AND CREEP}

Change in properties of polymers in the absence of any load is referred to as 'aging' (Haskins, 1989). Polymers used for manufacturing of composites exhibit viscoelastic behavior. Aging phenomenon can be very significant during the life span of the constructed facilities over 5075 years. Aging can be chemical or physical. Chemical aging involves changes in the chemical or molecular structure of the polymer such as chain scission, oxidation or cross-linking. Physical aging involves action by macromolecules to regroup into a new equilibrium state below the glass transition temperature, $\mathrm{T}_{\mathrm{g}}$. In addition, mechanical properties are related to the amount of free volume contained in the bulk polymer (Haskins, 1989; Janas and McCullogh, 1987), which is a function of temperature. Change in the bulk polymer temperature produces a thermodynamic driving force for the polymer chains to rearrange themselves into a new equilibrium free volume state. At temperatures above glass transition $\left(\mathrm{T}_{\mathrm{g}}\right)$, polymer molecules have sufficient instantaneous mobility to get back towards equilibrium during temperature changes. When a polymer is quenched from above to below $\mathrm{T}_{\mathrm{g}}$, lack of instantaneous mobility results in free volume in the system. This change in free volume during the movement towards equilibrium alters mechanical properties of the bulk polymer.

Quenching is commonly employed for polymer processing. Changes in mechanical properties depend on processing history, i.e., aging temperature and the difference between $\mathrm{T}_{\mathrm{g}}$ and quenching temperature $\left(\mathrm{T}_{\mathrm{q}}\right)$. If an aged polymer is raised above $\mathrm{T}_{\mathrm{g}}$, it reestablishes its free volume equilibrium and there will be no trace of past thermal history. Quenching it back to $\mathrm{T}_{\mathrm{q}}$ will again 
result in aging. If the polymer is subjected to cycles of thermal history comprising of increase in temperature above $\mathrm{Tg}$ and quenching it back to $\mathrm{Tq}$, mechanical properties due to physical aging follow identical time dependent paths during each cycle.

\subsubsection{Time Temperature-Stress Superposition Principle}

In viscoelastic materials, data at one temperature can be superimposed upon data taken at a different temperature merely by shifting curves (Neilsen, 1962). Reduced stress relaxation curves were obtained at different temperatures for polyisobutylene polymer. A master curve was obtained

for $298 \mathrm{~K}$ by shifting the corrected (reduced) experimental curves along the time-axis until they were superimposed on the curve for $298 \mathrm{~K}\left(25^{\circ} \mathrm{C}\right)$. Before the experimental curves were shifted to make the master curve, the modulus values were corrected for density and temperature:

$E(t)$ reduced $=\left(T_{o} d_{o} / T_{d}\right) E_{r}(t)$

Where, $\mathrm{T}_{\mathrm{o}}=$ reference temperature.

$$
\begin{aligned}
& d_{o}=\text { density at temperature } T_{0} . \\
& T_{d}=\text { data at temperatures } T \text { which should be reduced to data } T_{0} .
\end{aligned}
$$

The W-L-F (Williams-Landel-Ferry) equation for time shift factors is:

$$
\log \mathrm{A}_{\mathrm{T}}=\log \mathrm{t} / \mathrm{t}_{0}
$$

Aging leads to horizontal shifts $\left(\mathrm{A}_{\mathrm{T}}\right)$ on creep compliance versus time plot. If the horizontal shift is represented by $\log A_{T}$, then aging is characterized by the double-logarithmic shift rate, $\mu$ given as a ratio of $\log \mathrm{A}_{\mathrm{T}}$ to $\log \mathrm{t}_{\mathrm{e}}$ (Janas and McCullogh, 1987); $\mathrm{t}_{\mathrm{e}}$ is the time for which a specimen is aged at the test temperature before initiating a creep test. The shift rate approaches the value of 
unity as aging temperature $\left(\mathrm{T}_{\mathrm{a}}\right)$ approaches $\mathrm{T}_{\mathrm{g}}$ of the polymer. Tensile creep and dynamic mechanical analysis (DMA) are the two types of tests employed to characterize physical aging shift factors (Janas and McCullogh, 1987).

A review of literature indicates that aging is a function of degradation rate of fiber - resin interface, moisture ingress and temperature variations, reaction of fiber reinforced polymer composites with foreign chemicals and so on. These issues, with emphasis on mechanical properties are discussed as follows.

\subsubsection{Fiber-Resin Interface}

Interface between glass-couplant-resin has two boundaries where sizing (couplant or lubricant) helps bundle fibers and prevents abrasive contact. Typically, failure occurs at the interface between glass and coupling agent, although either alkaline reaction or polymer plasticization due to moisture, including localized residual stress build-up may have initiated it.

\subsubsection{Moisture Ingress and Temperature Variations}

Resins with high molecular weight and with an additive minimizing moisture absorption do offer good resistance to moisture ingress into the composite core. Therefore, resins with higher molecular weight and minimum number of end groups, which modify viscosity using monobasic acids, improve durability of a composite.

Moisture penetrates a glass fiber composite through diffusion or through micro-cracks. During diffusion, moisture consisting of molecules linked together by hydrogen bonding dissolve in the surface layer of the polymer and migrate into the material. However, moisture penetration can also occur through micro cracks or other flaws by capillary flow. 
Moisture absorption in a polymer composite may increase toughness and decrease strength and stiffness. Temperature affects the rate of moisture absorption as well as mechanical

properties of a polymer composite. Elevated temperatures $\left(35^{\circ} \mathrm{C}\right.$ to $\left.190^{\circ} \mathrm{C}\right)$ decrease strength and stiffness of a composite and increase creep coefficient. Similarly, decrease in temperatures can increase modulus, tensile and flexural strength and stiffness, may decrease fracture toughness, impact strength, compressive strength, and coefficient of expansion.

Lower coefficient of thermal expansion of glass fibers than that of matrix produces residual stresses during temperature changes. Such residual stress build up may be high enough to cause micro-cracking within the matrix-fiber interface. Many researchers have documented effect of temperature and moisture on the flexural strength (Springer, 1982). Matrix tensile strength reductions up to $50 \%$ have been noted by residual stress build up due to low temperature effects.

\subsubsection{Reaction of Composites with Chemicals}

When composites are exposed to reactive environment, it is desirable to have no susceptible linkages between resin and glass. If partial linkage breakdown is unavoidable, then it is desirable to have high concentration of linkages. For example, in GFRPs, two types of chemical bonds (siloxane linkage between glass and coupling agent and within coupling agent, ester linkage in polymer resins and in anhydride-hardened epoxies) are susceptible to bond breakage, and thus lead to higher rate of degradation (aging) of bond forces under sustained stresses.

Better chemical resistance of polymer composites can be achieved if maximum fiberresin bond exists. Chemical resistance of a composite can be severely reduced because of 
wicking leading to capillary action along the fiber strands. Therefore, thick resin-rich gel-coated composites perform better under chemical attack than those with thin gel coats. In addition, thin tissue of glass monofilaments of acrylic or polyester-fiber is suggested to eliminate protrusion of glass fibers from the main laminate to prevent ingress of chemicals. Furthermore, fibers are protected from abrasive damage using sizings, which improve adhesion between fibers and resins in a composite.

Vulnerability of polymers to different forms of degradation (aging) is a concern as the structural composite systems made of polymers may experience reductions in mechanical and chemical properties. Therefore, preventive as well as arrestive stabilization steps are suggested to prevent these possibilities. Preventive stabilization is carried out by adding polymers with special structure and composition, by using monomers of higher purity, and by adding a small percent of comonomers. Similarly, assertive stabilization can be accomplished by removing/neutralizing degradation sources and by introducing reactive chemicals into polymers. For example, surface modification and adhesion improvement can be achieved by blending small amounts of similar or dissimilar polymers, resulting in thin surface coatings. Such coatings can be hygrophobic, and may lead to better aging characteristics of polymer composites.

\subsubsection{Creep}

Data on Creep coefficient for GFRP reinforced concrete beams are very few as noted by Brown et al. (1996). Brown notes the similarity of creep coefficients between steel and GFRP reinforced concrete beams, based on the tests conducted on small scale beams reinforced with GFRP bars. Creep data are also available for glass fibers alone, as well as GFRP bars. Creep strains for GFRP bars are not found to be significant for stress levels under 60\%, although some 
researchers have reported minor increases in creep strains at stress levels as high as $75 \%$ (Rahman et al., 1995).

\subsection{CONCLUSIONS}

The following conclusions are drawn based on the literature review of GFRP bars and GFRP reinforced concrete members:

\subsubsection{GFRP Bars}

At present, durability of GFRP reinforcing bars for concrete application are not extensively researched and not well understood. Resins play an important role in protecting glass fibers from moisture ingress or alkaline attack, and the use of generic thermoset resins without evaluating their durability characteristics leads to undesirable results. No study has been conducted so far on the screening of resin systems suitable for GFRP bars under different stress, $\mathrm{pH}$, and temperature environments. Strength and stiffness degradation rates of GFRP reinforcing bars are also not available either in the form of design charts or tables with respect to their expected habitat, i.e., alkaline or salt environment with freeze-thaw, temperature or hygrothermal variations. This knowledge is very important for designers aiming extended service life of concrete structures.

Moisture transport phenomenon in the GFRP bars with respect to solutions of different $\mathrm{pH}$-concentrations has not been comprehensively evaluated and its effect on the strength and stiffness with different temperature levels has not been established. Similarly, bond degradation rates of GFRP bars of different surface configuration under different exposure conditions need to be established to provide a safe design. 


\subsubsection{GFRP Reinforced Concrete Beams}

Experiments conducted so far on the behavior of concrete beams with GFRP bars are oriented towards bending in comparison to shear behavior evaluation. Interaction between failure modes such as flexural tension or flexural compression of the structural system with the strength, serviceability and safety are not well established. Hence, mathematical models, design and construction specifications similar to those widely used for steel bars, as in ACI 318-95 building code, need to be developed for FRP reinforced concrete members. Designers as well as researchers are beginning to consider unconventional failure modes (other than conventional flexural tension failures) in light of the fact that both flexural tension and flexural compression failure involve two brittle materials, i.e., concrete and GFRP. Energy absorbing capabilities either in the form of ductility or deformability of these two failure modes for GFRP reinforced concrete beams need to be evaluated with respect to serviceability requirements of deflection and crack-width in order to avoid catastrophic failures. Lack of data on durability GFRPs has lead to unscientific assumption of safety factors, which may lead to performance uncertainties and catastrophic structural failures.

Limited research data are available on creep characteristics of concrete structural elements reinforced with GFRP bars, though such data are extensively available for beams reinforced with steel bars. Independent data available for accelerated testing of concrete structural elements reinforced with GFRP bars are not sufficiently comprehensive, and do not address the different field exposure conditions at different stress levels. Hence, a concerted research effort is required to address this issue and develop suitable test procedures. Guidelines for conducting accelerated tests on GFRP bars as concrete reinforcing elements are not specifically formed. Also, the available accelerated data are not calibrated with respect to 
naturally weathered samples exposed to actual field conditions. This gap in correlating the accelerated tests and natural aging needs to be bridged.

Some of the existing limitations in design methodology, lack of design data, lack of durability information as identified in this chapter on literature review, have been addressed in Chapters 3 to 9 . 


\section{CHAPTER 3}

\section{SCREENING TESTS FOR SELECTION OF DURABLE THERMOSET RESIN}

\subsection{INTRODUCTION}

This chapter describes the accelerated tests conducted for screening \#4 and \#6 E-glass fiber reinforced bars (GFRP), manufactured by Reichhold Chemicals Inc., with different resins and surface veils, to evaluate the effect of environmental factors and durability. Conditioning schemes included exposure to ambient and freeze-thaw temperature cycles, moisture, chemical environments ( $\mathrm{pH}$ 7-13) and sustained stress. GFRP bars used in this study were manufactured with five specially selected thermoset polymeric resins. The conditioned bars were tested in tension to evaluate the changes in strength and stiffness with respect to unconditioned bars.

\subsection{OBJECTIVE}

The objective of the screening tests is to evaluate the strength and stiffness of GFRP bars made of several resin matrix systems, under accelerated adverse environmental conditions. Close research interaction was established with Reichhold Chemicals, Inc. for the purpose of conducting screening tests on their resin systems, and designing GFRP bars having maximum strength and stiffness under different environmental conditions. Smooth surface (plain or undeformed) GFRP bars of two different diameters ( $1 / 2$ " and $3 / 4$ " respectively) were obtained from Reichhold Chemicals, Inc., with five different resin systems, which were subjected to five conditioning schemes for varying exposure time periods. These bars were tested in uniaxial tension, to determine tension moduli and failure stresses. Strength and stiffness of conditioned GFRP bars was compared and discussed with 
respect to unconditioned specimens. Finally, based on the performance of rebars with different resins under different conditioning schemes, further testing was carried out as explained in the following chapters.

\subsection{RESIN SYSTEMS AND CONDITIONING ENVIRONMENTS}

\subsubsection{Resin Systems}

Reichhold Chemicals, Inc. manufactured \#4 and \#6 GFRP bars with a fiber volume fraction of approximately $45 \%$ using five different polymer resins. Resin and lamination description and their commercial identification are listed in Table 3.1. Two additional systems with a unique resin rich barrier on the surface through the use of glass and synthetic veils were also evaluated.

Table 3.1 Bar Identification and Resin

\begin{tabular}{|l|l|l|}
\hline Rebar & Reichhold \# & \multicolumn{1}{c|}{ Description } \\
\hline A & $31022-00$ & Medium reactivity isophthalic unsaturated polyester (UPE) \\
\hline B & $31020-01$ & High reactivity isophthalic unsaturated polyester (UPE) \\
\hline C & $7730-101$ & High reactivity, tough, corrosion grade hybrid (UPE) \\
\hline 632 & $31632-00$ & High reactivity, isocyanurate vinyl ester (IVE) \\
\hline $632 / \mathrm{C}$ & $31632-00$ & $\begin{array}{l}\text { IVE with (C glass) corrosion resistant glass fiber veil covering the } \\
\text { surface (Nicofibers 287C; 20 mil thick) }\end{array}$ \\
\hline $632 / \mathrm{N}$ & $31632-00$ & $\begin{array}{l}\text { IVE with P.E.T. fiber overwrap (Nexus style \#111-00010; } \\
\text { 10 mil thick) }\end{array}$ \\
\hline 580 & IV & Low viscosity, urethane modified vinyl ester (VER) \\
\hline
\end{tabular}

Resin formulation of different bars is shown in Table 3.2. Dion 31022-00 which is a 1:1 isophthalic acid/malaic anhydride all propylene glycol unsaturated polyester was included 
in this study as a control case. This type of unsaturated polyester has been used for over 30 years in underground gasoline storage tanks, chemical tanks, piping, and the like.

Table 3.2. Bar Identification and Formula for Production

\begin{tabular}{|c|c|c|}
\hline Bar Type & \multicolumn{2}{|c|}{ Resin Formulation } \\
\hline \multirow[t]{5}{*}{ A } & Dion 31022-00 & $100 \mathrm{pph}$ \\
\hline & Calcium Carbonate & $15 \mathrm{pph}$ \\
\hline & Percadox 16 & $0.9 \mathrm{pph}$ \\
\hline & Esperox 570-P & $0.1 \mathrm{pph}$ \\
\hline & Axel PS-125 & $0.75 \mathrm{pph}$ \\
\hline \multirow[t]{5}{*}{ B } & Dion 31020-01 & $100 \mathrm{pph}$ \\
\hline & Calcium Carbonate & $25 \mathrm{pph}$ \\
\hline & Percadox 16 & $0.75 \mathrm{pph}$ \\
\hline & Axel PS-125 & $0.75 \mathrm{pph}$ \\
\hline & Microthene FN 510 & $3 \mathrm{pph}$ \\
\hline \multirow[t]{5}{*}{$\mathrm{C}$} & $7730-101$ & $100 \mathrm{pph}$ \\
\hline & Calcium Carbonate & $15 \mathrm{pph}$ \\
\hline & Percadox 16 & $0.9 \mathrm{pph}$ \\
\hline & Esperox 570-P & $0.1 \mathrm{pph}$ \\
\hline & Axel PS-125 & $0.75 \mathrm{pph}$ \\
\hline 632 & Dion 31632-00 & $100 \mathrm{pph}$ \\
\hline $632 / \mathrm{C}$ & Calcium Carbonate & $30 \mathrm{pph}$ \\
\hline \multirow[t]{4}{*}{$632 / \mathrm{N}$} & VAZO 52 & $0.25 \mathrm{pph}$ \\
\hline & Alpha Methyl Styrene & $3 \mathrm{pph}$ \\
\hline & Microthene FN 510 & $3 \mathrm{pph}$ \\
\hline & Axel PS-125 & $0.75 \mathrm{pph}$ \\
\hline \multirow[t]{5}{*}{580} & Dion 31038-00 & $100 \mathrm{pph}$ \\
\hline & Calcium Carbonate & $25 \mathrm{pph}$ \\
\hline & Percadox 16 & $0.9 \mathrm{pph}$ \\
\hline & Esperox 570-P & $0.1 \mathrm{pph}$ \\
\hline & Axel PS-125 & $0.75 \mathrm{pph}$ \\
\hline
\end{tabular}

Dion 31038-00 was chosen over more conventional vinylesters (like Dion 9100, Dow 411) due to previous corrosion test data in alkaline conditions. Under ASTM C-581 coupon 
testing (5\% sodium hydroxide ( $\mathrm{pH} \mathrm{14),} 6$ months at ambient), the urethane modification of 31038-00 demonstrated no loss in flexural or tensile properties, while conventional vinylesters demonstrated over $10 \%$ loss in flexural strength, and over $20 \%$ in tensile strength.

All samples were produced using PPG's Hybond-2011, 113 yield, direct draw E-glass at approximately $45 \%$ by volume. Bar $632 / \mathrm{C}$ and $632 / \mathrm{N}$ incorporated veils as identified in Table 3.1. Line speeds were controlled at $16 \mathrm{in} / \mathrm{min}$ for \#4 bars and $12 \mathrm{in} / \mathrm{min}$ for \#6 bars. Zone 1 (entry) temperature was controlled at $275^{\circ} \mathrm{F}$, while Zone \#2 (exit) was controlled at $300^{\circ} \mathrm{F}$.

\subsubsection{Conditioning Environment and Duration}

Six different conditioning schemes, including accelerated exposures, were simulated on both \#4 and \#6 GFRP bars (previously described) as shown in Table 3.3. No post curing or treatments were done to the bars prior to conditioning.

Table 3.3 Conditioning and Testing Schemes

\begin{tabular}{|l|l|l|}
\hline No. & Conditioning & Testing Type and Duration \\
\hline 1 & Unconditioned & tested as received \\
\hline 2 & Salt $(\sim \mathrm{pH} 7)$ & 203 days \\
\hline 3 & Freeze-Thaw and Salt & 141 cycles \\
\hline 4 & Alkaline $(\sim \mathrm{pH} 13)$ & 203 days \\
\hline 5 & Freeze-Thaw and Alkaline & 141 cycles \\
\hline 6 & Stressed Alkaline (only \#4 bars) & $\sim 25-30 \%$ of ultimate tensile load for 102 days \\
\hline
\end{tabular}




\subsection{CONDITIONING METHODS AND TESTING PROCEDURES}

Conditioning methods consisted of exposing the GFRP bars to a particular environment in special containers or environmental chamber for the desired duration. Following the desired conditioning period, bars were tested under uniaxial tension. Different conditioning methods are explained as follows.

\subsubsection{Unconditioned Test}

Bars were tested as received directly from the manufacturer without simulating any environmental effects. Data obtained from these bars were utilized as a basis for evaluating performance (strength and stiffness) of the conditioned bars.

\subsubsection{Salt Test}

Bars were placed in a capped PVC pipe filled with salt solution, consisting of $97 \%$ water and 3\% sodium chloride. Rebars were conditioned in the pipe from for 203 days, at room temperature.

\subsubsection{Freeze-Thaw and Salt Test}

Bars were placed in a $4 \mathrm{ft}$. $\mathrm{x} 4 \mathrm{ft}$. polyurethane tank containing the same salt solution as described in the salt test. The tank was covered with a lid and positioned inside an environmental chamber. Several pilot tests were conducted on the computer-controlled environmental chamber to verify the programming sequence for the desired freeze-thaw cycles. Continuous freeze-thaw conditioning was conducted at a rate of 3 cycles/day for 47 days. Each freeze-thaw cycle consisted of a constant $70^{\circ} \mathrm{F}$ temperature for two hours, 
transition from $70^{\circ} \mathrm{F}$ to $0^{\circ} \mathrm{F}$ for two hours, constant $0^{\circ} \mathrm{F}$ for two hours, followed by another transition from $0^{\circ} \mathrm{F}$ to $70^{\circ} \mathrm{F}$ in two hours. Rebars were conditioned for a total of 141 cycles.

\subsubsection{Alkaline Test}

Bars were placed in a capped PVC pipe filled with an alkaline solution of $\mathrm{pH} 13$. Alkaline solution consisted of $0.2 \%$ calcium hydroxide, $1.4 \%$ potassium hydroxide, $1 \%$ sodium hydroxide, and $97.4 \%$ water. Rebars were conditioned in the pipe at room temperature for 203 days.

\subsubsection{Freeze-Thaw and Alkaline Test}

Bars were conditioned similar to the bars in the alkaline test, in a polyurethane tank containing alkaline solution. They were subjected to continuous freeze-thaw exposure for a total of 141 cycles at a rate of 3 cycles/day, as explained earlier.

\subsubsection{Stressed Alkaline Test}

Bars were conditioned in a specially designed steel frame, treated with anti-corrosive coatings. The frame was drilled with holes conforming to the bar diameters. Prestressing chucks and a jack were used for stressing the bars. At a time, seven bars were stressed sequentially. The resulting sustained stresses were found to be equal to approximately 25 to $30 \%$ of the ultimate stress after losses. Only \#4 bars were stressed and the container holes were water-sealed. Alkaline solution was filled in the tank, and covered with a lid at room temperature. 
Salt and alkaline solutions used for conditioning of the specimens were periodically checked for any variation in the $\mathrm{pH}$ values.

\subsection{TEST PROCEDURES}

Uniaxial tension tests were performed on the conditioned and unconditioned GFRP bars using the 200 kips-capacity Baldwin Universal Testing Machine, with specially modified grips, developed at the CFC laboratory. Four-feet long bars were used as test specimens. Instrumentation consisted of strain gauges and data acquisition system, with the former mounted on the bars at mid-height. Strain vs. applied load was automatically recorded through the data acquisition system. Loads were also manually recorded from the Baldwin machine for comparison purposes.

\subsection{TEST RESULTS AND DISCUSSION}

The results of the tension tests of GFRP bars with seven different resin/construction systems and five different exposure conditions have been presented for \#4 and \#6 bars in Tables 3.4 through 3.9 and Figs. 3.1 through 3.8.

\subsubsection{Unconditioned Test}

GFRP bars made with the Isocyanurate vinylester (IVE) family of resins $(632,632 / \mathrm{C}$, and 632/N) exhibited the highest tensile strength, ranging from 105.7 to $108.5 \mathrm{ksi}$ for \#4 bars, and 90.0 to 105.5 ksi for \#6 bars. Strength in bars with resins A, B, and C varied from 94.0 to $102.1 \mathrm{ksi}$ for \#4 bars, and 86.2 to $89.3 \mathrm{ksi}$ for \#6 bars. Bars with resin system 580 carried $99.3 \mathrm{ksi}$ and $88.5 \mathrm{ksi}$ for \#4 and \#6 bars, respectively. 
Similar to strengths, higher stiffness values were observed for bars with IVE family of resins varying between 5.25 to $5.58 \mathrm{msi}$ for \#4 bars and 4.2 to $6.0 \mathrm{msi}$ for \#6 bars (Table 3.4). Stiffness of bars with A, B, and C resins varied between 4.86 to 5.19 msi for \#4 bars and 4.39 to $5.3 \mathrm{msi}$ for \#6 bars. Stiffness of 5.54 and $5.22 \mathrm{msi}$ were observed respectively for \#4 and \#6 bars with resin system 580 .

\#4 bars typically carried about $100 \mathrm{ksi}$ load, whereas \#6 bars carried about $90 \mathrm{ksi}$, i.e., approximately $10 \%$ less stress than \#4 bars. Stiffness values of \#4 bars were similar or slightly better than \#6 bars. Stiffness values for both \#4 and \#6 bars ranged typically between 5.2 and 5.5 msi.

Table 3.4 Observed Strength and Stiffness in Unconditioned Bars

\begin{tabular}{|c|c|c|}
\hline $\begin{array}{c}\text { Bars with Resin } \\
\text { Family }\end{array}$ & Observed Range of Strength & Observed Range of Stiffness \\
\hline $\mathrm{A}, \mathrm{B}, \mathrm{C}$ & $\begin{array}{l}94.0 \text { to } 102.1 \mathrm{ksi}(\# 4) \\
86.2 \text { to } 89.3 \mathrm{ksi}(\# 6)\end{array}$ & $\begin{array}{l}4.86 \text { to } 5.19 \mathrm{msi}(\# 4) \\
4.39 \text { to } 5.3 \mathrm{msi}(\# 6)\end{array}$ \\
\hline $\begin{array}{l}\text { Isocyanurate } \\
\text { Vinylester } \\
(632,632 / \mathrm{C}, 632 / \mathrm{N})\end{array}$ & $\begin{array}{l}105.7 \text { to } 108.5 \mathrm{ksi}(\# 4) \\
90.0 \text { to } 105.5 \mathrm{ksi}(\# 6)\end{array}$ & $\begin{array}{l}5.25 \text { to } 5.58 \mathrm{msi}(\# 4) \\
4.2 \text { to } 6.0 \mathrm{msi}(\# 6)\end{array}$ \\
\hline 580 & $\begin{array}{l}99.3 \mathrm{ksi}(\# 4) \\
88.5 \mathrm{ksi}(\# 6)\end{array}$ & $\begin{array}{l}5.54 \mathrm{msi}(\# 4) \\
5.22 \mathrm{msi}(\# 6)\end{array}$ \\
\hline
\end{tabular}

Some of the unconditioned bars exhibited stiffness values significantly different from typical ranges, and hence considering them for comparison would lead to misinterpretation. For example, a \#4 bar with resin system $\mathrm{C}$ and \#6 bars with resin systems B and 632/C have comparatively low stiffness values; stiffness values for three of the four conditioned test results were also higher than unconditioned results for these bars. In contrast, \#6 bar with 
resin system 632 has a relatively higher stiffness as compared to the typical range of 5.2 to $5.5 \mathrm{msi}$. Unconditional tests on these bars with corresponding resins may have to be repeated to obtain more accurate results for proper comparison. Hence, stiffness comparisons are avoided for \#4 bars with resin system $\mathrm{C}$ and \#6 bars with resin systems B, 632, and 632/C.

\subsubsection{Salt Test}

No significant strength loss was observed for most of the bars conditioned in salt although some of them carried a higher load than unconditioned bars. Only \#6 bar with resin system A had a high $21.9 \%$ reduction in strength.

Table 3.5. Strength and Stiffness Loss in Salt Conditioned Bars

\begin{tabular}{|c|c|c|}
\hline $\begin{array}{c}\text { Bars with Resin } \\
\text { Family }\end{array}$ & \% Loss or Gain in Strength & \% Loss or Gain in Stiffness \\
\hline $\mathrm{A}, \mathrm{B}, \mathrm{C}$ & $\begin{array}{l}5.1 \% \text { gain to } 13.5 \% \operatorname{loss}(\# 4) \\
1.5 \text { to } 21.9 \% \text { loss (\#6) }\end{array}$ & $\begin{array}{l}1.8 \text { to } 5.9 \% \text { gain }(\# 4) \\
3.3 \text { to } 16.2 \% \text { loss (\#6) }\end{array}$ \\
\hline $\begin{array}{l}\text { Isocyanurate } \\
\text { Vinylester (632, } \\
632 / \mathrm{C}, 632 / \mathrm{N})\end{array}$ & $\begin{array}{l}7.5 \% \text { gain to } 8.2 \% \operatorname{loss}(\# 4) \\
1.9 \% \text { gain to } 10.6 \% \text { loss }(\# 6)\end{array}$ & $\begin{array}{l}0.4 \% \text { gain to } 7.6 \% \text { loss }(\# 4) \\
16.2 \% \text { loss }(\# 6)\end{array}$ \\
\hline 580 & $\begin{array}{l}6.2 \% \text { gain }(\# 4) \\
8.7 \% \text { gain }(\# 6)\end{array}$ & $\begin{array}{l}7.7 \% \text { loss }(\# 4) \\
4.3 \% \text { loss }(\# 6)\end{array}$ \\
\hline
\end{tabular}

When removed from the capped PVC pipe, this bar was visibly corroded. Since three other bars of this resin family in \#4 and \#6 diameters do not show any significant strength loss under salt conditioning, it is believed that the bar had a manufacturing defect such as improper curing. Strength and stiffness losses for the majority of bars were under $10 \%$ and 
$8 \%$ respectively, and gains were within $7.5 \%$ and $6 \%$ respectively. Generally, all the bars with different resin systems performed well under salt conditioning.

\subsubsection{Freeze-Thaw Salt Test}

Freeze-thaw and salt conditioning tests for \#4 and \#6 bars did not result in significant strength or stiffness loss. Strength reductions were less than $11 \%$, and in one case a strength gain of $22.6 \%$ was observed. Stiffness losses within $8.5 \%$ were observed for all the bars. Generally, all bars with different resin systems performed well under salt and freeze-thaw conditioning.

Table 3.6 Strength and Stiffness Loss in Freeze-Thaw and Salt Conditioned Bars

\begin{tabular}{|c|c|c|}
\hline $\begin{array}{c}\text { Bars with Resin } \\
\text { Family }\end{array}$ & \% Loss or Gain in Strength & \% Loss or Gain in Stiffness \\
\hline $\mathrm{A}, \mathrm{B}, \mathrm{C}$ & $\begin{array}{l}0.2 \% \text { gain to } 10.6 \% \text { loss }(\# 4) \\
11 \% \text { gain to } 1.6 \% \text { loss (\#6) }\end{array}$ & $\begin{array}{l}2.1 \text { to } 4.1 \% \operatorname{loss}(\# 4) \\
3.3 \text { to } 8.4 \% \operatorname{loss}(\# 6)\end{array}$ \\
\hline $\begin{array}{l}\text { Isocyanurate } \\
\text { Vinylester } \\
(632,632 / \mathrm{C}, 632 / \mathrm{N})\end{array}$ & $\begin{array}{l}6.6 \% \text { to } 8.0 \% \text { gain }(\# 4) \\
2.1 \% \text { gain to } 6.7 \% \text { loss }(\# 6)\end{array}$ & $\begin{array}{l}0.1 \% \text { gain to } 12.6 \% \text { loss (\#4) } \\
7.9 \% \text { loss (\#6) }\end{array}$ \\
\hline 580 & $\begin{array}{l}22.6 \% \text { gain }(\# 4) \\
15.5 \% \text { gain }(\# 6)\end{array}$ & $\begin{array}{l}4.9 \% \text { loss }(\# 4) \\
2.9 \% \text { gain }(\# 6)\end{array}$ \\
\hline
\end{tabular}

\subsubsection{Alkaline Test}

All the bars experienced strength and stiffness loss under alkaline attack. Isocyanurate vinylester (IVE) resin bars suffered serious strength losses up to $64.3 \%$. Stiffness performance of bars with IVE resins was satisfactory. Stiffness losses were within $10 \%$ for all bars with different resin systems. Strength losses for bars with resin systems 
A,B,C and 580 were under 19\%. Generally, bars with resin systems A,B,C and 580 performed well under alkaline conditioning. Optical microscopy of an alkaline conditioned bar is shown in Fig. 3.9.

Table 3.7 Strength and Stiffness Loss in Alkaline Conditioned Bars

\begin{tabular}{|c|c|c|}
\hline Bars with Resin Family & \% Loss in Strength & \% Loss in Stiffness \\
\hline $\mathrm{A}, \mathrm{B}, \mathrm{C}$ & $\begin{array}{l}8.9 \text { to } 11.4 \% \text { loss }(\# 4) \\
10.5 \text { to } 18.5 \% \text { loss }(\# 6)\end{array}$ & $\begin{array}{l}4.0 \text { to } 8.5 \% \text { loss (\#4) } \\
3.3 \text { to } 8.4 \% \text { loss (\#6) }\end{array}$ \\
\hline Isocyanurate Vinylester & $\begin{array}{l}44.5 \text { to } 64.3 \% \text { loss (\#4) } \\
25.4 \text { to } 36 \% \text { loss (\#6) }\end{array}$ & $\begin{array}{l}4.4 \text { to } 9.3 \% \text { loss }(\# 4) \\
0.4 \% \text { loss (\#6 }\end{array}$ \\
\hline 580 & $\begin{array}{l}16.9 \% \text { loss }(\# 4) \\
8.4 \% \text { loss }(\# 6)\end{array}$ & $\begin{array}{l}5.3 \% \text { loss (\#4) } \\
7.7 \% \text { loss (\#6) }\end{array}$ \\
\hline
\end{tabular}

\subsubsection{Freeze-Thaw and Alkaline Test}

Reductions in strength and stiffness were observed for all bars under freeze-thaw and alkaline attack. Particularly bars with isocyanurate vinylester (IVE) resins suffered serious strength losses similar to alkaline attack.

Table 3.8 Strength and Stiffness Loss in Freeze-Thaw and Alkaline Conditioned Bars

\begin{tabular}{|l|l|l|}
\hline Bars with Resin Family & \% Loss in Strength & $\%$ Loss in Stiffness \\
\hline A,B,C & 10.6 to $19.7 \%$ loss (\#4) & 7.7 to $10.1 \%$ loss (\#4) \\
& 11.3 to $19.6 \%$ loss (\#6) & 18.8 to $23.1 \%$ loss (\#6) \\
\hline $\begin{array}{l}\text { Isocyanurate Vinylester } \\
(632,632 / \mathrm{C}, 632 / \mathrm{N})\end{array}$ & 28.0 to $49.1 \%$ loss (\#4) & 3.0 to $11.2 \%$ loss (\#4) \\
\hline 580 & $15.6 \%$ to $35.7 \%$ loss (\#6) & $0.7 \%$ loss (\#6) \\
& $6.6 \%$ loss (\#6) & $13.3 \%$ loss (\#6) \\
\hline
\end{tabular}

Strength and stiffness reductions in bars with IVE resin systems were as high as $49.1 \%$ and $11.2 \%$ respectively. Strength losses in bars with resin systems A,B,C, and 580 
were within $20 \%$. Stiffness losses ranged between 7.7 to $23.1 \%$ for bars with resins A, B, and $\mathrm{C}$, whereas reductions within $13.3 \%$ were observed for bars with resin 580. Bars with resin system 580 performed better than other bars under freeze-thaw and alkaline conditioning. Bars with resin A performed better than resin systems B and C.

\subsubsection{Stressed Alkaline Test}

Stressed and alkaline environment test was performed only on \#4 GFRP bars. Once again, very high reduction in strengths and stiffnesses were observed for bars with IVE resins. Strength reduction ranged between 37.1 to $76.5 \%$, whereas stiffness losses were as high as 31.6\%. Bars with resin system 580 performed better under stressed alkaline conditioning with negligible strength loss and $15.2 \%$ stiffness losses. Bars with resin system A performed better than bars with resin systems $\mathrm{B}$ and $\mathrm{C}$, with strength and stiffness reduction of $1.8 \%$ and $5.2 \%$ respectively.

Table 3.9 Strength and Stiffness Loss in Stressed and Alkaline Conditioned Bars

\begin{tabular}{|l|l|l|}
\hline Bars With Resin Family & \% Loss in Strength & \% Loss in Stiffness \\
\hline A,B,C & 1.8 to $27.9 \%$ loss (\#4) & 5.2 to $7.3 \%$ loss (\#4) \\
\hline Isocyanurate Vinylester & 37.1 to $76.5 \%$ loss (\#4) & 6.1 to $31.6 \%$ loss (\#4) \\
$(632,632 / \mathrm{C}, 632 / \mathrm{N})$ & & $15.2 \%$ loss (\#4) \\
\hline 580 & $0.8 \%$ loss (\#4) & \\
\hline
\end{tabular}




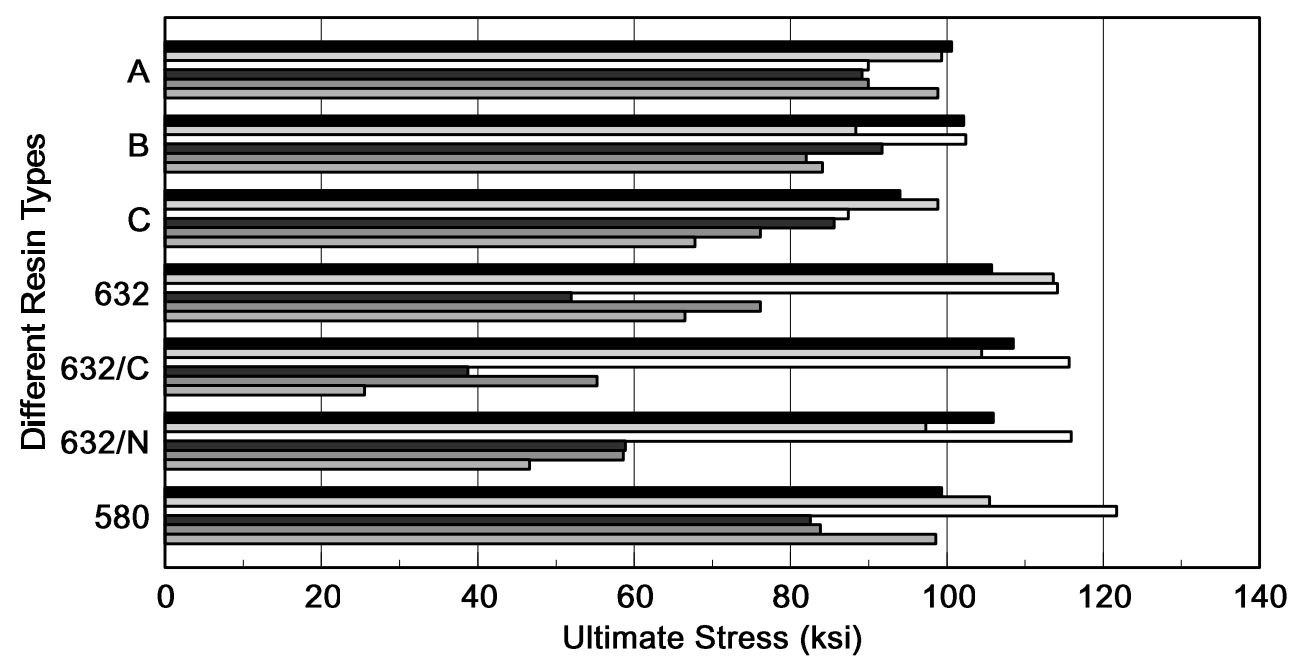

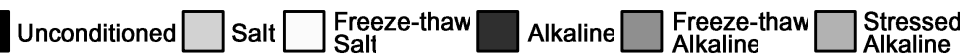

Fig.3. 1. Tensile Strength of \#4 GFRP Bars

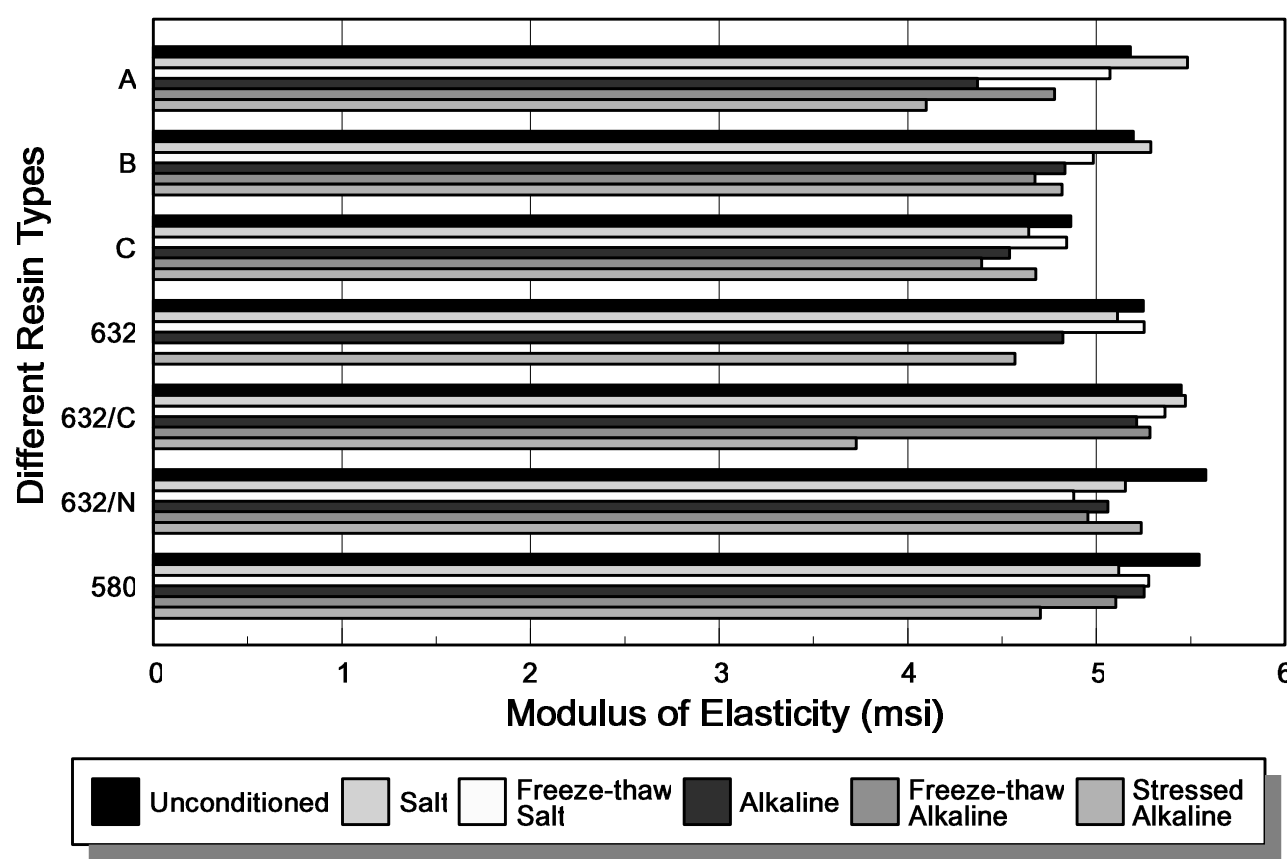

Fig. 3. 2 Stiffness of \#4 GFRP Bars 


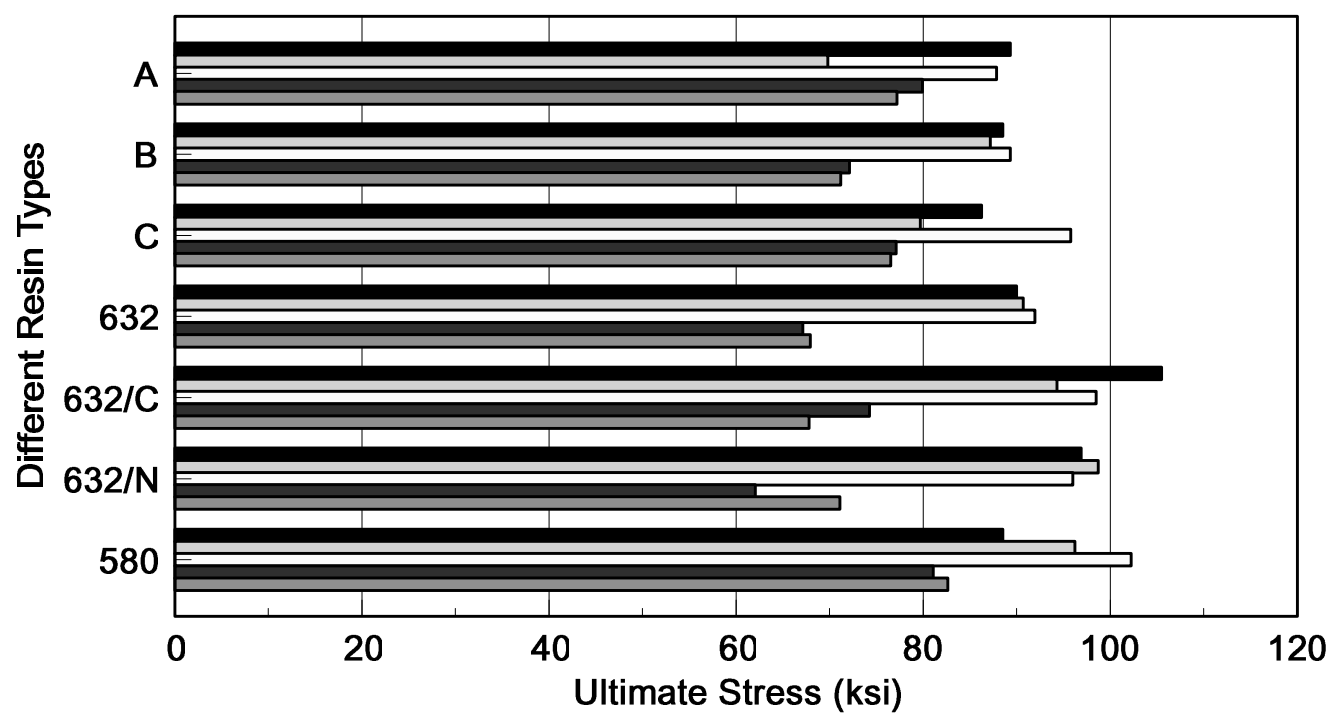

Unconditioned

Sat

Freeze-thaw

Salt Alkaline

Fig. 3. 3 Tensile Strength of \#6 GFRP Bars

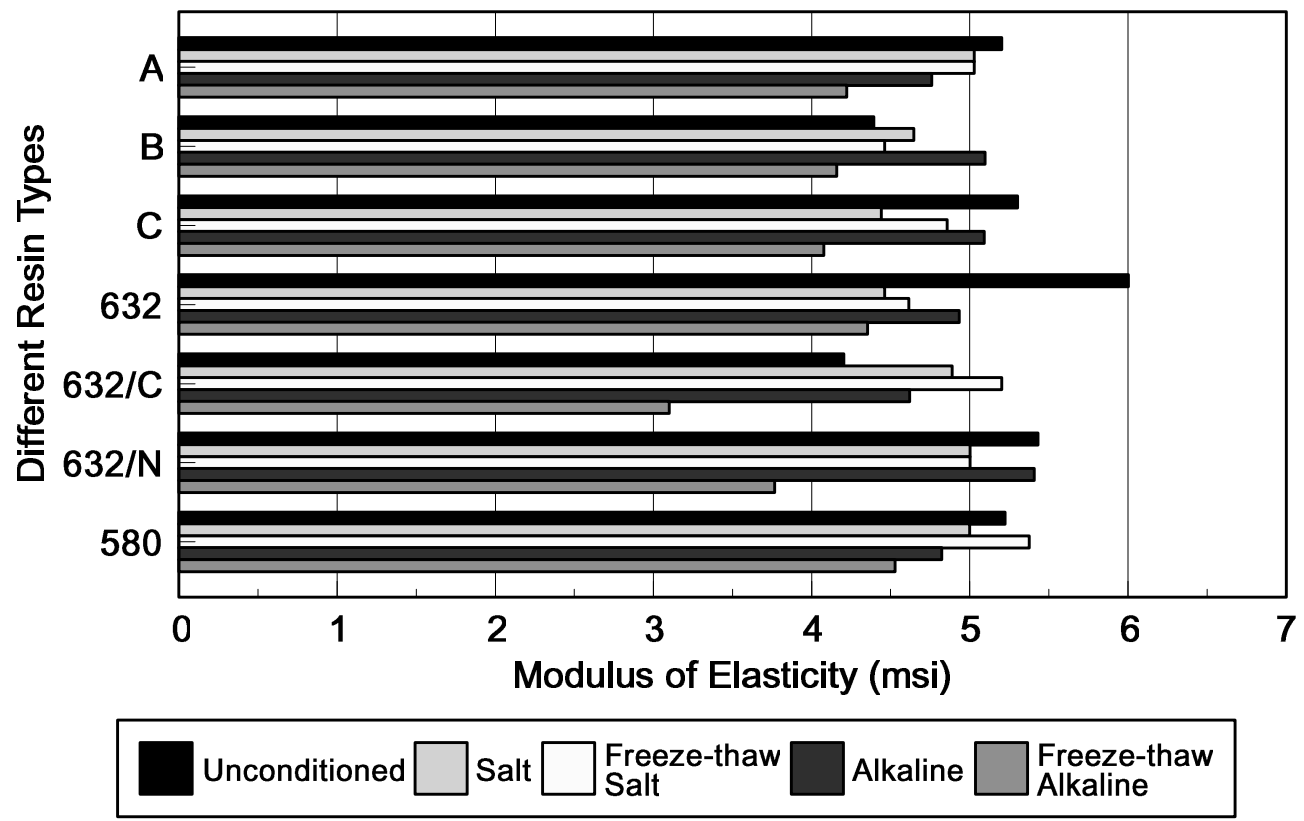

Fig3. 4 Stiffness of \#6 GFRP Bars 


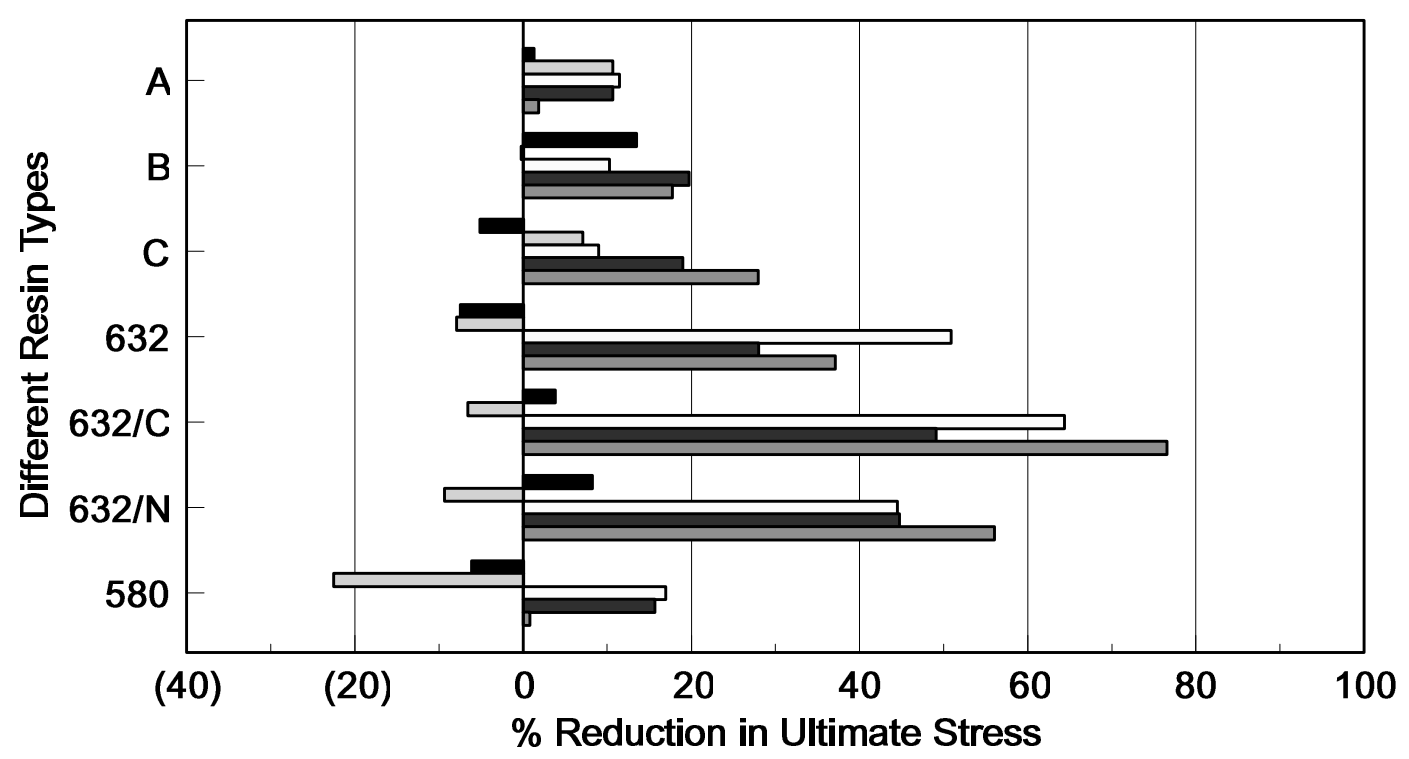

Salt

Freeze-thaw Salt Alkaline Freeze-thaw Alkaline

Stressed Alkaline

Fig. 3. 5. Variation of Tensile Strength in Conditioned \#4 GFRP Bars

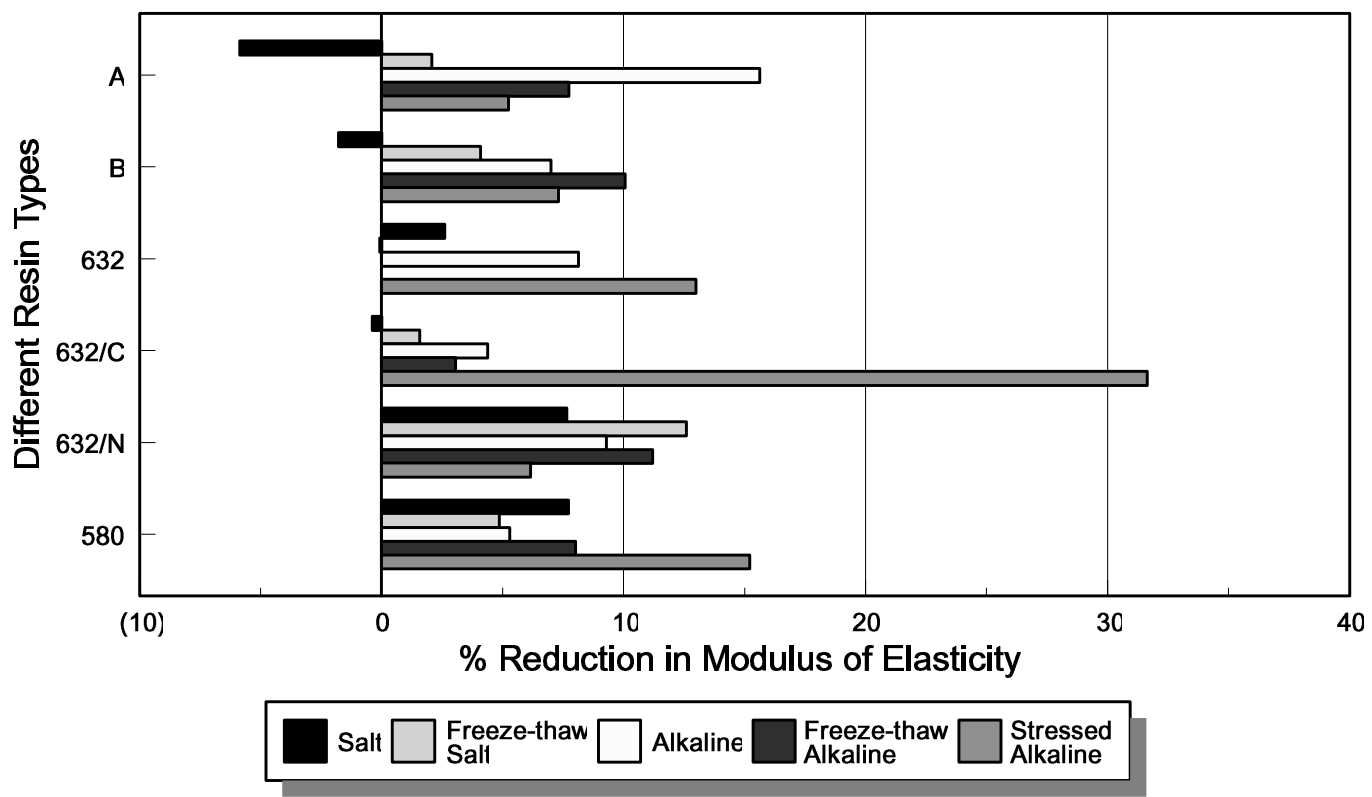

Fig. 3.6. Variation of Stiffness in Conditioned \#4 GFRP Bars 


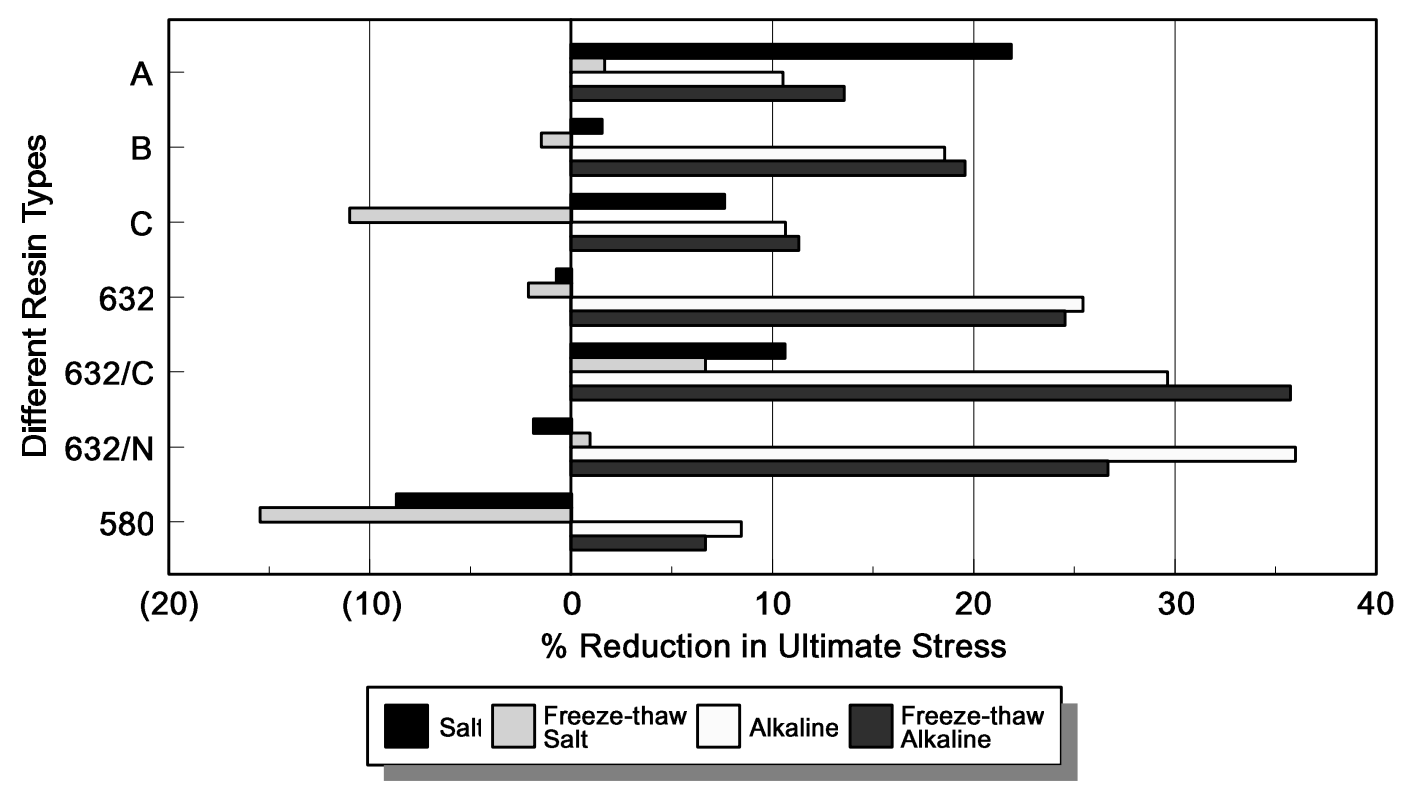

Fig. 3.7. Variation of Tensile Strength in Conditioned \#6 GFRP Bars

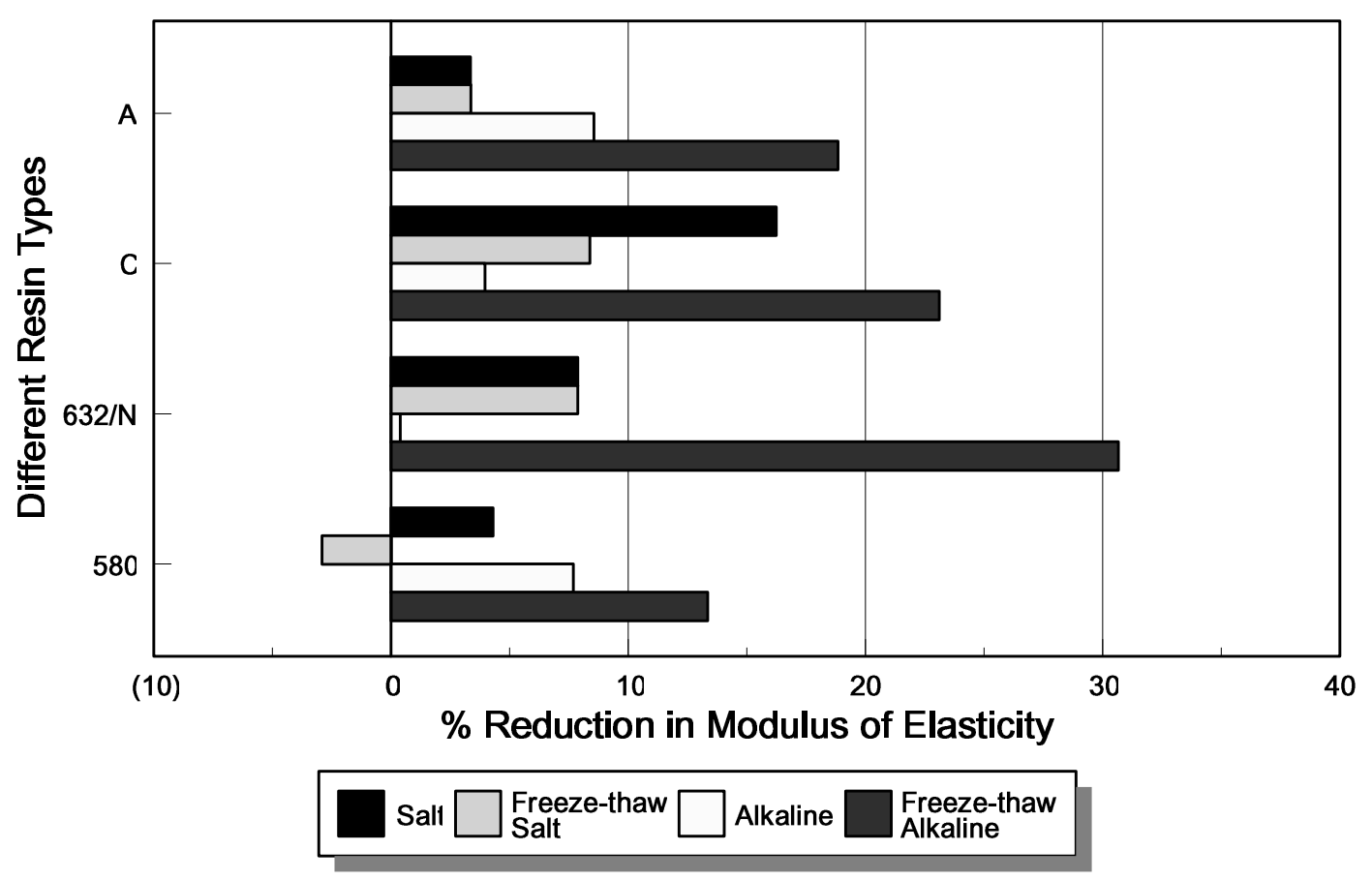

Fig. 3.8. Variation of Stiffness in Conditioned \#6 GFRP Bars 


\subsection{MICROSCOPY}

Optical microscopy was conducted on the conditioned samples with digital enhancement by video acquisition system that produced resolutions comparable to scanning electron microscopy for the purpose of observing the fibers. Results indicated better integrity of the bar provided with resin system 580 as compared to other resin systems as shown in Fig. 3.9.
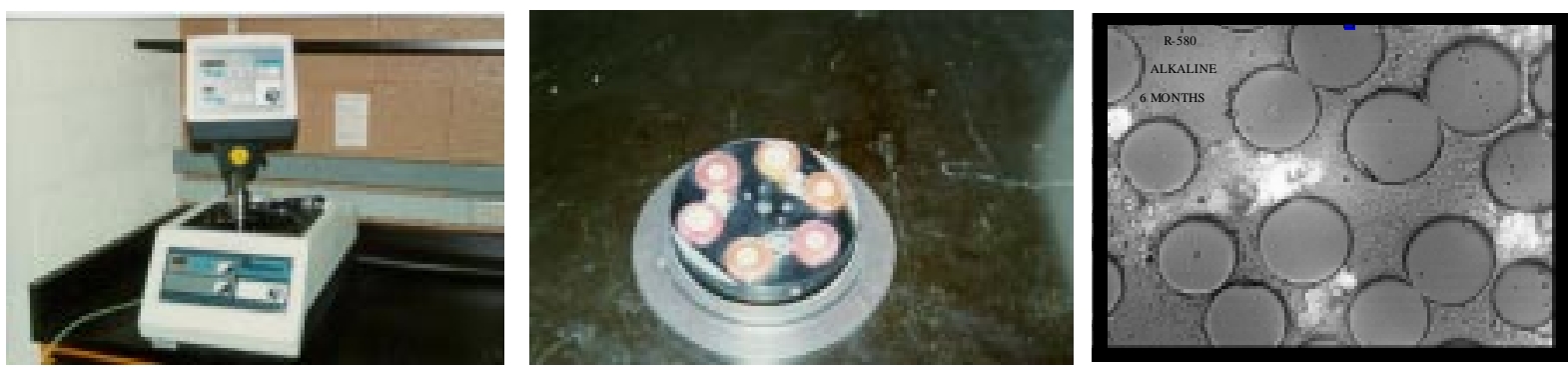

Fig.3.9 Sample Preparation and Micrography of an Alkaline Conditioned GFRP Rebar

\subsection{CONCLUSIONS}

GFRP bars exhibited excellent load carrying capacities in excess of 100 ksi. Stiffness values typically ranged between 5.2 to $5.5 \mathrm{msi}$ for unconditioned bars. Compared to \#4 bars, the higher diameter \#6 bars carried less stress. Strength reductions were more of a problem than stiffness reduction. Among conditioning environments, alkaline conditioning or a combination thereof was more detrimental and was a critical factor in the final resin selection.

Bars with urethane modified bisphenol vinylester exhibited the lowest vulnerability to different harsh environments. Though bars with isocyanurate vinylester resins (IVE) exhibited superior strength and stiffness in unconditioned, salt conditioned and freeze-thaw salt conditioned environments, severe reductions as high as $76.5 \%$ and $31.6 \%$ were observed, 
respectively, in alkaline environments. Among bars with resin system A, B or C, bars with resin system A exhibited a better overall strength and stiffness performance, particularly under alkaline environment.

Based on test results, it was concluded to research GFRP bars with resin systems 580 to establish long term durability as described in chapter 1 . This conclusion was drawn based on tension tests conducted on GFRP bars and microscopic observation of cross-sections taken from the conditioned bars. 


\section{CHAPTER 4}

\section{HYGROTHERMAL RESPONSE OF GFRP BARS UNDER DIFFERENT CONDITIONING SCHEMES}

\subsection{INTRODUCTION}

It is known that continuous exposure of FRPs to moisture causes a change in their mechanical and physical properties. Durability issues of glass fiber reinforced polymer (GFRP) bars under different environmental exposure are not yet fully understood. GFRP bars experience strength and stiffness variations and significant strength loss when exposed to solutions of high $\mathrm{pH}$ (alkaline). Use of durable and moisture impervious resins significantly increases the alkaline resistance. In this chapter, moisture absorption responses of different small scale (2" long) GFRP bars under tap water, salt water and alkaline water are studied. Moisture up-take under different temperatures including freeze-thaw cycles was also studied. To confidently design and apply the composites such as FRP bars for infrastructure applications, their response to long term moisture exposure must be known. Results obtained in this chapter will help understand the mechanical property variations of the full scale (48 in. long) GFRP bars subjected to accelerated aging described in chapter 5 .

\subsection{OBJECTIVES}

Objectives of the moisture absorption tests are:

- To determine amount of moisture absorbed in small scale GFRP bars (2" long) immersed in different conditioning solutions that represent tap water, marine water with salts, and alkaline (concrete) environment. 
- To use the information obtained from moisture absorption studies in understanding variations in strength and stiffness of full-scale GFRP bars (48 inch. long) subjected to similar environment.

\subsection{OVERVIEW}

The following parameters are necessary to describe the behavior of composite materials exposed to an environment with temperature ' $\mathrm{T} a$ ' and moisture content ' $\mathrm{c}_{\mathrm{a}}$ ' as a function of time ' $\mathrm{t}$ ' (Springer, 1981):

1. Temperature distribution inside the composite as a function of position and time $\mathrm{T}(\mathrm{x}, \mathrm{t})$

2. Moisture concentration inside the composite as a function of position and time $\mathrm{c}(\mathrm{x}, \mathrm{t})$

3. Total amount (mass) of moisture inside the composite as a function of time $\mathrm{m}(\mathrm{t})$

4. Changes in performance (e.g., physical, chemical or mechanical property) of the composite as a function of time $\mathrm{P}(\mathrm{t})$

5. For determining items 1 to 3 analytical methods can be employed if the diffusion process is "Fickian", i.e., no non-linear absorption behavior induced by cracking.

\subsubsection{Fickian Diffusion}

The diffusion process is said to be "Fickian", if the following conditions are met (Springer, 1981):

1. Heat transfer through the composite is by conduction only, and can be described by Fourier's law.

2. Moisture diffusion can by expressed by a concentration-dependent form of Fick's law. 
3. Energy (Fourier) and mass transfer (Fick) equations are decoupled.

4. Thermal conductivity and mass diffusivity depend only on temperature, and are independent of moisture concentration or the stress levels in the core.

Analytical predictions based on Fickian diffusion are a function of geometry, boundary conditions, initial conditions, and material properties such as density ( $\rho$ ), specific heat $C$, thermal conductivity $\mathrm{K}$, maximum moisture content $\mathrm{M}_{\mathrm{m}}$, and a relationship between the maximum moisture content and the ambient conditions (Shen and Springer, 1981).

Fourier's Equation of Heat Transfer:

$$
\rho C \frac{\partial T}{\partial t}=\frac{\partial}{\partial x} K_{x} \frac{\partial T}{\partial x}
$$

Where, $\rho=$ density, $C=$ specific heat, $T=$ temperature, $t=$ time, $x=$ distance, $K_{x}=$ thermal conductivity.

\section{Fick's equation of Mass Transfer:}

$$
\frac{\partial c}{\partial t}=\frac{\partial}{\partial x} D_{x} \frac{\partial c}{\partial x}
$$

where, $\mathrm{c}=$ moisture concentration, $\mathrm{D}_{\mathrm{x}}=$ diffusion coefficient, $\mathrm{x}=$ distance, $\mathrm{t}=$ time.

Diffusion is said to be non-Fickian (Shen and Springer, 1981), if:

1. Cracks develop in the composite, or delamination occurs, leading to altered structural characteristics.

2. Moisture propagation is dominated by fiber-matrix interface.

Many composites under ambient conditions follow Fickian diffusion. Accordingly, this process is extensively used for modeling purposes. Non-Fickian diffusion models are sparsely 
used because the excessively cracked specimens are removed from service well before the nonFickian phenomenon sets in, leading to lack of experimental data on specimens under service conditions.

\subsubsection{Moisture Content (M)}

The percent moisture content $\mathrm{M}$ of a composite is defined on the basis of gain in weight.

$$
\mathrm{M}=\frac{\text { Weight of the moist FRP }(w)-\text { Weight of the dry } \operatorname{FRP}\left(w_{d}\right)}{\text { Weight of the dry } \operatorname{FRP}\left(w_{d}\right)} \times 100
$$

$\mathrm{M}_{\mathrm{m}}$ is defined as the maximum moisture content that can be attained in a given environment. It is found to be insensitive to temperature fluctuations, but depends on the moisture content in the environment. For a composite material exposed to humid air, $\mathbf{M}_{\mathrm{m}}$ depends on the relative humidity $\phi$, and is given by:

$$
M_{m}=a \phi^{b} \quad \text { (for humid air exposure) }
$$

Where, $\mathrm{a}$ and $\mathrm{b}$ are constants. For a composite material immersed in a liquid, $\mathrm{M}_{\mathrm{m}}$ remains constant with time after the material reaches saturation level.

$$
\boldsymbol{M}_{m}=\text { constant } \quad \text { (for liquid immersion) }
$$

\subsubsection{Diffusion Coefficient $\left(\mathrm{D}_{\mathrm{c}}\right)$}

Diffusion coefficient characterizes the speed at which moisture is transported through the composite. The temperature dependence of diffusion coefficient for a rectangular composite exposed to moisture is characterized by Arrhenius relationship (Rao et al., 1981):

$$
D_{c}=D_{o} \exp ^{-E_{d}} / R T
$$

where, $D_{o}$ is the diffusion coefficient with respect to reference temperature, $E_{d}$ is the 
activation energy for diffusion. $\mathrm{R}$ and $\mathrm{T}$ are the universal gas constant and the absolute temperature, respectively. Diffusion coefficient $\left(D_{c}\right)$ can be calculated from Eq. 4.7 (Rao et al., 1981):

$$
D_{c}=\pi\left[\left(\frac{h}{4 M_{m}}\right)^{2}\left(\frac{M 2-M 1}{\sqrt{t_{2}}-\sqrt{t_{1}}}\right)^{2}\right]
$$

where, $\mathrm{h}=$ thickness of the composite, $\mathrm{M}_{\mathrm{m}}$ is the maximum moisture content, $\mathrm{t}_{1}$ and $\mathrm{t}_{2}$ are the time taken to reach the moisture contents $\mathrm{M}_{1}$ and $\mathrm{M}_{2}$. However, for FRP bars immersed in an alkaline or salt solution, the diffusion coefficient is a function of the depth of liquid penetration $\left(\mathrm{r}_{\mathrm{d}}\right)$, concentration of the liquid (mol/ltr.), exposure duration ( $\left.\mathrm{t}\right)$ and the bar diameter.

\subsection{TEST PROCEDURE}

\subsubsection{Moisture Absorption}

Moisture absorption tests were conducted on 2 inch long \#4 FRP bar specimens. The FRP bars were made of low viscosity, urethane modified vinylester resin matrix. The two ends of each bar were sealed using durable resin to permit moisture penetration along the radial direction only.

Moisture absorption tests were performed at room temperature, freeze-thaw temperature $\left(12^{0} \mathrm{~F}\right.$ and $\left.120^{\circ} \mathrm{F}\right)$, and $150^{\circ} \mathrm{F}$ as mentioned in Chapter 1 . Tests were also performed at $90^{\circ} \mathrm{F}$ and $120^{\circ} \mathrm{F}$. Three types of bars (one sand coated and two types of C-bars) were immersed in the required solution in small containers closed with air-tight lids as shown in Fig. 4.1. Sodium chloride $(\mathrm{NaCl})$ solution of $3 \%$ by weight was used to produce an environment typical of sea water. Alkaline solution comprised of $\mathrm{Ca}(\mathrm{OH})_{2}, \mathrm{Na}(\mathrm{OH})$, and $\mathrm{KOH}$ in concentrations of $0.2,1.0$ and $1.4 \%$ by weight, respectively, to produce an environment typical of wet Portland Cement concrete $(\mathrm{pH} 13) . \mathrm{pH}$ values were regularly monitored through a digital $\mathrm{pH}$ meter, by suitable 
calibration procedures using the buffer solutions. $\mathrm{pH}$ values in the range of 12 and 13 were maintained through regular monotoring.

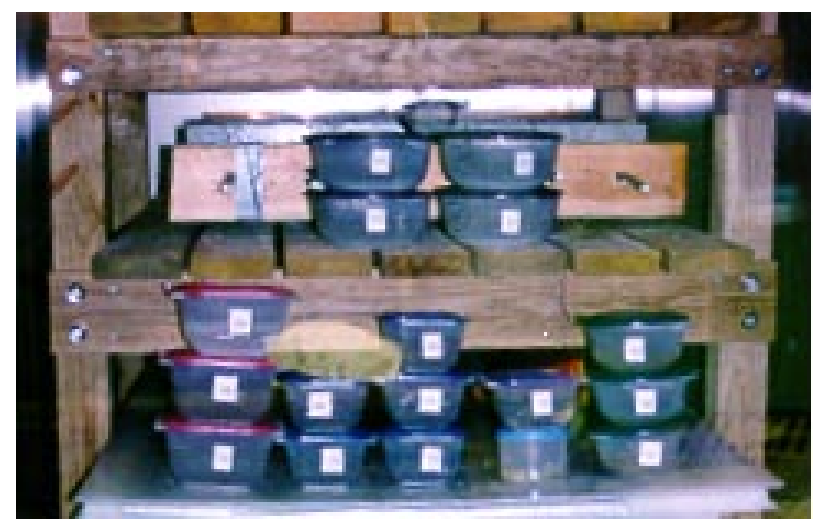

Fig. 4.1 FRP Sample Conditioning in the Thermotron Chamber

\subsubsection{Moisture and Dimension Measurements}

Changes in weight and dimensions (diameter and length) were continuously monitored for 540 days using electronic balance and digital calipers with a $10^{-3}$-sensitivity. Readings were recorded every day during the first two weeks, and later once every two weeks. Fifty-four containers were used, with three samples in each container. Samples labeled 1-18, 19-36 and 3754 were subjected to room temperature, $150^{\circ} \mathrm{F}$, and Freeze-thaw conditioning, respectively, as shown in Table 4.1. Each of the three samples in each container was identified with manufacturers name and container number, e.g., M1, M2 and I.G., for container numbers 1 to 54. 
Table 4.1 Sample Conditioning Scheme for Different Containers

\begin{tabular}{|l|l|l|l|}
\hline \multirow{2}{*}{ Conditioning } & \multicolumn{3}{|c|}{ Sample Identification Number Range } \\
\cline { 2 - 4 } & Room temp. & $\mathbf{1 5 0} \mathbf{F}$ & Freeze-thaw \\
\hline Tap water & $1-6$ & $19-24$ & $37-42$ \\
\hline Salt water & $7-12$ & $25-30$ & $43-48$ \\
\hline Alkaline solution & $13-18$ & $31-36$ & $49-54$ \\
\hline
\end{tabular}

\subsection{TEST RESULTS AND DISCUSSION}

Moisture absorption test results of samples are shown in Figs. 4.2 through 4.9 for various room temperatures and freeze-thaw conditioning. When compared at the end of about 200 days, alkaline immersion produced at least twice the moisture absorption by weight, as compared to those of the tap and salt water immersion under room temperature, freeze-thaw conditioning, and $90^{\circ} \mathrm{F}$ and $150^{\circ} \mathrm{F}$ (Tables $4.2,4.3$ and 4.4 ). Variation in the magnitude of moisture absorption in different solutions is an indication of the degradation rate caused by alkaline solution in comparison to tap water and salt solution. Maximum moisture content for different bars immersed in different $\mathrm{pH}$ solutions, different temperatures, and time intervals are listed in Tables 4.2-4.4. It may be noted that comparison at $150^{\circ} \mathrm{F}$ is limited to only 50 days of time interval. Due to chamber malfunctioning, and a fire problem experiments were not conducted at $150^{\circ} \mathrm{F}$ beyond 50 days. Alkaline conditioning at $150^{\circ} \mathrm{F}$ produced large cracks in the resin matrix. Resin matrix cracking was also observed under alkaline conditioning at $120^{0} \mathrm{~F}$ after 250 days of conditioning. The following observations are made from these tests.

- For tap water, salt water and alkaline solution, maximum moisture content generally increased with temperatures, i.e., room temperature, freeze-thaw temperature, $90^{0} \mathrm{~F}, 120^{0} \mathrm{~F}$ (Fig. 4.8) and $150^{\circ} \mathrm{F}$ (Fig. 4.9). 
- Under room temperature, rate of moisture uptake nearly leveled off after about 200 days. Prior to leveling-off, bi-linear moisture pick-up was found and absorption was noted to be high during the initial 25 to 50 days.

- Under freeze-thaw conditioning, rate of moisture uptake leveled off after 300 days or earlier. Prior to leveling-off, bi-linear moisture pick-up found and absorption was noted to be high during the initial 25 to 50 days.

- In the room temperature and freeze-thaw conditioning schemes for 543 days, maximum moisture content was found to be $0.35,0.61$, and 0.48 , respectively, for bars M1, M2, and IG in alkaline solution.

- In the $90^{\circ} \mathrm{F}$ and $120^{\circ} \mathrm{F}$ conditioning schemes for 200 days, maximum moisture content was found to be $0.80,0.98$ and 1.1, respectively, for bars M1, M2 and IG in alkaline solution. Bars also exhibited matrix cracking in the alkaline solution at $120^{\circ} \mathrm{F}$ temperature. In comparison, at same temperatures, the moisture absorption noted to vary from one-third to one-half in salt and tap water solutions.

Table 4.2 Comparison of Moisture Content (\% by weight) of Marshall Bars (M1) for Different Conditioning Schemes

\begin{tabular}{|c|c|c|c|c|c|c|c|c|c|c|c|c|c|c|c|c|c|}
\hline \multirow[b]{2}{*}{ Days } & \multicolumn{4}{|c|}{ Room Temperature } & \multicolumn{4}{|c|}{ Freeze-Thaw Temp. } & \multicolumn{4}{|c|}{$90^{0} \mathrm{~F}$} & \multicolumn{4}{|c|}{$120^{0} \mathrm{~F}$} & $150^{0} \mathrm{~F}$ \\
\hline & 50 & 100 & 150 & 200 & 50 & 100 & 150 & 200 & 50 & 100 & 150 & 200 & 50 & 100 & 150 & 200 & 50 \\
\hline TAP & .148 & .192 & 209 & .214 & .206 & .205 & .214 & 245 & .185 & .205 & .231 & .265 & .198 & .220 & .254 & .271 & .363 \\
\hline SALT & .170 & .192 & 215 & .213 & .145 & .184 & .203 & .207 & .174 & .198 & .235 & .261 & .201 & .229 & .268 & .280 & .308 \\
\hline ALK. & .295 & .388 & .416 & .418 & .235 & 285 & .369 & .302 & .421 & .599 & .655 & .735 & .457 & .627 & .703 & .796 & .611 \\
\hline
\end{tabular}


Table 4.3 Comparison of Moisture Content (\% by weight) of Marshall Bars (M2) for Different Conditioning Schemes

\begin{tabular}{|c|c|c|c|c|c|c|c|c|c|c|c|c|c|c|c|c|c|}
\hline & \multicolumn{4}{|c|}{ Room Temperature } & \multicolumn{4}{|c|}{ Freeze-Thaw Temp. } & \multicolumn{4}{|l|}{$90^{0} \mathrm{~F}$} & \multicolumn{4}{|c|}{$120^{0} \mathrm{~F}$} & $150^{\circ} \mathrm{F}$ \\
\hline Days & 50 & 100 & 150 & 200 & 50 & 100 & 150 & 200 & 50 & 100 & 150 & 200 & 50 & 100 & 150 & 200 & 50 \\
\hline TAP & .149 & .232 & .267 & .292 & .190 & .261 & .297 & .370 & .244 & .294 & .341 & .390 & .346 & .410 & .454 & .484 & .428 \\
\hline SALT & .169 & .218 & .261 & .273 & .188 & .253 & .303 & .385 & .245 & .284 & .299 & .334 & .269 & .306 & 6.316 & .392 & .374 \\
\hline ALK. & .247 & .336 & .392 & .456 & .212 & .295 & .331 & .335 & .613 & .737 & .778 & .793 & .715 & .8 & 7.922 & .978 & .765 \\
\hline
\end{tabular}

Table 4.4 Comparison of Moisture Content (\% by weight) of IG Bars for Different Conditioning Schemes

\begin{tabular}{|c|c|c|c|c|c|c|c|c|c|c|c|c|c|c|c|c|c|}
\hline \multirow[b]{2}{*}{ Days } & \multicolumn{4}{|c|}{ Room Temperature } & \multicolumn{4}{|c|}{ Freeze-Thaw Temp. } & \multicolumn{4}{|l|}{$90^{0} \mathrm{~F}$} & \multicolumn{4}{|c|}{$120^{0} \mathrm{~F}$} & \multirow{2}{*}{\begin{tabular}{|l|}
$150^{0} \mathrm{~F}$ \\
50
\end{tabular}} \\
\hline & 50 & 100 & 150 & 200 & 50 & 100 & 150 & 200 & 50 & 100 & 150 & 200 & 50 & 100 & 150 & 200 & \\
\hline TAP & .169 & .256 & .285 & .291 & 215 & .273 & .286 & .325 & .156 & 256 & .309 & .325 & 321 & .359 & .384 & .397 & .362 \\
\hline SALT & .144 & .184 & .203 & .215 & 126 & .163 & .191 & .245 & .158 & 199 & .191 & .251 & 374 & .470 & .506 & .538 & .411 \\
\hline ALK. & .087 & .198 & .232 & .286 & .136 & .169 & .201 & .195 & .351 & .445 & .201 & .611 & .387 & .556 & .809 & 1.056 & .459 \\
\hline
\end{tabular}

Table 4.5 Maximum Moisture Content (\% by weight) for Different GFRP Bars

\begin{tabular}{|l|c|c|c|c|c|c|c|c|c|c|c|c|c|}
\hline & \multicolumn{3}{|c|}{ Room Temp. } & \multicolumn{3}{|c|}{ Freeze-Thaw Temp. } & \multicolumn{3}{c|}{$90^{0}$ F } & \multicolumn{3}{c|}{ 120 F $^{\mathbf{0}}$} \\
\hline Days & \multicolumn{3}{|c|}{$\mathbf{5 4 3}$} & \multicolumn{3}{c|}{$\mathbf{5 4 3}$} & \multicolumn{3}{c|}{$\mathbf{2 0 0}$} & \multicolumn{3}{c|}{200} \\
\hline Bar & M1 & M2 & IG & M1 & M2 & IG & M1 & M2 & IG & M1 & M2 & IG \\
\hline TAP & 0.22 & 0.33 & 0.30 & 0.28 & 0.49 & 0.41 & 0.27 & 0.39 & 0.33 & 0.27 & 0.48 & 0.40 \\
\hline SALT & 0.22 & 0.33 & 0.22 & 0.30 & 0.57 & 0.32 & 0.26 & 0.33 & 0.25 & 0.28 & 0.39 & 0.54 \\
\hline ALK. & 0.49 & 0.49 & 0.40 & 0.35 & 0.61 & 0.48 & 0.74 & 0.80 & 0.61 & 0.80 & 0.98 & 1.1 \\
\hline
\end{tabular}




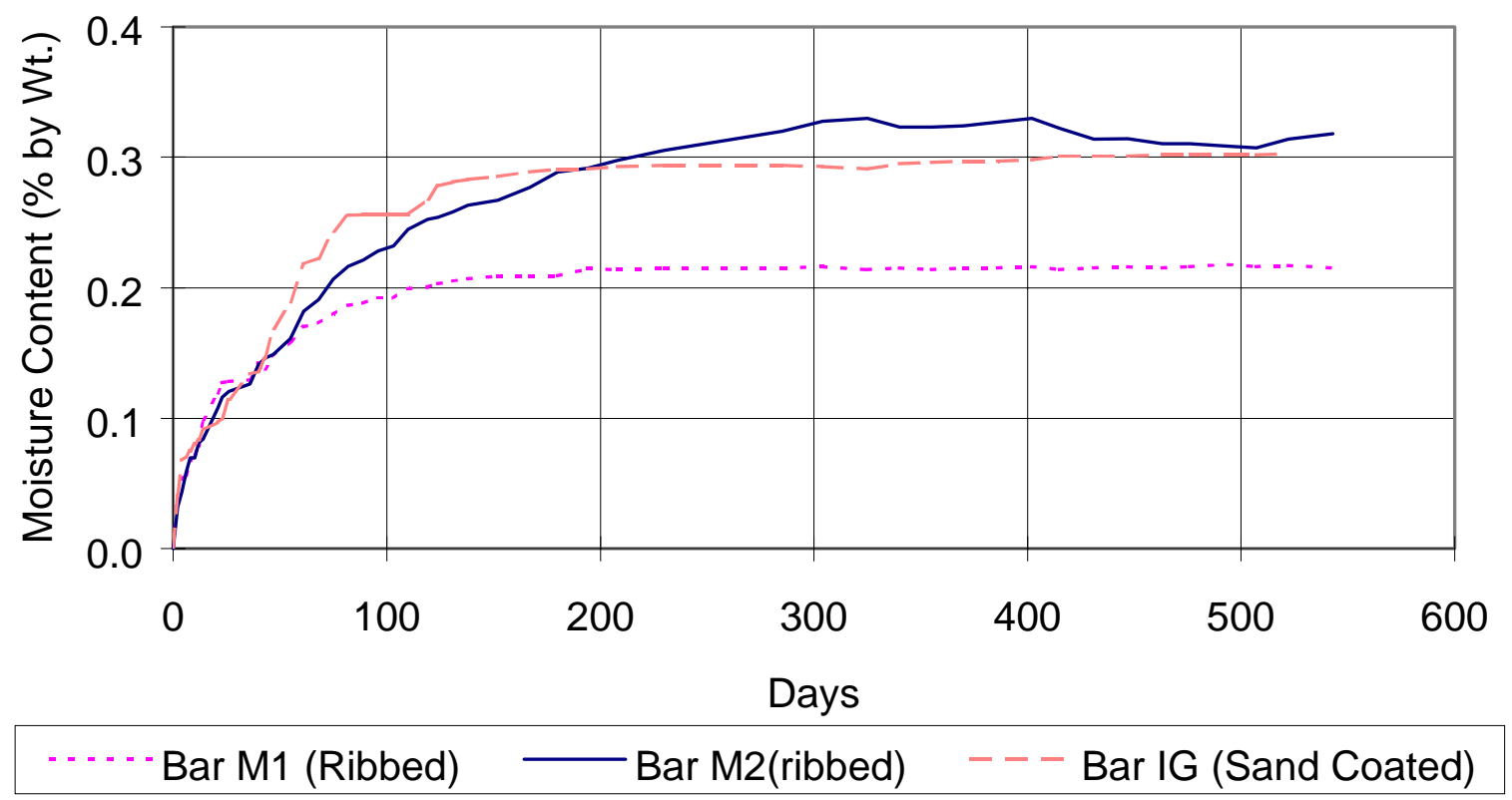

Fig. 4.2 Moisture Content of GFRP Bars Immersed in Tap Water at Room Temperature (Each Data Point is Average of 6 Specimens)

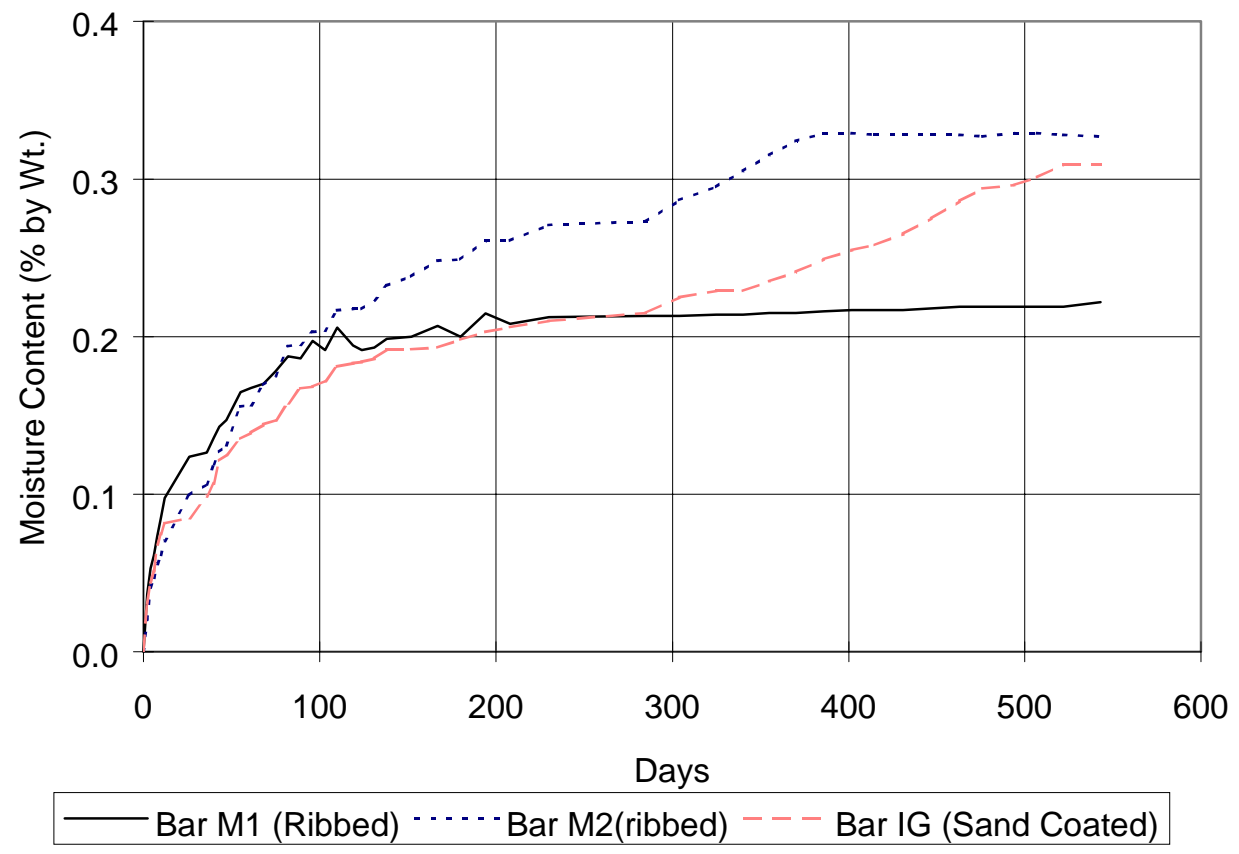

Fig. 4.3 Moisture Content of GFRP Bars Immersed in Salt Water at Room Temperature (Each Data Point is Average of 6 Specimens) 


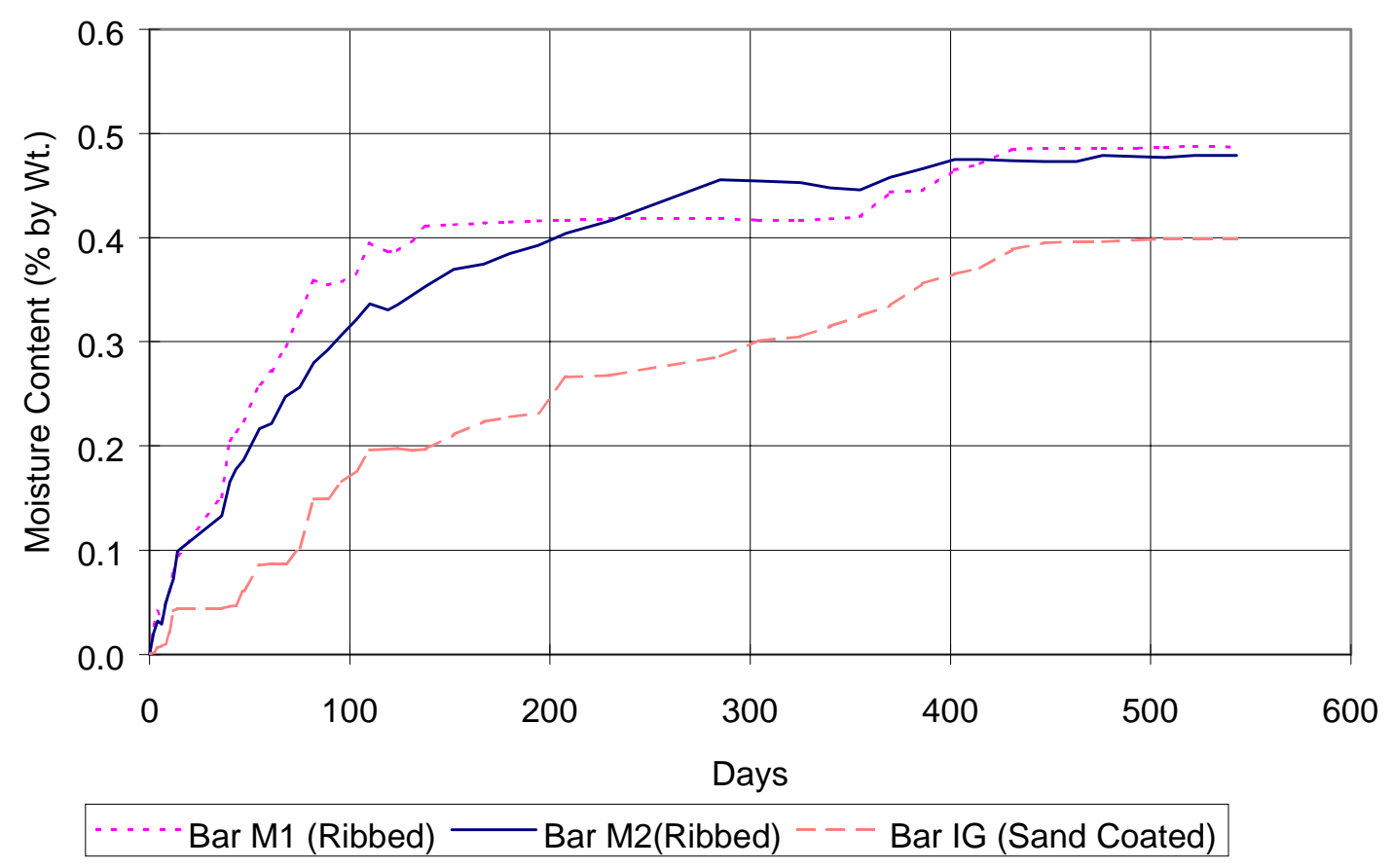

Fig. 4.4 Moisture Content of GFRP Bars Immersed in Alkaline Water at Room Temperature (Each Data Point is Average of 6 Specimens)

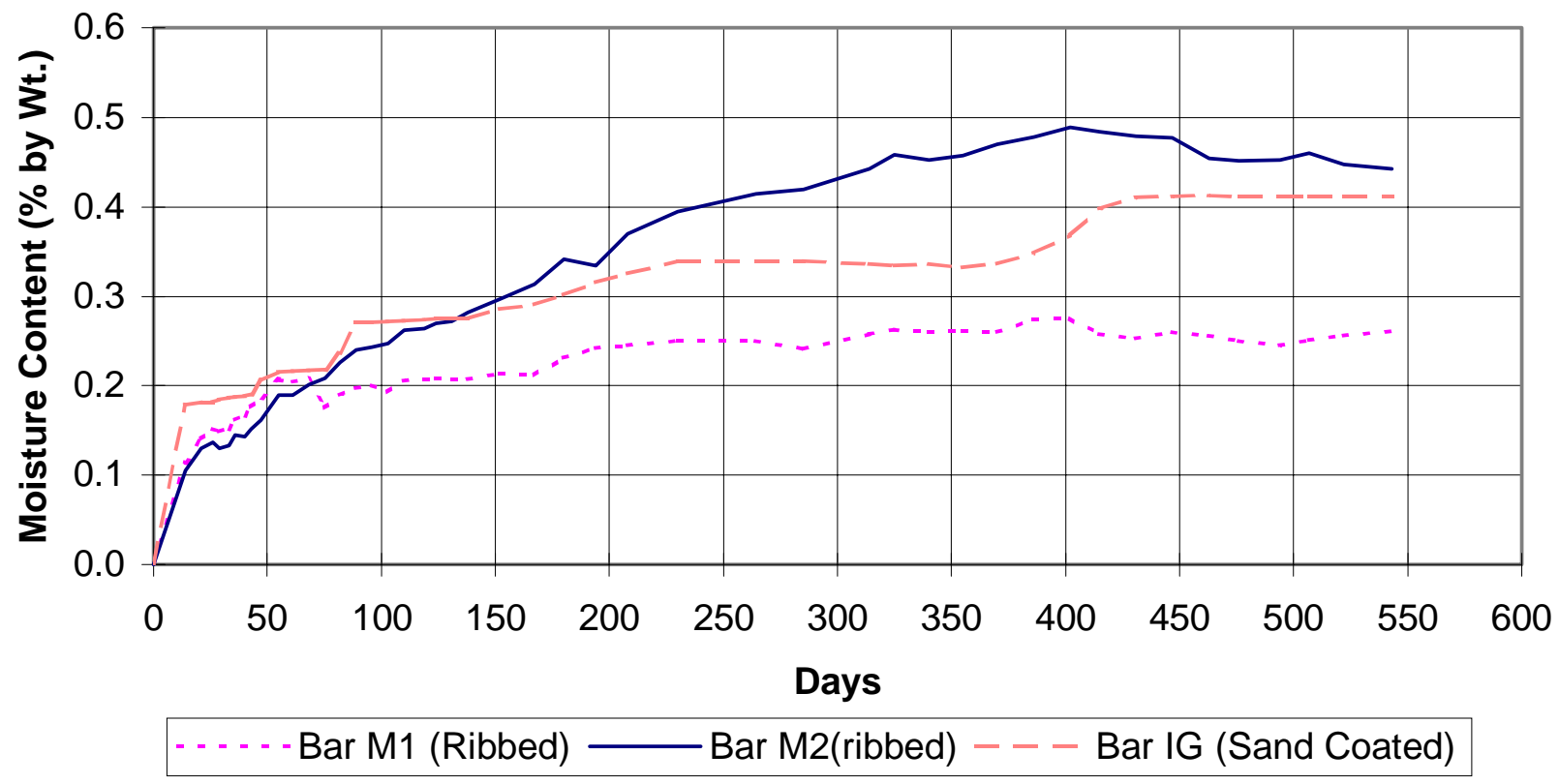

Fig.4.5 Moisture Content of GFRP Bars Immersed in Tap Water under Freeze-thaw Conditioning (Each Data Point is Average of 6 Specimens) 


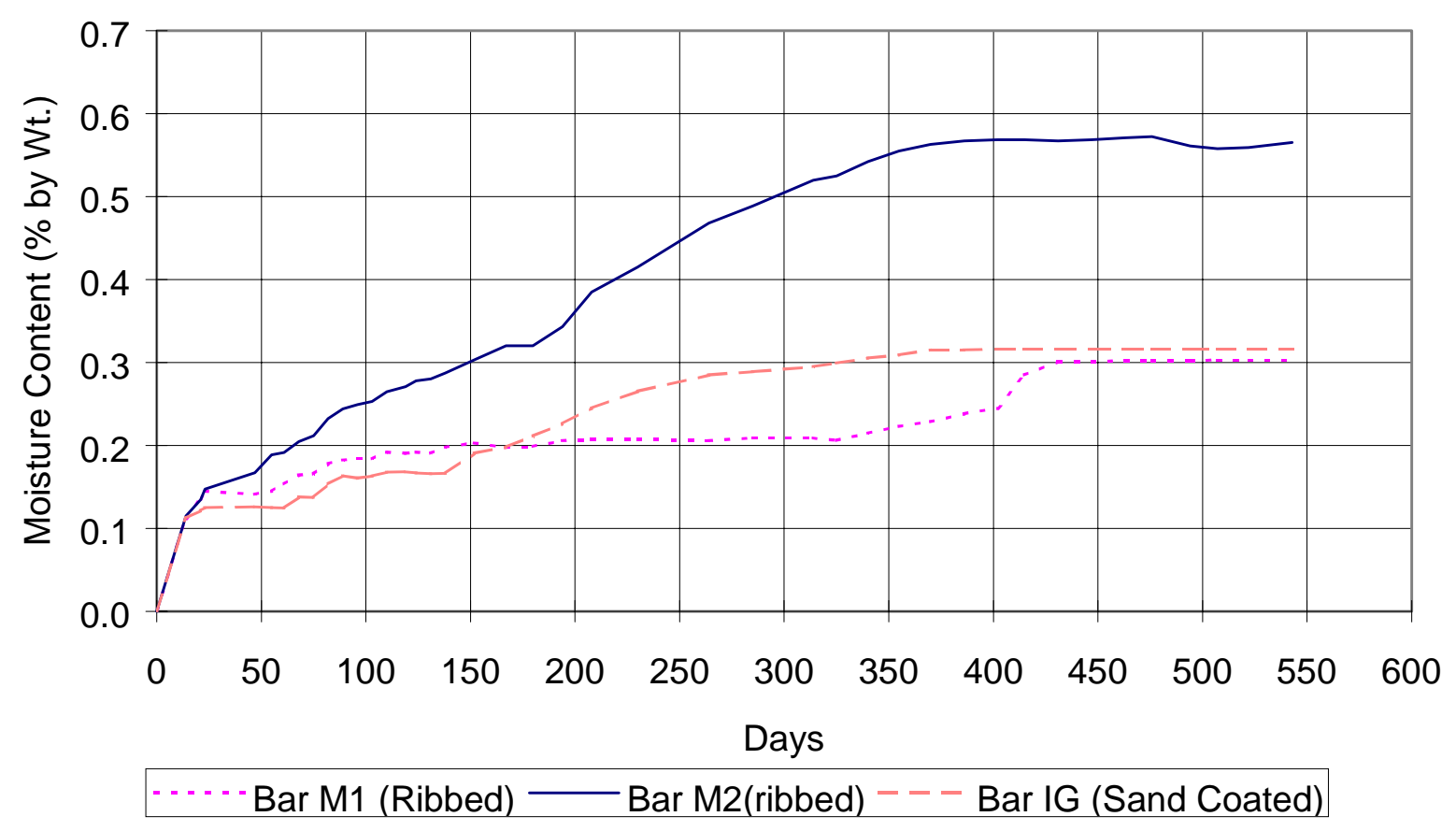

Fig.4.6 Moisture Content of GFRP Bars Immersed in Salt Water under Freeze-thaw Conditioning (Each Data Point is Average of 6 Specimens)

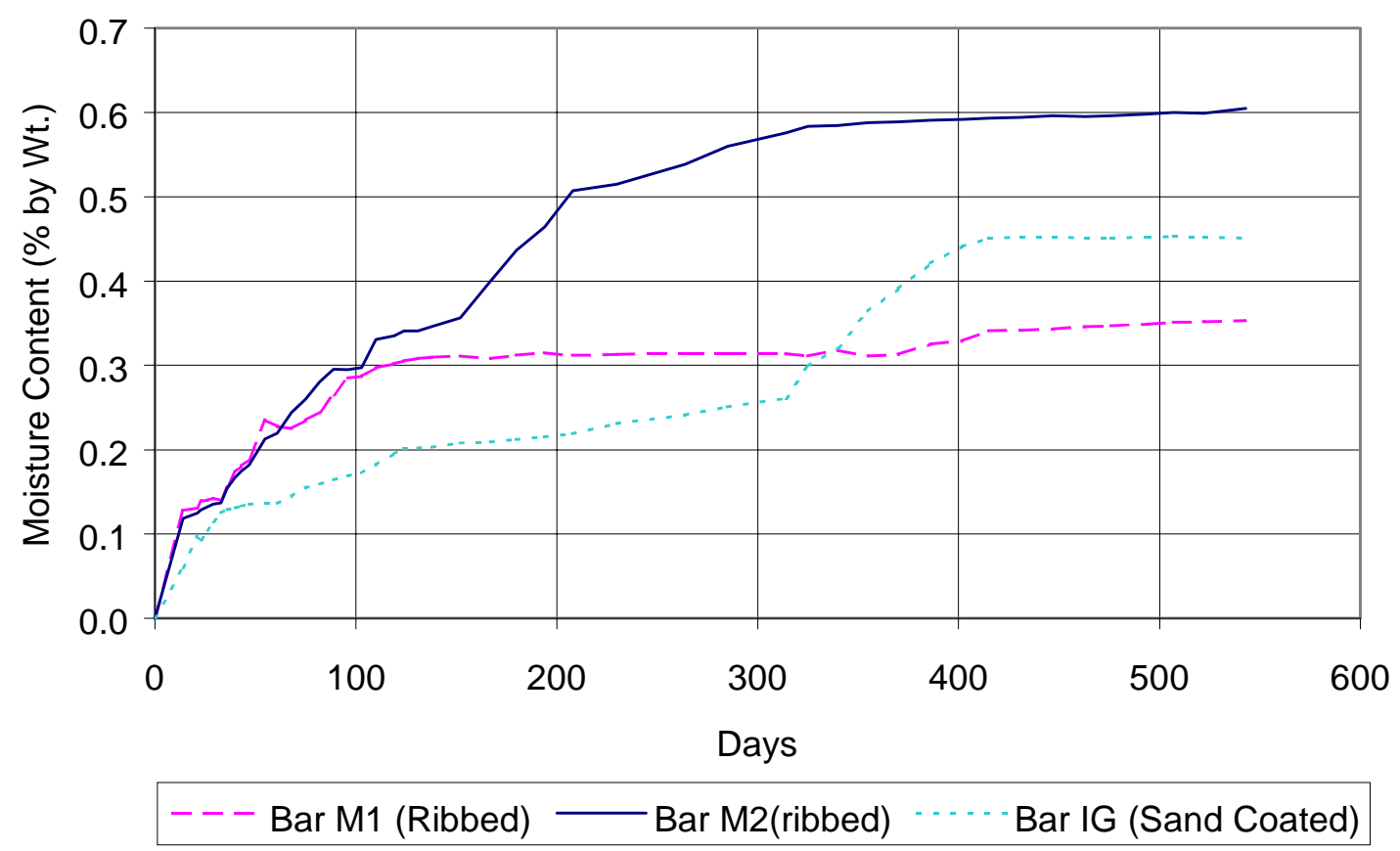

Fig.4.7 Moisture Content of GFRP Bars Immersed in Alkaline Water under Freeze-thaw Conditioning (Each Data Point is Average of 6 Specimens) 


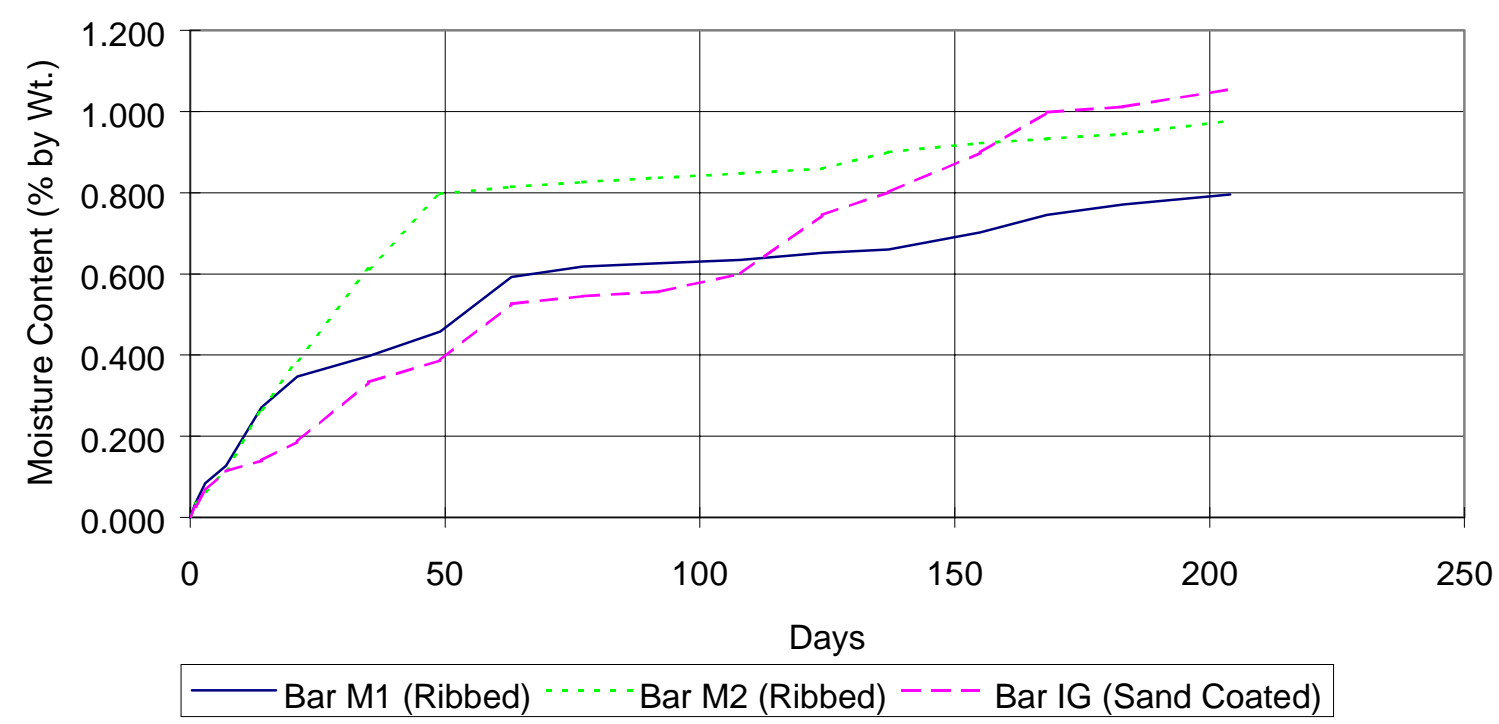

Fig.4.8 Moisture Content of GFRP Bars Immersed in Alkaline Water under ${ }^{120}{ }^{\circ} \mathrm{F}$ Conditioning (Each Data Point is Average of 3 Specimens)

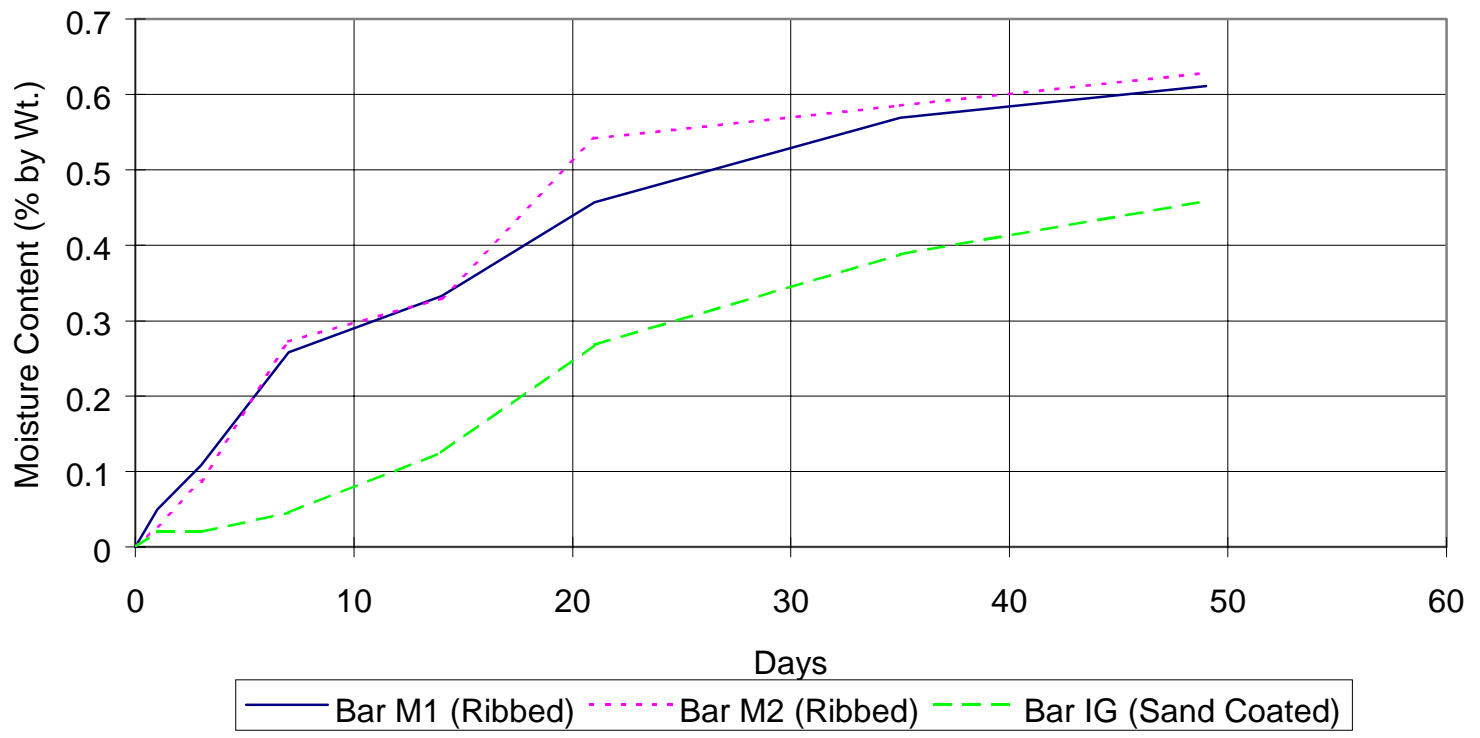

Fig.4.9 Moisture Content of GFRP Bars Immersed in Alkaline Water under $150^{\circ} \mathrm{F}$ (Each Data Point is Average of 3 Specimens) 


\subsection{CONCLUSIONS}

Tables 4.2-4.5 and Figs. 4.2-4.9 indicate strong temperature dependence of moisture absorption in GFRP bars under different conditioning schemes. Moisture absorption was found to increase with temperature. Alkaline conditioning resulted in maximum moisture absorption as compared to other solutions. Maximum moisture content less than $0.6 \%$ was observed after 543 days of conditioning under room and freeze-thaw temperatures for tap water, salt water, and alkaline solution immersions. On an average, alkaline conditioning produced about twice, and in some cases three times the moisture content as compared to tap and salt-water conditioning. Higher absorption of alkaline solution in relation to other solutions is an indication of the relative degradation in tensile strength of GFRP bars, and anticipated in accelerated aging tests (described in the chapter 5).

Scanning Electron Microscopy (SEM) tests will be conducted on these samples to establish the rate of diffusion for deriving diffusion contents, and correlate them to strength and stiffness degradation rates. The diffusion coefficient is a function of not only the voids in GFRP bars, but also of sustained tensile stress, temperature, and hydrostatic pressure. 


\section{CHAPTER 5}

\section{ACCELERATED AND NATURAL WEATHERING OF GFRP BARS}

\subsection{INTRODUCTION}

Fiber Reinforced Polymer (FRP) reinforcing bars are known to be superior to steel bars. Also, FRP composites are simple and economical structural materials for rehabilitating our deteriorating infrastructure facilities, and for reinforcing the new construction. However, selection of proper FRP materials to reinforce or repair an aged concrete structure is key to the success of FRP construction, as noted by the American Concrete Institute in its draft publication ACI-440 H. Commercial use of FRP products is seriously hindered by lack of experimental or field data and lack of understanding of durability aspects under real-life weathering, such as freeze-thaw cycles, alkaline and deicing chemical exposure, and mechanical stress cycles (live loads).

Objective of this research is to conduct accelerated tests for establishing durability of GFRP bars and understanding long-term behavior of GFRP reinforced concrete members, including strength and stiffness degradation rates due to physical and chemical aging. In this chapter, results of accelerated aging of GFRP bars exposed to varying humidity levels, temperatures, sustained stresses, and $\mathrm{pH}$ levels are presented. Aging results are calibrated using natural weathering data obtained by other researchers (Litherland, 1981). Also, a WVU methodology is presented for correlating natural weathering data to the accelerated aging data developed by using an environmental chamber. 


\subsection{OVERVIEW}

\subsubsection{Glass Composition}

Glass composition, glass homogeneity, temperature, stress, corrosion media influence the changes in mechanical, thermal, and chemical properties of glass (Adams, 1984). Resins play an important role in protecting glass fibers. Chemical Composition of E-Glass fibers is given in Table 5.1.

Table 5.1 Chemical Composition of E-Glass Fibers

\begin{tabular}{|c|c|c|c|c|c|c|}
\hline $\mathbf{S i O}_{2}$ & $\mathbf{A l}_{\mathbf{2}} \mathbf{O}_{\mathbf{3}}$ & $\mathbf{C a O}$ & $\mathbf{M g O}$ & $\mathbf{B}_{\mathbf{2}} \mathbf{O}_{\mathbf{3}}$ & $\mathbf{N a}_{\mathbf{2}} \mathbf{O}_{\mathbf{3}}$ & Others \\
\hline 54.5 & 14.5 & 17 & 4.5 & 8.5 & 0.5 & $0.5 \%$ \\
\hline
\end{tabular}

\subsubsection{Glass Corrosion}

Corrosion mechanism in glass can be due to the presence of: (1) alkali solution; (2) acidic solution, and (3) solutions of neutral $\mathrm{pH}$.

5.2.2.1 Alkaline attack : Alkaline attack is described by two theories, viz., (1) etching (Adams, 1984), (2) hydroxilation and dissolution leading to notching (Yilmaz and Glasser, 1991). Etching is produced by an alkali attack. As the silica network is attacked, other components of the glass are released (Fig. 5.1). If there is no further accumulation of reaction products on the remaining glass surface and no change in the activity of the surrounding solution, reaction proceeds at a constant rate. However, any accumulation of reaction products in solution suppresses the reaction rate, such that saturated silica will reduce the reaction rate to zero (Adams, 1984).

$$
2 \times \mathrm{NaOH}+\left(\mathrm{SiO}_{2}\right) \times \text {-----> } \mathrm{x} \mathrm{Na}_{2} \mathrm{SiO}_{3}+\mathrm{x} \mathrm{H}_{2} \mathrm{O}
$$




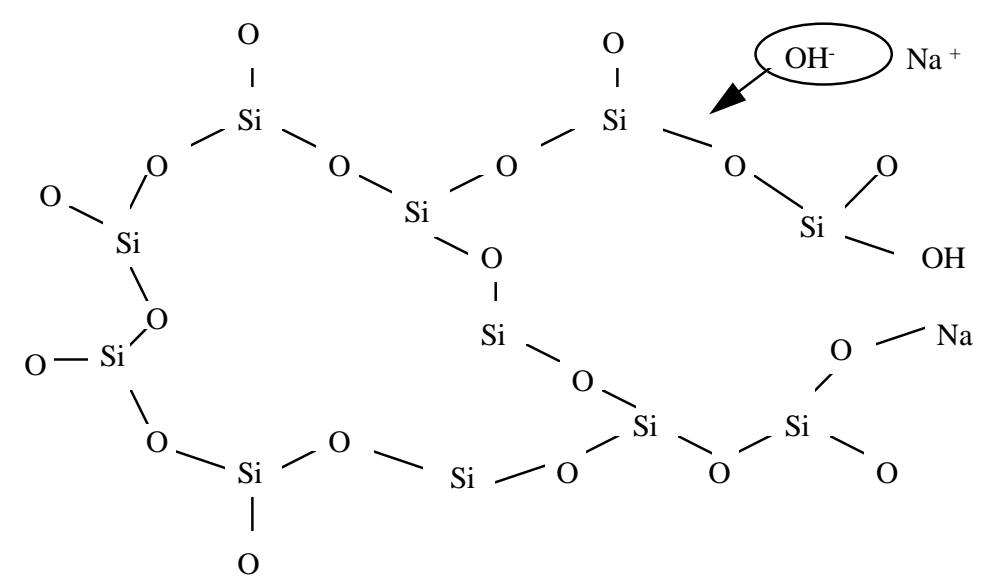

Fig. 5.1 Schematic Representation of Etching Process (Adams, 1984)

The two mechanisms involved in alkaline attack are hydroxilation and dissolution, and notching (Yilmaz and Glasser, 1991). Hydroxilation and dissolution is caused by chemical hydroxilation of silica in the glass. Deposition of the hydroxilation product on the glass surface slows down the reaction. Hydroxilation is associated with dissolution and is characterized by leaching of calcium from the glass. The leached calcium when combined with water, deposits a calcium hydroxide compound on the surface of the glass and drastically reduces the rate of reaction. Following hydroxilation and dissolution, notching is caused by the formation of calcium hydroxide crystals on the glass surface as found by X-ray diffraction analysis (Al Cheikh and Murat, 1988).

5.2.2.2 Acid attack: Acid attack leads to leaching process, where, hydrogen or hydronium ions exchange for alkali and other positive mobile ions in the glass (Fig. 5.2). The remaining glass network, mainly silica, retains its integrity. It may become hydrated if the network is relatively unstable; or it may become more dense and stable than original glass. Unless the leached layer is removed or altered, reaction rate reduces even to zero. Acid reacts slowly with glass in 
comparison to reaction with alkali. There is not much difference in the effect of low acidic $\mathrm{pH}$ or that of $\mathrm{pH} 5$ to 6 (Adams, 1984).

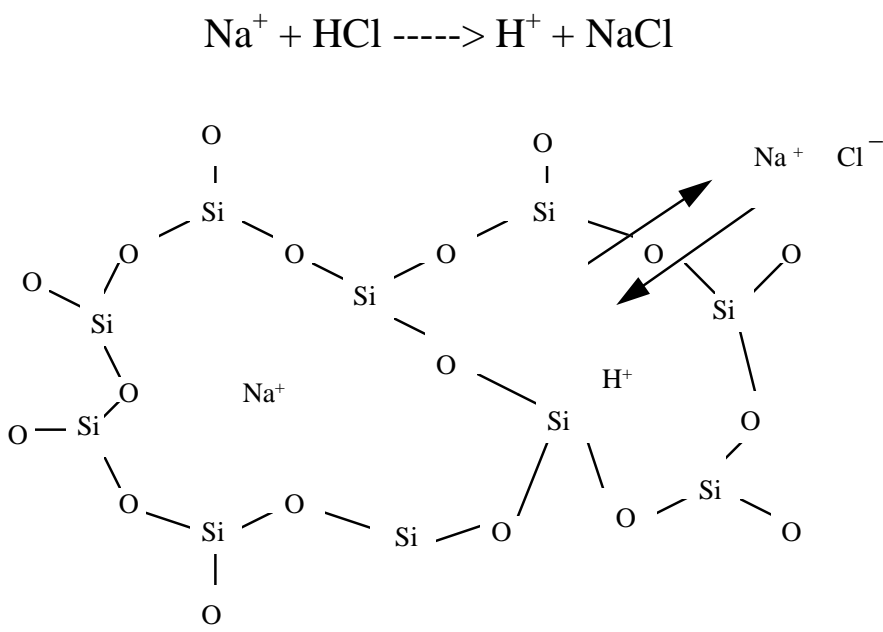

Fig. 5.2 Schematic Representation of Leaching Process (Adams, 1984)

5.2.2.3 Neutral pH solution attack: Water, salt and other solutions of neutral pH produce attack on glass similar to those of acids. Also, neutral or acidic solution attack on glass may in turn become alkali attack. Alkalies removed during acidic or neutral $\mathrm{pH}$ solution attack will again reenter the solution surrounding the bulk glass and proceed to cause etching described earlier.

In this study, response of salt and alkaline attack on GFRP bars used for reinforcing concrete structures is studied. Concrete structures are naturally alkaline. Reinforced concrete structures are exposed to rain, deicing salts or other chemicals depending on their function and location. Hence, the objective of this investigation is to establish mechanical properties of GFRP bars under salt and alkaline conditioning with temperature variations typical of the harsh field conditions, and establish their service life durability for design purposes. Different conditioning schemes selected in this study are described in section 5.3. 


\subsection{CONDITIONING METHODS AND TESTING PROCEDURES FOR GFRP BARS}

Conditioning methods consisted of exposing GFRP bars to a particular environment in specially coated steel containers stiffened with steel angles or high-density polyurethane containers. Tightly covered containers with the bars immersed in chemical solutions were placed in an environmental chamber for the desired duration, or stored at room temperature. Following the desired conditioning period, bars were tested under uniaxial tension.

\subsubsection{Salt Conditioning and Freeze-Thaw Temperature}

For tests at room temperature, bars were placed in a $3 \mathrm{ft} . \mathrm{x} 4 \mathrm{ft}$. polyurethane tank filled with salt solution, consisting of 3\% sodium chloride and $97 \%$ water. Sand-coated bars of type IG1 were conditioned in the covered container for 3, 8 and 15 months at room temperature, whereas, ribbed C-bars M1 and M2 were conditioned for about 30 months. Salt and alkaline solutions used for conditioning the specimens were periodically checked for any variation in the $\mathrm{pH}$ values using digital $\mathrm{pH}$ meter periodically calibrated against buffer solutions of standard $\mathrm{pH}$ values (7.0 and 13.0).

For freeze-thaw temperature conditioning, bars were placed in another $3 \mathrm{ft} . \mathrm{x} 4 \mathrm{ft}$., high density polyurethane (HDPE) tank containing salt solution with 3\% sodium chloride and 97\% water. The tank was covered with a lid and positioned inside the Thermotron environmental chamber as shown in Fig. 5.3. Several pilot tests were conducted on the computer-controlled environmental chamber to verify the programming sequence for the desired freeze-thaw cycles (Table 5.2). 
Table 5.2 Thermotron Chamber Temperature and Humidity

\begin{tabular}{|c|c|c|c|c|c|}
\hline \multirow[t]{2}{*}{$\begin{array}{l}\text { Number of } \\
\text { Hours }\end{array}$} & \multicolumn{2}{|c|}{ Chamber Temperature } & \multicolumn{2}{|c|}{$\begin{array}{c}\text { Average Chamber } \\
\text { Temperature }\end{array}$} & \multirow[t]{2}{*}{$\begin{array}{c}\text { Humidity } \\
(\%)\end{array}$} \\
\hline & ${ }^{0} \mathbf{F}$ & ${ }^{0} \mathrm{C}$ & ${ }^{0} \mathbf{F}$ & ${ }^{0} \mathrm{C}$ & \\
\hline 1 & 69.8 to 109.4 & 21 to 43 & 89.6 & 32 & 0 to 95 \\
\hline 23 & 109.4 & 43 & 109.4 & 43 & 95 \\
\hline 1 & 109.4 to 120.2 & 43 to 49 & 114.8 & 46 & 95 to 10 \\
\hline 23 & 120.2 & 49 & 120.2 & 49 & 10 \\
\hline 1 & 120.2 to 71.6 & 49 to 22 & 95.9 & 35.5 & 10 to 95 \\
\hline 23 & 69.8 & 22 & 69.8 & 22 & 95 \\
\hline 4 & 71.6 to 12.2 & 22 to -11 & 41.9 & 5.5 & 95 to 0 \\
\hline 8 & 12.2 & -11 & 12.2 & -11 & 0 \\
\hline 3 & 12.2 to 109.4 & -11 to 43 & 60.8 & 16 & 0 to 95 \\
\hline 31 & 109.4 & 43 & 109.4 & 43 & 95 \\
\hline 3 & 109.4 to 69.8 & 43 to 21 & 89.6 & 32 & 95 to 0 \\
\hline
\end{tabular}

Note: Weighted chamber temperature was calculated by considering the duration of each temperature, because, while correlating the accelerated weathering to natural weathering, single representative average temperature is necessary. 


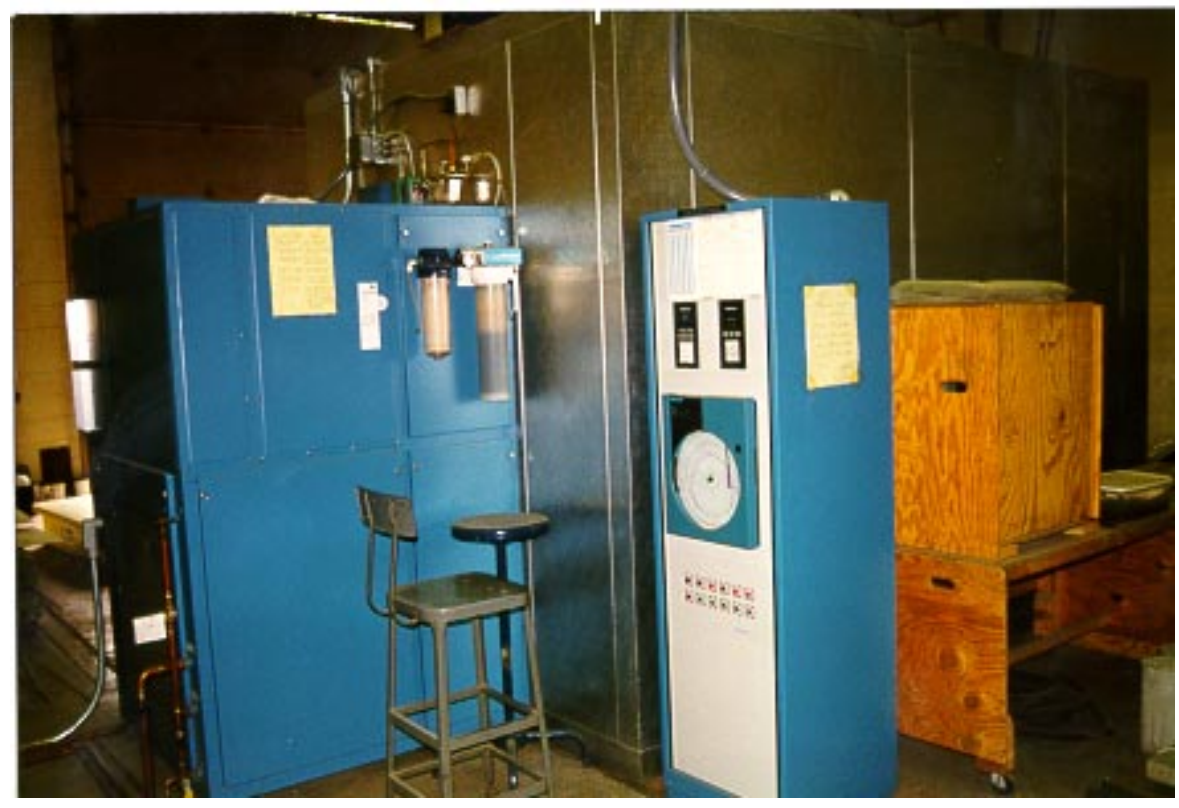

Fig. 5.3 Thermotron Environmental Chamber

\subsubsection{Alkaline Conditioning at Room and Freeze-Thaw Temperatures}

Bars were placed in polyurethane tanks filled with alkaline solution of $\mathrm{pH} \sim 13$, representing the alkalinity of Portland cement. Alkaline solution consisted $0.2 \%$ calcium hydroxide, $1.4 \%$ potassium hydroxide, $1 \%$ sodium hydroxide, and $97.4 \%$ water.

For freeze-thaw tests, bars were placed in polyurethane container with $\mathrm{pH} \approx 13$ solution and conditioned inside the Thermotron environmental chamber.

\subsubsection{Stressed-Salt and Stressed-Alkaline Conditioning at Room/Freeze Thaw Temperatures}

Bars were conditioned in a specially designed steel frame, treated with anti-corrosive coatings. Single cell and multiple cell type frames were manufactured at CFC-WVU laboratories. The frames were drilled with holes conforming to the bar diameter. Bars inserted into each steel frame were stressed using prestressing chucks and a Dywidag jack. Stressing frame provided two 
locations within the stressed region of the bar, one for conditioning and the other for monitoring strain through the strain gage mounted prior to stressing.

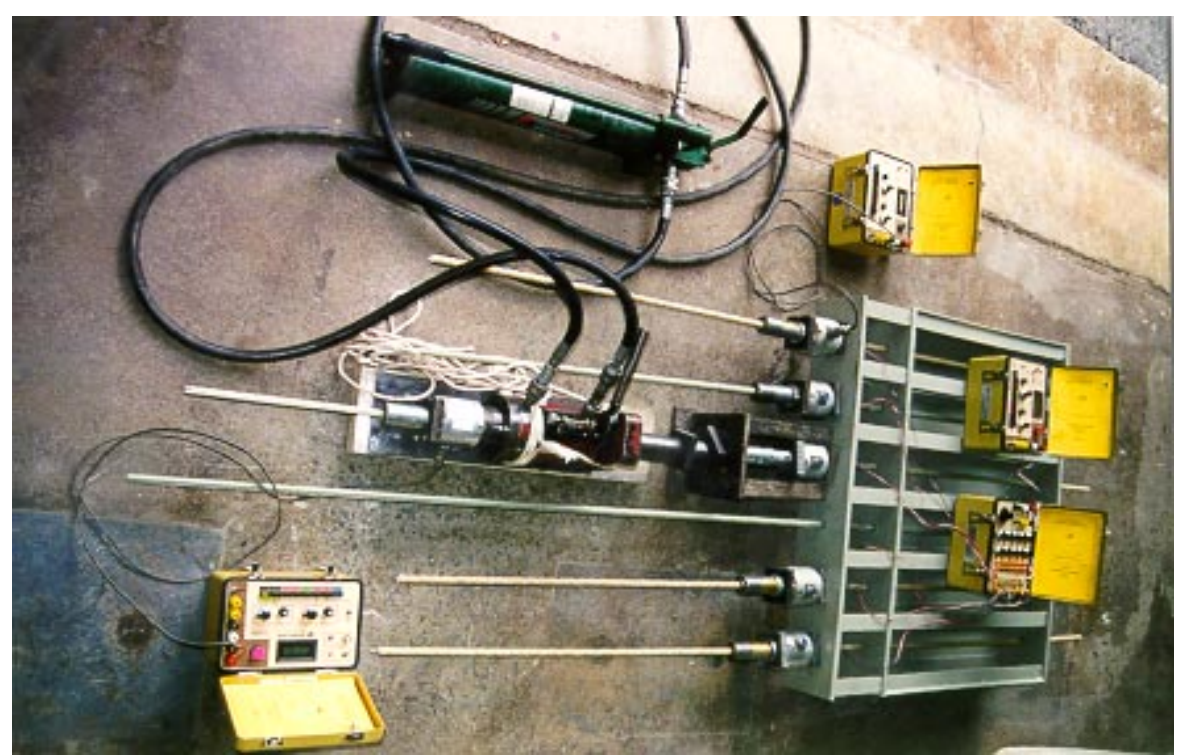

\section{Fig. 5.4 Monitoring Stress Relaxation and Stress Loss for Sand Coated and C- Bars in a Multiple Cell Frame}

At a time, six bars were stressed sequentially in a multiple cell frame (Fig. 5.4). It was intended to use two stress levels: $20 \%$ and $40 \%$. Resulting sustained stresses were found to vary from 15 to $42 \%$ of the ultimate stress after losses. Relaxation and loss of stress were monitored on the bars having sustained stress corresponding to $25 \%$ to $50 \%$ of the ultimate stress for several months as shown in Fig. 5.4. Maximum reduction in the applied stress due to relaxation and losses were under $20 \%$ of the applied stress in 8 months, and were stabilized long before. After stressing, container holes were water sealed with silicone based sealants. Salt or alkaline solution was filled in the tank and covered with a lid at room temperature as shown in Fig. 5.5. 

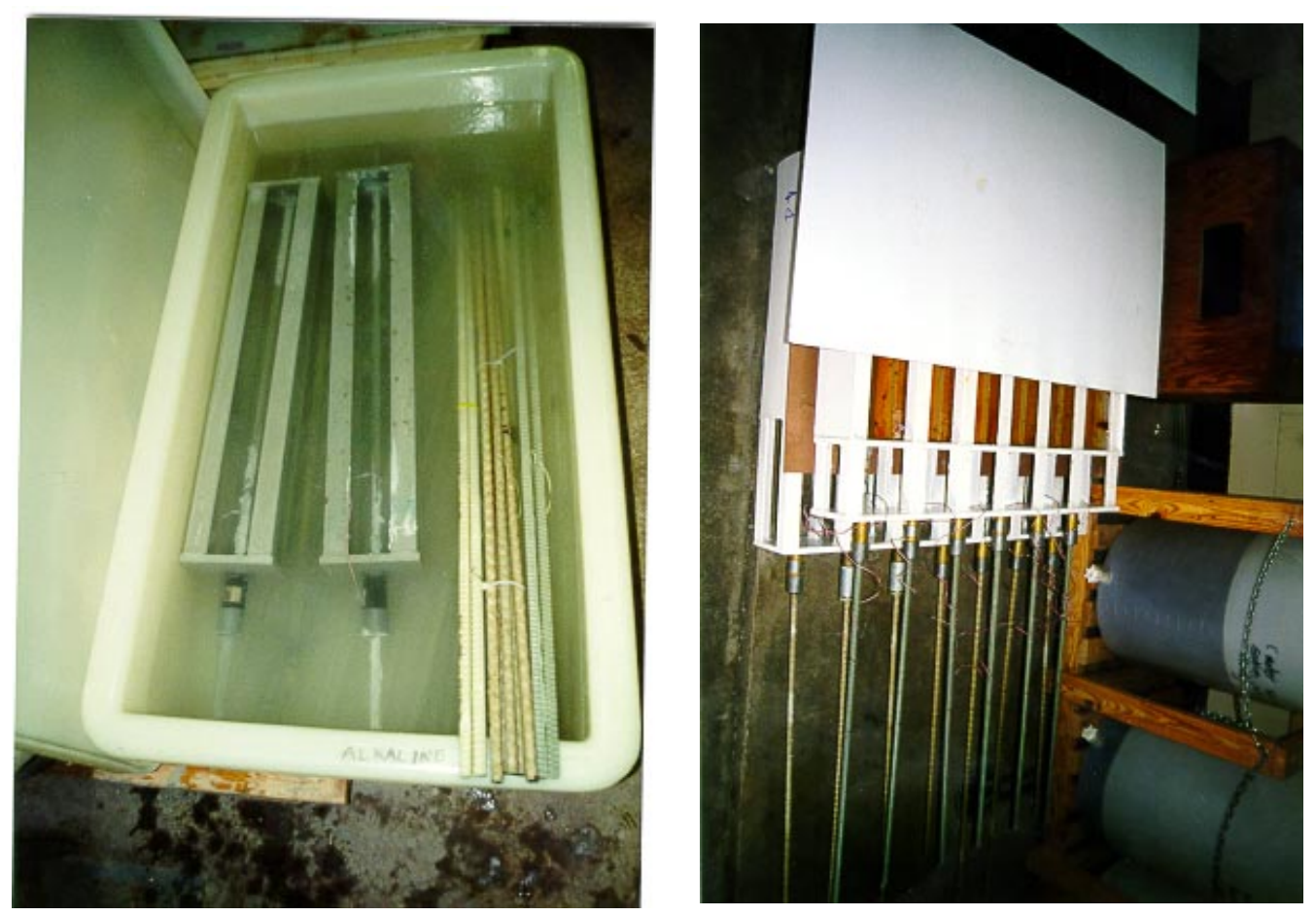

Fig. 5.5 Bars with and without Stress being Conditioned in Salt and Alkaline Solution at

\section{Room Temperature}

For freeze-thaw conditioning, stressed multiple cell frames were stacked on a heavy wooden frame inside the chamber. After filling in the required salt or alkaline solution, frames were covered with plexi-glass sheets and sealed.

\subsection{TENSION TEST PROCEDURES}

Uniaxial tension tests were performed on the unconditioned and conditioned GFRP bars using 200-kips capacity Baldwin Universal Testing Machine, equipped with specially modified grips, developed at the CFC laboratory. Schedule 80 split steel pipes were used for gripping the bars. Four types of adhesives, one manufactured by Ashland Chemicals and the three by Loctite Corporation, were used for attaching the grips. Resin by Ashland chemical proved to be better in terms of ease of application as well as transferring the applied force. Split pipe length of 8-inch was found to be sufficient for testing \#4 and \#6 bars. For testing bar diameters \#8 and larger, 12- 
inch split pipe length was used. Four feet long bars were used for testing purposes. Some of the stressed bars were about 36 inches in length and tested with mid-zone failures. Instrumentation consisted of strain gauges connected to data acquisition system, with the gages mounted on the bars at mid height. Strain versus applied load was automatically recorded through the data acquisition system. Loads were also manually recorded from the Baldwin machine for comparison purposes.

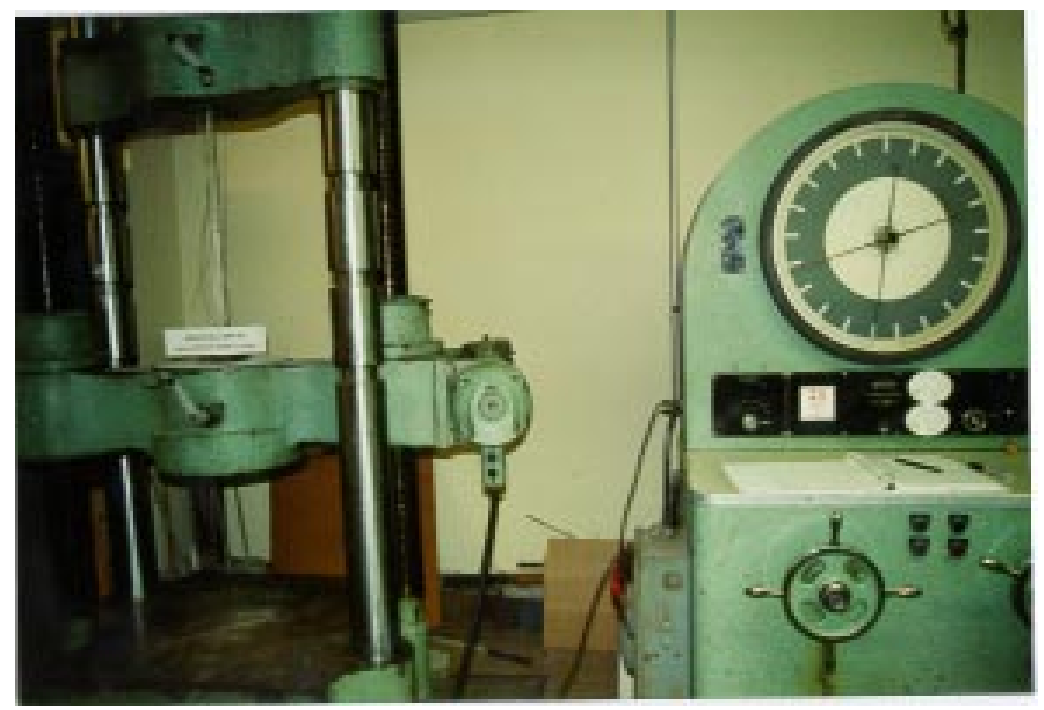

Fig. 5.6 Tension Testing of GFRP Bars in Baldwin Machine

\subsection{TENSION TEST RESULTS AND DISCUSSIONS}

\subsubsection{Unconditioned Test}

Bars were tested as received directly from the two manufacturers, viz., (1) International Grating Inc. (sand coated bars designated as IG1 and IG2), (2) Marshall Industries, Inc. (bars with deformed surface configuration designated as type M1, M2, and M3) without simulating any environmental effects. Data obtained from these bars were utilized as a basis for evaluating the performance (strength and stiffness) of the bars conditioned under accelerated aging. Six 
specimens were tested for each bar type, manufactured by International Grating Inc., and Marshall Industries. Average test values obtained are shown in Table 5.3.

Table 5.3 Unconditioned Tensile Strength and Stiffness of Bars

\begin{tabular}{|c|c|c|c|c|c|}
\hline Bar & \multirow{2}{*}{$\begin{array}{l}\text { Surface } \\
\text { Texture }\end{array}$} & \multicolumn{2}{|c|}{ Strength } & \multicolumn{2}{c|}{ Stiffness } \\
\cline { 3 - 6 } & & $\begin{array}{c}\text { Average } \\
\text { (ksi) }\end{array}$ & $\begin{array}{c}\text { Standard } \\
\text { Deviation }\end{array}$ & $\begin{array}{c}\text { Average } \\
\text { (Msi or 10 }\end{array}$ & $\begin{array}{c}\text { Standard } \\
\text { psi) } \\
\text { Deviation }\end{array}$ \\
\hline IG1 & Sand coated & 87.82 & 2.43 & 6.21 & 0.07 \\
\hline IG2 & Sand coated & 80.63 & 2.97 & 5.15 & 0.15 \\
\hline M1 & Ribbed & 88.28 & 2.29 & 4.42 & 0.12 \\
\hline M2 & Ribbed & 98.68 & 2.91 & 5.76 & 0.08 \\
\hline M3 & Ribbed & 108.53 & 3.43 & 5.61 & 0.13 \\
\hline
\end{tabular}

All conditioned and unconditioned bars tested exhibited typical linear stress-strain relationship as shown in Fig. 5.7. It was difficult to measure the failure strain as strain gages stopped functioning long before failure, and readings were affected by bar wrap failure, matrix cracking or sand particle popping.

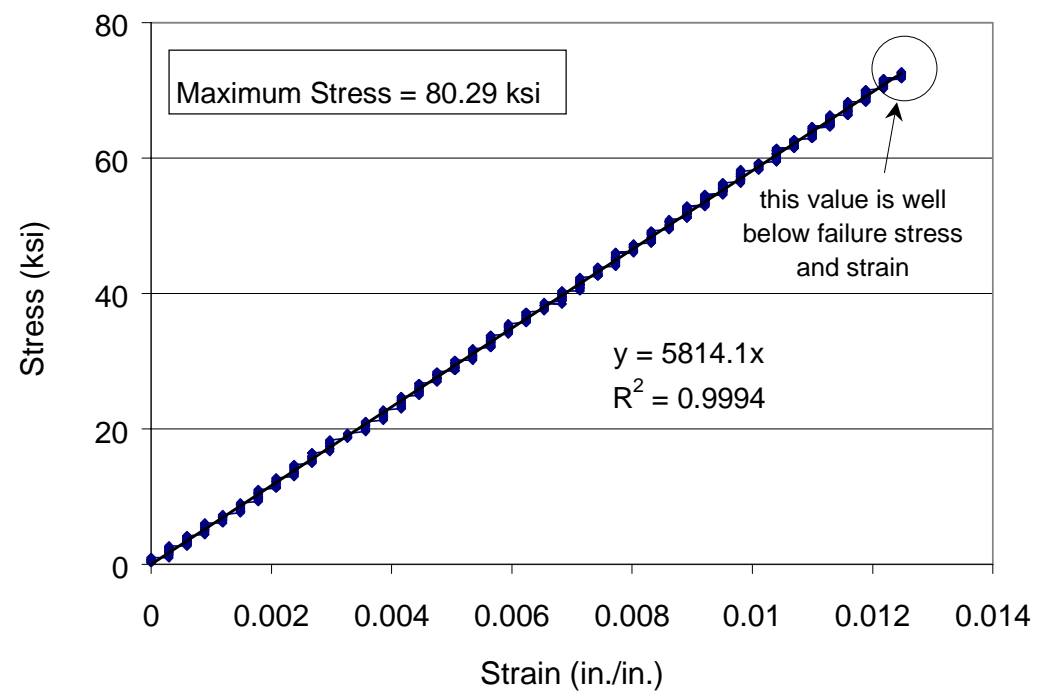

Fig. 5.7 Linear Stress-Strain Relation of a Salt and Freeze-Thaw

Conditioned C-Bar (M2) 


\subsubsection{Salt and Alkaline Conditioning}

Following the conditioning duration, a minimum of two bars were taken out of the conditioning locations and tension-tested by attaching grips and strain gages. Between salt and alkaline conditioning, alkaline conditioning proved to be more detrimental to the strength of GFRP bars. High moisture absorption in GFRP bars in alkaline conditioning was discussed in Chapter 4 and the mechanisms of alkaline attack were described in section 5.2. Freeze-thaw conditioning proved to degrade the GFRP bars earlier than the room temperature (Fig. 5.8). It should be noted that the room temperature in these experiments was maintained at $71.6^{0} \mathrm{~F}$, whereas, the average temperature of the freeze-thaw conditioning through environmental chamber was maintained at $93.68^{0} \mathrm{~F}$ (Table 5.2).

For the sand-coated bars, maximum strength reductions under salt and alkaline conditioning at room temperature were $18.5 \%$ and $32.2 \%$, respectively, over 15 month duration. Similarly, the maximum strength reduction in salt and alkaline conditioning under freeze-thaw conditions were $21.9 \%$ and $37.5 \%$, respectively, over 15-month duration (Fig. 5.8).

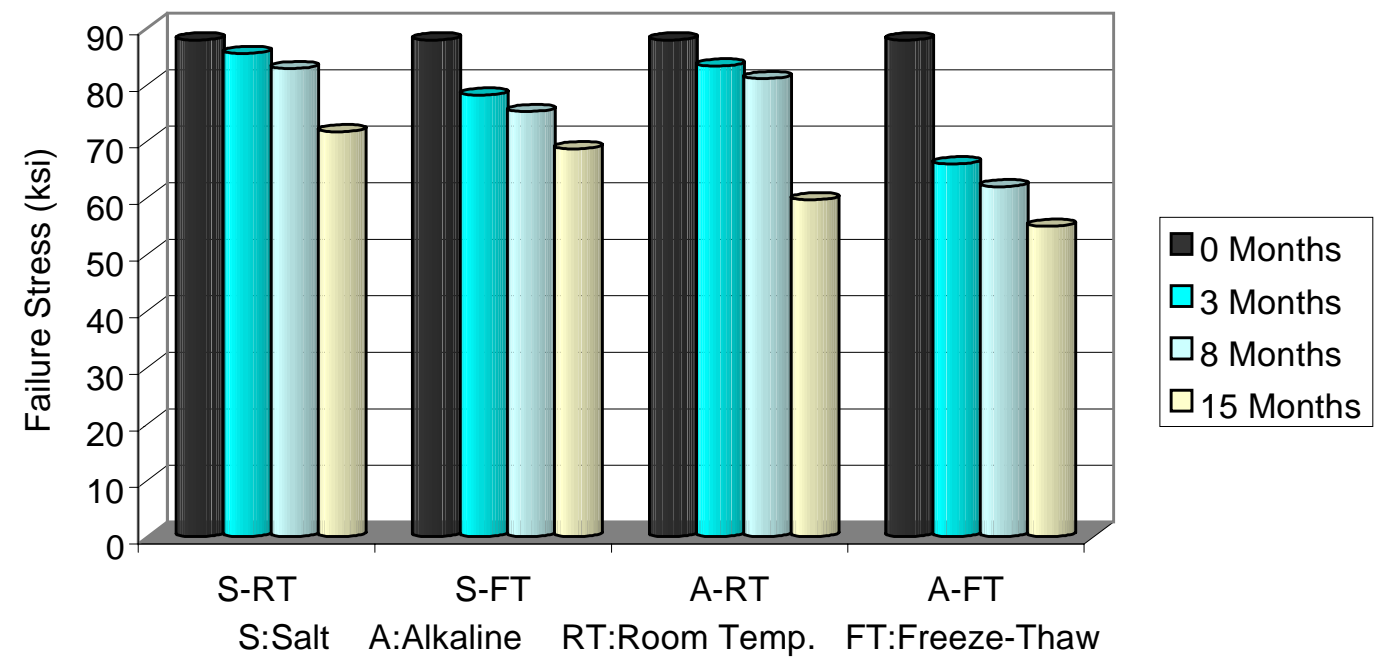

Fig. 5.8 Tensile Stress Variation in Sand-Coated Bars under Different Conditioning (Each Value is an Average of Two or More Samples) 
For C-bars, maximum strength reductions in salt and alkaline conditioning at room temperature were $24.5 \%$ and $30 \%$, respectively, over 30 month duration (Fig. 5.9).

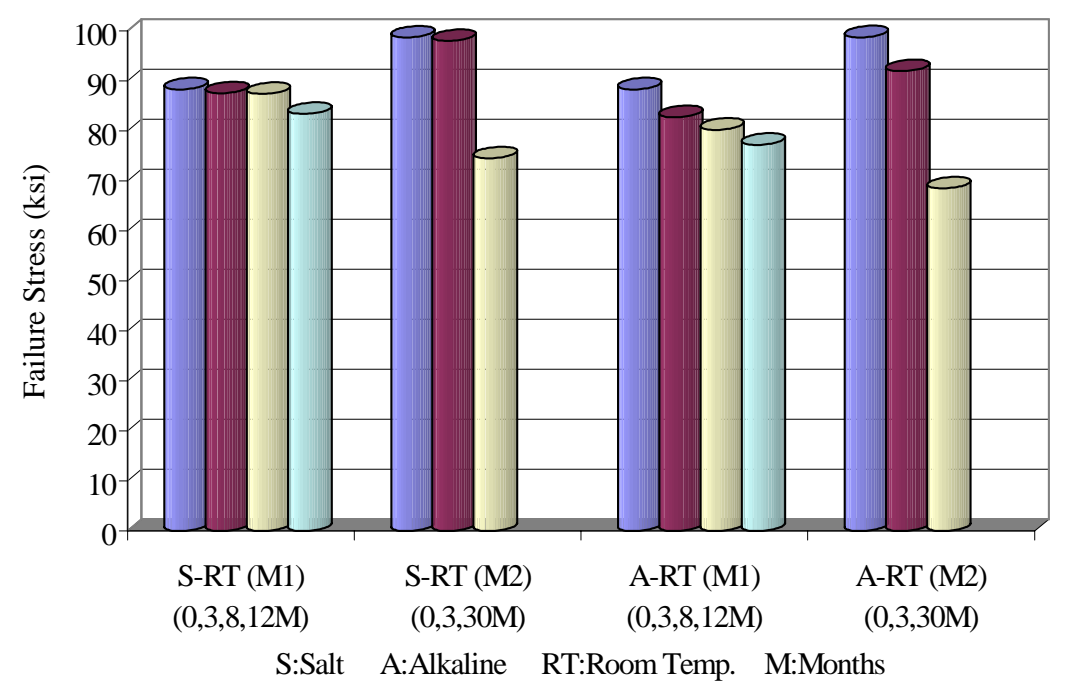

Fig. 5.9 Tensile Stress Variation in C-bars under Salt and Alkaline Conditioning at Room Temperature (Each Value is an Average of Two or more Samples)

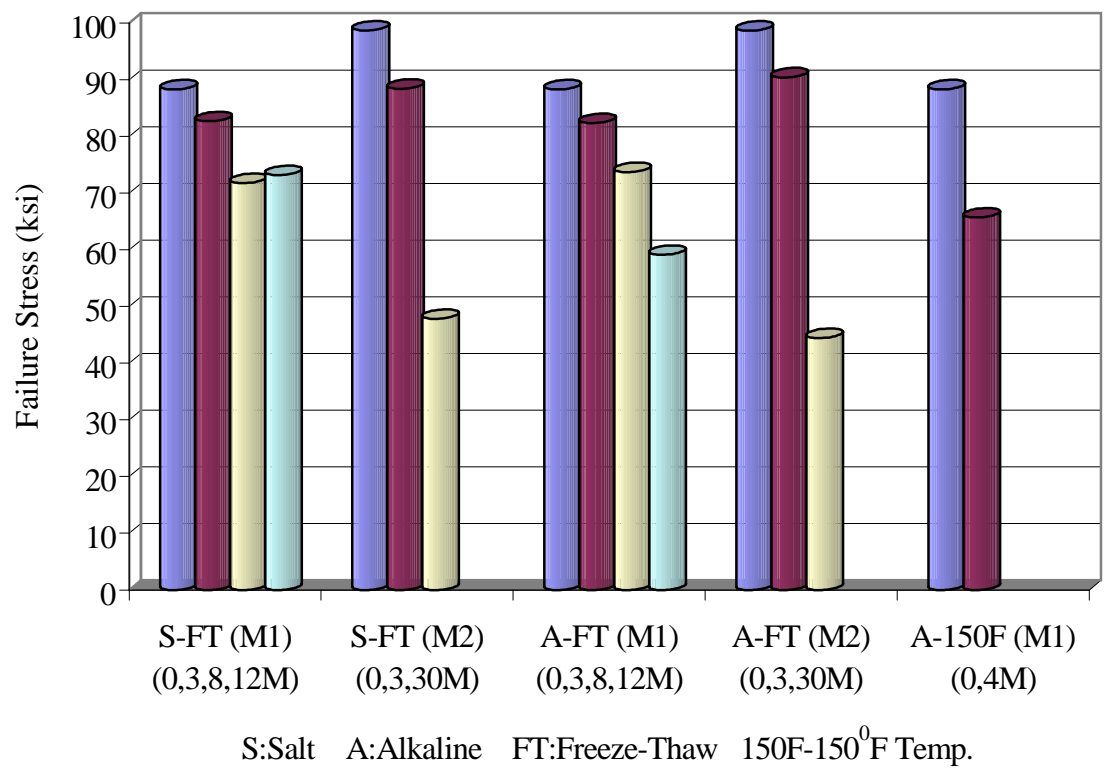

Fig. 5.10 Tensile Stress Variation in C-bars under Salt and Alkaline Conditioning at Freeze-Thaw and ${ }^{150} 0^{\circ} \mathrm{F}$ Temperatures (Each Value is an Average of Two or More Samples) 
Similarly maximum strength reductions in salt and alkaline conditioning under freezethaw conditions for C-bars were 51.5\% and 55\%, respectively, over 30-months duration (Fig. 5.10).

\subsubsection{Salt and Alkaline Conditioning with Stress}

Following the conditioning duration, bars were de-stressed from the steel frame using the Dywidag jack, and by following opposite steps used for stressing (Fig. 5.11).

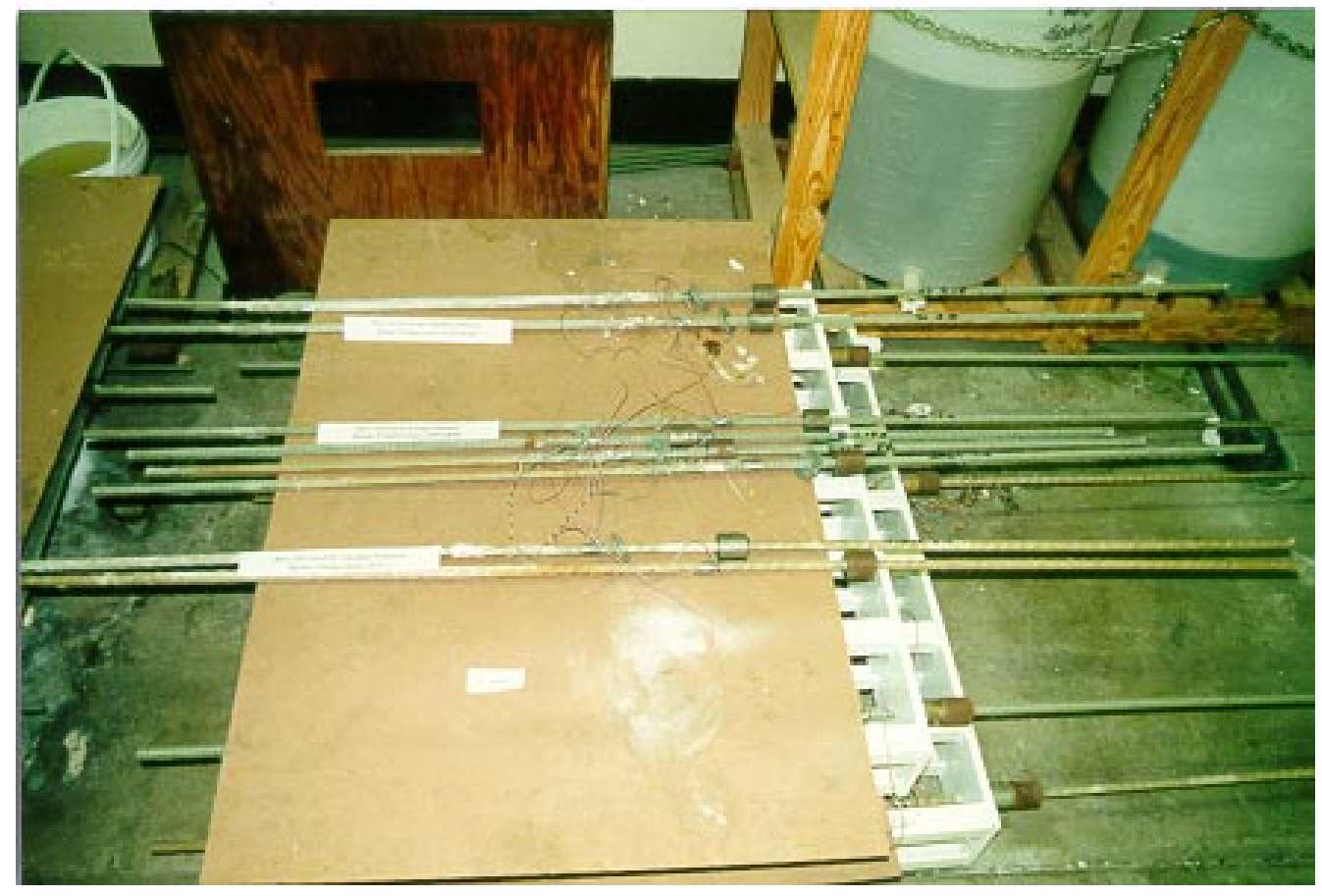

Fig. 5.11 Bars removed from Frames after Conditioning Duration and Stress Removal

Application of stress increased the rate of strength reduction in both types of bars at room as well as freeze-thaw temperature. Stress application resulted in higher strength reductions in alkaline conditioning as compared to salt conditioning. The following points were observed. 
- Strength reductions under salt conditioning generally increased with sustained stress. The reductions were a maximum of $70.75 \%$ of the applied stress (in percent) as compared to the bar at same age and salt-conditioning without any applied stress. This relationship can be represented as

$$
\sigma_{\text {salt }(X, t)}=\sigma_{\text {salt }(t)}-\left(\frac{S . S . F}{100}\right)\left(\frac{X}{100}\right) \sigma_{\text {salt }(t)}
$$

where,

$\sigma_{\text {salt }(X, t)}=\quad$ Failure stress of salt conditioned bar with applied sustained stress $\mathrm{X} \%$ and age ' $\mathrm{t}$ '

$\sigma_{\text {salt }(t)}=\quad$ Failure stress of salt conditioned bar at age 't' without sustained stress

S.S.F. $=$ Salt Stress Factor (Conservatively $75 \%$ is chosen from the results)

$\mathrm{X}=\%$ Sustained Stress 
Table 5.4 Salt Stress Factor (S.S.F) for I.G. (IG1) and Marshall (M1) Bars

\begin{tabular}{|c|c|c|c|c|c|}
\hline \multirow[t]{3}{*}{ Duration } & \multirow{3}{*}{$\begin{array}{l}\text { Condition/ } \\
\text { Bar Type }\end{array}$} & \multicolumn{3}{|c|}{ Tensile Strength Results } & \multirow{3}{*}{$\begin{array}{c}\text { S.S.F. } \\
\text { (from eqn. } \\
5.1)\end{array}$} \\
\hline & & \multirow{2}{*}{$\begin{array}{c}\text { Bars without Stress } \\
\text { Failure Stress }\end{array}$} & \multicolumn{2}{|c|}{ Bars with Stress } & \\
\hline & & & $\begin{array}{c}\text { Failure } \\
\text { Stress }\end{array}$ & $\begin{array}{c}\text { Sustained } \\
\text { Stress }\end{array}$ & \\
\hline$t$ & & $\sigma_{\text {salt }(t)}$ & $\sigma_{\text {salt }(X, t)}$ & $X$ & \\
\hline (Months) & & (ksi) & (ksi) & $(\%)$ & \\
\hline 3 & \multirow{3}{*}{ S-RT/IG1 } & 85.42 & 67.97 & 38 & 53.75 \\
\hline 8 & & 83.52 & 67.69 & 27 & 70.18 \\
\hline 12 & & 78.28 & 70.83 & 19 & 50.13 \\
\hline 3 & \multirow{3}{*}{ S-RT/M1 } & 78.21 & 78.21 & 31 & 34.27 \\
\hline 6 & & 76.41 & 76.41 & 27 & 46.68 \\
\hline 10 & & 66.05 & 66.05 & 32 & 70.75 \\
\hline 3 & \multirow{4}{*}{ S-FT/IG1 } & 78.07 & 84.85 & 22 & $*$ \\
\hline 6 & & 76.32 & 75.87 & 30 & 1.95 \\
\hline 12 & & 71.39 & 70.47 & 30 & 4.30 \\
\hline 12 & & 71.39 & 65.38 & 35 & 24.05 \\
\hline
\end{tabular}

\section{Notes:}

- * Not calculated because stressed bars did not show a reduction as compared to bars without sustained stress.

- In some cases, bars without sustained stress were not tested at the same time duration as those with sustained stress. In those cases, linear interpolation (which is conservative) is adopted between the time duration immediately below and above the duration considered.

- S-Salt; RT-Room Temperature; FT-Freeze-Thaw Temperature

Strength reductions in alkaline conditioning generally increased with stress. The reductions were a maximum of $150 \%$ of the applied stress (in percent) as compared to the similar unstressed bar at same age and alkaline conditioning. This relationship can be represented as: 
$\sigma_{a l k(X, t)}=\sigma_{a l k(t)}-\left(\frac{A . S . F}{100}\right)\left(\frac{X}{100}\right) \sigma_{a l k(t)}$

Where,

$$
\begin{array}{ll}
\sigma_{a l k(X, t)}= & \text { Failure stress of alkaline conditioned bar with applied stress } \\
& X \% \text { and age ' } \mathrm{t} \text { ' } \\
\sigma_{a l k(t)}=\quad & \text { Failure stress of alkaline conditioned bar at age ' } \mathrm{t} \text { ' without } \\
& \text { sustained stress }
\end{array}
$$
A.S.F. $=\quad$ Alkaline Stress Factor (conservatively $150 \%$ is chosen)
$\mathrm{X} \quad=\quad \%$ Sustained Stress

For sand-coated bars under room temperature with sustained stress, maximum strength reductions in salt and alkaline conditioning were $22.9 \%$ (8 months of $27 \%$ applied stress) and 49.2\% (6 months of 37\% applied stress) respectively (Fig. 5.12). This is consistent with the expected trends of strength reduction due to salt and alkaline conditioning. 
Table 5.5 Alkaline Stress Factor (A.S.F) for I.G. (IG1) and Marshall (M1) Bars

\begin{tabular}{|c|c|c|c|c|c|}
\hline \multirow[t]{3}{*}{ Duration } & \multirow{3}{*}{$\begin{array}{c}\text { Condition/ } \\
\text { Bar Type }\end{array}$} & \multicolumn{3}{|c|}{ Tensile Strength Results } & \multirow{3}{*}{$\begin{array}{c}\text { A.S.F. } \\
\text { (from eqn. } \\
5.2)\end{array}$} \\
\hline & & \multirow{2}{*}{$\begin{array}{c}\text { Bars without Stress } \\
\text { Failure Stress }\end{array}$} & \multicolumn{2}{|c|}{ Bars with Stress } & \\
\hline & & & $\begin{array}{c}\text { Failure } \\
\text { Stress }\end{array}$ & $\begin{array}{c}\text { Sustained } \\
\text { Stress }\end{array}$ & \\
\hline$t$ & & $\sigma_{a l k(t)}$ & $\sigma_{a l k(X, t)}$ & $X$ & \\
\hline (Months) & & (ksi) & (ksi) & $(\%)$ & \\
\hline 6 & \multirow{4}{*}{ A-RT/IG1 } & 81.86 & 44.63 & 37 & 122.94 \\
\hline 8 & & 80.98 & 48.74 & 30 & 132.70 \\
\hline 12 & & 68.73 & 51.00 & 24 & 107.46 \\
\hline 12 & & 68.73 & 73.23 & 15 & $*$ \\
\hline 6 & \multirow{2}{*}{ A-RT/M1 } & 81.21 & 79.19 & 25 & 9.95 \\
\hline 8 & & 80.21 & 75.76 & 25 & 22.21 \\
\hline 6 & \multirow{4}{*}{ A-FT/IG1 } & 63.87 & 46.78 & 33 & 81.09 \\
\hline 8 & & 60.87 & 25.51 & 39 & 148.95 \\
\hline 12 & & 58.36 & 35.76 & 30 & 129.07 \\
\hline 12 & & 58.36 & 15.68 & 49 & 149.24 \\
\hline
\end{tabular}

\section{Notes:}

- A-Alkaline; RT-Room Temperature; FT-Freeze-Thaw Temperature (Table 5.2)

- * - Not calculated because stressed bars did not show a reduction as compared to bars without sustained stress.

- In some cases, bars without sustained stress were not tested at same time duration as those with sustained stress. In those cases, linear interpolation (which is conservative) is adopted between the time duration immediately below and above the duration considered. 


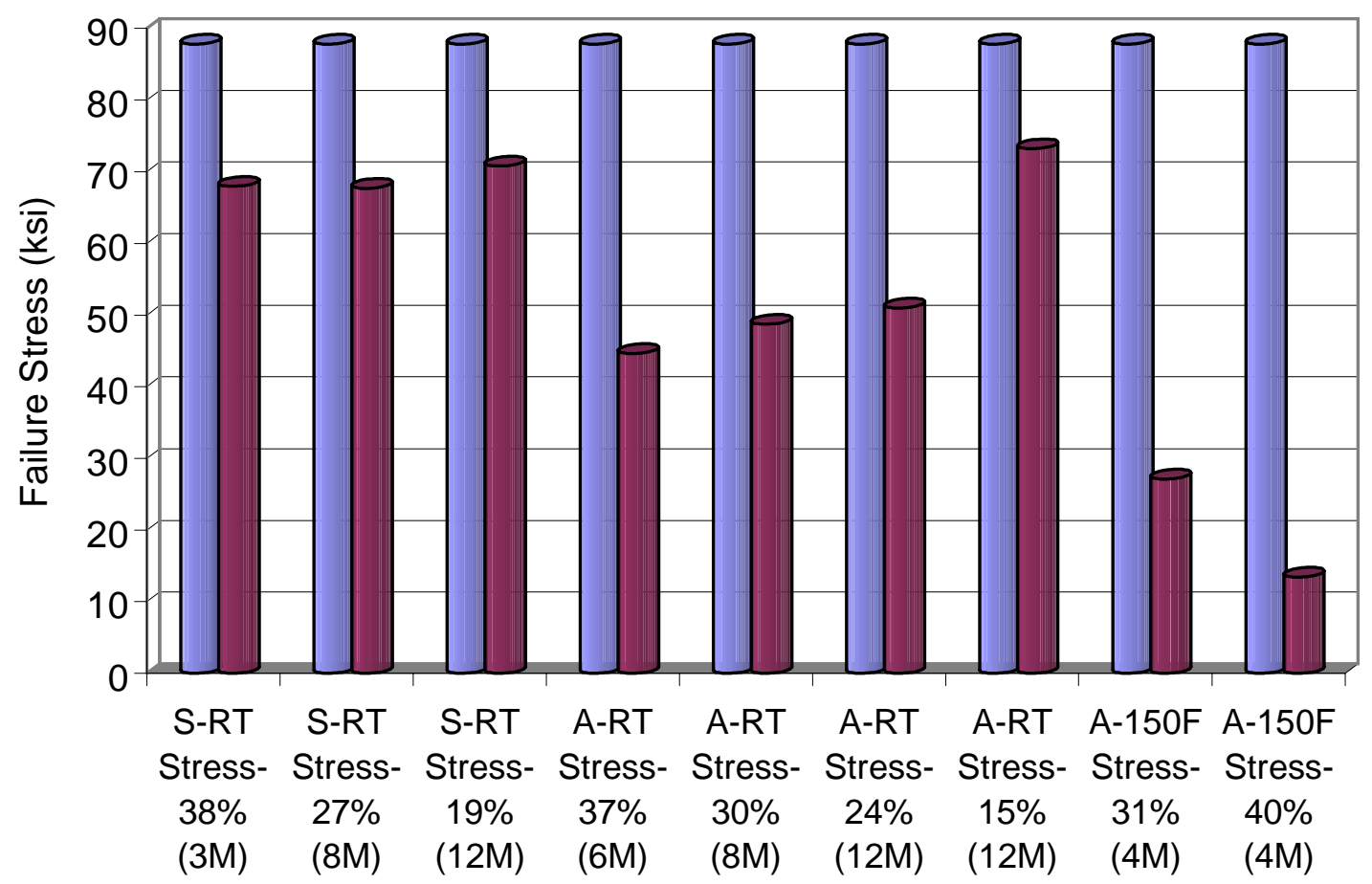

S:Salt A:Alkaline RT:Room Temp. 150F:150 ${ }^{\circ} \mathrm{F}$ Temperature M:Months

Fig. 5.12 Tensile Stress Variation in Sand-coated Bars under Different Conditioning (Each Value is an Average of Two or More Samples)

For sand-coated bars under freeze-thaw conditioning with sustained stress, maximum strength reductions in salt and alkaline conditioning were 25.6\% (12 months of 35\% applied stress) and $82.1 \%$ (12 months of $40 \%$ stress application) respectively (Fig. 5.13). Stress corrosion failures were also observed in some bars under this conditioning as shown in Fig. 5.14. 


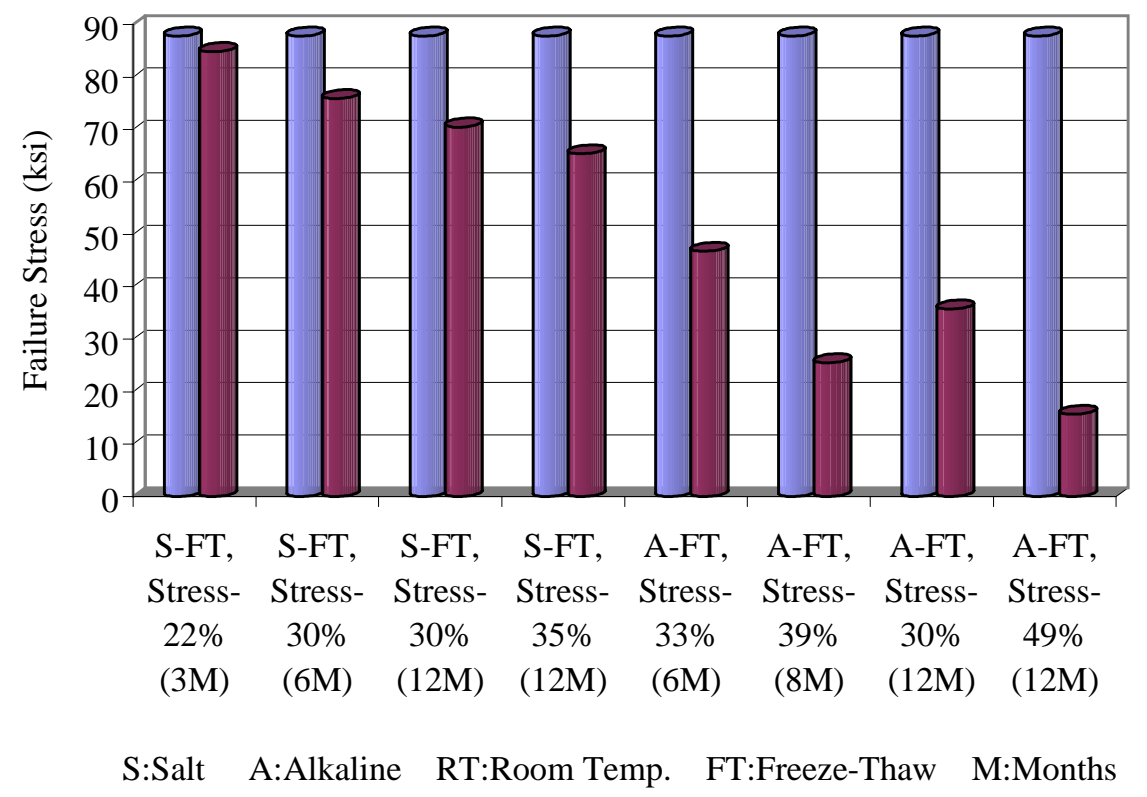

Fig. 5.13 Tensile Stress Variation in Sand-Coated Bars under Different Conditioning with Sustained Stress (Each Value is an Average of Two or more Samples)
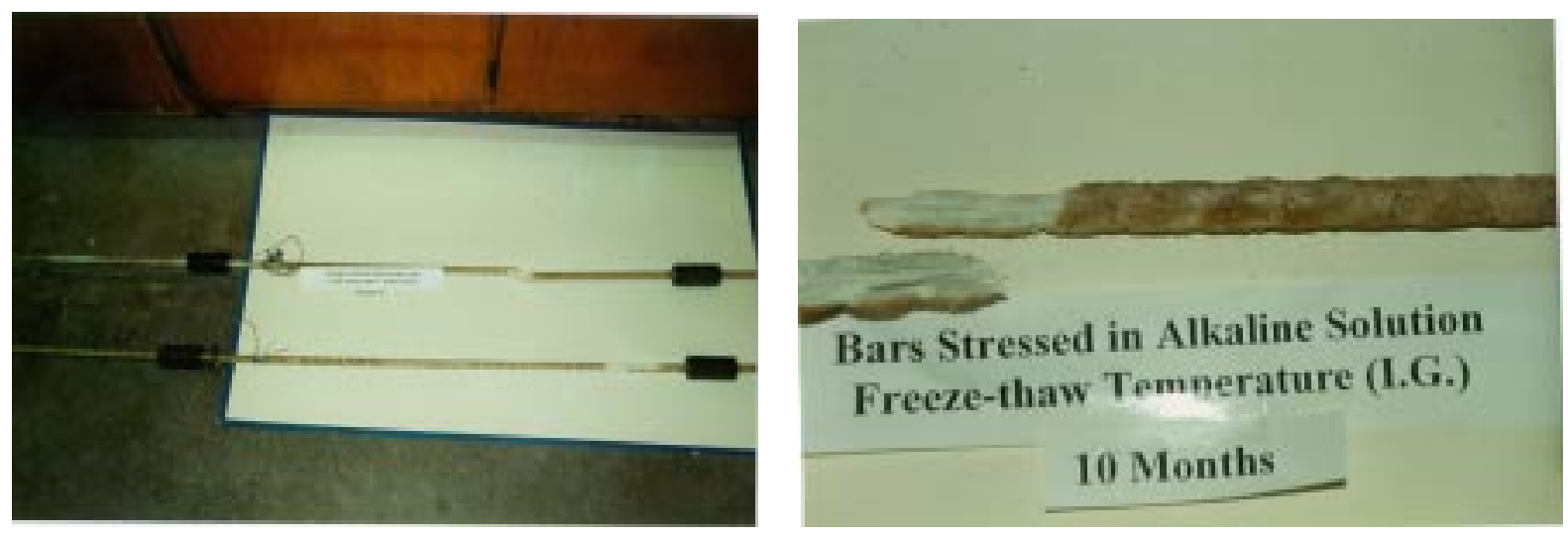

Fig. 5.14 Stress-Corrosion Failures in Alkaline Solution with Stress and FreezeThaw Temperature

For C-bars with sustained stress, maximum strength reductions in salt and alkaline conditioning at room temperature were $25.2 \%$ (10 months of $32 \%$ applied stress) and $14.2 \%$ (8 months of 25\% stress application) respectively (Fig. 5.15). 


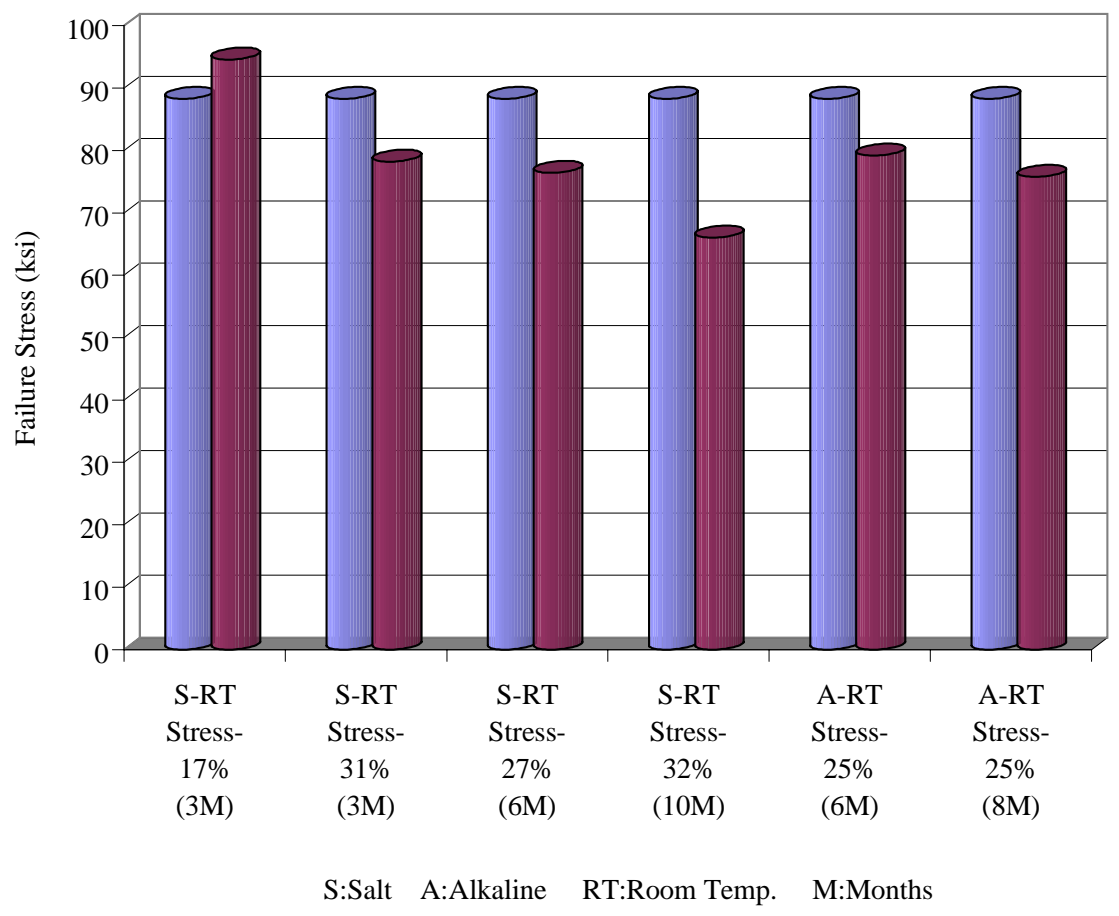

Fig. 5.15 Tensile Stress Variation in C-bars under Salt and Alkaline Conditioning at Room Temperature with Sustained Stress (Each Value is an Average of Two or More Samples)

\subsubsection{Stress Corrosion at High Temperature}

High temperature, particularly $150^{\circ} \mathrm{F}$ with stress and alkaline conditioning proved to be more detrimental than any other conditioning. Moisture transport increase in GFRP bars with temperature was described in Chapter 4. Only sand-coated bars were stressed and conditioned at $150^{0} \mathrm{~F}$ in the alkaline solution, whereas, C-bars were conditioned without stress. Stress reductions at $150^{\circ} \mathrm{F}$ coupled with alkaline solution were dramatic. Stress reduction was $84.7 \%$ within 4 months of $40 \%$ stress application as shown in Fig. 5.12. Some of the sand-coated bars experienced stress rupture in 4 months (under $40 \%$ sustained stress). Malfunctioning of the chamber and a fire problem did not allow further experimentation at this temperature level. 


\subsection{TENSILE STIFFNESS OF GFRP BARS UNDER ACCELERATED AGING}

Stiffness of both types of GFRP bars (sand coated and ribbed) did not show reduction trends observed in strength under different conditioning schemes. While providing best-fit curve to the stress-strain data, generally, small initial stress and/or failure stage stresses were not included to exclude possible effect of matrix cracking or fiber rupture at strain gage location (Fig. 5.7). Many of the conditioned bars showed an increase in stiffness. An increase in stiffness associated with reduction in failure stress implies that the bar is more brittle than the unconditioned reference bar. A reduction in the stiffness associated with stress loss implies that the bar would elongate more at a given stress than the unconditioned bar. Some bars exhibited small loss of stiffness for both bar types. Due to relatively small variations in stiffness of all bars under a particular conditioning scheme and also as whole, average and standard deviation values

of stiffness for each conditioning scheme are presented in Figs. 5.16 through 5.18. At the end of each graph, a summary of the stiffness change and standard deviation is provided for all conditioning schemes. Sand coated International Grating bars on a whole showed 5.9\% increase in the stiffness as shown in Fig. 5.16.

Stiffness variation for both types of Marshall bars is shown in Figs. 5.17 and 5.18. Considering all the test data, average stiffness increase was found to be $4.1 \%$ for M1 type and stiffness loss of $4.8 \%$ for M2 type Marshall Bars. 


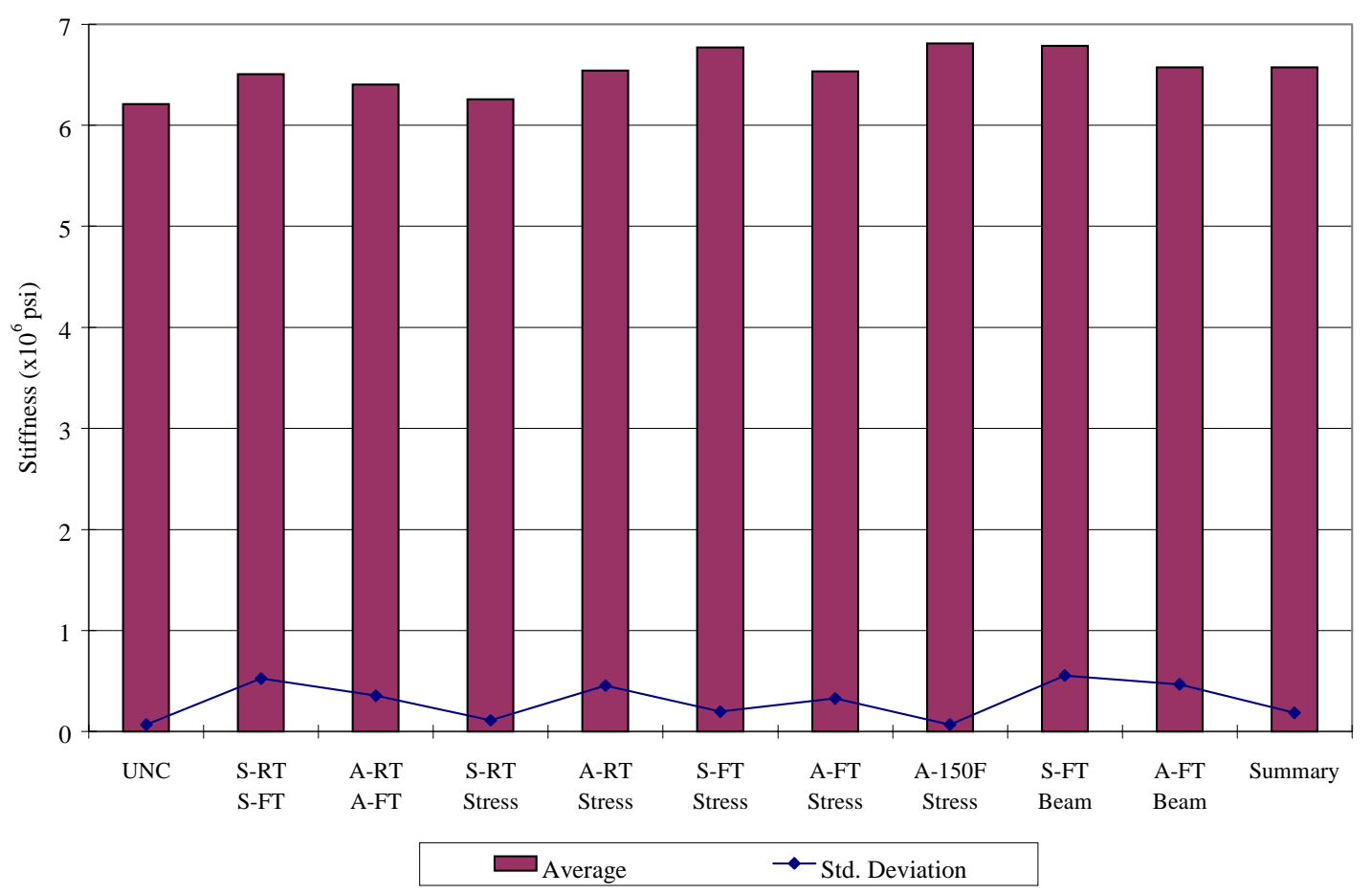

UNC: Unconditioned S:Salt A:Alkaline RT:Room Temp. FT-Freeze-Thaw 150F:150 ${ }^{\circ} \mathrm{F}$ Temperature

Fig. 5.16 Variation of Stiffness in IG Bars under Accelerated Aging

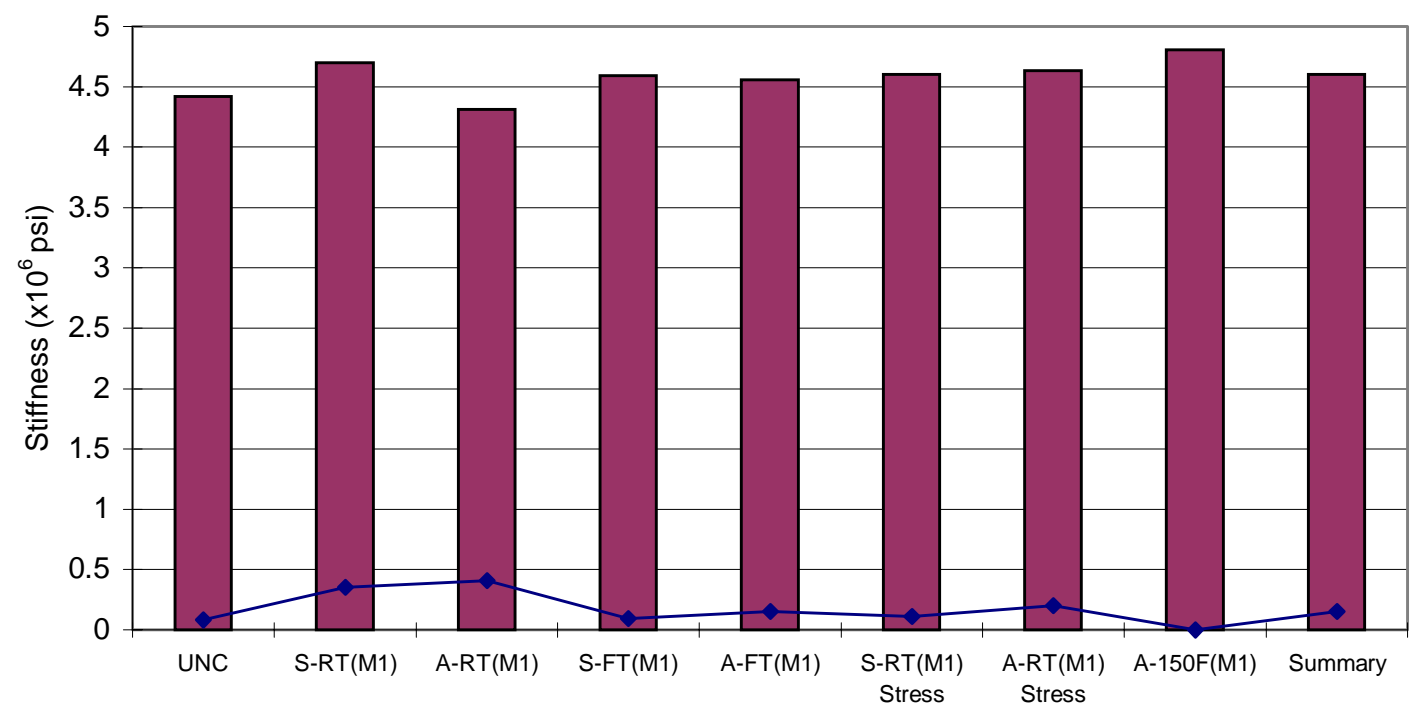

UNC: Unconditioned S:Salt A:Alkaline RT:Room Temp. FT: Freeze-Thaw 150F:1500F Temperature

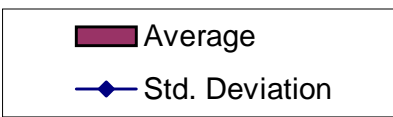

Fig. 5.17 Variation of Stiffness in Marshall Bars (M1) under Accelerated Aging 


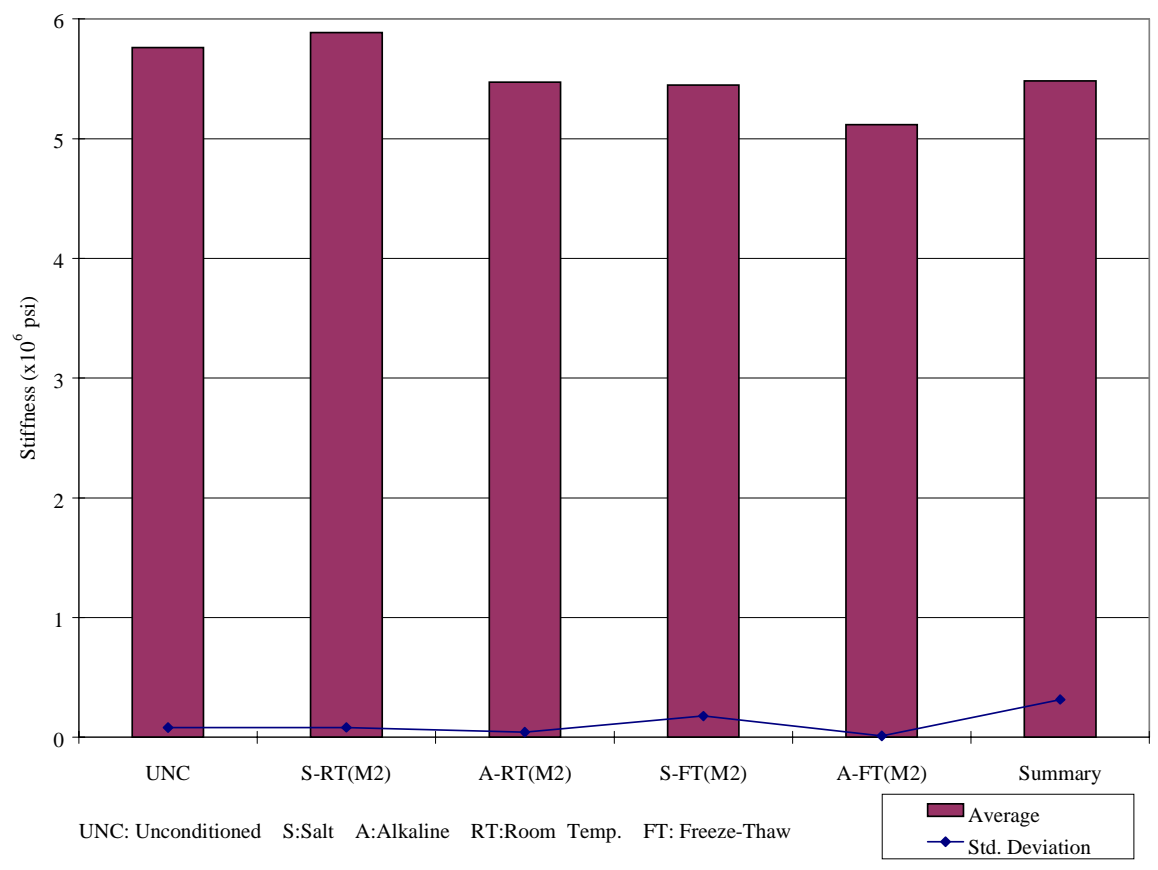

Fig. 5.18 Variation of Stiffness in Marshall Bars (M2) under Accelerated Aging

\subsection{FAILURE MODES IN BARS UNDER TENSION}

In most of the tension tests on sand coated bars, the helical wrappings started to fail (Fig. 5.19.a and Fig. 5.19.b) at stress levels between 50 to $60 \%$ of the ultimate stress, typically in the middle-third of the gripped zone. Helical wrapping provided on sand coated bars is intended for improving bond capacity between concrete and the bar. Salt conditioned bars had typical wrap failure followed by vertical splitting and fiber blooming in the middle third zone. Alkaline conditioned bars typically had "necking" failures, characterized by stretching and failure of the outer portion affected by alkalinity, followed by failure of the inner core as shown in Fig. 5.19.

The C-bars under salt conditioning typically failed with vertical splitting, whereas the alkaline conditioning typically exhibited "necking" failures as shown in Figs. 5.20 (b) and (c). Generally, failure in C-bars initiated at middle of the bar, followed by vertical splitting along the entire length. 


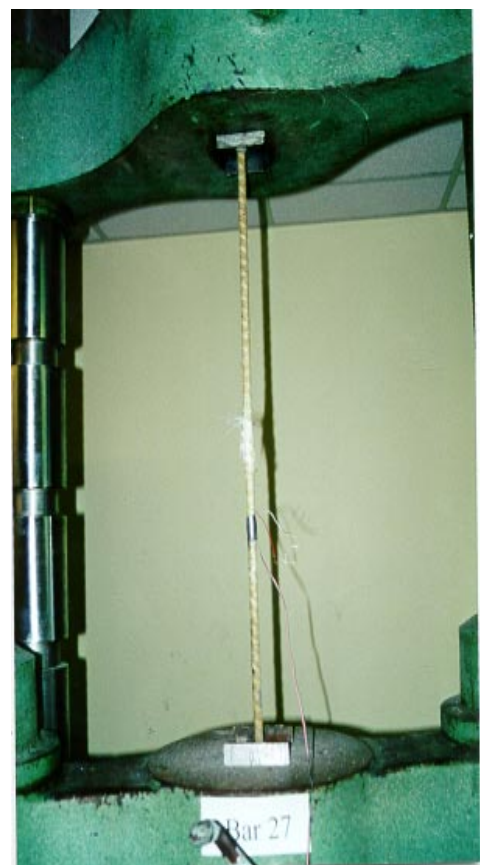

(a)

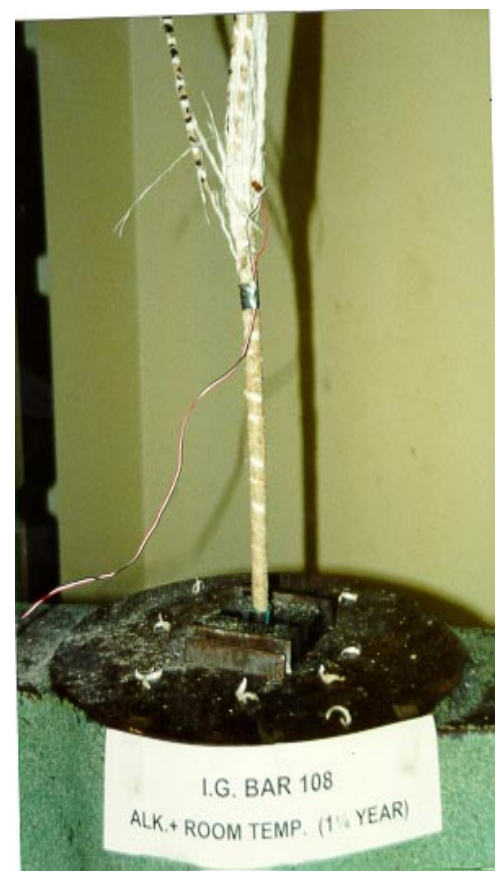

(b)

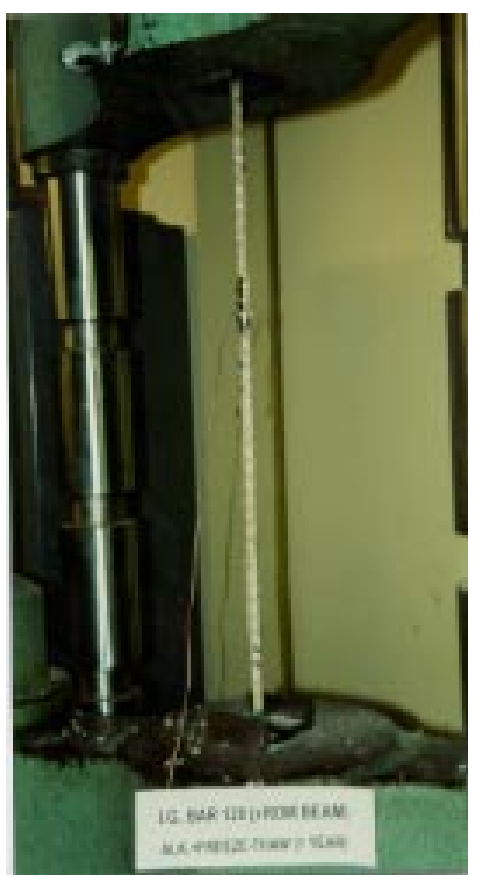

(c)

Fig. 5.19 Sand-coated Bars (a) Freeze-Thaw Conditioned (b) Alkaline Conditioned (15 months, room temp.) (c) Extracted from a Beam Alkaline and Freeze-Thaw Conditioned for 12 Months

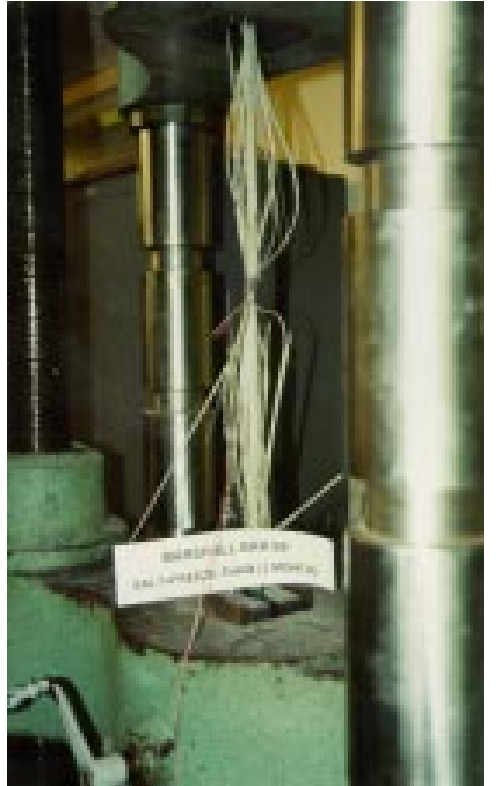

(a)

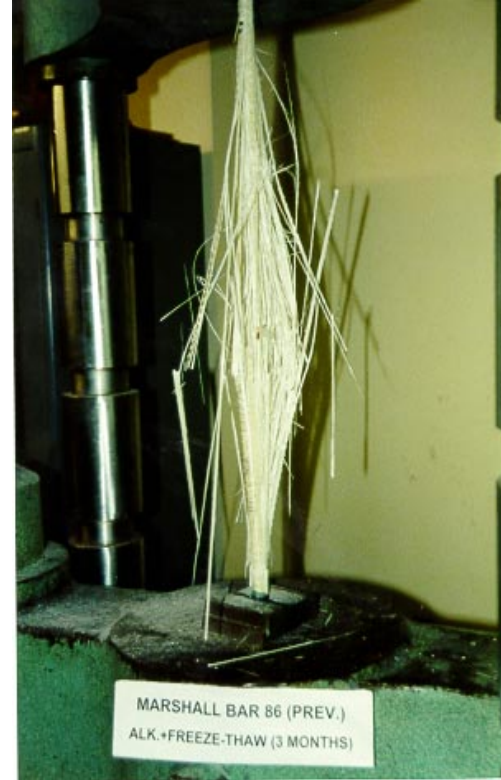

(b)

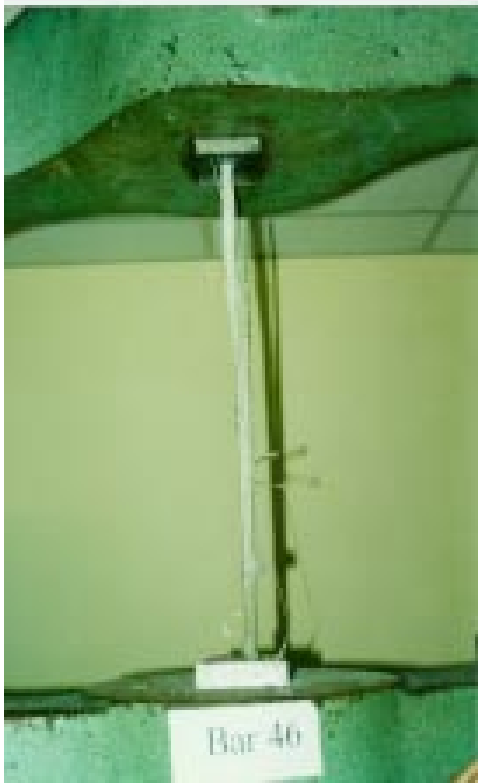

(c)

Fig. 5.20 Ribbed C-Bars Tested at 3 Months (a) Salt and Freeze-Thaw Conditioned (b) Alkaline and Freeze-Thaw Conditioned (c) Alkaline and Room Temperature Conditioned 


\subsection{COMPRESSIVE STRENGTH OF AGED GFRP BARS}

Compression tests were conducted on unconditioned and conditioned \#4 GFRP bars, manufactured by International Grating Inc. and Marshall Industries Inc. Standard length of the compression bars was kept as $2.5 \mathrm{D}$, where, $\mathrm{D}$ is the bar diameter. Other lengths such as $2 \mathrm{D}, 3 \mathrm{D}$, 4D and 5D were also experimented. It was found that the length of $2.5 \mathrm{D}$ statistically had the least variations in the results with maximum observed compressive strengths. Compressive strengths and tensile strengths of both sand coated and C-bars are shown in Table 5.6.

Based on the stiffness results of tension tests on both unconditioned and conditioned bars, the tests on the compression tests were mainly focused on reduction in compressive strengths under accelerated aging. Compressive strength of sand coated bars was found to be $40 \%$ of its tensile strength (Table 5.6). The main reason for such low compressive strengths in sand coated bars is explained in section 5.8.2. Compressive strength of C-bars was found to be $94 \%$ of their tensile strengths.

Table 5.6 Comparison of Compressive and Tensile Strengths of Unconditioned \#4 GFRP Bars

\begin{tabular}{|c|c|c|c|c|}
\hline \multirow{2}{*}{ Manufacturer } & \multicolumn{2}{|c|}{$\begin{array}{c}\text { Compressive } \\
\text { Strength }\end{array}$} & Tensile Strength & Compr. Strength \\
\cline { 2 - 4 } & $\begin{array}{c}\text { Average } \\
\text { (ksi) }\end{array}$ & $\begin{array}{c}\text { Standard } \\
\text { Deviation }\end{array}$ & $\begin{array}{c}\text { Average } \\
\text { (ksi) }\end{array}$ & Tensile Strength \\
\hline $\begin{array}{c}\text { International Grating } \\
\text { (Sand Coated, IG1) }\end{array}$ & 35.08 & 3.11 & 87.82 & 0.40 \\
\hline $\begin{array}{c}\text { Marshall Inc. } \\
\text { (Ribbed C-Bars of type, M1) }\end{array}$ & 83.03 & 2.85 & 88.28 & 0.94 \\
\hline
\end{tabular}




\subsubsection{Compressive Strength of Aged GFRP Bars}

Maximum compressive strength reduction of sand coated bars under aging was found to be $60 \%$. Similar $60 \%$ maximum reductions were found in tension tests of sand coated GFRP bars subjected to 15 months of alkaline and freeze-thaw conditioning under stress and also in the bars extracted from 12 months of alkaline and freeze-thaw conditioned concrete beams (Fig. 5.21 and refer Chapter 9).

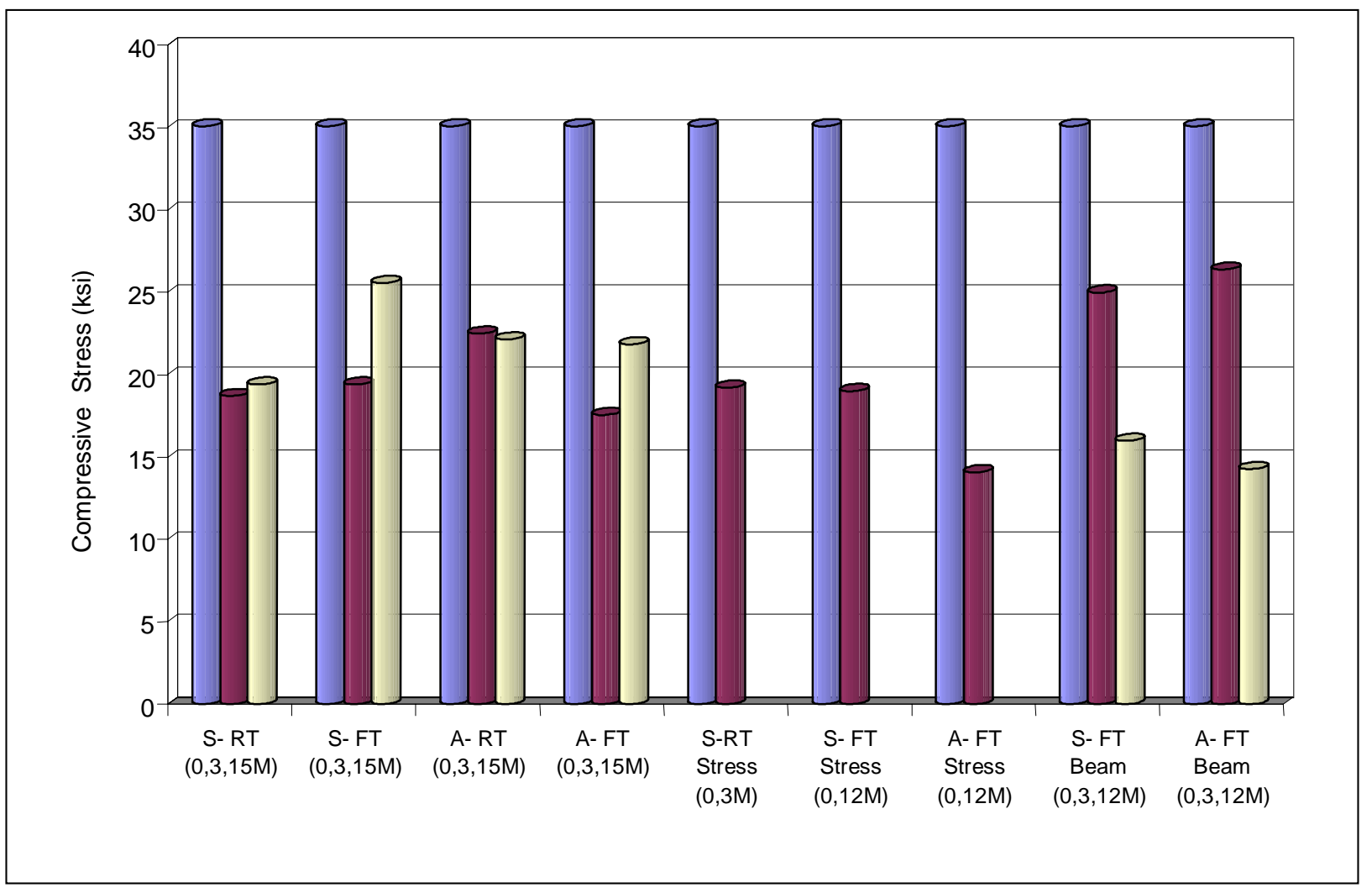

Fig. 5.21 Compressive Failure Strength of IG Bars Subjected to Accelerated Aging

Maximum compressive strength reduction of C-bars was found to be $39 \%$ in alkaline and freeze-thaw conditioned bars (Fig. 5.22). Majority of the bars, including bars extracted from concrete beams, retained high percentage of their original compressive strength under different accelerated conditioning schemes. 


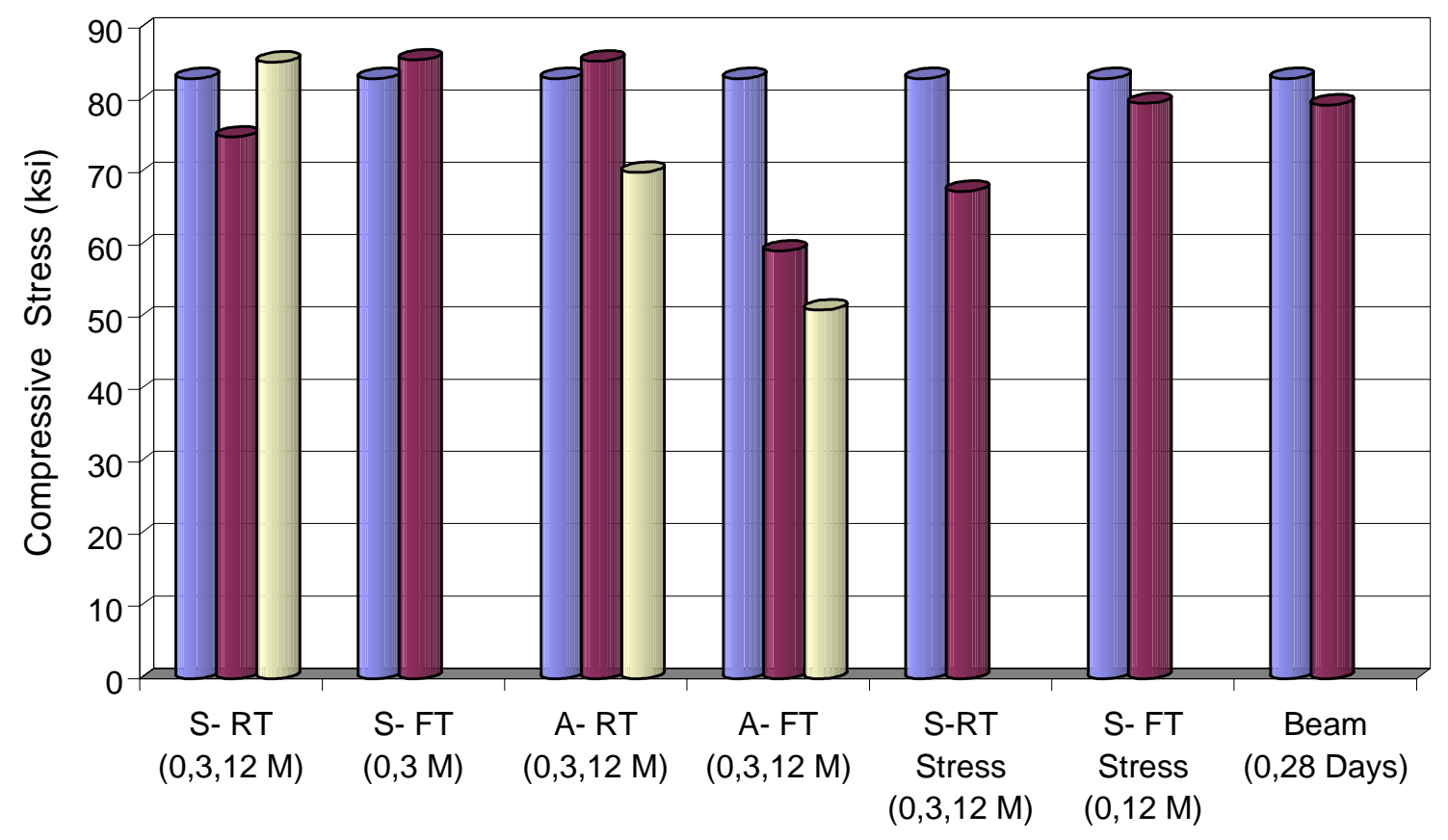

Fig. 5.22 Compressive Failure Strength of Marshall Bars (M1) subjected to

\section{Accelerated Aging}

\subsubsection{Failure Modes in Bars under Compression}

Failure of sand coated bars initiated along the wrap used for improving bond strength. The failure was found to mostly originate along the wrap, and in many cases a slip plane was created along the wrap. Failure modes in sand coated bars also included splitting, crushing and buckling. In C-bars, outer SMC layer separation, fiber splitting and buckling, and vertical splitting were the major modes of failure. Localized crushing was also observed in some cases. Different modes of compression failure for GFRP bars are shown in Fig. 5.23. 

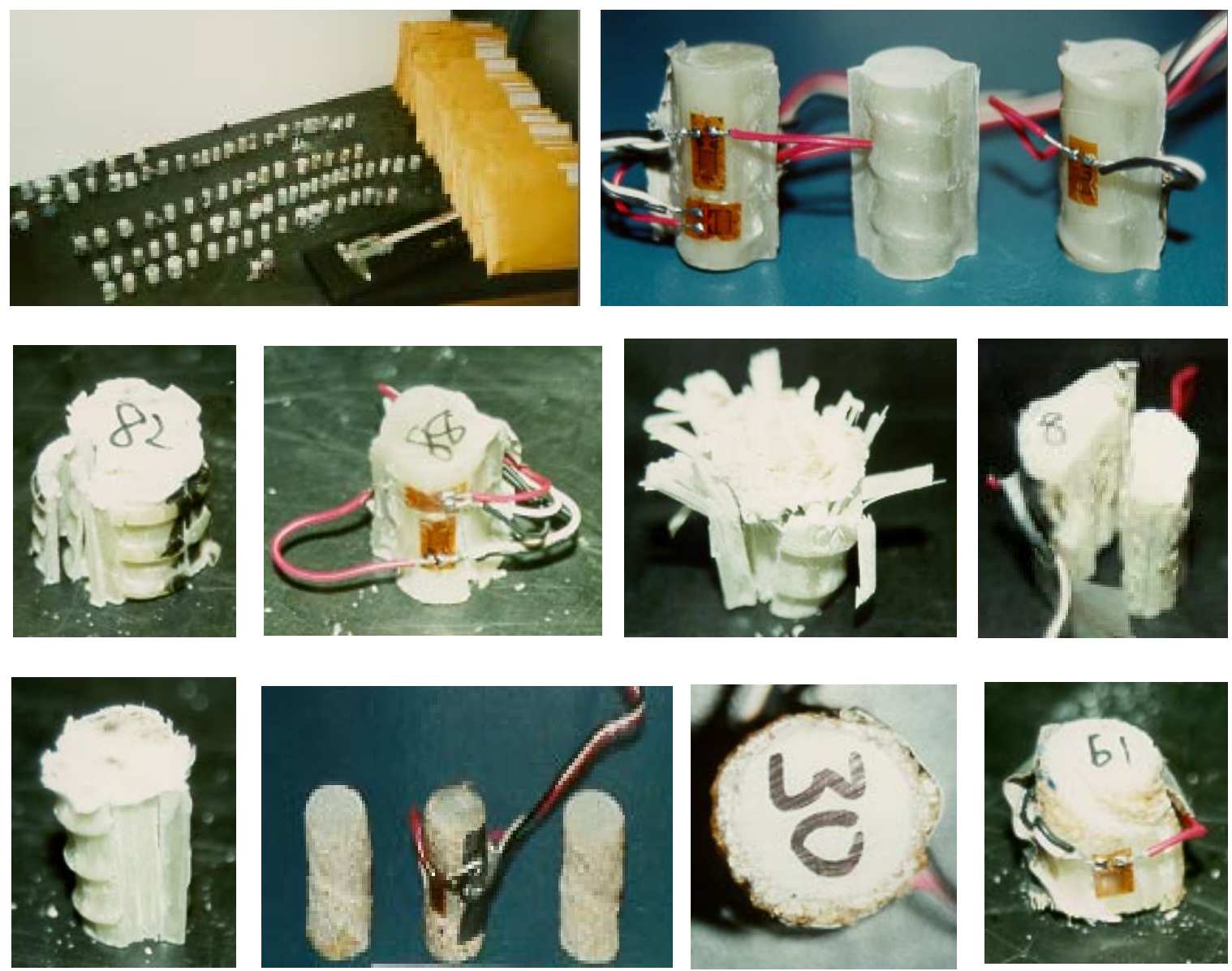

Fig. 5.23 Compression Testing of GFRP Bars Subjected to Accelerated Aging and Different

Failure Modes

\subsection{CORRELATION OF ACCELERATED AND NATURAL WEATHERING}

Accelerated aging methodologies can be used for predicting the long-term mechanical properties of FRP bars embedded in concrete. An accelerated aging methodology has been suggested by Litherland et al. (1981) for predicting the degradation in the mechanical properties of FRP over a given duration and its correlation with the natural aging. Their principles are summarized in the following steps: 


\section{STEP 1}

Subject the composite specimens immersed in cement representative $\mathrm{pH}$ solutions for 6 to 7 evenly spread different temperatures between $-20^{\mathrm{O}} \mathrm{F}$ (low temperature may slow down aging, but causes brittle failures) to $180^{\circ} \mathrm{F}$ (below glass transition temperature).

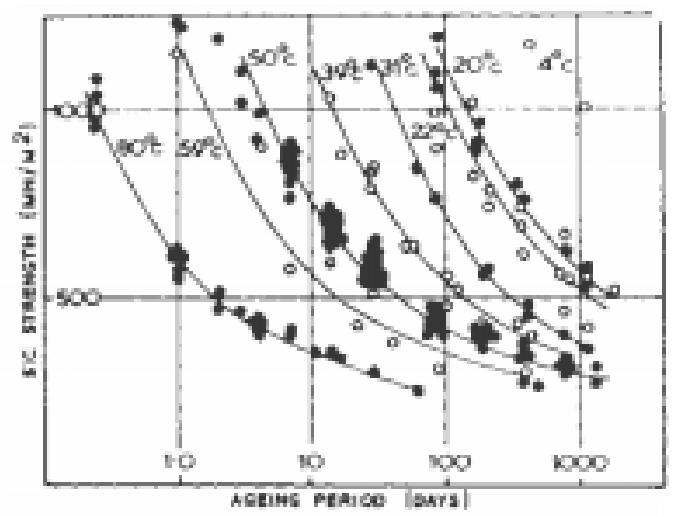

Fig. 5.24 SIC (Glass Strand in Cement) Strength Retention in Water at Different

Temperatures (Litherland et al., 1981)

\section{STEP 2}

Plot Strength loss curves (non-linear curves conforming to some power law, e.g., $C=\mathrm{C}_{\mathrm{o}}+\mathrm{mt}^{\mathrm{n}}$, which appear linear when plotted as semi-log curves) with respect to aging period (No. of Days).

- $\quad$ Strength loss (y-axis) vs. aging period (x-axis)

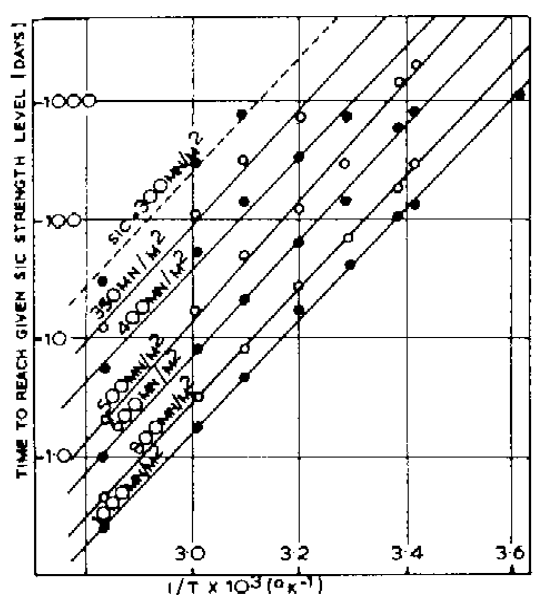

Fig. 5.25 Arrhenius Plot (Litherland et al., 1981) 


\section{STEP 3}

Plot the curves in step 2 for Arrhenius type relationship, i.e., $A=A_{o} \exp (-\Delta E / R T)$

- Plot log (time to reach particular strength value, i.e., 90, $75 \mathrm{ksi}$ etc.) vs. inverse of temperature $\left({ }^{0} \mathrm{~K}\right)$

\section{$\underline{\text { STEP } 4}$}

Normalize the curves in step 3 into a single curve by plotting:

- Logarithm of time (for a given strength loss) at different aging temperatures $\left(\mathrm{T}=273+\mathrm{t}^{0} \mathrm{c}\right.$, selected in STEP 1) along $\mathrm{y}$-axis (relative to the time at some REFERENCE temperature), against (1/T) along X-axis.

\section{Normalization procedure}

- Select a REFERENCE temperature, say $70^{\circ} \mathrm{F}$.

- Calculate logarithm of the ratio of the time taken for the composite strength to fall to a given value at $\mathrm{T}=273+\mathrm{t}^{0} \mathrm{C}$ (pick all the temperatures individually as selected in STEP 1) relative to the time to fall to that value at $70^{\circ} \mathrm{F}$ (REFERENCE temperature). Plot the value calculated against the inverse of the absolute temperature corresponding to $\mathrm{t}^{0} \mathrm{C}$ (where time is read from the fitted curves plotted as per STEP 2). 


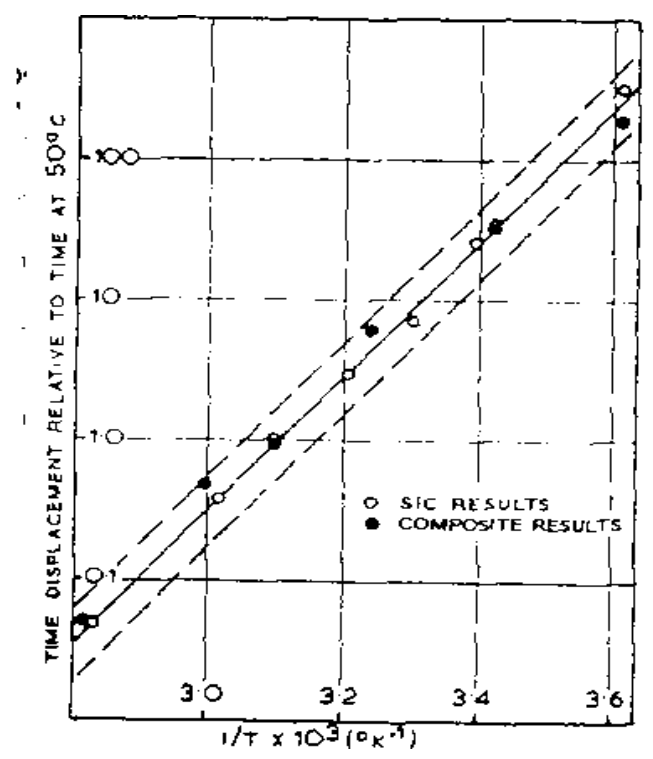

Fig. 5.26 Normalized Arrhenius Plot (Litherland et al., 1981)

\section{$\underline{\text { STEP5 }}$}

- Normalized Arrhenius plot gives one overall curve of the relative acceleration of strength or stiffness loss at different temperatures.

- From the known time-scale shift (i.e., plot of STEP 4), changes expected over long period under lower service temperature are predicted by considering following calibration.

- Strength loss data from naturally weathered samples.

- Use mean annual temperature (M.A.T.) and other factors (say moisture, freeze-thaw and $\mathrm{pH}$ level) as basis for calibration. 


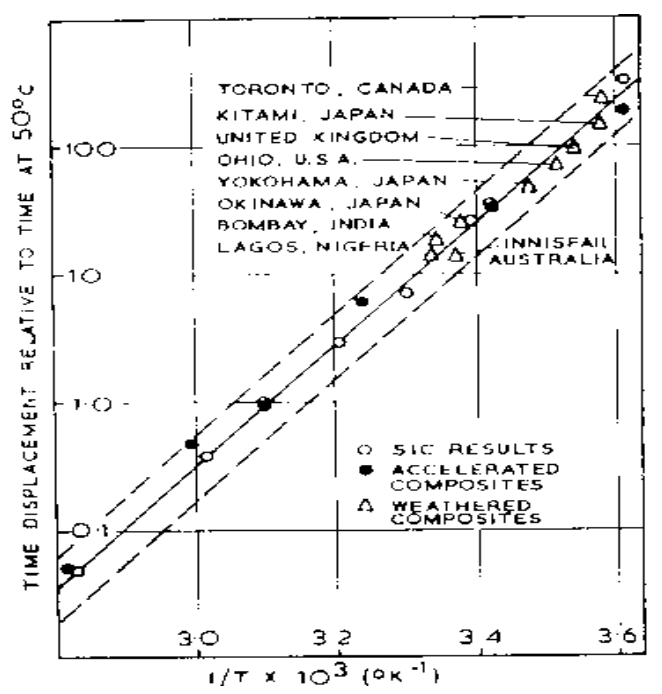

Fig. 5.27 Normalized Arrhenius Plot Including Weathering Data (Litherland et al, 1981)

Litherland et al. (1981) have correlated their data with natural weathering samples of about 10 years. In their tests, the media surrounding glass was cement representative, so as to achieve meaningful correlation of natural weathering to accelerated weathering. Some of the factors to be considered before using Litherland's method are:

- Mean annual temperature is taken as the sole criteria for determining the accelerating factors. Identical mean annual temperature at different locations does not necessarily account for the geographical variations in magnitude and distribution of temperature, humidity and precipitation throughout the year.

- Correlation of natural and accelerated weathering is carried out on samples without stress.

- Present day manufacturing methods and durable resins offer a better degree of protection against water, salt or alkaline attack, thus taking more time to fall to a given strength under identical aging conditions considered by Litherland. In effect, shift of the time scale factor is necessary while interpreting Litherland's data. 
Our data on aging of bars carried out by direct exposure to the conditioning solution and designated as the WVU data in Fig. 5.24 (only $34.27^{\circ} \mathrm{C}$ comparison is shown) were compared with data at two temperature levels of $19^{\circ} \mathrm{C}$ and $35^{\circ} \mathrm{C}$ given by Litherland et al. (1981) on strength reductions. Tension test data on bars extracted (Fig. 5.29) from 4-point bending tested concrete beams that were pre-cracked, immersed in the conditioning solution and exposed to

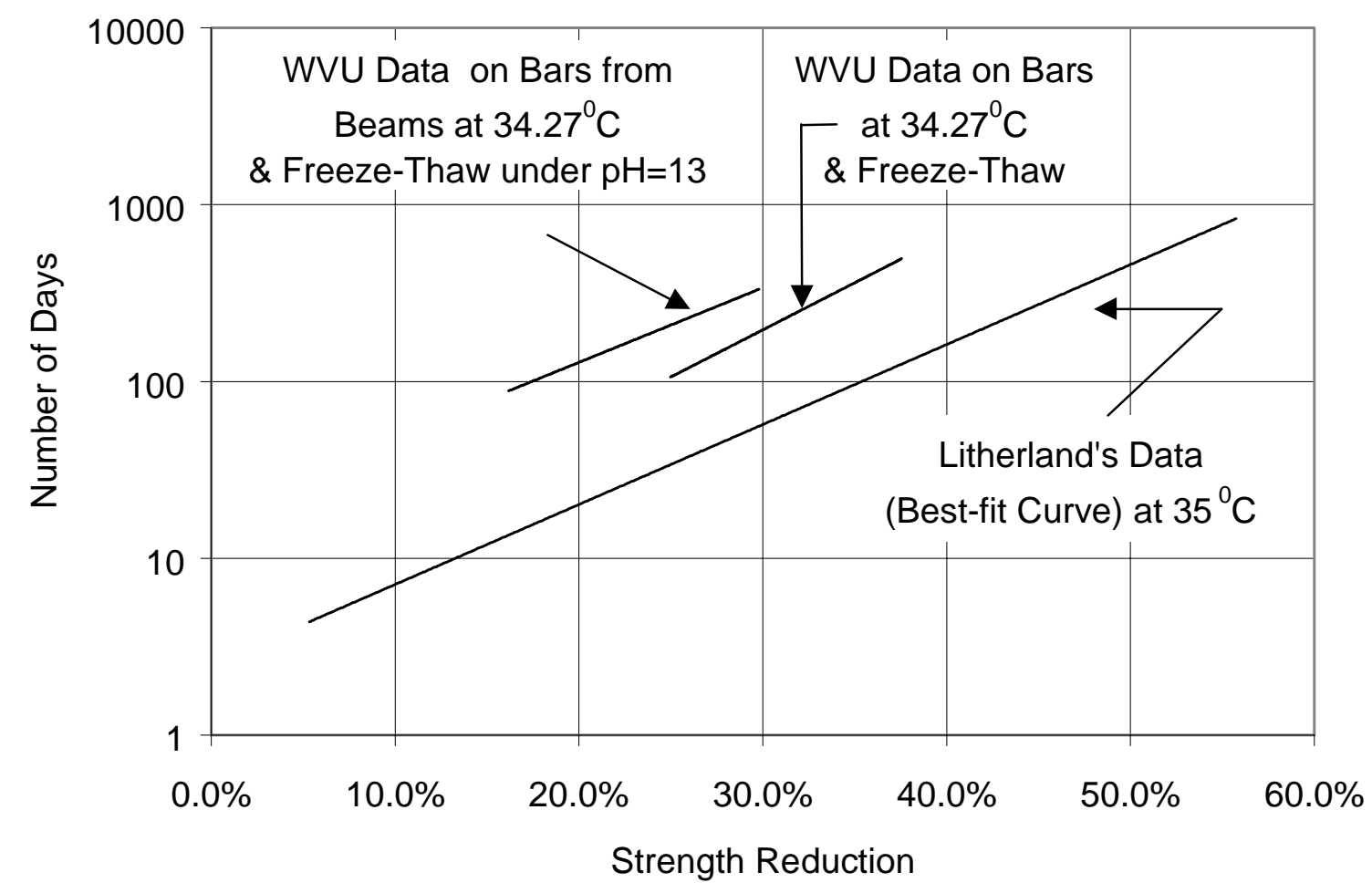

Fig. 5.28 Calibration of WVU Data on Accelerated Weathering and Data by Litherland et al. (1981)

temperature variations is also shown in Fig. 5.28. Since accelerated aging under alkaline conditioning for freeze-thaw temperature fluctuations produced maximum strength reduction in the unstressed bars, these data were chosen for correlation with natural weathering. Good 
correlation is observed between WVU data (at $34.27^{\circ} \mathrm{C}$ and $21^{\circ} \mathrm{C}$ ) and Litherlands data (at $35^{\circ} \mathrm{C}$ and $21^{\circ} \mathrm{C}$ ) in terms of data lines being nearly parallel to each other and data consistent with temperature variation. It is noted that the bars embedded in pre-cracked concrete beams and exposed to alkaline solution $(\mathrm{pH}=13)$ experienced lower strength reductions as compared to the same bars exposed directly to same alkaline solution at the same temperature fluctuation, i.e., freeze-thaw. This shows that, concrete cover helps in protecting GFRP bars.

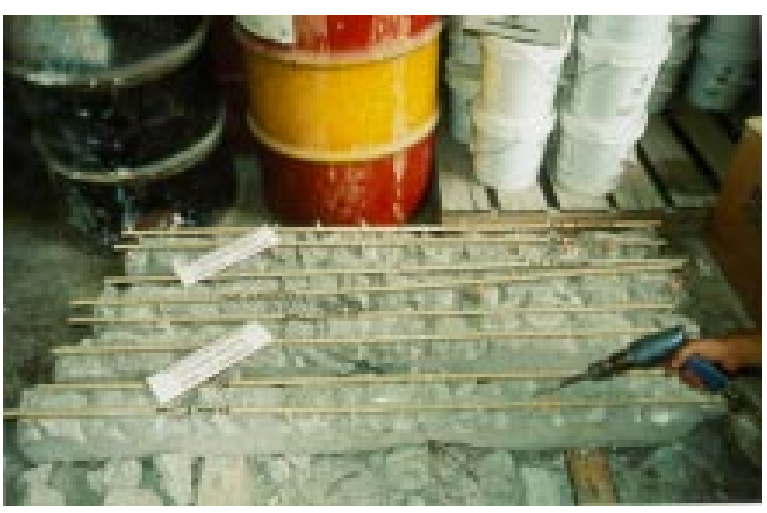

(a)

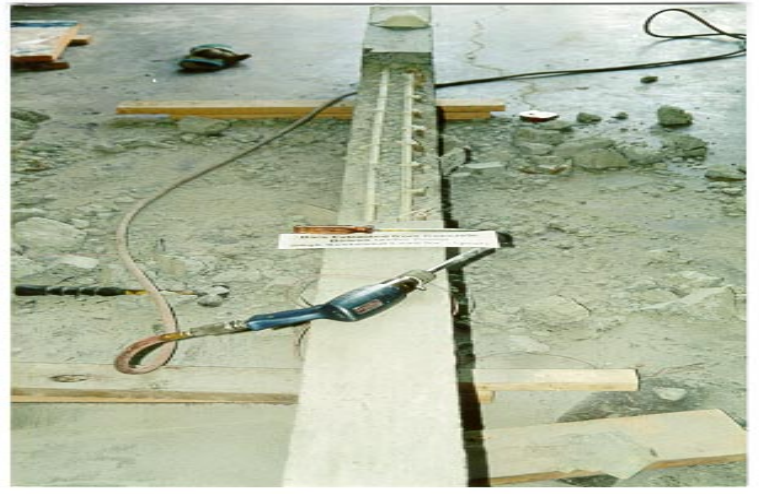

(c)

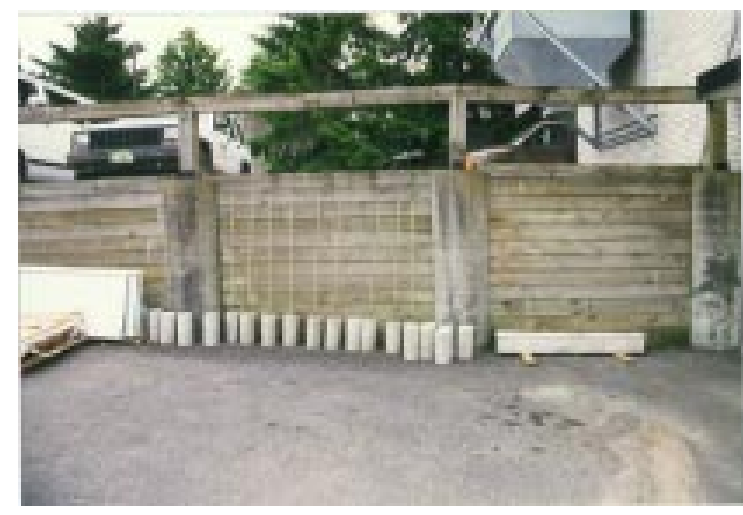

(b)

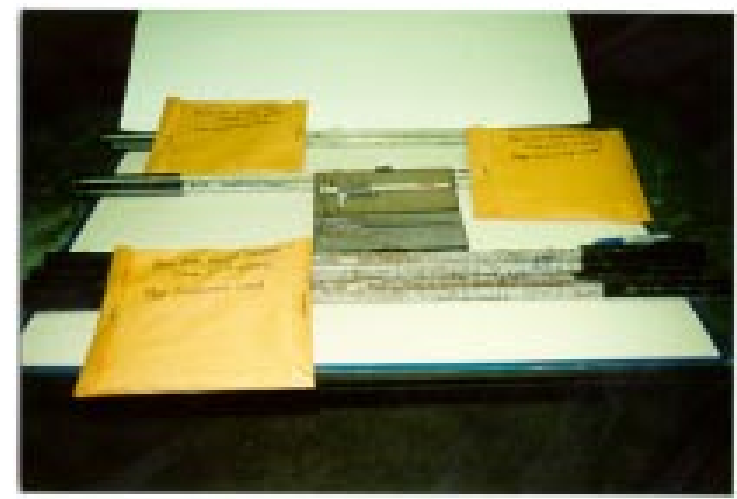

(d)

Fig. 5.29 (a) Bars Extracted from Tension Side of Concrete Beams after 3 Months of Salt and Alkaline Conditioning and Freeze-Thaw Fluctuations (b) Beams, Bars and Bond Specimens under Natural Weathering (c) Bar Extraction from a Concrete Beam (d) Extracted Bars with Grips Ready for Testing 
It is interesting to note that the state-of-the-art GFRP products with better resins and manufacturing techniques have taken three times longer duration than Litherland's specimens to attain the same reduction in strength after aging (Fig. 5.28). This implies that any calibration of our results with the natural weathering data given by Litherland on strength reduction is more conservative due to better protection offered by the screened resin (described in chapter 3) used in this investigation. Accelerated chamber weathering carried out in these experiments is calibrated (Fig. 5.26) with respect to natural weathering at Morgantown, West Virginia, having a mean annual temperature of $52.5^{0} \mathrm{~F}$ (see Fig. 5.28 and 5.30).

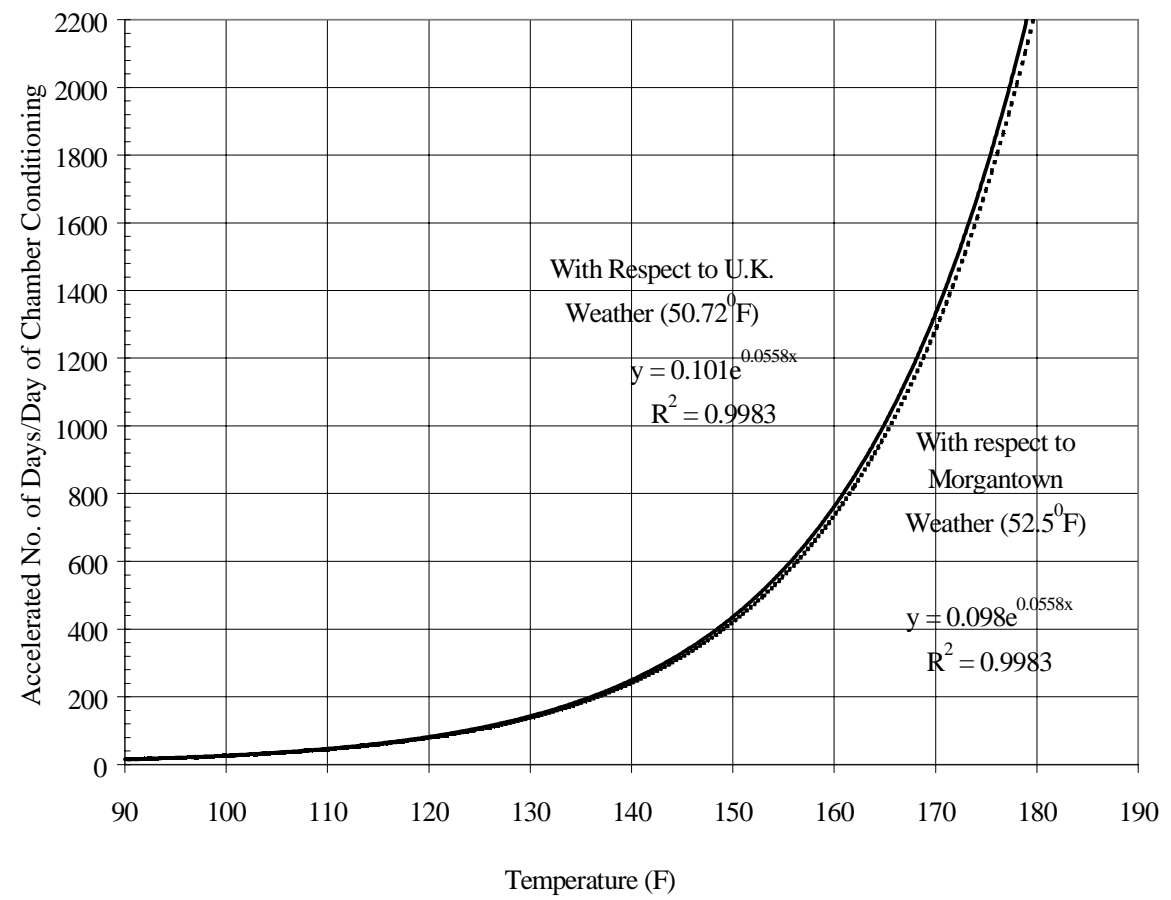

Fig. 5.30 Chart for Converting Accelerated Weathering to Natural Weathering

It follows from Fig. 5.30 that one day of chamber conditioning with a mean temperature of $93.68^{0} \mathrm{~F}$ in these tests is equivalent to 17 days of natural weathering at Morgantown, WV or 18 days of U.K. weathering as given by the calibrated Eqn. 5.3. 


\title{
Age in Natural Days/Day of Chamber Conditioning $(y)=0.098 \mathrm{e}^{0.0558 \mathrm{~T}}$
}

\author{
Where, $\mathrm{T}=$ Temperature in ${ }^{0} \mathrm{~F}$.
}

Since, our results have a time scale factor of about 3 times those of Litherland's results (Fig. 5.28), conservatively a time scale factor of two is used. With a conservative time scale factor of two, it follows that, one day of chamber conditioning in this study is equivalent to 34 days of natural weathering at Morgantown, WV, or 36 days of U.K. weathering.

Thus, chamber weathering of 30 months in alkaline conditioning corresponds to natural weathering of 1020 months, i.e., about 85 years (calculated with an average of 30.41 days/month or 365 days/year) at Morgantown, WV. This conversion is calibrated for specimens without stress. However, applying a reduction factor similar to Eqn. (5.2) for a structure with $20 \%$ sustained load, Eqn. (5.3) gives:

Age in natural days/day $\quad=34-(150 / 100) \times(20 / 100) \times 34=23.8$ days .

of chamber conditioning

Hence, chamber weathering of 30 months under alkaline conditioning and selected freeze-thaw temperature corresponds to natural weathering of 704 months or 58.68 years of natural weathering with $20 \%$ sustained stress (calculated with an average of 30.41 days/month or 365 days/year). 


\subsection{LIMITATION OF LITHERLAND'S METHOD}

Limitation of Litherland's approach is that it considers Mean Annual Temperature (M.A.T) as the basis for constructing normalized strength reduction curve without accounting for magnitude of precipitation and its distribution on the naturally weathered specimens. However, research (Springer, 1981) indicates that the strength variations are strongly dependent on temperature, moisture, pressure and stress variations.

\subsection{SUMMARY}

\subsubsection{Accelerated Aging Results on Tension Bars}

- For sand-coated bars, maximum strength reductions in salt and alkaline conditioning at room temperature were $18.5 \%$ and $32.2 \%$, respectively, over 15 months duration. Similarly maximum strength reductions in salt and alkaline conditioning under freeze-thaw conditioning were $21.9 \%$ and $37.5 \%$, respectively, over 15 months duration.

- For C-bars, maximum strength reductions in salt and alkaline conditioning at room temperature were $24.5 \%$ and $30 \%$, respectively, over 30 months duration. Similarly maximum strength reductions in salt and alkaline conditioning under freeze-thaw conditioning were $51.5 \%$ and $55 \%$, respectively, over 30 months duration.

- For sand-coated bars at room temperature with sustained stress, maximum strength reductions in salt and alkaline conditioning were $22.9 \%$ (8 months of $27 \%$ applied stress) and 49.2\% (6 months of 37\% applied stress), respectively.

- For sand-coated bars under freeze-thaw condition and sustained stress, maximum strength reductions in salt and alkaline conditioning were $25.6 \%$ (12 months of 35\% applied stress) 
and $82.1 \%$ (12 months of $40 \%$ stress application), respectively. Stress corrosion failures were observed in some bars under this conditioning.

- For C-bars under sustained stress, maximum strength reductions in salt and alkaline conditioning at room temperature were $25.2 \%$ (10 months of 32\% applied stress) and $14.2 \%$ (8 months of $25 \%$ stress application), respectively.

- Stress reduction in bars at $150^{\circ} \mathrm{F}$ and immersed in alkaline solution was $84.7 \%$ within 4 months under an applied $40 \%$ sustained stress. One of the bars in this conditioning scheme failed under static fatigue.

- On an average, sand coated International Grating bars showed 5.9\% increase in the tensile stiffness considering different conditioning schemes and duration.

- On an average, tensile stiffness increase was found to be $4.1 \%$ for M1 type and stiffness loss of $4.8 \%$ for M2 type C-bars under aging.

- Salt conditioned bars had typical wrap failure followed by vertical splitting and fiber blooming in the middle third zone. Alkaline conditioned bars typically had "necking' failures, where, the outer portion affected by alkalinity would stretch and fail earlier than the core.

- C-bars under salt conditioning generally failed with vertical splitting similar to the unconditioned bars, whereas the alkaline conditioned typically exhibited 'necking' failures.

\subsubsection{Accelerated Aging Results on Compression Bars}

- Length of 2.5D (ASTM D695), where, D is the diameter of the bar, statistically provided least variation in the compression test results and maximum strength. 
- Compressive strength of sand coated bars (regular and unconditioned) was about $40 \%$ of the tensile strength.

- Compressive strength of C-bars (regular and unconditioned) was 94\% of the tension strength.

- Maximum reduction in compressive strength of sand coated bars was found to be $60 \%$ under accelerated aging.

- Maximum compressive strength reduction of C-bars was found to be $39 \%$ for bars immersed in alkaline solution and subjected to freeze-thaw fluctuations. Majority of the bars retained high percent of their original compressive strength under different accelerated conditioning schemes.

- Failure of sand coated bars initiated along the wrap used for improving bond strength. Failure plane was found to originate mostly along the wrap. Failure modes in sand coated bars were splitting, crushing and buckling.

- In C-bars, outer SMC layer separation, fiber splitting and buckling, and vertical splitting were the major modes of failure. In addition, localized crushing was also observed in some cases.

\subsubsection{Calibration of Accelerated and Natural Weathering}

- Calibration charts developed for the non stressed GFRP bars show that one day of chamber conditioning in this study is equivalent to 34 days of natural weathering at Morgantown, West Virginia, or 36 days of U.K. weathering.

- Chamber weathering (freeze-thaw between 12.2 to $120.2^{0} \mathrm{~F}$ or -11 to $49^{\circ} \mathrm{C}$ ) of 30 months in alkaline conditioning $(\mathrm{pH}=13)$ carried out in these experiments on GFRP bars corresponds to natural weathering of 1020 months or 85 years. 
- Chamber weathering of 30 months under alkaline conditioning under the selected freezethaw temperature also corresponds to natural weathering of 704 months or conservatively 58.68 years of natural weathering with $20 \%$ sustained stress. However, concrete cover on the bars extends the service life to 90 to 120 years as described in Chapter 9 . 


\section{CHAPTER 6}

\section{BOND BEHAVIOR OF GFRP BARS UNDER ACCELERATED AGING}

\subsection{INTRODUCTION}

The bond between GFRP bar and concrete surface interface plays a critical role in the transfer of applied forces. Use of smooth surfaced bar can lead to partial compositeness or premature bond failure of reinforced concrete elements. GFRP manufacturers have adopted various measures to modify the surface texture of bars in order to improve bond. Different methods for increasing bond include; providing deformed/ribbed surfaces through sheet molding compound (SMC) sandwich, helical wraps, and secondary curing of the surface with sand particle coatings. In this chapter, bond strength of GFRP bars is examined, and compared with those of steel bars, through cylinder pull-out specimens. Accelerated tests were conducted on cylinder pull-out specimens immersed in salt and tap water at both room temperature and under freeze-thaw conditions. In addition, tests were conducted on cylinder pull-out samples with bundled bars.

\subsection{OVERVIEW}

Bond stress is defined as the shear force per unit surface area of the bar. For a cylinder pull-out specimen with circular bar, the bond stress is given by:

$$
u=\frac{T}{\left(\pi d_{b}\right) l_{d}}
$$

Where, $\mathrm{u}=$ Bond stress, $\mathrm{T}=$ tensile force carried by the bar, $\mathrm{d}_{\mathrm{b}}=$ bar diameter, $\ell_{\mathrm{d}}=$ development length. Bond strength is known to develop mainly by: (a) shearing stresses developed by adhesion along the bar surface, (b) bearing stresses developed against the face 
of the rib, and (c) shear stresses acting on the concrete surface between adjacent ribs. Important implication of bond is the contribution to cracking of the concrete. Better bond results in lower slip between the bar and concrete, and provides better composite action.

\subsection{TEST SPECIMENS, INSTRUMENATION AND TEST PROCEDURES}

Cylinder pull-out specimens were cast with 3.5" bond lengths. Top and bottom of the bar embedded in the 12" high cylinder were covered with 4.25 " long flexible split plastic tubes. 3.5" bonding length of the bars were located at the center of the cylinder. About eight inches of the un-bonded length of the bar at the loading end was coated with special resins to prevent any degradation in the bar during immersion itself to avoid tension failures during testing. Water curing was carried out on all cylinders. Following curing, cylinders were placed in containers (Fig.6.1) filled with salt $(3 \% \mathrm{NaCl})$ and tap water solution at room temperature and under freeze-thaw conditions in the environmental chamber. After immersion, water level of 1" was maintained above the cylinders, thus giving access to the solution at both ends of the bar embedded in concrete.

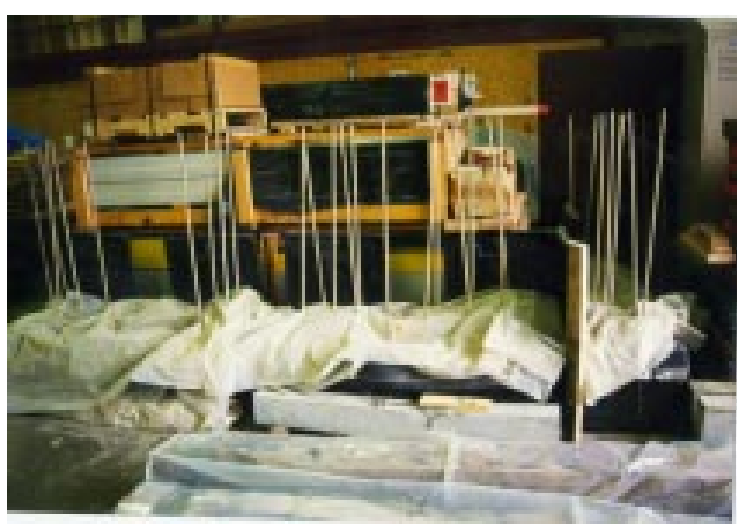

Fig. 6.1 Bond Specimens Placed in Containers with Salt and Alkaline Solutions at Room Temperature 
After the end of respective conditioning duration, grips were attached at the loading end and tested using Baldwin universal testing machine (UTM). Bar slips at the loaded and free end were recorded using LVDT's. On some of the bond samples, strains were measured on the bars 6" away from the bonded location.
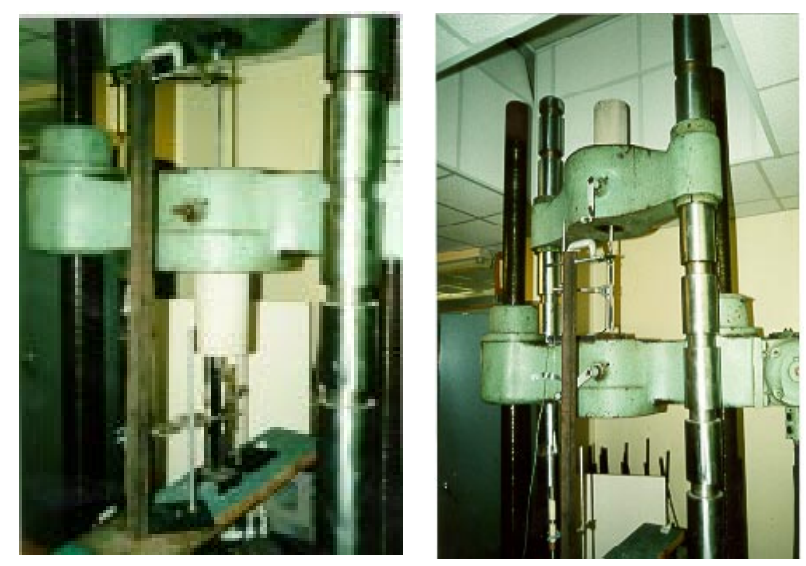

Fig. 6.2 Testing of Bond Specimens in Up-Right and Inverted Positions

\subsection{TEST RESULTS AND DISCUSSION}

\subsubsection{Bond-Stress}

Bond stresses of the unconditioned specimens were found to be 2026 psi for sand coated bars as shown in Table 6.1. Overall, maximum bond strength gain of $14 \%$ and a maximum loss of $5.3 \%$ were observed in a duration of 15 months (Table 6.1).

Table 6.1 Bond Strength of GFRP Bars after Conditioning

\begin{tabular}{|c|c|c|c|c|c|c|c|}
\hline \multirow{3}{*}{$\begin{array}{c}\text { Cond. } \\
\text { Scheme }\end{array}$} & \multicolumn{4}{|c|}{ Bond Strength (psi) } & \multicolumn{3}{|c|}{ \% Reduction in Bond Strength } \\
\hline & \multirow{2}{*}{$\begin{array}{c}\text { UNC } \\
\text { OM }\end{array}$} & \multicolumn{3}{|c|}{ After Conditioning (psi) } & & & \\
\hline & & 3M & 11M & $15 \mathrm{M}$ & $3 \mathbf{M}$ & 11M & $15 \mathrm{M}$ \\
\hline Tap+RT & \multirow{4}{*}{2026.6} & 2293.1 & 2222.0 & 2232.0 & $13.1 *$ & $9.6 *$ & $10.1 *$ \\
\hline Tap+FT & & 2247.6 & 2134.9 & 2309.4 & $10.9 *$ & $5.3 *$ & $14.0 *$ \\
\hline Salt+RT & & 2028.2 & 1919.0 & 2059.3 & $0.1 *$ & -5.3 & $1.6^{*}$ \\
\hline Salt+FT & & 1966.7 & 1952.9 & 2143.8 & -3.0 & -3.6 & $5.8 *$ \\
\hline
\end{tabular}

*-These values are gains in bond strengthUNC:Unconditioned; RT:Room Temperature; FT:Freeze-Thaw Temperature; M:Months 


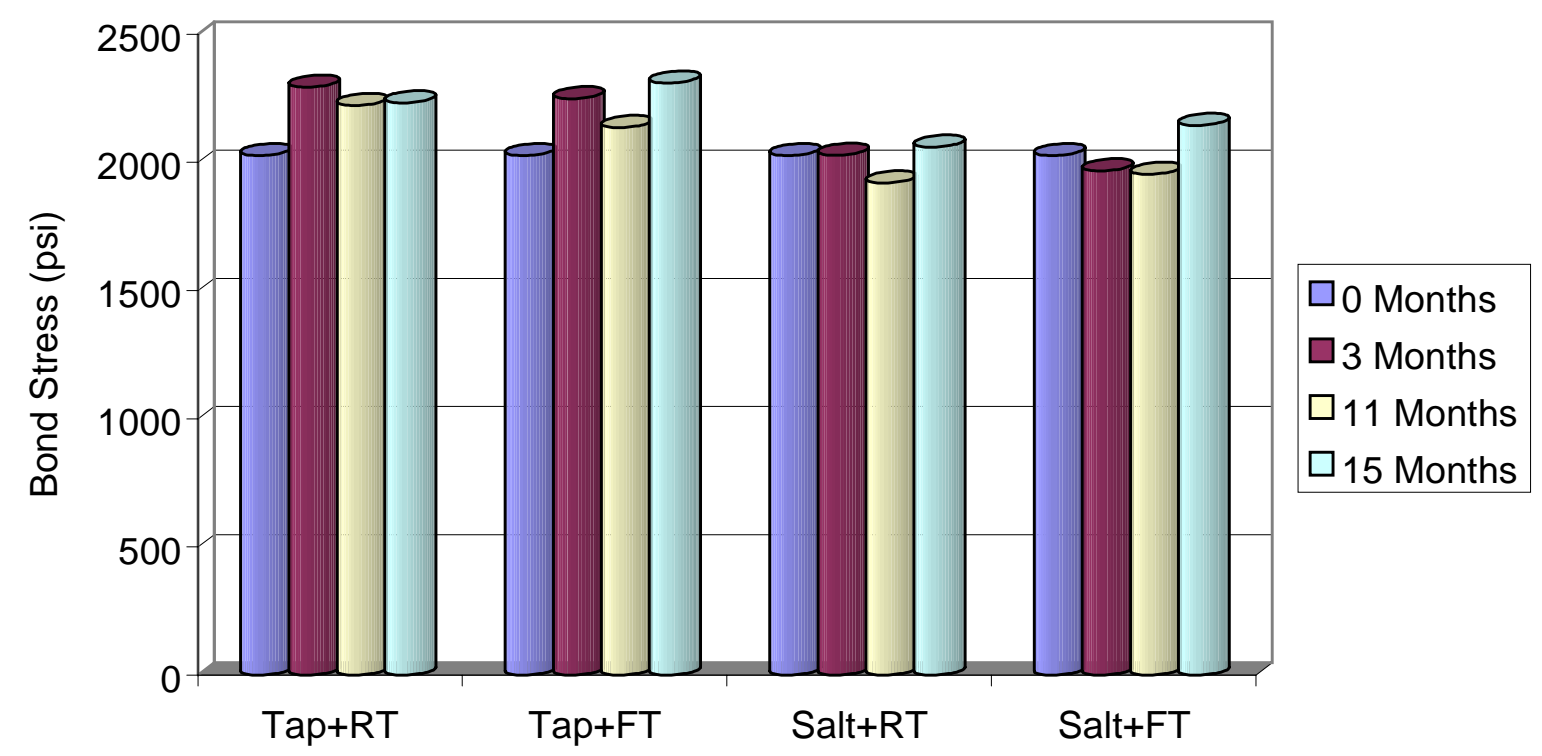

Fig. 6.3 Variation of Bond Strength of IG Bars under Accelerated Aging

- At the end of 15 months of conditioning duration, maximum bond strength gains of $10.1 \%, 14.0 \%, 1.6 \%$ and $5.8 \%$ were observed in tap water at room temperature, and under freeze-thaw conditioning, and salt water at room temperature and freeze-thaw conditioning, respectively.

- Bond strength drop of $3.0 \%$ and $3.6 \%$ was noted at at 3 and 11 months in freeze-thaw and salt conditioning. Statistically, these variations are not significant. Mean temperature of the chamber with freeze-thaw conditioning scheme was $93.68^{0} \mathrm{~F}$, which was above the room temperature of $71.6^{0} \mathrm{~F}$. However, after 15 month conditioning, gain in bond strength was observed for the same conditioning scheme (Table 6.1 and Fig. 6.1).

- Similarly, bond strength loss of 5.3\% was observed under salt and room temperature after 11 months. However, bond strength gain was observed at the end of 15 months for the same conditioning scheme. Although gain in the bond strength is attributed to increase in 
the concrete cylinder strength, magnitude of change indicates that the percent gain is within typical statistical variation of bond between FRP bars and concrete.

\subsubsection{Bond-Stress vs. Slip}

Bond-stress vs. slip of a sand coated GFRP bar pull-out specimen is shown in Fig. 6.4. Both loaded end and free end slip were measured using LVDT's. On the loaded end, slips were measured at least 6" away from the bonded location, and suitable correction factors were applied to account for the bar elongation. Comparison of load-slip relationship between GFRP bars and concrete to those of steel and concrete suggest comparable or better slip modulus. Slip modulus or secant modulus is defined as the slope of the tangent drawn to bond-stress vs. slip curve from the origin.

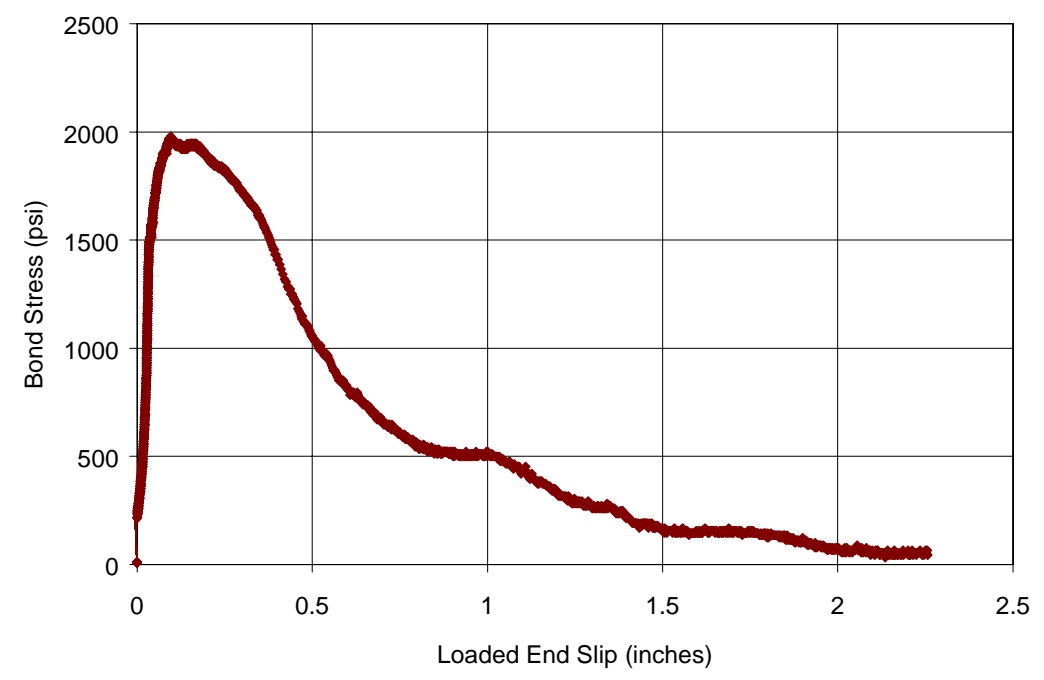

Fig. 6.4 Bond-Stress and Slip Relation for an Unconditioned GFRP Bar Pull-Out Specimen 


\subsection{COMPARISON OF BOND STRENGTHS OF GFRP AND STEEL BARS}

Pull-out tests were conducted on nine cylinders with embedded steel reinforcement, Cbars (M1 type) and sand coated bars. \#4 Bars were chosen for comparison and three replications were tested for each bar type. Both types of GFRP bars exhibited superior bond properties over steel. Compared to steel bar, bond strengths of C-bar and sand coated bar were $33.5 \%$ and $55.5 \%$ higher, respectively (Fig. 6.5). In these tests a bond length of 3 inches was used. Smaller bond lengths produce more uniform bond stresses throughout the embedment length; hence slightly higher bond strengths can be expected. Higher bond strengths with smaller bond lengths are also noted in the pull-out bond tests of aramid FRP bars (Zahid, 1994).

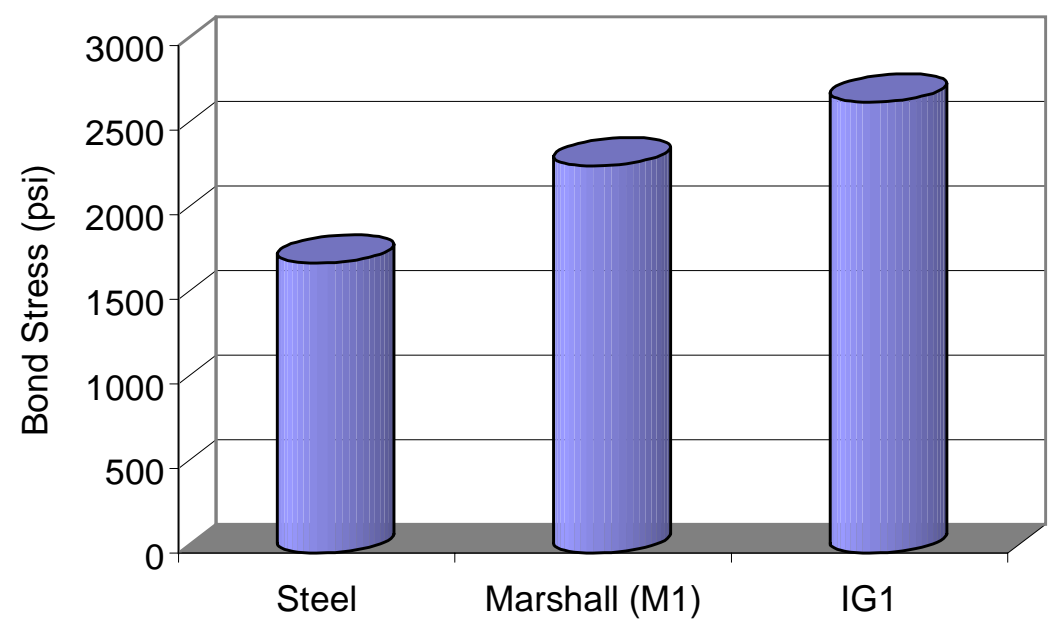

Fig. 6.5 Comparison of Bond Strength between Steel and GFRP (M1 and IG1) Bars

\subsection{BOND STRENGTH OF BUNDLED BARS}

Bond strength of bundled bars was evaluated by conducting pull-out tests. Two barbundle, three-bar bundle (similar to a triangle bundle) and four-bar bundle (square) were fastened with ties, and bond length of 2.5 " was cast in the cylinder. Bundled bars extended all 
the way in the cylinder. Except the middle 2.5" length, the top and bottom portions of a bar were maintained bond-free through the use of removable styrofoam. To minimize the splitting forces during testing, steel hoop reinforcement with a radius of 4.5 inches and height of 12 inches was provided in the cylinders during casting. During pilot testing it was found that grip length of 8 inches was inadequate to transfer the pulling forces, and hence increased to 12 inches in other specimens.

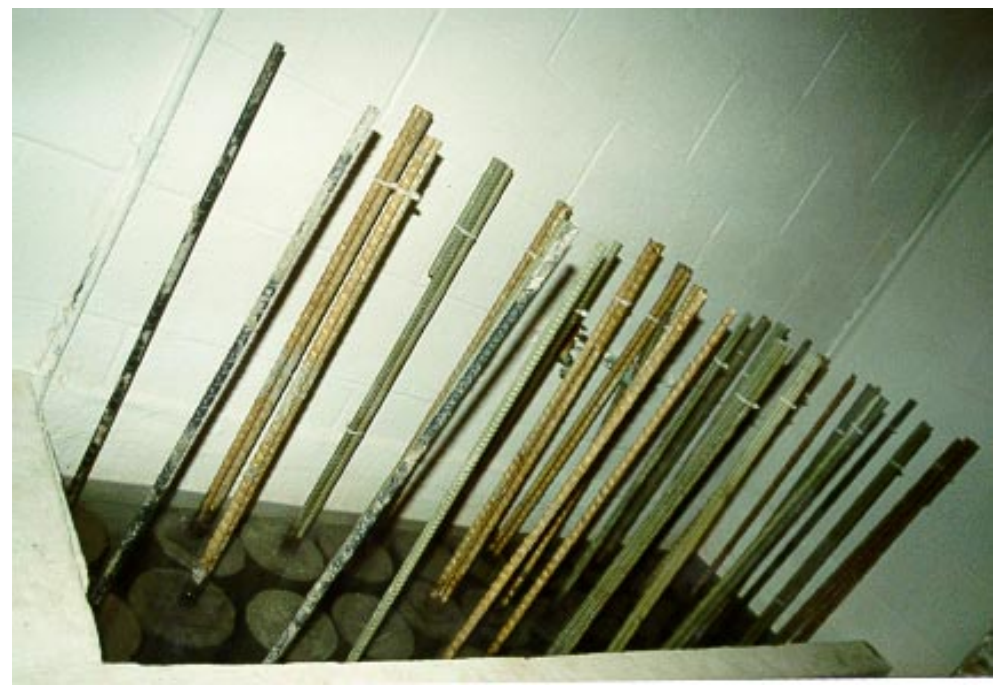

Fig 6.6 Curing of Cylinder pull-out Specimens with Bundled Bars

Geometric properties of bundled bars are shown in Table 6.2. Perimeter of equivalent single bar replacing each bundle with an equivalent area is also shown. From Table 6.2, use of single equivalent diameter bar should result in conservative estimate of bond stress in bundled bars. Bond strength values of the bundled GFRP bars manufactured by Marshall (M1 Type) Industries, Inc. is shown in Table 6.3. 
Table 6.2 Geometric Properties of Normally Spaced Bars, Bundled Bars and Equivalent Single Bar (Nawy, 1990)

\begin{tabular}{|c|c|c|c|c|}
\hline $\begin{array}{l}\text { Bundle } \\
\text { Type }\end{array}$ & $\begin{array}{l}\text { Normal } \\
\text { Spacing }\end{array}$ & $\begin{array}{l}\text { Bundled } \\
\text { Bar }\end{array}$ & $\begin{array}{l}\text { Equivalent } \\
\text { Single Bar }\end{array}$ & $\begin{array}{c}\text { Perimeter Comparison of Bundled Bar } \\
\text { with normally spaced and equivalent } \\
\text { single Bar }\end{array}$ \\
\hline & & & & \\
\hline \multirow[t]{2}{*}{2 Bars } & $A_{f}=\frac{\pi d^{2}}{2}$ & $A_{f}=\frac{\pi d^{2}}{2}$ & $A_{f}=\frac{\pi d^{2}}{2}$ & \multirow[t]{2}{*}{$\begin{array}{l}\text { - } \quad \text { Perimeter } \% \text { same as normally spaced } \\
\text { - } 30 \% \text { more than equivalent single bar }\end{array}$} \\
\hline & $P=2 \pi d$ & $P=2 \pi d$ & $P=\sqrt{2} \pi d$ & \\
\hline \multirow[t]{2}{*}{3 Bars } & $A_{f}=\frac{3}{4} \pi d^{2}$ & $A_{f}=\frac{3}{4} \pi d^{2}$ & $A_{f}=\frac{3}{4} \pi d^{2}$ & \multirow[t]{2}{*}{$\begin{array}{l}\text { - Perimeter } 16.7 \% \text { less than normally } \\
\text { spaced } \\
\text { - } 44 \% \text { more than equivalent single bar }\end{array}$} \\
\hline & $P=3 \pi d$ & $P=2 \frac{1}{2} \pi d$ & $P=\sqrt{3} \pi d$ & \\
\hline \multirow[t]{2}{*}{4 Bars } & $A_{f}=\pi d^{2}$ & $A_{f}=\pi d^{2}$ & $A_{f}=\pi d^{2}$ & \multirow{2}{*}{ 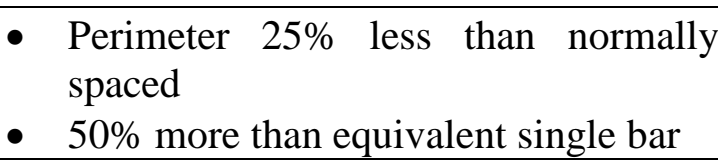 } \\
\hline & $P=4 \pi d$ & $P=3 \pi d$ & $P=2 \pi d$ & \\
\hline
\end{tabular}

$$
A_{f}=\mathrm{c} / \mathrm{s} \text { area of the FRP bar; } \quad P=\text { Perimeter of the bar }
$$

Table 6.3 Pull-out Cylinder Test Results of Bundled Bars (Marshall M1 Type) and Comparison with Two Bar Bundle

\begin{tabular}{|c|c|c|c|c|c|c|}
\hline $\begin{array}{c}\text { Type of } \\
\text { Bundle }\end{array}$ & $\begin{array}{c}\text { Perimeter } \\
\text { of Bundled } \\
\text { Bars }\end{array}$ & $\begin{array}{c}\text { Perimeter } \\
\text { of } \\
\text { Equivalent } \\
\text { Bar }\end{array}$ & $\begin{array}{c}\text { Pull-out } \\
\text { Load } \\
\text { (lbs) }\end{array}$ & $\begin{array}{c}\text { Ratio of } \\
\text { Loads } \\
\text { Carried }\end{array}$ & $\begin{array}{c}\text { Ratio of } \\
\text { Perimeter } \\
\text { of Bundled } \\
\text { Bars }\end{array}$ & $\begin{array}{c}\text { Ratio of } \\
\text { Perimeter of } \\
\text { Equivalent } \\
\text { Bar }\end{array}$ \\
\hline 2-Bar & $P=2 \pi d$ & $\sqrt{2} \pi$ & 10,900 & 1 & 1 & 1 \\
\hline 3-Bar & $P=2 \frac{1}{2} \pi d$ & $\sqrt{3} \pi$ & 14,200 & 1.30 & 1.25 & 1.22 \\
\hline 4 Bar & $P=3 \pi d$ & $2 \pi$ & 15,600 & 1.43 & 1.5 & 1.41 \\
\hline
\end{tabular}

From Table 6.2, ratio of pull-out load carried by bundled bars is proportional to the perimeters of either bundled bars or a conceptual equivalent single bar. However, pull-out 
load for a single bar with similar bond length of 2.5 " was 8900 lbs.. Hence, bond strength of two bar bundle is $38.8 \%$ and $18 \%$ lower, by considering available perimeter of the bundled bar (colums 2, Table 6.2) and that of the equivalent single bar (column 3, Table 6.2) respectively. Therefore, for bundled bars, perimeter of a single bar with an equivalent area can be used for bond strength calculations by applying suitable reduction or modification factors. Before recommending such reduction factors more number of bundled bar pull-out samples need to be tested with different bar diameters, bundle configurations and concrete strengths.

\subsection{CONCLUSIONS}

- At the end of 15 months of conditioning duration maximum bond strength gains of $10.1 \%$, $14.0 \%, 1.6 \%$ and $5.8 \%$ were observed in tap water at room and freeze-thaw temperature, and salt water at room and freeze-thaw temperature, respectively.

- For bundled bars, perimeter of a single bar with an equivalent area can be used for bond strength calculations. Bond strength is found to be proportional to the perimeter of the bundled bars.

- These findings help in arriving at suitable reduction factors on the bond strength equations developed for single GFRP bars with concrete. However, further studies are needed to establish accurate reduction factors with respect to bar diameter and concrete cylinder strength. 


\section{CHAPTER 7}

\section{BENDING BEHAVIOR OF CONCRETE BEAMS REINFORCED WITH GFRP}

\subsection{INTRODUCTION}

In this chapter, flexural behavior of rectangular concrete beams reinforced with sand coated and ribbed Glass Fiber Reinforced Plastic (GFRP) bars is presented along with the aging behavior. Discussion on the bending behavior of the GFRP reinforced concrete members includes the influence of strength and stiffness properties of concrete and GFRP bars on failure modes. Energy absorption concept is introduced to unify deflection and crack-width limit states and to establish deformability factors to preclude catastrophic failures. Energy absorption at ultimate to that at a limiting serviceability curvature (deformability) is suggested for concrete beams under bending. The effect of compression reinforcement on moment capacity and deformability factor is also investigated.

\subsection{OVERVIEW}

While designing a concrete beam with nonprestressed GFRP bars, engineers have to identify and design for a failure mode considering implications on ductility, deformability and curvature. Pre- and post-cracking results on the aforementioned issues for GFRP reinforced concrete beams under bending are presented. Extensive amount of research has been carried out in the area of concrete beams reinforced with GFRP bars as described in the ACMBS-II Proceedings (1996), Canadian Standard Association Report (1997), Japanese Ministry of Construction Report (1998), ICCI Proceedings (1996), and ASCE Proceedings (1996). 


\subsection{OBJECTIVES}

The objectives of this study are:

- To identify failure modes and optimize bending capacity of concrete beams with GFRP reinforcement.

- To establish deformability criteria by unifying deflection and crack width limit states for underreinforced and overreinforced concrete sections with GFRP bars.

- To review and formulate design aspects such as theoretical moment capacity computations for underreinforced and overreinforced sections, deflection, and crack width control.

- To study the effect of compression reinforcement on flexural strength, moment capacity, and deformability.

\subsection{BENDING TESTS}

Six concrete beams (6"x12"x120") were tested under four-point bending (Fig. 7.1). Details of test specimens are shown in Table 7.1. The beams were designed to exhibit under and overreinforced failure conditions. Testing consisted of several load cycles until physical failure of the beam was reached. The parameters of interests were central deflection, residual deflections (after unloading), crack spacing and widths, strains on concrete and FRP bars, and ultimate moment capacity. Strains were also monitored on some FRP stirrups near supports. Strains and deflections were monitored through strain gages and LVDTs, respectively, using data acquisition system. 


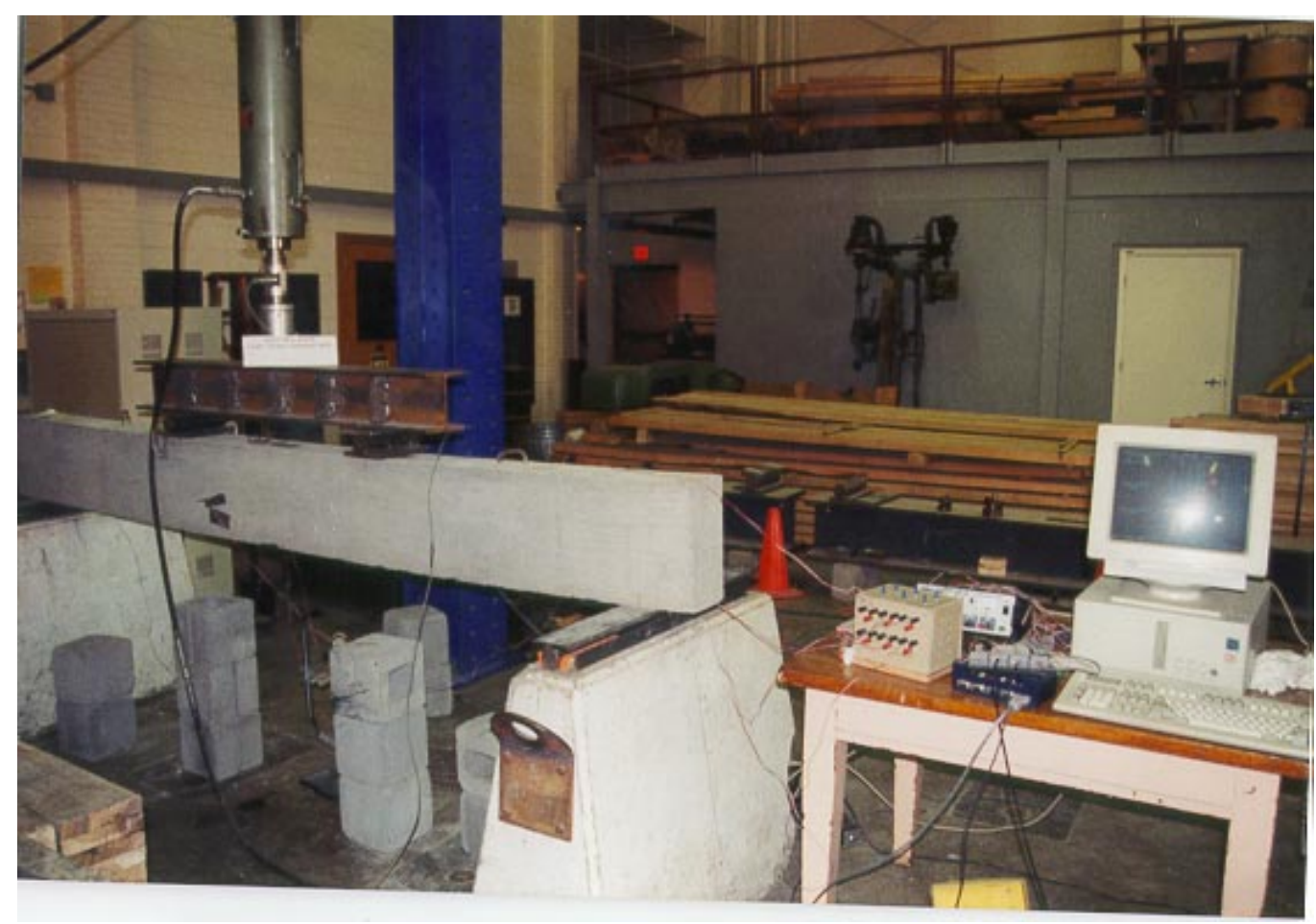

Fig. 7.1 Four-point Bending Test Set-up with data Acquisition System

Table 7.1 Beams Tested with GFRP Reinforcement Under Four-Point Bending

\begin{tabular}{|c|c|c|c|c|c|}
\hline $\begin{array}{c}\text { Type of } \\
\text { Bar }\end{array}$ & Beam & $\begin{array}{c}f_{c}{ }^{\prime} \\
(\mathbf{k s i})\end{array}$ & $\begin{array}{c}\text { Tension } \\
\text { Bars }\end{array}$ & Comp.Bars & $\begin{array}{c}\text { \#3 Shear } \\
\text { Stirrups }\end{array}$ \\
\hline \multirow{3}{*}{$\begin{array}{c}\text { Sand } \\
\text { Coated }\end{array}$} & $\mathrm{T} 1$ & 6.5 & $2-\# 4$ & $2-\# 3$ & 4 "c/c \\
\cline { 2 - 6 } & $\mathrm{C} 2$ & 6.5 & $2-\# 6$ & $1-\# 3$ & $6 " \mathrm{c} / \mathrm{c}$ \\
\cline { 2 - 6 } & $\mathrm{T} 3$ & 6.5 & $2-\# 4$ & $1-\# 3$ & $6 " \mathrm{c}$ \\
\cline { 2 - 6 } & $\mathrm{C} 4$ & 6.5 & $2-\# 6$ & $2-\# 3$ & 4"c/c \\
\hline \multirow{2}{*}{ Deformed } & $\mathrm{M} 1$ & 4.5 & $2-\# 6$ & $1-\# 3$ & $6 " \mathrm{c} / \mathrm{c}$ \\
\cline { 2 - 6 } & $\mathrm{M} 2$ & 4.5 & $4-\# 6$ & $1-\# 3$ & $6 " \mathrm{c} / \mathrm{c}$ \\
\hline
\end{tabular}

\subsection{TEST RESULTS AND DISCUSSIONS}

\subsubsection{Failure Modes}

Failure modes of different beams and their flexural strength are shown in Table 7.2. Test results indicate the anticipated failure modes. Test beams in tension failure were loaded up to GFRP bar rupture and exhibited fairly large deflections. Beams in compression failure were 
loaded until localized concrete crushing in compression zone, either at mid-span or under the load points. Failure modes indicate tension failure for $\mathrm{c} / \mathrm{d}$ (neutral axis/effective depth) ratio under 0.16 (for concrete and FRP bar strain values of 0.003 and 0.015 respectively) and compressive failure for a c/d ratio over 0.16 . This $\mathrm{c} / \mathrm{d}$ ratio for a balanced failure may vary between 0.14 to 0.18 depending on the maximum strain values of concrete and GFRP bars at failure.

\section{Table 7.2 Flexural Test Results on GFRP Reinforced Beams under Four-Point Bending}

\begin{tabular}{|c|c|c|c|}
\hline $\begin{array}{c}\text { Type of } \\
\text { Bar }\end{array}$ & Beam & $\begin{array}{c}\text { Ultimate Load } \\
\text { exptl. (kip) }\end{array}$ & Failure Mode \\
\hline \multirow{3}{*}{$\begin{array}{c}\text { Sand } \\
\text { Coated }\end{array}$} & $\mathrm{T} 1$ & 18.4 & Tension \\
\cline { 2 - 4 } & $\mathrm{C} 2$ & 26.7 & Comp. \\
\cline { 2 - 4 } & $\mathrm{T} 3$ & 16.4 & Tension \\
\cline { 2 - 4 } & $\mathrm{C} 4$ & 23.8 & Comp. \\
\hline Deformed & $\mathrm{M} 1$ & 24.5 & Comp. \\
\cline { 2 - 4 } & $\mathrm{M} 2$ & 26.1 & Comp. \\
\hline
\end{tabular}

Since GFRP bars have high failure strains (1.5-2.5\%) as compared to $0.2 \%$ yield strain of Grade-60 steel reinforcement, loading GFRP bars to their maximum strain value limits the depth of concrete compression block in a reinforced concrete beam (due to near-linear variation of strains along the beam depth). Smaller depth of concrete compressive block in a tension failure case results in the development of lower moment resistance. By increasing the percentage of GFRP reinforcement, higher moment resistance can be obtained because of larger compressive area satisfying the force equilibrium criteria. However such increase is not proportional to the percentage increase in reinforcement, and failure modes depend on the new equilibrium. For example, 126 percent increase in the area of reinforcement for beams C2 and C4 resulted in 46.33 and 45.02 percent moment increase over T1 and T3, respectively (Table 7.3). Increase in the reinforcement in beams $\mathrm{C} 2$ and $\mathrm{C} 4$ also changed failure mode from tension to compression. 
However, 104 percent increase in the area of reinforcement in beam M2 as compared to M1 increased the moment capacity by only $6.4 \%$, with no change in compression failure mode. These results indicate a limit on the concrete compressive block depth available for generating matching compressive forces in a GFRP reinforced concrete beam subjected to bending.

Table 7.3. Effect of Reinforcement on Moment Capacity and Failure Mode

\begin{tabular}{|c|c|c|c|}
\hline $\begin{array}{c}\text { Beams } \\
\text { Compared }\end{array}$ & $\begin{array}{c}\text { \% Reinf. } \\
\text { Increase }\end{array}$ & $\begin{array}{c}\text { \% Moment } \\
\text { Increase }\end{array}$ & $\begin{array}{c}\text { Change in } \\
\text { Failure Mode }\end{array}$ \\
\hline T1 and C2 & 126 & 46.33 & Tension to comp. \\
\hline T3 and C4 & 126 & 45.02 & Tension to comp. \\
\hline M1 and M2 & 104 & 6.42 & -No- \\
\hline
\end{tabular}

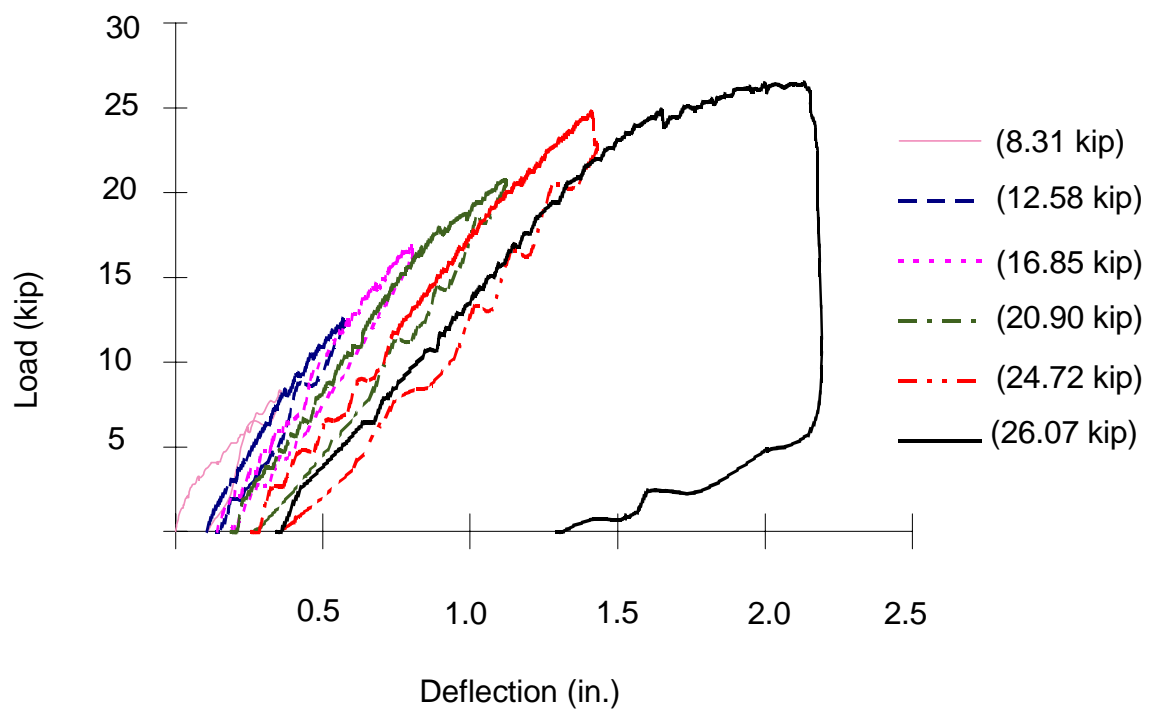

Fig. 7.2 Testing of Beam M2 for Compression Failure in Several Cycles 


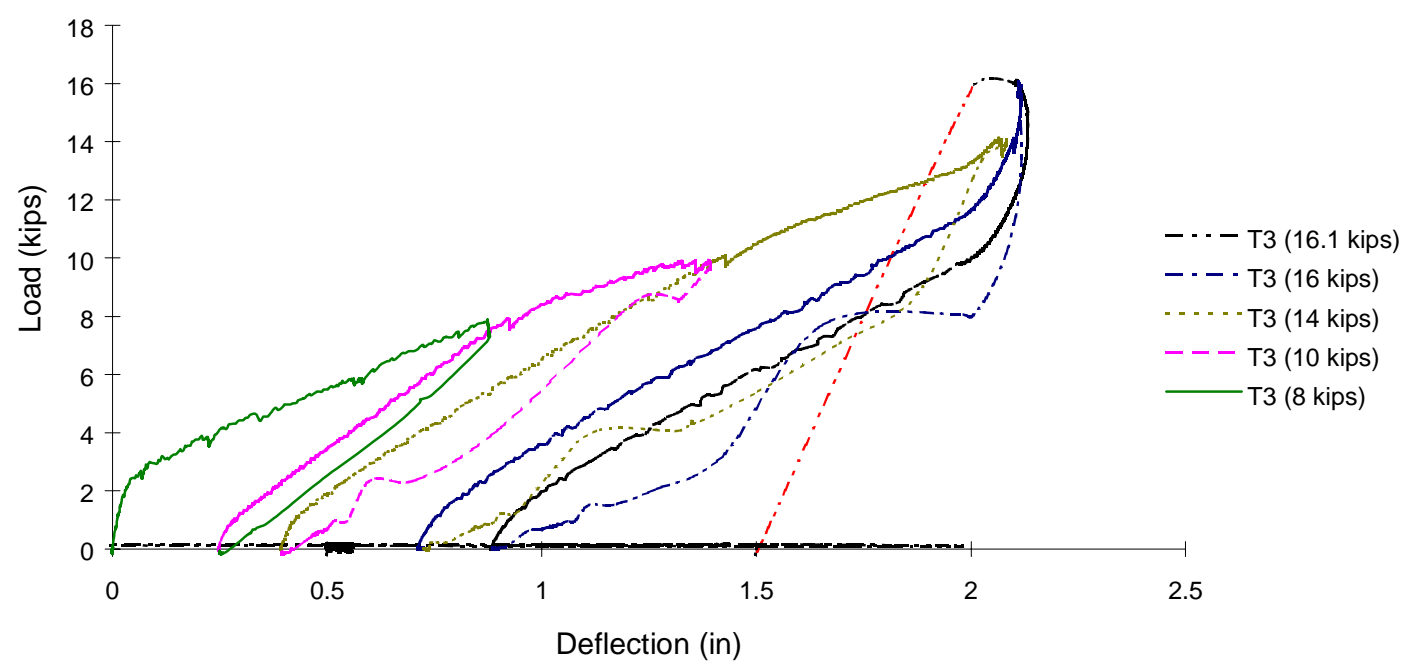

Fig. 7.3 Testing of Beam T3 for Tension Failure in Several Cycles

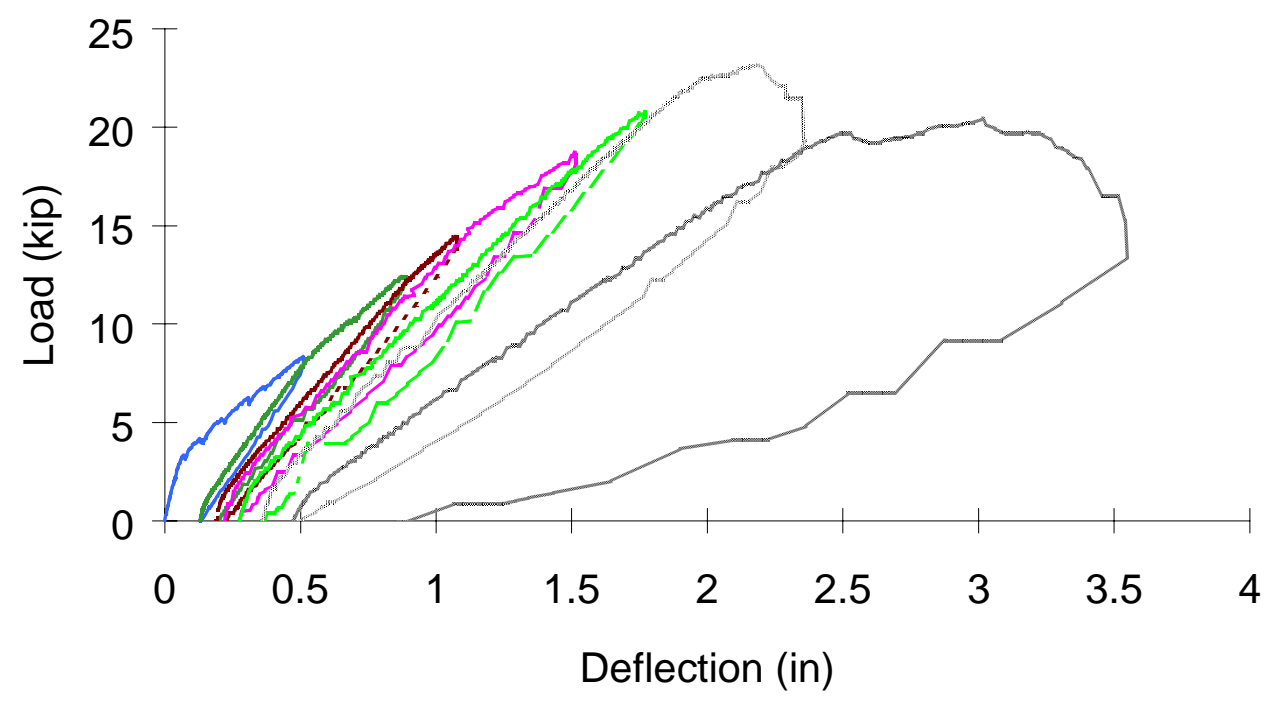

Fig. 7.4 Testing of Beam M1 for Compression Failure in Several Cycles

\subsubsection{Deformability and Ductility}

Deformability/ductility of reinforced concrete beams is a measure of the energy absorption capacity. Ductility of concrete beams with steel bars is defined as a ratio of deflection or curvature or rotation values at ultimate to yield. These definitions mainly depend upon the 
distinct yielding level, and post-yielding plateau of steel bars. Interpretation of ductility of FRP reinforced concrete beams on the basis of conventional definitions is misleading due to linear stress-strain relation of FRP bars until failure. Hence, an acceptable definition of ductility for FRP reinforced concrete beams has to represent the following factors:

- Uniform elongation of FRP bars i.e., uniform crack-width at different locations as compared to localized bar yielding.

- Confinement effect.

- Uniform crack location and spacing in case of FRP reinforced concrete beams.

- Bond between bar and concrete.

- Plastic hinge formation at several locations in concrete or a single large plastic zone.

- Frictional force development along diagonal and wedge cracks.

Conventional definitions of ductility indices ( $\mu$ ) are as follows (Park and Paulay, 1975 ):

$$
\begin{array}{ll}
\text { Deflection }(\Delta) \text { Based } & \mu=\Delta_{u} / \Delta_{y} \\
\text { Rotation }(\theta) \text { Based } & \mu=\theta_{u} / \theta_{y} \\
\text { Curvature }(\varphi) \text { Based } & \mu=\varphi_{u} / \varphi_{y}
\end{array}
$$

Where, subscripts ' $u$ ' and 'y' refer to ultimate and yield conditions, respectively.

One of the alternative approaches to define ductility of FRP reinforced concrete beams is to adopt the conventional plasticity approach applicable to metals, which takes into account the energy absorption (Naaman and Jeong, 1995). In the energy based approach ductility index is given by:

$$
\mu=\frac{\Delta_{u}}{\Delta_{y}}=\frac{1}{2}\left(\frac{E_{\text {total }}}{E_{\text {elastic }}}+1\right)
$$


where,

$$
\begin{gathered}
E_{\text {total }}=\text { area under the load-deflection curve during loading . } \\
E_{\text {elastic }}=E_{\text {total }} \text { - area under the load-deflection curve during } \\
\text { loading and unloading . }
\end{gathered}
$$

To account for zero elastic energy ( $E_{\text {elastic }}$ ), when FRP bars rupture in case of tension failure of FRP reinforced beams, energies are considered at 80-90\% load levels in the above equation.

Another approach suggested by Jaeger et al. (1995), consists of accounting for both moment capacity and curvature to obtain deformability factor. Moment factor and curvature factor are defined as a ratio of respective moment or curvature values at ultimate to the values corresponding to a concrete strain of 0.001 . The concrete strain of 0.001 is chosen to represent the linear stress-strain behavior in concrete in compression above the neutral axis (under elastic steel stress situation) during post-cracking stage and to facilitate comparison between ductility and deformability of steel reinforced beams.

To properly account for different energy absorbing mechanisms and to satisfy both deflection and crack-width criteria, unified serviceability based approach is developed in this research for defining deformability as explained in Section 7.6.

\subsection{UNIFIED SERVICEABILITY CRITERIA FOR DEFORMABILITY}

Energy absorption in concrete beams can be estimated by considering the areas under load-deflection or moment-curvature diagrams. Consideration of serviceability based energy level with respect to total energy in a moment curvature plot provides a basis for addressing ductility and deformability in the design of GFRP reinforced beams. Overall moment-curvature 
diagrams, similar to load-deflection curves shown in Figs. 7.2 to 7.4, were plotted for all beams to calculate the energy ratios as explained below.

Considering deflection and serviceability criteria in accordance with ACI 318-95, for maximum allowable crack width of 0.016 in. (R.10.6.4, ACI 318R-95), and a deflection of 0.6 inches (based on a span/180 limit, Table 9.5 (b), ACI 318-95), curvature values were analyzed from the experimental results. The curvature satisfying both deflection and crack-width criteria was found to vary between $(0.005 / \mathrm{d})$ and $(0.006 / \mathrm{d})$ radians/inch, where ' $\mathrm{d}$ ' is depth of the beam. Ratio of total energy at ultimate to that at curvature of 0.0005 is calculated in Table 7.4. If more stringent serviceability criterion were to be chosen, the curvature limit will be lower than $(0.005 / \mathrm{d})$, leading to increased safety and cost of a structure.

\section{Table 7. 4. Serviceability Based Approach for Deformability}

\begin{tabular}{|c|c|c|c|}
\hline Beam & $\begin{array}{c}\text { Curvature at } \\
\text { limiting crack } \\
\text { width }\end{array}$ & $\begin{array}{c}\text { Curvature at } \\
\text { limiting } \\
\text { deflection }\end{array}$ & $\left(\mathrm{E}_{\text {ult. }} / \mathrm{E}_{0.005}\right)$ \\
\hline T1 & 0.0006 & 0.00049 & 9.78 \\
\hline C2 & 0.000465 & 0.00048 & 6.71 \\
\hline T3 & 0.00058 & 0.00048 & 6.17 \\
\hline C4 & 0.00041 & 0.00047 & 6.90 \\
\hline M1 & - & 0.00049 & 8.59 \\
\hline M2 & - & 0.00048 & 8.2 \\
\hline
\end{tabular}

GFRP rebar rupture under tension failure led to sudden member collapse, whereas relatively gradual member failure was observed in beams with compression failure. Energy absorption of GFRP reinforced concrete beams M2 in compression failure can be observed in Fig. 7.2. Energy absorption of the beam is equal to the area under load-deflection curve. High 
amount of energy absorption is observed during final cycle of loading. Moment-curvature diagrams, which resemble load-deflection curve, were plotted for all beams. Deformability factors in compression failures were calculated and found to be about 7 or better (Table 7.4).

\subsection{EFFECT OF COMPRESSION BARS ON MOMENT CAPACITY AND DEFORMABILITY FACTOR}

For studying the effect of compression reinforcement on the flexural strength of GFRP reinforced concrete beams, four beams were tested. These were reinforced with two tension bars at the bottom, and zero, one, two, and three compression bars at the top, respectively. Marshall C-bars were used in this study. Reference beam with two tension bars and no compression bar was designed to fail in compression so that contribution of compression reinforcement on the flexural strength could be experimentally verified. However, no significant increase in moment capacity was expected, because:

- Compression bars were close to neutral axis due to small beam depth of 6 inches.

- Concrete compressive failure strain is generally around 0.003 in./in. Relative compressive strain in concrete with GFRP bars is about 0.002 in./in. or less, which is $1 / 10$ th to $1 / 12$ th of the bar failure strain, and hence its full potential is underused. 
Table 7.5 Effect of Compression Reinforcement on Moment Capacity and Deformability in a Compression Failure

\begin{tabular}{|c|c|c|c|c|c|c|c|}
\hline Beam & $\begin{array}{c}\text { No. of } \\
\text { Comp. } \\
\text { Bars }\end{array}$ & $\mathrm{f}_{\mathrm{c}}{ }^{\prime}$ & $\begin{array}{c}\text { Comp. } \\
\text { reinf }\end{array}$ & $\begin{array}{c}\text { Increase } \\
\text { in comp. } \\
\text { Reinf. }\end{array}$ & $\begin{array}{c}\text { Max } \\
\text { Moment }\end{array}$ & $\begin{array}{c}\text { Increase } \\
\text { in } \\
\text { Moment }\end{array}$ & $\begin{array}{c}\text { Normalized } \\
\text { Deformability } \\
\text { Factor }\end{array}$ \\
\hline & & $\mathrm{psi}$ & $\%$ & $\%$ & kip-inch & $\%$ & \\
\hline B-0C & 0 & 6300 & 0.0 & - & 103 & - & 1.00 \\
\hline B-1C & 1 & 6300 & 0.9 & 90 & 93 & $-9.7^{*}$ & 1.09 \\
\hline B-2C & 2 & 6300 & 1.8 & 180 & 105 & 1.16 & 1.15 \\
\hline B-3C & 3 & 6300 & 2.7 & 270 & 110 & 6.8 & 1.04 \\
\hline
\end{tabular}

Note: Dimensions of the test beams were 5"x6"x60".

* This value is a reduction

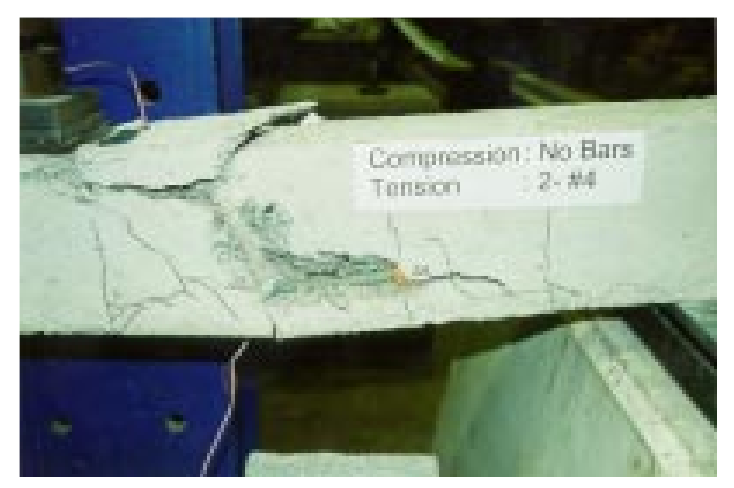

(a)

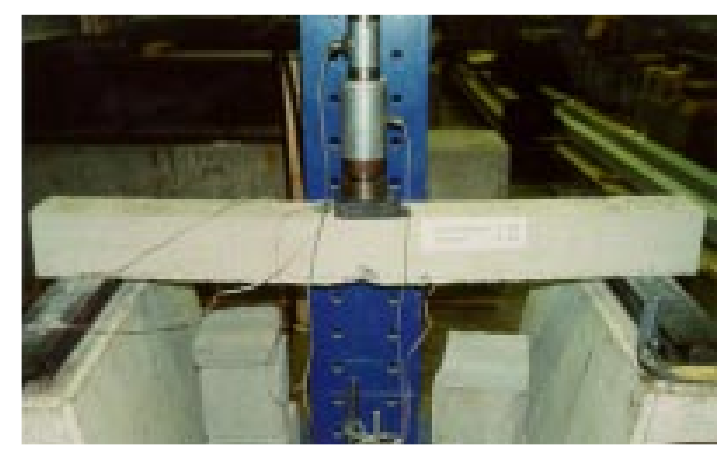

(c)

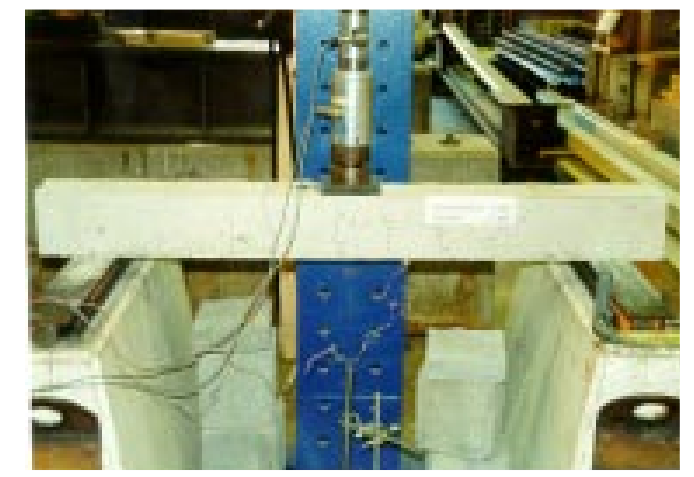

(b)

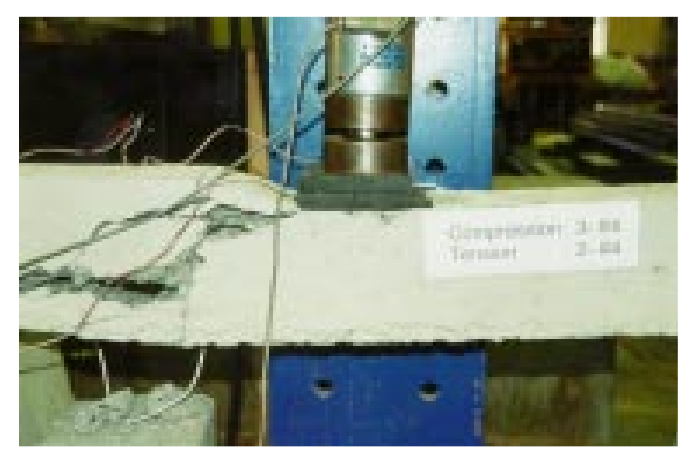

(d)

Fig. 7.5 Testing of Beams with 4 Different Compression GFRP Reinforcement Configurations a)Zero; b)1; c)2; and d)3 Compression Bars 
Results on the influence of compression reinforcement on bending capacity and deformability factor are presented in Table 7.5. Deformability factor increased in all the cases as compared to the beam without any compression reinforcement. Maximum moment increase of $6.8 \%$ was observed in the beam with three compression bars (equivalent to $2.7 \%$ compression reinforcement). It is to be noted that all the beams were designed for a compression failure, and they failed as expected, through shear compression failures.

\subsection{DESIGN CONSIDERATIONS}

Based on the understanding of bending behavior, the key design aspects necessary for designing of GFRP reinforced concrete members are: 1) failure under bending; 2) balanced, tension and compression failure philosophy; 3) deflection control; 4) crack-width control; and 5) deformability. These aspects have been elaborated in sections 7.8.1 through 7.8.8. Since deformability and its importance were discussed earlier, its implications on design are briefly discussed.

\subsubsection{Failure under Bending}

For a given bending moment, a designer can chose a tension (failure of rebar) or compression failure (of concrete) mode. Concrete beams and slabs with steel reinforcement are designed for tension failure to take advantage of the elastic-plastic behavior of steel, i.e., leading to higher ductility. Since GFRP reinforcement exhibits linear stress-strain behavior, the ultimate failure mode of GFRP reinforced concrete members has to be based upon the nature of failure, magnitude of energy absorption, and other advantages or disadvantages. Proper identification of 
failure modes including some of the experimental and theoretical comparisons are provided in subsequent sections.

\subsubsection{Balanced Failure}

Balanced failure condition is defined as the situation, where strains in concrete and GFRP bars simultaneously reach their predefined limiting values, i.e., $\varepsilon_{c}(=0.003)$ and $\varepsilon_{f}\left(=f_{f} / E_{f}\right)$ in concrete and GFRP bars, respectively. Although the balanced failure condition is difficult to achieve in practice, the concept of balanced failure helps in defining the tension and compression failure modes. The balanced failure condition corresponds to:

7.8.2.1 Percentage reinforcement $(\rho)$ approach : Substituting the material properties of GFRP instead of steel in Section 8.4.3 of ACI 318-95, from strain compatibility, we obtain Eq. 7.5. For a tension failure $\rho<\left(\rho_{b-b}\right)$ and for a compression failure $\rho>\left(\rho_{b-b}\right)$.

$$
\rho_{b-b}=\frac{0.85 \beta_{1} f_{c}^{\prime}}{f_{f}} \frac{0.003 E_{f}}{f_{f}+0.003 E_{f}}
$$

7.8.2.2 Ratio of neutral axis depth to effective depth (c/d) approach : Based on linear stress-strain assumption between GFRP and concrete, Eq. 7.6 is obtained. For tension failure $(\mathrm{c} / \mathrm{d})<(\mathrm{c} / \mathrm{d})_{\mathrm{b}-\mathrm{b}}$ and for a compression failure $(\mathrm{c} / \mathrm{d})>(\mathrm{c} / \mathrm{d}) \mathrm{b}-\mathrm{b}$.

$$
\left(\frac{c}{d}\right)_{b-b}=\frac{0.003}{0.003+\frac{f_{f}}{E_{f}}}
$$




\subsubsection{Tension Failure}

Tension failure in GFRP reinforced concrete beams results in bar rupture leading to catastrophic failure. In case of steel reinforced concrete beams primary tension failure may consist of steel yielding which might manifest into either secondary compression failure or tension steel rupture in highly under-reinforced sections. In GFRP reinforced concrete sections either primary tension failure in the form of bar rupture or primary compression failures are observed. Other failure modes such as concrete cover failure, debonding, etc., are not discussed herein. Moment capacity of a beam failing in tension is given by Eqs. 7.7 and 7.8 obtained through force equilibrium and linear strain variation considerations:

$$
\begin{aligned}
& M_{n}=A_{f} f_{f}\left(d-\frac{a}{2}\right) \\
& a=\left(\frac{A_{f} f_{f}}{0.85 f_{c}^{\prime} b}\right)
\end{aligned}
$$

\subsubsection{Compression Failure}

In case of compression failure, minimum reinforcement is dictated by a reinforcement ratio to avoid tension failure. Hence, minimum reinforcement for a compression failure is given by $\rho_{\mathrm{b}-\mathrm{b}} /\{1-(3 \sigma)\}$, where $\sigma$ is the standard deviation for ultimate moment capacity of concrete beams reinforced with GFRP bars in compression failure. $\sigma$ is found to be equal to $8.3 \%$ based on the statistical analysis of experimental results (Appendix-A). Use of $\sigma$ provides a basis for obtaining minimum reinforcement in a compression failure. Compliance with deformability criteria ensures the minimum reinforcement criteria for a cracked section in compression. 
Moment capacity of concrete section having compression failure can be calculated using Eqs. (7.9) and (7.10) obtained through force equilibrium and expressing GFRP strains in terms of the known concrete strain at failure.

$$
\begin{aligned}
& M_{n}=0.85 f_{c}^{\prime} a b\left(d-\frac{a}{2}\right) \\
& \left(\frac{0.85 f_{c}{ }^{\prime} b}{A_{f} E_{f} \varepsilon_{c u}}\right) a^{2}+a-\beta_{1} d=0
\end{aligned}
$$

Accounting for compression reinforcement eqns. 7.9 and 7.10 are represented by Eqs.

7.11 and 7.12.

$$
M_{n}=0.85 f_{c}^{\prime} a b\left(d-\frac{a}{2}\right)+A_{f}{ }^{\prime} \varepsilon_{f}{ }^{\prime} E_{f}{ }^{\prime}\left(d-d^{\prime \prime}\right)
$$

' $a$ ' is solved through the following quadratic equation 7.12 obtained by force equilibrium.

$$
\left[0.85 f_{c} b\right] a^{2}+\left[(0.003)\left(A_{f}{ }^{\prime} E_{f}{ }^{\prime}+A_{f} E_{f}\right)\right] a-\left[\left(0.003 \beta_{1}\right)\left(A_{f}{ }^{\prime} E_{f}{ }^{\prime} d^{\prime \prime}+A_{f} E_{f} d\right)\right]=0
$$

Experimental and theoretical moment capacities of GFRP reinforced concrete beams in tension and compression failures are shown in Table 7.8, for different cross-sections, bar dimensions and properties, reinforcement ratios and concrete grades. Eqs. 7.7 to 7.10 have been used for computational purposes.

\subsubsection{Comparison of Moments in Tension and Compression Failure}

As shown in Table 7.6, balanced failure provides an upper and a lower limit on the moment capacity of GFRP reinforced concrete beams in tension and compression failures respectively. Moment increase due to compression failure is compared with beam moment under 
tension failures in Table 7.7. This comparative analysis is carried out for different concrete strengths, rebar properties, and $(\alpha=\mathrm{c} / \mathrm{d})$ ratios using Eq. 7.13., which is obtained by substituting $(\alpha=\mathrm{c} / \mathrm{d})$ and $\left(\mathrm{a}=\beta_{1} \mathrm{c}\right)$ in to Eq. 7.9,

$$
M_{n}=0.85 f_{c}^{\prime}\left[\left(\alpha \beta_{1}\right)\left(1-\frac{\alpha \beta_{1}}{2}\right)\right] b d^{2}
$$

Two values of $\alpha_{b-b}$ in Table 7.7 correspond to ultimate strain values observed in tension tests of sand coated and ribbed GFRP bars having different diameters and fiber volume fractions. Shear reinforcement for those beams were also provided through GFRP stirrups. Experimentally it is observed that at about $\alpha=0.30$, shear compression failures are likely to occur. Reaching $\alpha=0.35$ depends upon the concrete grade and confinement effect generated by stirrups such as steel stirrups instead of GFRP stirrups. Obtaining $\alpha>0.35$ may involve use of higher GFRP reinforcement disproportionate to the desired moment increase and physically it may be difficult to accommodate the bars. Therefore, two values of $\alpha_{\max }=0.30$ and 0.35 are used for computing the upper limit on the moment capacity in compression failure (Table 7.6).

Table 7.6 Flexural Strength Range in Tension and Compression Failure Modes

\begin{tabular}{|c|c|c|c|c|c|c|c|}
\hline \multirow[t]{2}{*}{$\varepsilon_{\mathrm{c}}$} & \multirow{2}{*}{$\begin{array}{c}\begin{array}{c}\text { Range } \\
\text { of } \mathbf{f}_{\mathbf{c}}\end{array} \\
\text { (ksi) }\end{array}$} & \multirow{2}{*}{$\begin{array}{c}\text { Range of } \\
\beta_{1} \\
\text { (correspo- } \\
\text { nding to } \\
\left.\mathbf{f}_{\mathbf{c}}{ }^{\prime}\right)\end{array}$} & \multicolumn{3}{|c|}{$\begin{array}{l}\text { Upper limit on the moment capacity } \\
\text { in tension failure }\end{array}$} & \multicolumn{2}{|c|}{$\begin{array}{l}\text { Upper limit on the moment } \\
\text { capacity in comp. failure }\end{array}$} \\
\hline & & & $\varepsilon_{\mathrm{f}=}\left(\sigma_{\mathrm{f}} / \mathbf{E}_{\mathrm{f}}\right)$ & $\begin{array}{l}\alpha_{\text {b-b }}{ }^{+} \\
(\mathbf{c} / \mathbf{d})\end{array}$ & $\begin{array}{l}\text { Range of } \\
\mathbf{M} /\left(\mathbf{b d}^{2} \mathbf{f}_{\mathbf{c}}{ }^{\prime}\right)\end{array}$ & $\begin{array}{c}\text { Range of } \\
\mathbf{M} /\left(\mathbf{b d}^{2} \mathbf{f}_{\mathbf{c}}^{\prime}\right) \text { for } \\
\alpha_{\max }=\mathbf{0 . 3 0}\end{array}$ & $\begin{array}{c}\text { Range of } \\
\mathbf{M} /\left(\mathbf{b d}^{2} \mathbf{f}_{\mathbf{c}}^{\prime}\right) \text { for } \\
\alpha_{\max }=\mathbf{0 . 3 5}\end{array}$ \\
\hline \multirow[b]{2}{*}{0.003} & $4-8$ & $0.65-0.85$ & 0.013 & 0.19 & $0.126-0.099$ & \multirow[b]{2}{*}{0.189 to 0.150} & \multirow[b]{2}{*}{0.215 to 0.17} \\
\hline & $4-8$ & $0.65-0.85$ & 0.020 & 0.13 & 0.089-0.069 & & \\
\hline
\end{tabular}

\footnotetext{
${ }^{+}$Computed using $\alpha=\varepsilon_{\mathrm{c}} /\left(\varepsilon_{\mathrm{c}}+\varepsilon_{\mathrm{f}}\right)$
} 
Table 7.7 Flexural Strength in Tension and Compression Failure Modes

\begin{tabular}{|c|c|c|c|c|}
\hline $\begin{array}{c}\text { Upper limit on } \\
\text { range of } \mathbf{M} /\left(\mathbf{b d}^{2} \mathbf{f}_{\mathbf{c}} \mathbf{c}^{\prime}\right) \\
\text { (tension failure) }\end{array}$ & \multicolumn{2}{|c|}{$\begin{array}{c}\text { Upper limit on range of } \\
\mathbf{M} /\left(\mathbf{b d}^{2} \mathbf{f}_{\mathbf{c}} \text { ) }\right. \\
\text { ref. Table 7.6 }\end{array}$} & \multicolumn{2}{|c|}{$\begin{array}{c}\text { Maximum \% increase in flexural } \\
\text { strength in comp. failure as } \\
\text { compared to tension failure }\end{array}$} \\
\hline Ref. Table 7.6 & $\alpha=0.30$ & $\alpha=0.35$ & $\alpha=0.3$ & $\alpha=0.35$ \\
\hline $0.126-0.099$ & & & $50.0-51.9$ & $70.8-74.0$ \\
\hline $0.189-0.069$ & $0.189-0.150$ & $0.215-0.171$ & $113.0-117.6$ & $142.5-149.3$ \\
\hline
\end{tabular}

Note: Comparison in Table 7.7 is for singly reinforced beams only.

It is evident from Table 7.7 that the compression failure provides higher moment of resistance in GFRP reinforced concrete beams as compared to tension failures. Most importantly, compression failures provide relatively more ductile and less catastrophic failure (as compared to bar rupture in a tension failure) due to better energy absorption and satisfy the deformability (analogous to ductility) criterion.

Use of high strength concrete $\left(f_{c}{ }^{\prime}=6\right.$ to $\left.8 \mathrm{ksi}\right)$ is more suitable with GFRP reinforcement for both tension and compression failure modes. Higher strength concrete allows better utilization of high strength properties of GFRP bars and contributes to the stiffness of a cracked concrete section. Practically, concrete grades above 6 ksi are more suitable and efficient for use with GFRP reinforcement than with steel bars. However, other factors such as creep and shrinkage characteristics have to be carefully considered while designing with high strength concrete. 


\subsubsection{Theoretical Correlation of Bending Results}

Theoretical correlation of the beams tested in this investigation as well as those from other researchers have been made using Eqs. 7.7 to 7.10. Very good correlation is obtained for the flexural strength of beams as shown in Table 7.8. Additional results are provided in Appendix A.

Table 7.8 Comparison of Bending Test Results in Concrete Beams with GFRP Bars

\begin{tabular}{|c|c|c|c|c|c|c|c|c|c|c|c|}
\hline Ref. & Beam & $\mathbf{f}_{c}^{\prime}$ & b & d & $\overline{f_{f}}$ & $\overline{\mathbf{E}_{\mathrm{f}}}$ & Reinf. & $\mathbf{M}_{\text {exp. }}$ & $\mathbf{M}_{\text {the }}$ & exp/the & $\begin{array}{c}\text { Failure } \\
\text { Mode }\end{array}$ \\
\hline & & ksi & in. & In. & (ksi) & (ksi) & & k-ft. & k-ft. & & \\
\hline $\mathrm{R} 1$ & $\mathrm{~T} 1$ & 6.5 & 0 & 10.38 & 85 & 150 & 4 & 27.82 & 27.46 & 1.01 & $\mathrm{~T}$ \\
\hline R1 & $\mathrm{C} 2$ & 6.5 & 0 & 10.63 & 85 & 150 & & 40.35 & 43.11 & 0.94 & C \\
\hline R1 & $\mathrm{M}$ & 4.5 & 0 & 10.70 & 83 & 550 & $2 \#$ & 36.74 & 3.10 & 1.11 & $\mathrm{C}$ \\
\hline $\mathrm{R} 2$ & A2 & 4.2 & 0 & 10.44 & 102 & 150 & $3 \# 3$ & 37.64 & 36.88 & 1.02 & $\mathrm{~T}$ \\
\hline R2 & C8 & 5.0 & 0 & 10.13 & 80 & 5500 & 2 \#7 & 41.62 & 1.38 & 1.01 & $\mathrm{C}$ \\
\hline R2 & EVH2 & 10.0 & 0 & 10.38 & 107 & 5500 & $4 \# 3$ & 43.50 & 43.66 & 0.99 & $\mathrm{C}$ \\
\hline R3 & ISO1 & 25 & 9 & 19.84 & 100 & 6530 & $2-19 \mathrm{~mm}$ & 133.93 & 139.21 & 0.96 & $\mathrm{~T}$ \\
\hline R3 & SER-1 & 7.55 & 9 & 10.33 & 112 & 5565 & $2-15 \mathrm{~mm}$ & 43.41 & 42.71 & 1.02 & C \\
\hline R3 & SER-2 & 7.55 & 9 & 10.33 & 112 & 5565 & $3-15 \mathrm{~mm}$ & 48.13 & 50.82 & 0.95 & C \\
\hline R3 & SER-3 & 6.53 & 7.9 & 9.45 & 112 & 5565 & $4-15 \mathrm{~mm}$ & 54.18 & 47.35 & 1.14 & C \\
\hline R3 & SER-4 & 6.53 & 7.9 & 9.45 & 112 & 5565 & $6-15 \mathrm{~mm}$ & 62.73 & \begin{tabular}{|l|}
55.49 \\
\end{tabular} & 1.13 & $\bar{C}$ \\
\hline \multicolumn{12}{|c|}{$\begin{array}{l}\text { Note: } \mathrm{T}=\text { Tension; C=Comp.; Some of the fractions in Table } 7.8 \text { are rounded off. Some unit } \\
\text { conversions are carried out for consistency. \#4, \#5 imply (4/8) and (5/8) inch dia. } \\
\text { respectively. } \\
\text { R1: Results of this research study; R2: Faza and GangaRao (1992): R3: Benmokrane et al. } \\
\text { (1996). }\end{array}$} \\
\hline
\end{tabular}

\subsubsection{Deflection Control}

Deflections of GFRP reinforced concrete sections depend on the modified moment of inertia as given by GangaRao and Faza (1992). Modified moment of inertia $\left[\mathrm{I}_{\mathrm{m}}\right]$ accounts for the cracking behavior of GFRP reinforced concrete sections and lies between the values of effective 
moment of inertia $\left[\mathrm{I}_{\mathrm{eff}}\right]$ and cracked moment of inertia $\left[\mathrm{I}_{\mathrm{cr}}\right]$. Because $\mathrm{I}_{\mathrm{m}}<\mathrm{I}_{\mathrm{eff}}$, initial depths should be chosen between span/13 to span/12 for GFRP reinforced concrete beams to satisfy deflection criteria of span/180 or less. Compression failure philosophy indirectly results in lower deflection due to higher GFRP bar area as compared to tension failure. In addition, reduced crack-widths contribute to overall stiffness of the cracked concrete section.

\subsubsection{Crack-Width Control for GFRP Reinforced Concrete}

Ribbed or sand coated GFRP bars have good bond characteristics with concrete. As seen in the bond strength comparison, better bond stresses are observed between concrete and sand coated/ribbed GFRP bars. However, higher strains in GFRP bars relative to steel at service stress levels lead to higher crack-widths in concrete sections (GangaRao and Faza, 1992). Interestingly, in compression failures, a reduction in the rate of crack-width increase is observed with increasing load application. This is attributed to the shifting of neutral axis with increasing load in an attempt to increase the depth of compression block to satisfy force equilibrium. Downward shift of neutral axis due to compression failure has a crack-closure effect on the existing cracks, but new cracks with smaller widths appear between the existing cracks.

\subsection{CONCLUSIONS}

- Comparison of failure modes based on experimental results and theoretical computations has indicated better member deformability (analogous to ductility in steel reinforced concrete beams) and gradual member failure in compression as compared to tension failure.

- Deformability factors computed with respect to curvature of $0.005 / \mathrm{d}$ radians/inch gives a unified limit state satisfying deflection, crack-width and energy absorption. 
- Deformability factors of about 7 or better were observed for the beams failing in compression.

- Beams under compression failure provide reduction in service load deflections and crackwidths due to higher stiffness and lower FRP bar stress (because of larger area of FRP reinforcement).

- Higher moment of resistance (by involving higher forces in the internal force-equilibrium as compared to a tension failure) was observed in compression failures.

- Deformability factor increases with the addition of compressive reinforcement. For a beam designed for compression failure, moment increase is not proportional to the increase in reinforcement percentage.

- Mathematical models developed in this study provided excellent correlation with respect to ultimate moment capacities of about 80 research results of other authors.

- Work conducted in this research on different aspects concrete beam behavior lead to the ACI specification approval in October/November 1998, with final approval slated for end of the first-half of 1999. 


\section{CHAPTER 8}

\section{SHEAR BEHAVIOR OF CONCRETE BEAMS WITH GFRP STIRRUPS}

\subsection{INTRODUCTION}

In this chapter, shear behavior of rectangular concrete beams reinforced with sand coated Glass Fiber Reinforced Plastic (GFRP) stirrups is presented. The study includes the effects of shear stirrup spacing and strength and stiffness properties of GFRP. A theoretical prediction of total shear capacity (similar to the ACI provisions) has been proposed.

\subsection{OVERVIEW}

According to ACI 426R-74, the mechanism of shear failure in reinforced concrete beams is more complex than the flexural failure mechanism. In some cases, flexural cracks result in shear or diagonal cracks and lead to shear failure in concrete beams. Shear behavior, including the failure modes, depend on shear forces and bending moments, and occasionally, axial loads, or torsion, or both.

The main types of shear transfer in a reinforced concrete beam occurs through:

- Uncracked portion of concrete section

- Aggregate interlocking forces through the interface along shear cracks

- Dowel action

- Arch action

- Stirrup action.

These mechanisms vary widely for different types of reinforced concrete structural elements. 
Shear failure mechanism in concrete beams reinforced with longitudinal FRP bars and FRP stirrups were influenced by lower modulus of elasticity of FRP. Shear cracks were wide which affect the bond between FRP and concrete and in turn reduce aggregate interlocking forces. A theoretical prediction of total shear capacity (similar to the ACI provisions) has been proposed, herein.

\subsection{OBJECTIVES}

The objectives of this investigation are:

- To understand the shear behavior of concrete beams reinforced with FRP bars (tension and compression reinforcement) and FRP stirrups.

- To model the shear capacity of FRP stirrups similar to existing ACI equations.

\subsection{TEST SPECIMENS, INSTRUMENTATION AND TEST PROCEDURES}

\subsubsection{Test Specimens}

Six concrete beams (6"x12"x60") were tested under four-point loading. The tests consisted of three categories of beams: two without stirrups, two with FRP stirrups spaced at 4" c/c and two with FRP stirrups spaced at 6" c/c. The beams were grouped in this manner to study the occurrence of diagonal cracks, shear capacity of concrete beams with and without FRP stirrups, and the effect of stirrup spacing on shear capacity. The beams were over-reinforced to avoid possible bending failure before shear failure. Table 8.1 provides details of the shear test specimens. 
Table 8.1 Details of the Shear Test Specimens

\begin{tabular}{|c|c|c|c|c|c|}
\hline Beam & Dimensions & $\begin{array}{c}\text { Concrete } \\
\text { Strength } \\
\mathbf{f}_{\mathbf{c}} \text { (ksi) }\end{array}$ & $\begin{array}{c}\text { Longitudianl } \\
\text { FRP Rebars }\end{array}$ & FRP Stirrups & $\begin{array}{c}\text { Stirrups } \\
\text { Spacing } \\
\text { (in.) }\end{array}$ \\
\hline S1 & 6"x12"X60" & 6.5 & 2-\#6 (sand) & No Stirrups & - \\
\hline S2 & 6"x12"X60" & 6.5 & 2-\#6 (sand) & \#3 (Sand) & $4 "$ \\
\hline S3 & 6"x12"X60" & 6.5 & 2-\#6 (sand) & \#3 (Sand) & $6 "$ \\
\hline S4 & 6"x12"X60" & 4.5 & 2-\#4(ribbed) & No Stirrups & - \\
\hline S5 & 6"x12"X60" & 4.5 & 2-\#4(ribbed) & \#3 (Sand) & $4 "$ \\
\hline S6 & 6"x12"X60" & 4.5 & 2-\#4(ribbed) & \#3 (Sand) & $6 "$ \\
\hline
\end{tabular}

(Note: Sand coated bars and stirrups were manufactured by International Gratings Inc. Ribbed bars were manufactured by Marshall Industries Composites Inc.)

Casting and curing of concrete beams were done under the laboratory conditions. Class $\mathrm{K}$ concrete (as per the WVDOH specification) was obtained from a local mixing plant for the casting of the specimens. Twelve cylinders were also cast in order to determine the 28-day compressive strength of the concrete mix. On the 28th day, the cured concrete cylinders were tested to determine the compressive strengths as per ASTM C-39.

\subsubsection{Instrumentation and Test Procedures}

Four-point loads were applied until failure, using a hydraulic jack connected to a manual pump (Fig.8.1). Constant load was maintained between each load increment. Strains on the longitudinal FRP bars and FRP stirrups, on the top concrete surface and deflections at various load levels were regularly measured. Crack patterns were also noted between each load increment. 

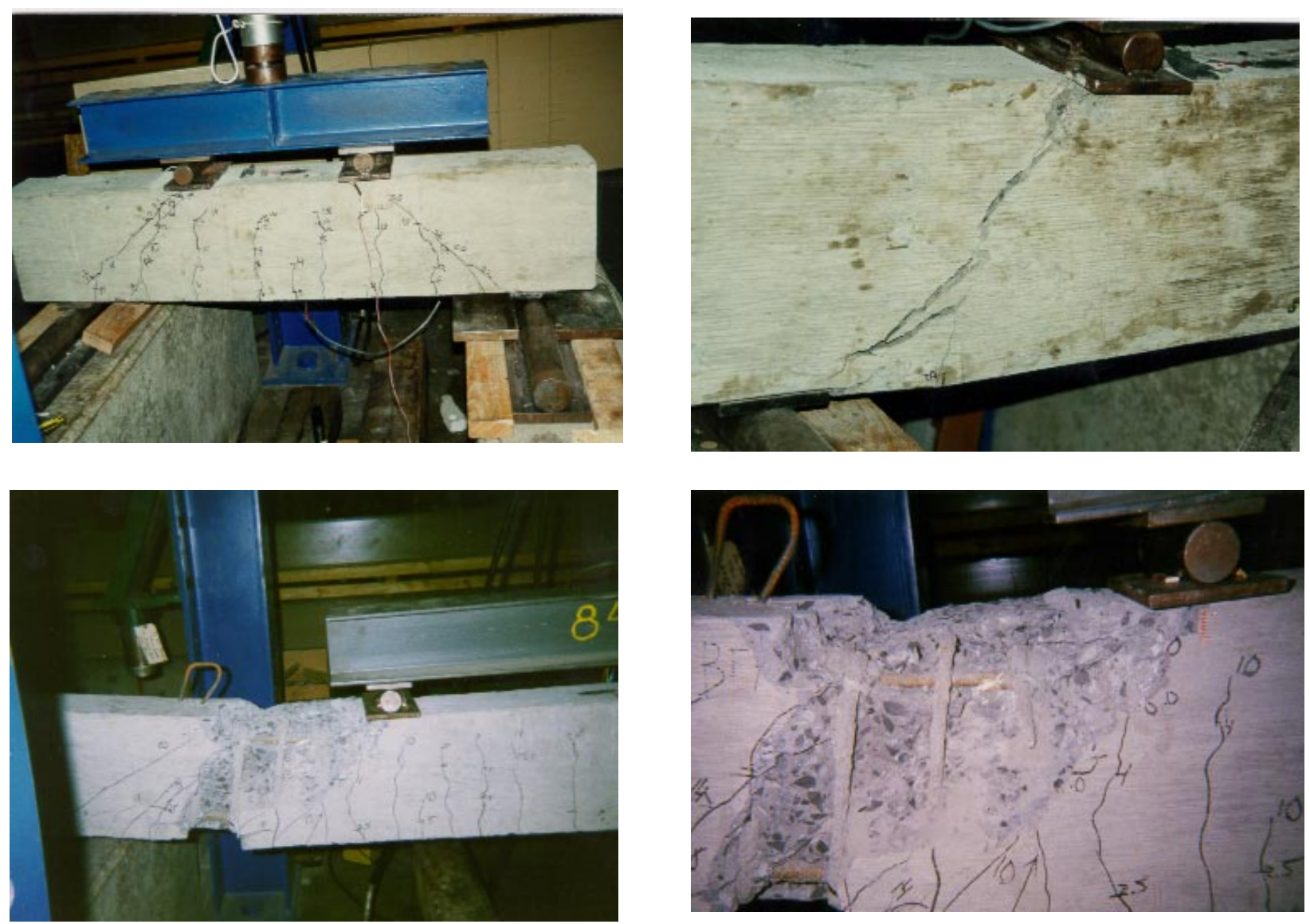

Fig. 8.1 Shear Test Set-Up and Different Shear Failures under Four-Point Loads

Shear failure in concrete beams occurred through diagonal shear cracks and the cracks further widened. At ultimate shear capacity of the concrete beams, large cracks followed by concrete cover delamination were observed. Figure 8.1 shows typical shear failures. Table 8.2 shows the level of shear at the formation of diagonal cracks during testing and the angle of diagonal cracks. In addition, comparison of experimental and theoretical values is made and reported in Table 8.2 . 
Table 8.2 Test Results-Shear Resistance of Concrete

\begin{tabular}{|c|c|c|c|c|c|}
\hline Beam & $\begin{array}{c}\text { Shear @ } \\
\text { Diagonal } \\
\text { Crack } \\
\text { (kips) }\end{array}$ & $\begin{array}{c}\text { Angle of } \\
\text { Diagonal } \\
\text { Crack }\end{array}$ & $\begin{array}{c}\text { Concrete Shear } \\
\text { Strength } \\
\mathbf{V}_{\mathbf{c}}=\mathbf{2} \sqrt{f^{\prime}{ }^{\prime}} \\
(\mathbf{b} \mathbf{~ d} \\
\text { [A] }]\end{array}$ & $\begin{array}{c}\text { Ratio } \\
{[\mathbf{B}]}\end{array}$ & $\begin{array}{c}\text { Experimental } \\
\text { Ultimate Shear } \\
\text { Capacity } \\
\text { (kip) }\end{array}$ \\
\hline S1 & 10.1 & $35^{0}$ & 9.9 & 1.02 & 19.3 \\
\hline S2 & 7.1 & - & 9.9 & 0.72 & 28.5 \\
\hline S3 & 10.1 & $36^{0}$ & 9.9 & 1.02 & 25.8 \\
\hline S4 & 10.1 & $35^{0}$ & 8.4 & 1.2 & 13.2 \\
\hline S5 & 7.1 & $40^{0}$ & 8.4 & 0.84 & 27.7 \\
\hline S6 & 9.1 & $37^{0}$ & 8.4 & 1.08 & 27.7 \\
\hline
\end{tabular}

It is evident from Table 8.2 (beam S2) that the contribution of uncracked concrete to shear can be lower by about $28 \%$ than that suggested by the ACI code $\left(\mathbf{V}_{\mathbf{c}}=\mathbf{2} \sqrt{f^{\prime}}{ }_{c} \mathbf{b}\right.$ d $)$ for steel stirrup reinforced concrete. Suitable reduction factors may be applied to the concrete shear strengths in the theoretical formulations to account for such phenomenon.

\subsection{DISCUSSION OF TEST RESULTS AND THEORETICAL ANALYSIS}

Shear failure in concrete beams reinforced with FRP bars and stirrups were found to be associated with wider crack widths and delamination of concrete cover. Contribution of dowel action to resist shear is minimal and hence neglected. In order to predict the experimental shear capacity in concrete beams reinforced with FRP bars and stirrups, the following approach is suggested.

Experimental results of this research indicated that lower stiffness in main GFRP bars and stirrups lead to larger crack-widths and greater delaminations around the stirrups than in steel. Hence, it is necessary to consider the average bond strain in FRP stirrup legs (based on bond between stirrup and concrete) for effective shear transfer by stirrups. 
Average bond strength of coated and ribbed bars is 2000 psi or better, which is higher than the bond between steel and concrete. Observed average axial strain values in FRP stirrup legs (with modulus of elasticity of $6000 \mathrm{ksi}$ ) at shear failure correspond to about 0.006 or slightly above. Shear stress corresponding to average bond strain of 0.006 in./in. is, $f_{f, s p}=0.006 \times E_{f}=$ 0.006 × $6000=36 \mathrm{ksi}$. GFRP shear stirrup spacing (s) for a shear force $\mathrm{V}_{\mathrm{s}}$ (to be carried by stirrup) can be computed using, the following equation similar to ACI (11-15).

$$
s=\frac{A_{f} f_{f, s p} d}{V_{s}}
$$

Average bond strain of GFRP shear stirrups as 0.006 in./in. provided good theoretical correlation. Table 8.3 shows comparison of experimental and theoretical shear capacities of concrete beams in this research. . Table 8.4 shows comparison of experimental and theoretical shear results of other researchers by using proposed approach.

Table 8.3 Test Results-Shear Strength of Concrete Beams

\begin{tabular}{|c|c|c|c|c|c|}
\hline Beam & $\begin{array}{c}\text { Expt. } \\
\text { Shear } \\
\text { Capacity } \\
\\
(\mathbf{k N}) \\
{[\mathrm{A}]} \\
\end{array}$ & $\begin{array}{c}\begin{array}{c}\text { Shear Strength } \\
\text { from Concrete }\end{array} \\
\mathbf{V}_{\mathbf{c}}=2 \sqrt{f_{c}} \text { 'bd } \\
\text { (kip) } \\
\text { [B] }\end{array}$ & $\begin{array}{l}\text { Shear Strength from } \\
\text { FRP stirrups } \\
\mathbf{V}_{\mathrm{s}}=\underline{\mathbf{A}}_{\mathbf{f}} \frac{\left[0.006\left(\mathrm{E}_{\mathrm{f}}\right)\right] \mathrm{d}}{\mathrm{s}} \\
(\text { kip) } \\
{[\mathrm{C}]}\end{array}$ & $\begin{array}{c}\text { Total Shear } \\
\text { Capacity } \\
V_{T}=V_{c}+V_{s} \\
{[D]=[B]+[C]}\end{array}$ & {$[\mathbf{A}] /[\mathbf{D}]$} \\
\hline $\mathrm{S} 2$ & 28.5 & 9.9 & 20.4 & 30.3 & 0.94 \\
\hline S3 & 25.8 & 9.9 & 13.6 & 23.5 & 1.10 \\
\hline S5 & 27.7 & 8.4 & 20.6 & 29.0 & 0.96 \\
\hline S6 & 27.7 & 8.4 & 13.8 & 22.2 & 1.25 \\
\hline
\end{tabular}


Table 8.4 Comparison of Experimental Shear Strengths

\begin{tabular}{|c|c|c|c|c|c|c|c|}
\hline No. & Beam & $\begin{array}{c}\text { Experimental } \\
\text { Shear } \\
\text { Capacity } \\
\\
\text { (kN) } \\
{[\mathrm{A}]}\end{array}$ & $\begin{array}{c}\text { Shear } \\
\text { Strength } \\
\text { from } \\
\text { Concrete } \\
(\mathbf{k N}) \\
{[\mathrm{B}]}\end{array}$ & $\begin{array}{c}\text { Shear } \\
\text { Strength } \\
\text { from FRP } \\
\text { stirrups } \\
(\mathbf{k N}) \\
{[\mathrm{C}]}\end{array}$ & $\begin{array}{c}\text { Total Shear } \\
\text { Capacity } \\
\\
(\mathbf{k N}) \\
{[\mathrm{D}]=[\mathbf{B}]+[\mathrm{C}]}\end{array}$ & Ratio & Ref. \\
\hline 1 & 2 & 13.1 & 8.5 & 4.7 & 13.2 & 1.00 & R1 \\
\hline 2 & 3 & 13.8 & 8.5 & 4.7 & 13.2 & 1.04 & R1 \\
\hline 3 & 4 & 12.2 & 8.5 & 4.7 & 13.2 & 0.93 & R1 \\
\hline 4 & 7 & 15.6 & 8.5 & 4.7 & 13.2 & 1.18 & R1 \\
\hline 5 & 8 & 16.1 & 8.5 & 4.7 & 13.2 & 1.22 & R1 \\
\hline 6 & 9 & 14.4 & 8.5 & 4.7 & 13.2 & 1.09 & R1 \\
\hline 7 & 19 & 16.5 & 8.5 & 6.6 & 15.1 & 1.09 & R1 \\
\hline 8 & 25 & 24.7 & 8.2 & 12.0 & 20.2 & 1.23 & R2 \\
\hline 9 & 26 & 24.0 & 8.2 & 12.0 & 20.2 & 1.19 & R2 \\
\hline 10 & 27 & 33.3 & 8.2 & 24.0 & 32.2 & 1.03 & R2 \\
\hline 11 & 28 & 29.4 & 8.2 & 24.0 & 32.2 & 0.92 & R2 \\
\hline
\end{tabular}

Note: R1 : Zhao (1995); R2: Maruyama (1995).

\subsection{CONCLUSIONS}

- Shear failure mechanism in concrete beams reinforced with main FRP bars and FRP stirrups is influenced by the lower modulus of elasticity of FRP bars since shear failure is associated with wider crack widths and delamination of concrete cover.

- Shear resistance from dowel action of longitudinal FRP bars is small and neglected.

- The current ACI equation (11-17), 318-95 for FRP stirrup shear contribution can be modified by suitably limiting stresses in FRP stirrups through average bond strain considerations.

- Average bond strain of 0.006 in./in. for GFRP stirrups provided good theoretical correlation with experimental results from this research as well as those of others. 


\section{CHAPTER 9}

\section{ACCELERATED AGING BEHAVIOR OF GFRP REINFORCED CONCRETE BEAMS}

\subsection{INTRODUCTION}

Similar to accelerated aging tests on GFRP bars discussed in Chapter 5, accelerated tests were conducted on pre-cracked concrete beams by immersing them in salt $(\mathrm{pH}=7)$ and alkaline solutions $(\mathrm{pH}=13)$ under freeze-thaw temperatures. A total of 48 beams were cast for this research including the reference beams. Except for the reference beams, the remaining beams were pre-cracked in two-cycle loading for a concrete strain of $1000 \times 10^{-6}$ and conditioned. Results of only twelve conditioned beams up to 12 months are reported here. Aging of additional beams is progressing as a part of long term data evaluation. Direct alkaline solution exposure of pre-cracked GFRP reinforced concrete beams gives a measure of the aging process under wet alkaline concrete environment. It would be recalled that the bars extracted from the beams of this study were tested in tension and compression as described in Chapter 5, and used for calibration purposes. The parameters of interest in this study are ultimate moment capacity, deflection, crack-width, deformability factors and failure modes. Since many factors governing the bending behavior of GFRP reinforced concrete beams are described in Chapter 7 only brief discussions of the test results are provided in this chapter.

\subsection{OBJECTIVES}

Objectives of this study are:

- To establish the behavior of pre-cracked GFRC reinforced concrete beams immersed in salt and alkaline solutions and subjected to freeze-thaw temperatures. 
- To establish degradation rates in ultimate bending moment capacity, deflection, cracking, ductility/deformability and changes in mode of failure.

- To perform theoretical comparisons in moment capacity and establish the effect of GFRP aging on moment capacity and deformability factor.

- To relate the direct aging behavior of GFRP in concrete to that of bare GFRP bars and relate them to natural aging.

\subsection{SPECIMENS, EQUIPMENT AND TEST PROCEDURES}

Forty-Eight concrete beams (6"x12"x60") were tested to failure, or pre-cracked under three point loading up to concrete strains of $1000 \times 10^{-6}$ in./in.. Deflections, crack-widths and strains were recorded for each beam. The purpose of pre-testing each beam was to compare the same beam before and after aging, so that comparisons with respect to other un-aged reference beams could be minimized. Following a two-cycle pre-cracking loading, the beams were conditioned in the environmental chamber by immersing them in polyurethane tanks with lids containing salt or alkaline solutions as described in chapter 5. Following the conditioning period, pre-cracked concrete beams were tested under three-point bending as shown in Fig. 9.1. Tables 9.1 and 9.2 provide details of test specimens on the beam specimens used for accelerated aging study. Sand coated bars were used for reinforcing all the beams. Results of only 18 beams are discussed herein. Tests are still progressing to obtain additional long-term results. 

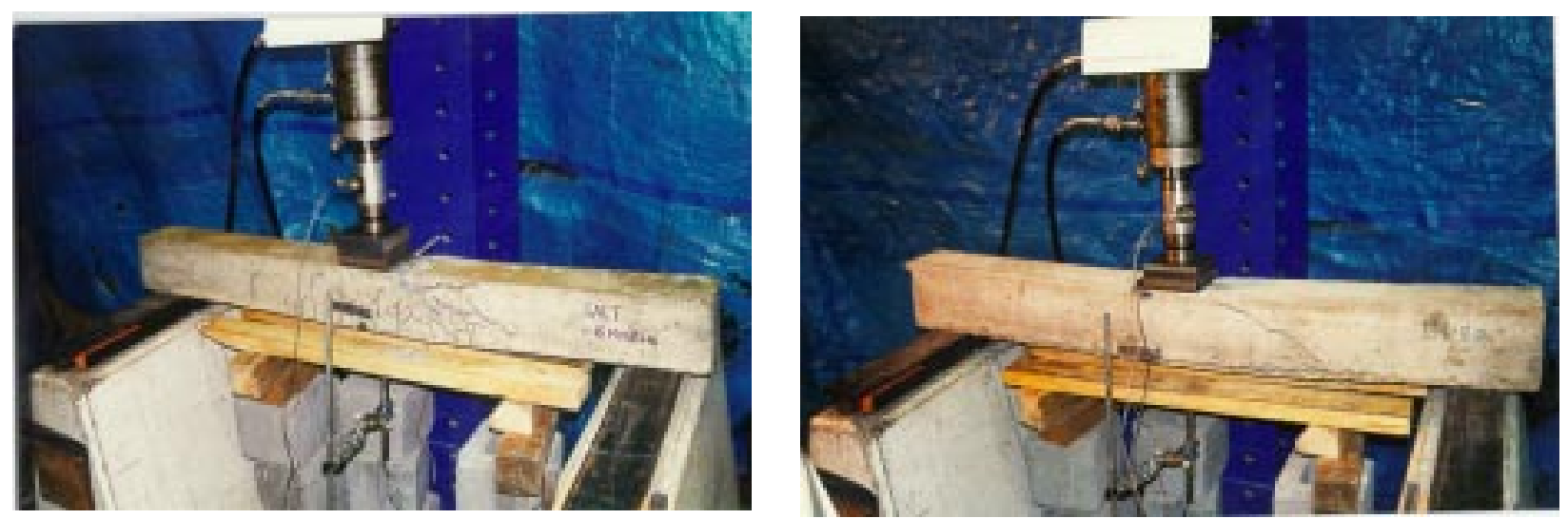

Fig. 9.1 Concrete Beams Tested after 8 months of salt (left) and alkaline (right) Conditioning under Freeze-Thaw Fluctuations

\subsection{FREEZE-THAW AND SALT CONDITIONING}

Six beams shown in Table 9.1 were conditioned under freeze-thaw and salt for 3, 8 and 12 months. Tests indicate maximum moment capacity loss of $8.7 \%$ in salt conditioning and a gain of $11.0 \%$. However, deformability factors showed a reducing trend with increasing exposure duration as shown in Fig. 9.2. and appeared to have stabilized. Deflections after conditioning did not show any appreciable loss of stiffness within the comparison range (of concrete strains of $1000 \times 10^{-6}$ or about 40 to $50 \%$ of ultimate load). Crack-patterns in salt conditioned beams were characterized by uniform spacing. Crack-widths of conditioned beams showed a very small increase in the width in some cases in comparison with its pre-cracking data obtained before conditioning. Load-deflection and moment-curvature relations of beams immersed in salt under freeze-thaw fluctuations are shown in Figs. 9.3 and 9.4. Fig. 9.5 shows the crack patterns in conditioned beams after testing. 
Table 9.1 Flexural Strength of Salt Conditioned Beams under Freeze-Thaw Conditions

\begin{tabular}{|c|c|c|c|c|c|c|c|}
\hline \multirow[t]{2}{*}{ Beam } & \multirow[t]{2}{*}{$\begin{array}{l}\text { Condition } \\
\text { Duration } \\
\text { (Months) }\end{array}$} & \multirow[t]{2}{*}{$\begin{array}{l}\mathbf{f}_{\mathbf{c}}{ }^{\prime} \\
\text { (psi) }\end{array}$} & \multirow[t]{2}{*}{$\begin{array}{l}\text { Depth } \\
\text { (in.) }\end{array}$} & \multicolumn{2}{|c|}{$\begin{array}{l}\text { Ultimate } \\
\text { Moment } \\
\text { (kip-in) }\end{array}$} & \multirow[t]{2}{*}{$\begin{array}{c}\begin{array}{c}\text { Moment } \\
\text { Change } \\
(\%)\end{array} \\
\end{array}$} & \multirow[t]{2}{*}{ DF } \\
\hline & & & & UNC & CON & & \\
\hline SB1 & 3 & 6150 & 6 & 91.0 & 89 & $2.2(\mathrm{~L})$ & * \\
\hline SB2 & 3 & 6150 & 6 & 91.0 & 101 & $11.0(\mathrm{G})$ & 11.6 \\
\hline SB3 & 8 & 6150 & 6 & 91.0 & 87 & $4.4(\mathrm{~L})$ & 9.3 \\
\hline SB4 & 8 & 6150 & 6 & 91.0 & 79 & $8.7(\mathrm{~L})$ & 13.9 \\
\hline SB5 & 12 & 6150 & 7 & 132.7 & 138 & $4.0(\mathrm{G})$ & 8.8 \\
\hline SB6 & 12 & 6150 & 6 & 91.0 & 89 & $2.2(\mathrm{~L})$ & 7.3 \\
\hline
\end{tabular}

Note: Overall width (5 in.) and length (60 in.) of all the beams were same; UNC:Unconditioned average reference values of minimum of 2 beams;

CON: Conditioned value; DF:Deformability Factor; G:Gain; L:Loss; *-incomplete data.

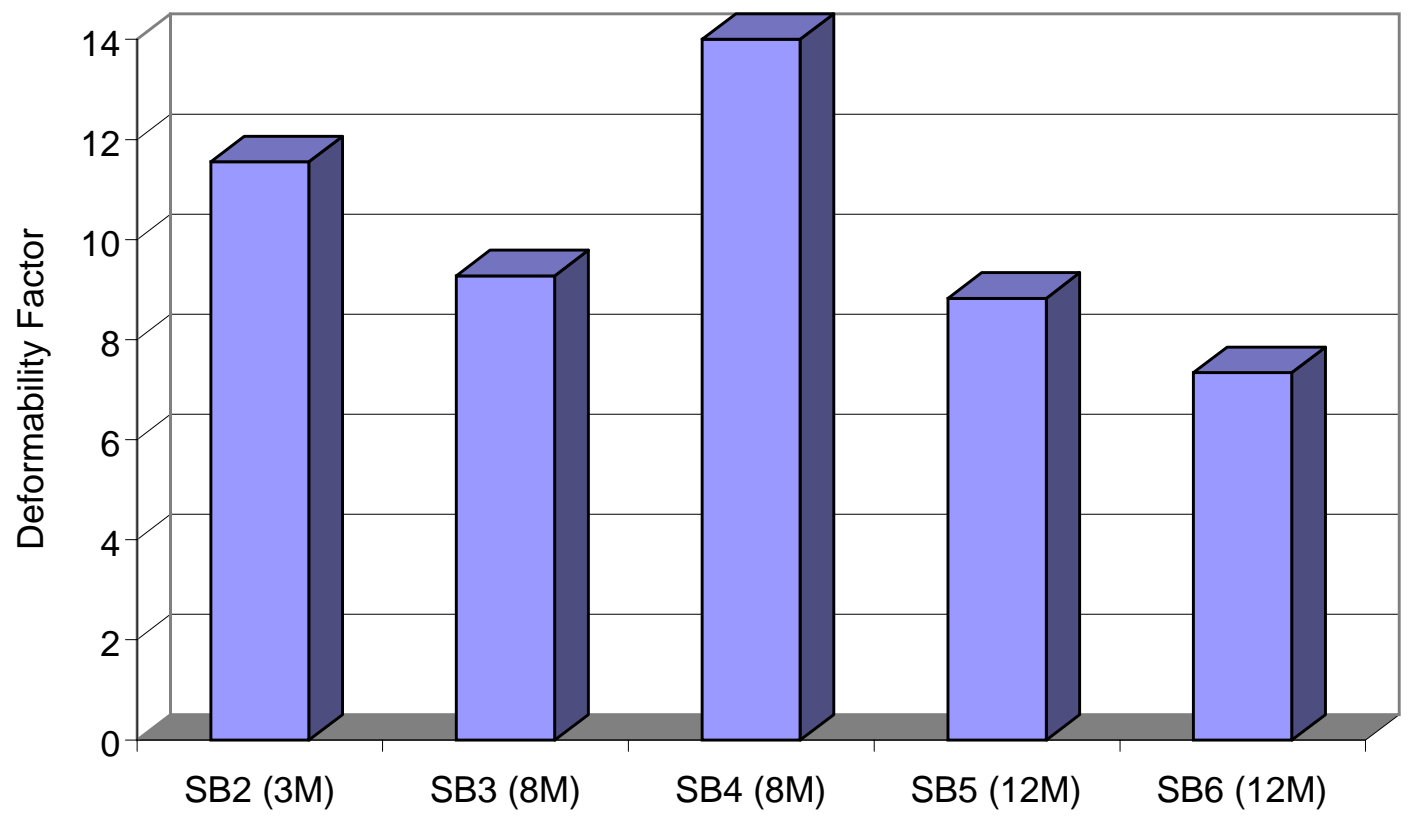

Fig. 9.2 Variation of Deformability Factor in Salt and Freeze-Thaw Conditioned GFRP Reinforced Beams 


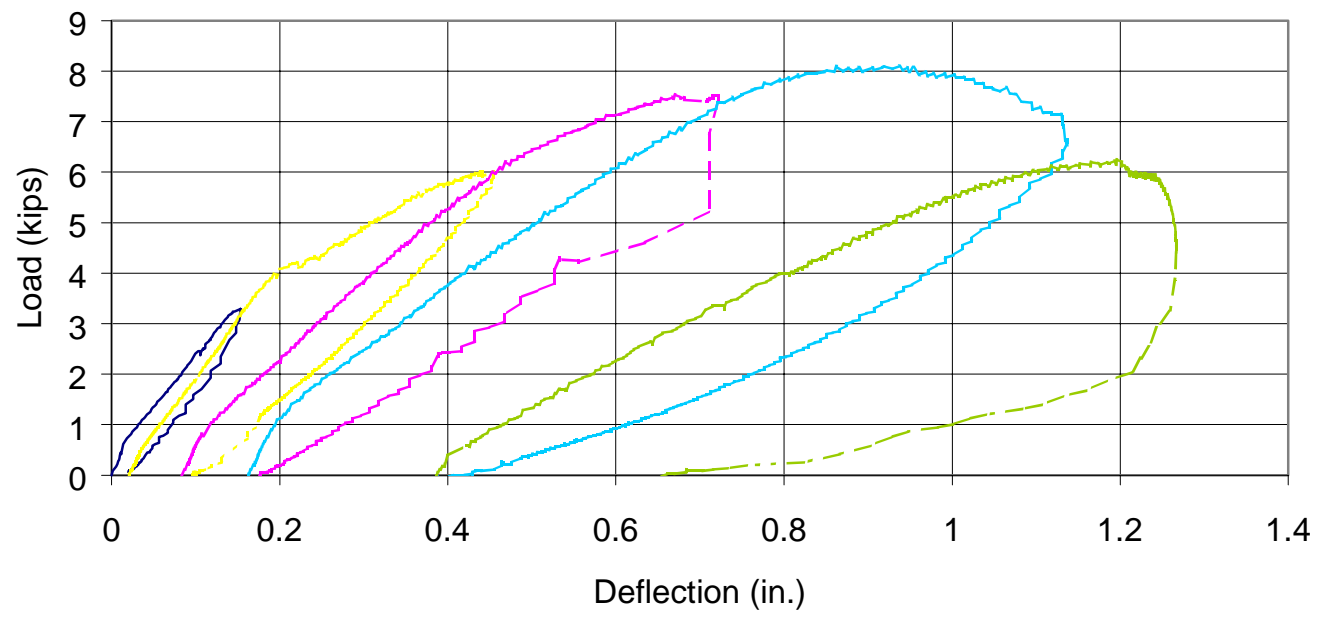

\begin{tabular}{|rr}
\hline 1st cycle (3.30 kips) & 2nd cycle (6.00 kips) --- 3rd cycle (7.54 kips) \\
--- 4th cycle (8.10 kips) & $-\cdots-5$ th cycle (6.25 kips)
\end{tabular}

\section{Fig. 9.3 Load Deflection of Beam SB2 immersed in Salt Solution under Freeze-Thaw}

\section{Fluctuation for 3 Months}

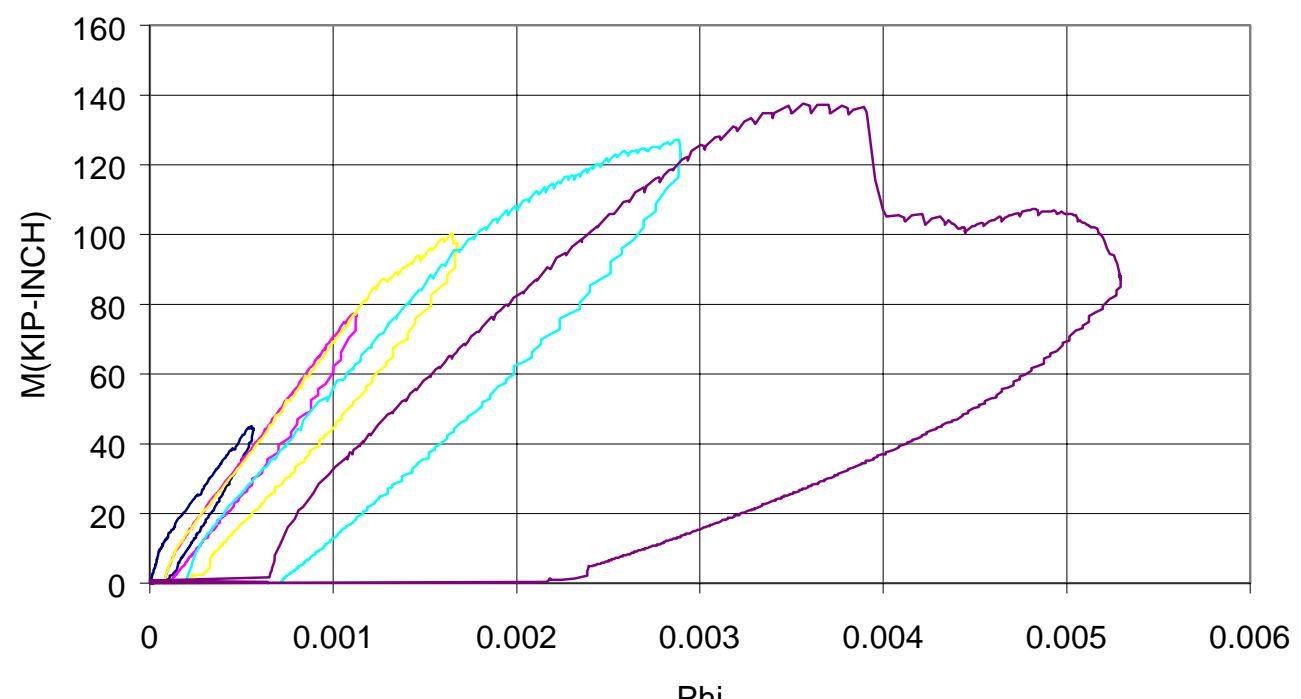

\begin{tabular}{|l}
- cycle1 (45 kip-inch) - cycle2 (78 kip-inch) - cycle3 (99 kip-inch) \\
cycle4 (126 kip-inch) - cycle5 (138 kip-inch)
\end{tabular}

Fig. 9.4 Moment Curvature of Beam SB5 immersed in Salt Solution under Freeze-Thaw Fluctuation for 12 Months 


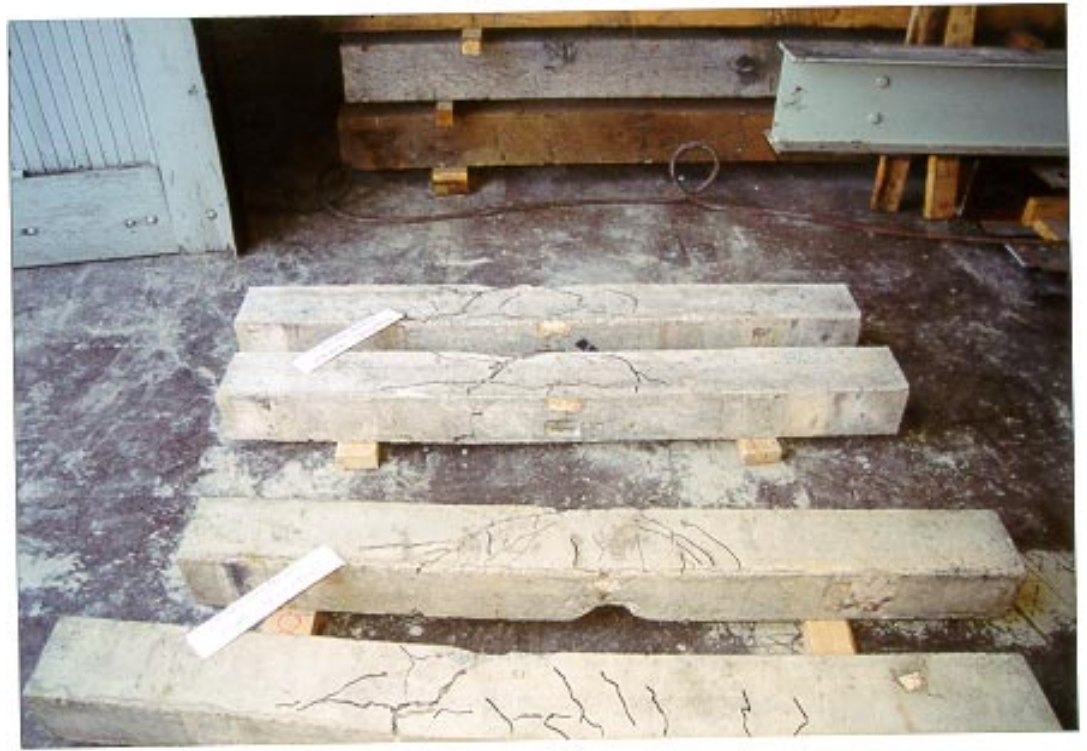

Fig. 9.5 Tested Concrete Beams after Conditioning for 3 Months in Salt (at bottom) and Alkaline (at top) Solution

\subsection{FREEZE-THAW AND ALKALINE CONDITIONING}

Six beams shown in Table 9.2 were immersed in alkaline solution under freeze-thaw fluctuation for 3, 8 and 12 months. Tests indicate maximum moment gain of $17.1 \%$ and no loss in any of the beams. However, deformability factors showed a reducing trend with increasing exposure duration as shown in Fig. 9.2. Deflections after conditioning did not show any appreciable loss of stiffness within the comparison range. Unconditioned deflection values for a particular beam were available up to the $50 \%$ of the ultimate load, obtained during cracking load tests conducted on the beams prior to aging. Crack patterns in alkaline conditioned beams were characterized by few cracks and cracking along the longitudinal bar indicated possible bond reduction. However, crack-widths of conditioned beams showed a very small increase in the width. Load-deflection and moment-curvature relations of some alkaline and freeze-thaw conditioned beams are shown in Figs. 9.7 and 9.8. 
Table 9.2 Flexural Strength of Alkaline Conditioned Beams under Freeze-Thaw Conditions

\begin{tabular}{|c|c|c|c|c|c|c|c|}
\hline Beam & $\begin{array}{c}\text { Condition } \\
\text { Duration } \\
\text { (Months) }\end{array}$ & $\begin{array}{c}\mathbf{f}_{\mathbf{c}} \\
\text { (psi) }\end{array}$ & $\begin{array}{c}\text { Depth } \\
\text { (in.) }\end{array}$ & \multicolumn{2}{|c|}{$\begin{array}{c}\text { Ultimate Moment } \\
\text { (kip-in) }\end{array}$} & $\begin{array}{c}\text { Moment } \\
\text { Change } \\
(\%)\end{array}$ & DF \\
\hline & & & & UNC & CON & & \\
\hline AB1 & 3 & 6350 & 6 & 101.9 & 102 & $1.1(\mathrm{G})$ & 8.1 \\
\hline AB2 & 3 & 6350 & 6 & 101.9 & 104 & $2.1(\mathrm{G})$ & 8.9 \\
\hline AB3 & 8 & 6350 & 7 & 136.3 & 141 & $3.4(\mathrm{G})$ & 7.2 \\
\hline AB4 & 8 & 6350 & 7 & 136.3 & 137 & $0.5(\mathrm{G})$ & 7.1 \\
\hline AB5 & 12 & 6350 & 6 & 101.9 & 116 & $13.8(\mathrm{G})$ & 6.9 \\
\hline AB6 & 12 & 6350 & 6 & 101.9 & 119 & $17.1(\mathrm{G})$ & 6.9 \\
\hline
\end{tabular}

Note: Overall width (5 in.) and length (60 in.) of all the beams were same; UNC:Unconditioned average reference values of minimum of 2 beams; UNC: Unconditioned value; CON: Conditioned value; DF:Deformability Factor; G:Gain.

Strength gain in the beams is attributed to an increase in concrete strength during conditioning and/or an increase in stiffness of the bar (as found in the results of tests presented in Chapter 5).

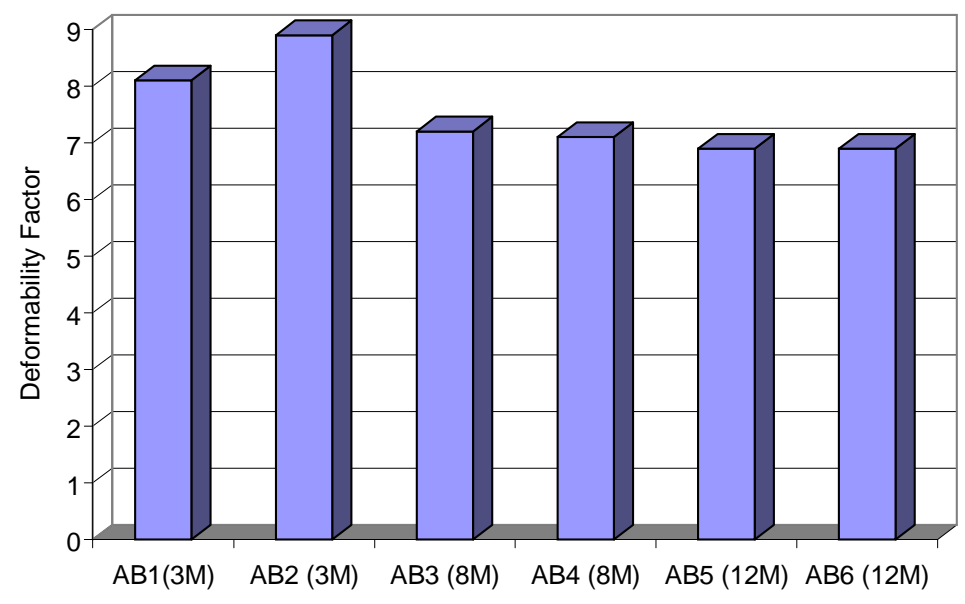

Fig. 9.6 Variation of Deformability Factor in Alkaline and Freeze-Thaw Conditioned $(3,8$ and 12 months) GFRP Reinforced Beams 


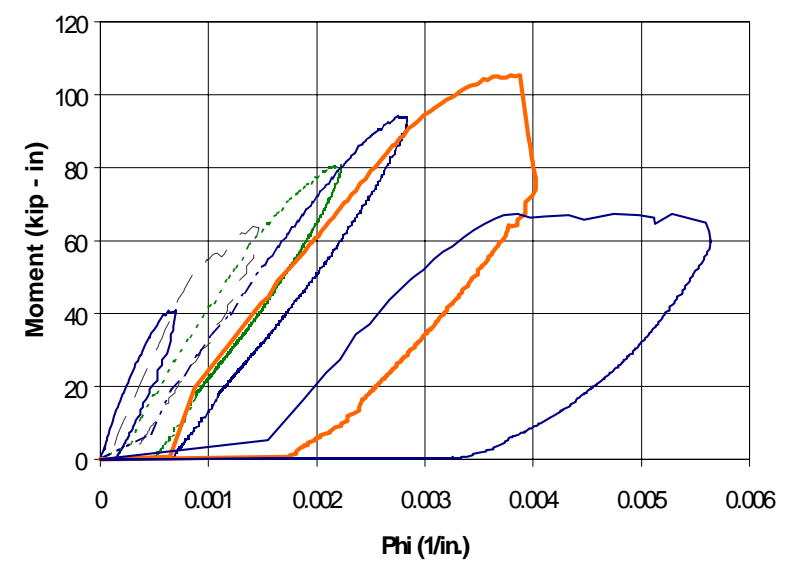

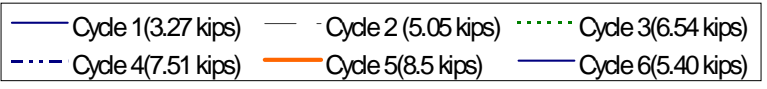

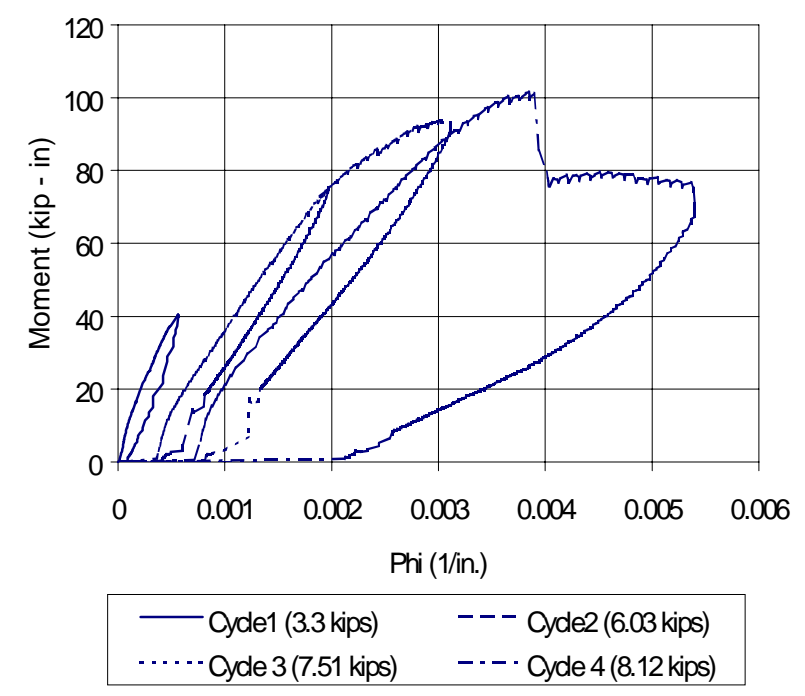

Fig. 9.7 Moment-Curvature Curves for Beams (AB1 on right and AB2 on left) Immersed for 3 Months in Alkaline Solution under Freeze-Thaw Fluctuation

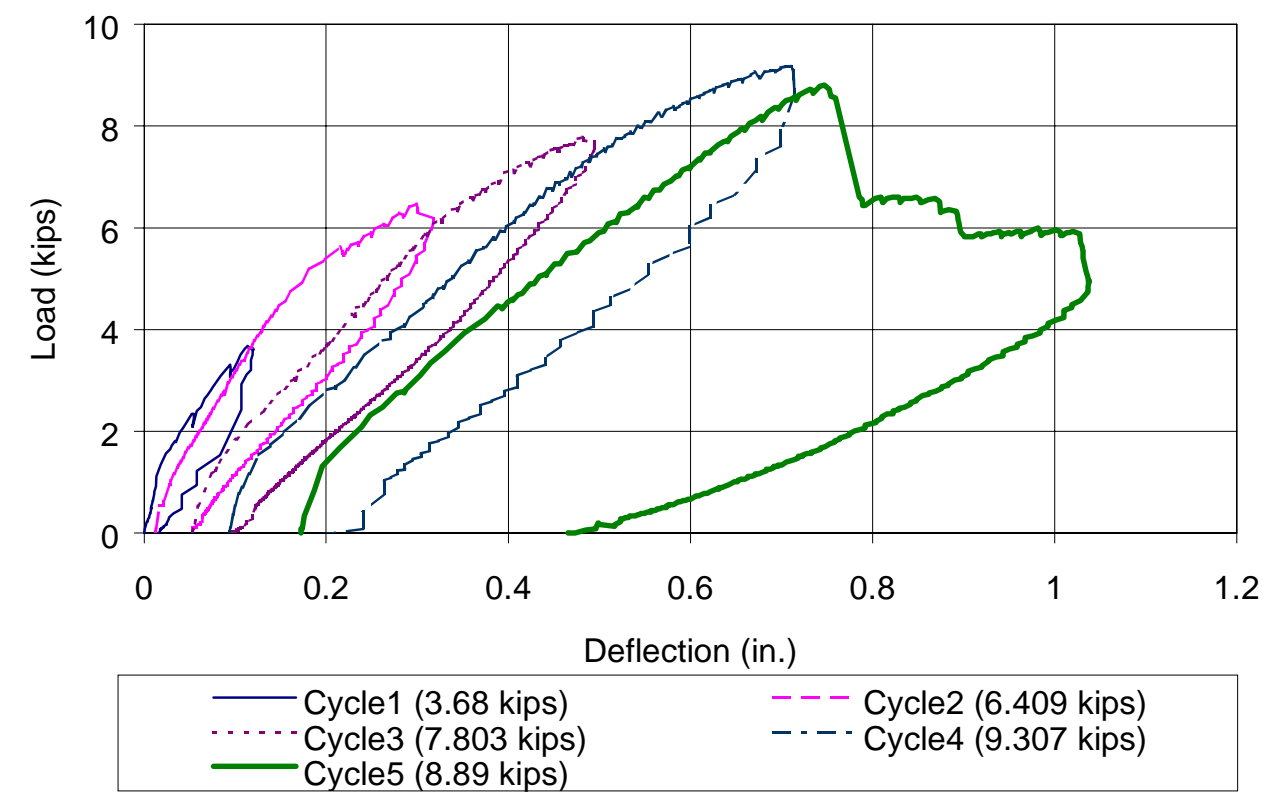

Fig. 9.8 Load-Deflection for Beam AB5 Immersed for 12 Months in Alkaline Solution under Freeze-Thaw Fluctuation 


\subsection{THEORETICAL COMPARISONS}

Theoretical moments of conditioned beams are computed using equations (7.9) and (7.10). It is important to note that for a conditioned beam designed for compression failure, no change in moment capacity is theoretically anticipated, as long as the failure mode, stiffness of the bar and area of the bar are unchanged. This is clearly reflected from the moment equations (7.9) and (7.10).

Table 9.3 Theoretical Comparison of Salt, and Alkaline Conditioned Beams

\begin{tabular}{|c|c|c|c|c|c|c|c|}
\hline \multicolumn{4}{|c|}{ Salt Conditioned Beams } & \multicolumn{4}{c|}{ Alkaline Conditioned Beams } \\
\hline & Expt. & Theory & $\begin{array}{c}\text { Expt } \\
\text { Theory }\end{array}$ & & Expt. & Theory & $\begin{array}{c}\text { Expt } \\
\text { Theory }\end{array}$ \\
\hline & kip-in & kip-in. & & & kip-in & kip-in. & \\
\hline SB1 & 89 & 85.3 & 1.04 & AB1 & 102 & 98.7 & 1.03 \\
\hline SB2 & 101 & 85.3 & 1.18 & AB2 & 104 & 98.7 & 1.05 \\
\hline SB3 & 87 & 85.3 & 1.02 & AB3 & 141 & 134.2 & 1.05 \\
\hline SB4 & 79 & 85.3 & 0.93 & AB4 & 137 & 134.2 & 1.02 \\
\hline SB5 & 138 & 118.9 & 1.16 & AB5 & 116 & 98.7 & 1.18 \\
\hline SB6 & 89 & 85.3 & 1.04 & AB6 & 119 & 98.7 & 1.20 \\
\hline
\end{tabular}

Note 1: while computing theoretical values, small variation in the cover to tension bars during casting were measured and accounted for.

\subsection{COMPARISON OF AGING OF GFRP BARS IN BEAMS AND DIRECT GFRP BAR AGING}

In this research bars were always extracted from concrete beams that were tested after conditioning schemes. Since many of the beams were designed for compression failure, bars at the tension side of aged and tested concrete beams were carefully extracted using a simple airchisel capable of cutting through both concrete and GFRP. Regular holes were drilled about 6 
inches apart and 2 inches away from the bar location at two beam surfaces. Concrete around the bar was carefully loosened through drilling and then the stirrups were cut through to recover the bars. This technique was perfected after making two extractions and yielded bars that were virtually undamaged during extraction.

Bars extracted from the concrete beams that were immersed in salt and alkaline solution and subsequently tested for evaluating beam bending behavior were attached with grips and tested under tension. Results of the tension tests are shown in Fig. 9.9. Tensile strength reductions of $21.2 \%$ in salt immersion and freeze-thaw conditioning and $29.8 \%$ in alkaline immersion and freeze-thaw conditioning at the end of 12 months are observed. These values are less than the strength reductions in the bars directly aged outside of the concrete environment under same conditioning by a factor of 2 as shown in Fig. 5.24. It is evident that, concrete cover has provided additional protection to the bars over direct alkaline solution exposure. However, protection offered by concrete cover may apparently diminish during 100-year service life, when the strength values of GFRP bars reach a stabilized value asymptotically. For calibration of accelerated weathering with natural weathering, bars having higher aging acceleration, i.e., the ones in direct contact with the alkaline solution are considered and discussed in Chapter 5. 


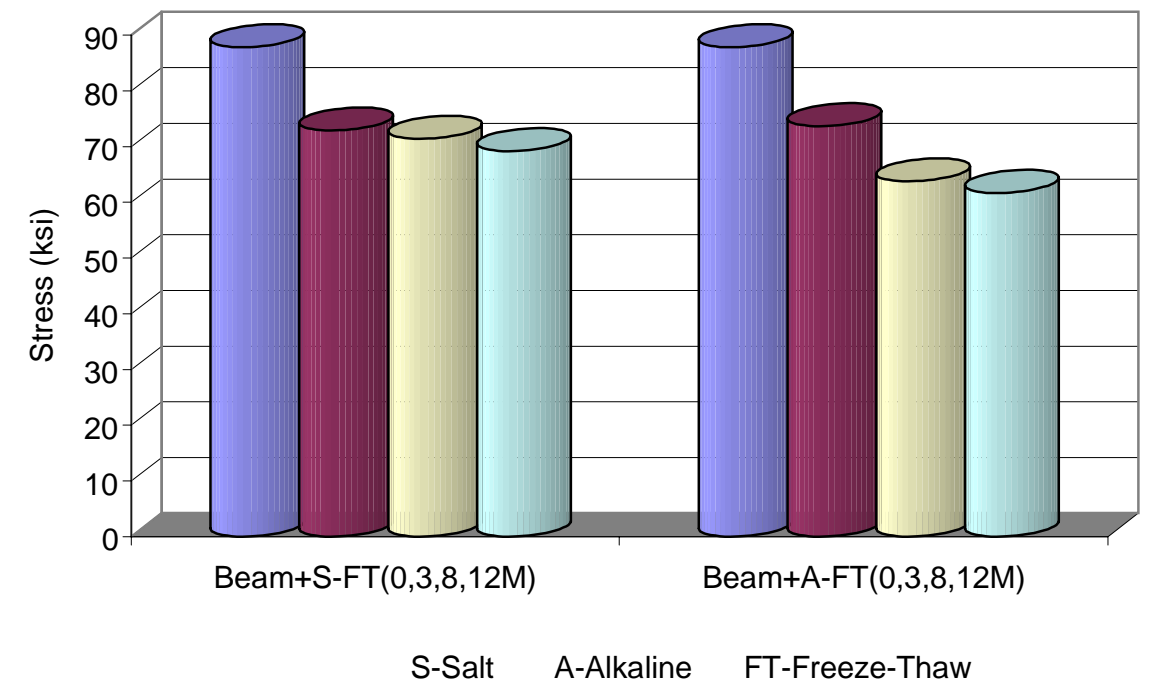

Fig. 9.9 Tension Test Results of Bars Extracted from Beams Subjected to Accelerated Aging

\subsection{CONCLUSIONS}

- Under freeze-thaw and salt conditioning, maximum moment capacity loss of $8.7 \%$ and a maximum gain of $11.0 \%$ were observed.

- Under alkaline and freeze-thaw conditioning, maximum moment gain of $17.1 \%$ was observed in all the beams; and no loss in moment capacity was noted.

- Deformability factors showed a reducing trend with increasing duration under salt and alkaline solution immersion under freeze-thaw conditioning.

- Deflections after salt or alkaline immersions and freeze-thaw conditioning did not show any appreciable loss of stiffness.

- Crack-patterns in salt and freeze-thaw conditioned beams were characterized by uniform spacing. Crack-widths of conditioned beams showed small increase (0.001 to $0.002 ")$ in the width. 
- Crack-patterns in alkaline and freeze-thaw conditioned beams were characterized by few cracks and cracking along the longitudinal bar indicated possible bond reduction. However, crack-widths of conditioned beams showed a very small increase in the width $(0.001$ to $0.002 ")$.

- Strength gain in moment capacity is attributed to an increase in the concrete strength during conditioning. Possible statistical variations in the test results is another contributing factor for the observed results.

- GFRP bar strength reductions do not necessarily reduce the moment capacity of the beams unless the reductions are such that the failure mode changes from compression to tension.

- Designing for compression failure guards the load factors (which includes safety factors) associated with the design loads, as long as the reduction in strength of GFRP bars do not result in change of failure mode, which can be easily verified through moment equations (7.9) and (7.10).

- Acceleration of aging is higher in GFRP bars directly exposed to alkaline and freeze-thaw conditioning as opposed to the bars embedded in pre-cracked concrete beams and exposed to the same conditioning by a factor of 2 .

- Protection offered by concrete cover may apparently diminish during 100-year service life, when the strength values of GFRP bars reach a stabilized value asymptotically. 


\section{CHAPTER 10}

\section{CREEP AND FATIGUE BEHAVIOR OF CONCRETE BEAMS WITH GFRP BARS}

\subsection{INTRODUCTION}

Over the past 10 years, research on strength, stiffness, bending, shear and bond characteristics of concrete structures reinforced with fiber reinforced polymer (FRP) bars has resulted in better understanding of those mechanical responses (Benmokrane and Masmoudi, 1996). However, research in the area of creep behavior of concrete beams with GFRP bars is limited (Brown, 1997). Knowledge of the long-term serviceability aspects is very essential for infrastructure facilities constructed with advanced composites such as FRP bars. In this study, key issues such as creep coefficients, creep deflections and crack-widths were evaluated for varying sustained load levels. Two GFRP reinforcement ratios were used for the concrete beams using C-bars and sand coated bars. Four-point sustained bending loads were applied on four concrete beams up to 847 days.

Fatigue tests are conducted on 4 concrete beams designed for tension and compression failure modes. Dynamic loading was applied at frequencies up to $4.25 \mathrm{~Hz}$. and 2.25 million cycles.

\subsection{CREEP STUDY}

\subsubsection{Overview}

Concrete creep is influenced by several factors such as concrete mix proportions, temperature, humidity, age of concrete at loading and stress levels. In addition to concrete creep, GFRP bars used as tension reinforcement in concrete beams also possess viscoelastic properties. 
Many empirical relations based on actual tests are available for the prediction of steel reinforced concrete beam creep coefficients $\left(\mathrm{C}_{\mathrm{t}}\right)$ for a given duration of loading. Wide variation (1.3 to 4.15) in ultimate concrete creep coefficient $\left(\mathrm{C}_{\mathrm{u}}\right)$ was observed (ACI 209R) by earlier researchers. Hence, an average ultimate creep coefficient of $2.35 \gamma_{\mathrm{c}}$ has been suggested by ACI 209R, where, $\gamma_{c}$ is the product of several correction factors (ACI 209R) representing the duration of loading, concrete age at the time of loading, humidity, member thickness, concrete slump, percentage fines and air content. Accounting for first two of the above mentioned factors, $C_{t}$ is given by:

$$
\begin{aligned}
& C_{t}=\frac{\text { Creep strain }}{\text { Initial elastic strain }}=\left(1.25 t_{i}^{-0.118}\right)\left(\frac{t^{0.6}}{10+t^{0.6}}\right) C_{u} \\
& C_{\mathrm{t}} \quad=\text { creep coefficient at time } \mathrm{t} . \\
& \mathrm{t}_{\mathrm{i}}=\text { age of concrete in days when the load is first applied. } \\
& \mathrm{t}=\text { duration of loading(days). } \\
& C_{\mathrm{u}} \quad=\text { the ultimate creep coefficient. }
\end{aligned}
$$

It is to be noted that shrinkage strains also form a part of concrete strains measured on concrete beams and are not experimentally separated in this study.

\subsubsection{Objectives}

The objectives of this creep study are:

- To evaluate and compare creep rate and creep deflection of concrete beams reinforced with GFRP bars under different levels of sustained bending loads. 
- To compare creep rate and deflection of GFRP reinforced concrete beams to theoretical values of similar beams with steel reinforcement.

- To compare crack-widths under two different sustained load conditions.

\subsubsection{Test Specimens}

Casting and curing of the concrete beam specimens were done under laboratory conditions. Beams were designed for tension and compression failure modes and cast separately in two batches. Details of the beam specimens are shown in Table 10.1.

Table 10.1 Details of the Test Specimens

\begin{tabular}{|c|c|c|c|c|c|c|}
\hline Beam & $\begin{array}{c}\text { Concrete } \\
\text { Strength } \\
\mathbf{f}_{\mathbf{c}} \text { ' (ksi) } \\
\mathbf{( 1 )}\end{array}$ & $\begin{array}{c}\text { Tension } \\
\text { Bars }\end{array}$ & $\begin{array}{c}\text { \% } \\
\text { Tension } \\
\text { Reinf. } \\
\mathbf{( 3 )}\end{array}$ & $\begin{array}{c}\text { Comp. } \\
\text { Bars }\end{array}$ & $\begin{array}{c}\text { Sustained } \\
\text { Load }\end{array}$ & $\begin{array}{c}\text { Duration } \\
\text { of loading } \\
\text { (Days) } \\
\text { (7) }\end{array}$ \\
\hline T1CR & 3.45 & $2-\# 4(\mathrm{~S})$ & 0.61 & $1-\# 3(\mathrm{~S})$ & $\cong 35 \%$ of Ult. & 57 \\
\hline $\mathrm{T} 2 \mathrm{CR}$ & 3.45 & $2-\# 4(\mathrm{~S})$ & 0.61 & $1-\# 3(\mathrm{~S})$ & $\cong 50 \%$ of Ult. & 847 \\
\hline $\mathrm{C} 1 \mathrm{CR}$ & 4.06 & $2-\# 4(\mathrm{C})$ & 0.96 & $1-\# 3(\mathrm{~S})$ & $\cong 20 \%$ of Ult. & 554 \\
\hline $\mathrm{C} 2 \mathrm{CR}$ & 4.06 & $2-\# 4(\mathrm{C})$ & 0.96 & $1-\# 3(\mathrm{~S})$ & $\cong 35 \%$ of Ult. & 560 \\
\hline
\end{tabular}

Note:

- Overall beam dimensions for all the beams 6"x12"x120"

- Beams T1CR, T2CR were designed for tension failure and beams C1CR, C2CR were designed for compression failure.

- Bars with designations (S) and (C) in column (3) represent sand coated and C-bars respectively. 
Two types of GFRP bars, viz., sand coated by International Grating Inc. and ribbed (Cbar) by Marshall Industries, Inc., were used for reinforcing the beams. Sand coated \#3 bars were used as compression bars for all beams. Sand coated \#3 stirrups were used as shear reinforcement for all beams.

\subsubsection{Sustained Load Application}

The concrete beams were tested under sustained four point bending load (20\% to $50 \%$ of ultimate load). Three of the beams T2CR, C1CR and C2CR were tested under sustained load application using Dywidag stressing bars as shown in Fig. 10.1, whereas, T1CR was tested under hydraulic loading. Applied loads were regularly monitored and maintained. Beams T1CR and T2CR were tested under a span of $9 \mathrm{ft}$., with the loading at third points, whereas beams C1CR and $\mathrm{C} 2 \mathrm{CR}$ were tested at a span of $8.5 \mathrm{ft}$,. with the load at third points. Due to problems in maintaining constant load through the hydraulic device, creep testing on beam T1CR was discontinued and fatigue tests were carried out on the same, which is explained later in section 10.10 .

Sustained load duration for the beam under hydraulic loading was 57 days, whereas mechanical stressing using Dywidag bars was conducted up to 847 days. The time dependent increases in mid-span deflection, strain values of the concrete and GFRP, and crack-widths were regularly recorded for all the beams. 

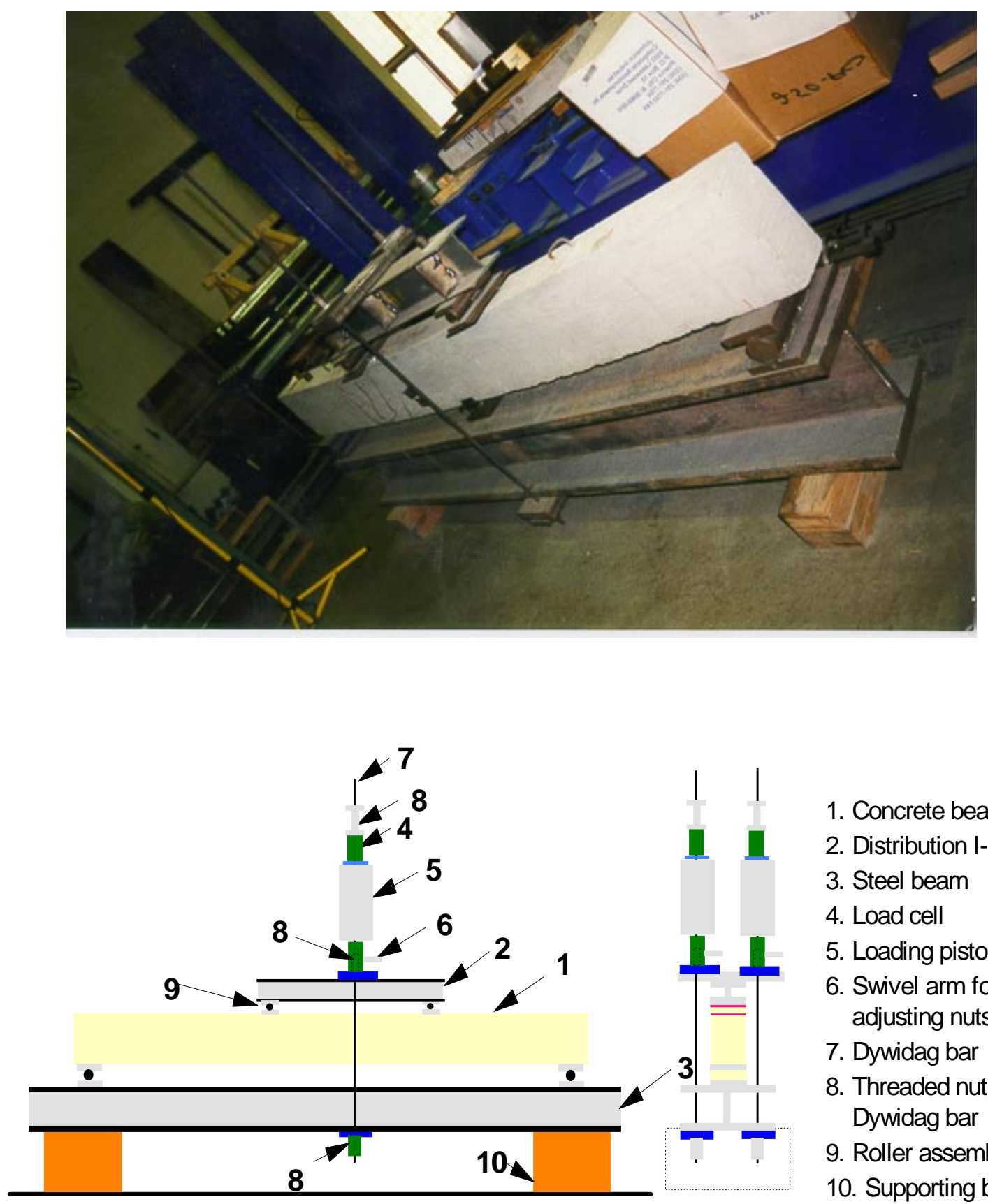

1. Concrete beam

2. Distribution I-Beam

3. Steel beam

4. Load cell

5. Loading piston

6. Swivel arm for adjusting nuts

7. Dywidag bar

8. Threaded nut for Dywidag bar

9. Roller assembly

10. Supporting block

Fig. 10.1 Longitudinal and Side Views of Concrete Beam Reinforced with GFRP Bars under Sustained Load and a Schematic Representation 


\subsubsection{Results and Discussion on Creep Study}

\subsubsection{Concrete Creep Strains}

Concrete creep strains were measured on the top of concrete surface using one or more strain gages. Concrete creep strains under two different load levels are shown in Fig. 10.2 for the beam C1CR. Significant creep was observed in the initial days of loading for all levels of sustained loading. This is usually referred to as the primary creep. Beam with lower sustained loading exhibited significant creep for about 75 days, whereas beam T2CR with higher sustained load exhibited significant creep for about 175 days. Time-dependent increase in concrete strains is mainly due to creep of concrete and partly due to cracking (influenced by low stiffness of GFRP bars).

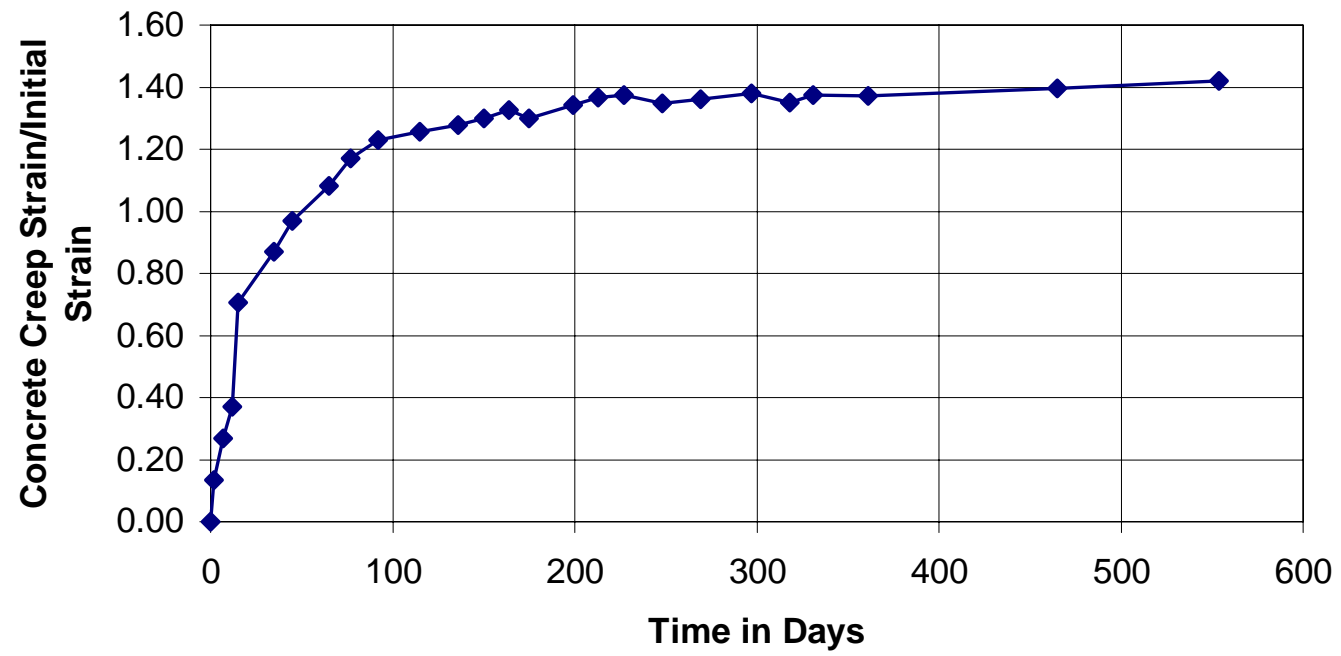

Fig. 10.2 Concrete Creep Strains in Beam(C1CR) Reinforced With GFRP Bars

Based on concrete strains, the creep coefficient was found to be 1.42 in low sustained stress level loading (C1CR) as compared to 1.18 in high sustained load level (C2CR) (Table 10.1). These experimental factors were less than the values given by eq. 10.1 for a similar steel 
reinforced concrete beam. In the study conducted by Brown (1997) on the creep behavior of concrete beams with GFRP bars, $\mathrm{C}_{\mathrm{u}}$ of 1.3 is suggested based on her experimental creep deflection data and also on a parametric study.

\subsubsection{Deflections}

Ratio of creep deflections to initial deflections is shown in Figs. 10.3 and 10.4 for beams T2CR and C1CR, where, $\mathrm{C}_{\mathrm{u}}$ were observed to be 0.87 and 1.14 respectively. Though initial deflections are high in concrete beams reinforced with GFRP bars as compared to those with steel reinforcement, relative creep deflections are less as compared to theoretical creep deflections of beams with steel reinforcement. Brown (1997) experimentally observed similar behavior. The results of this study indicate that overall creep is mainly due to concrete and the advantage of steel beams having low initial deflections is somewhat nullified and the long-term total deflections will be closer in two cases than the instantaneous deflection values.

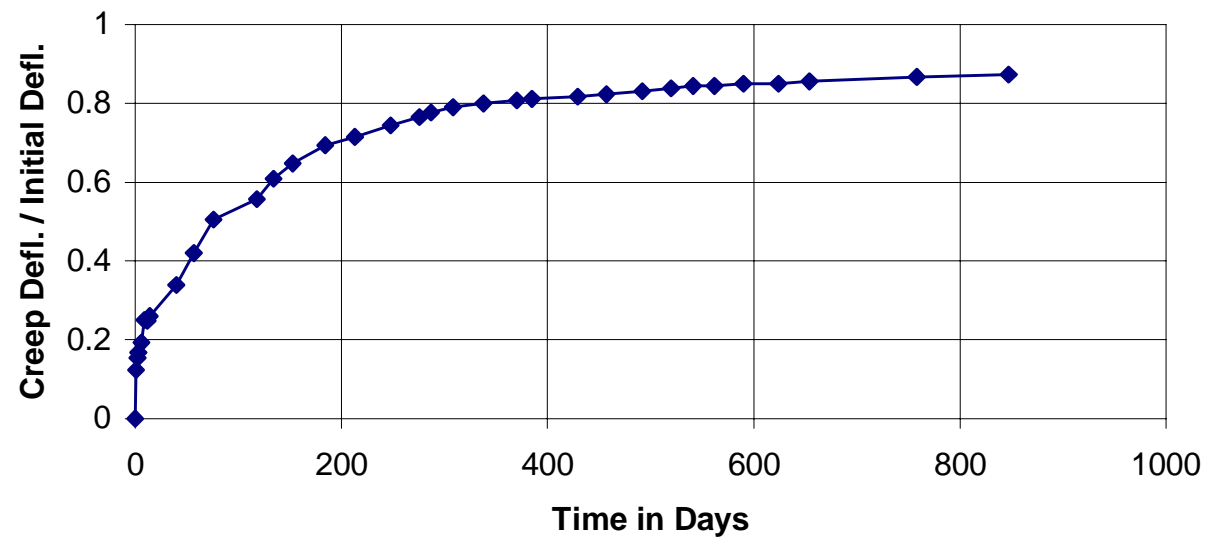

Fig. 10.3 Creep Deflections in Beam (T2CR) Reinforced with GFRP Bars 


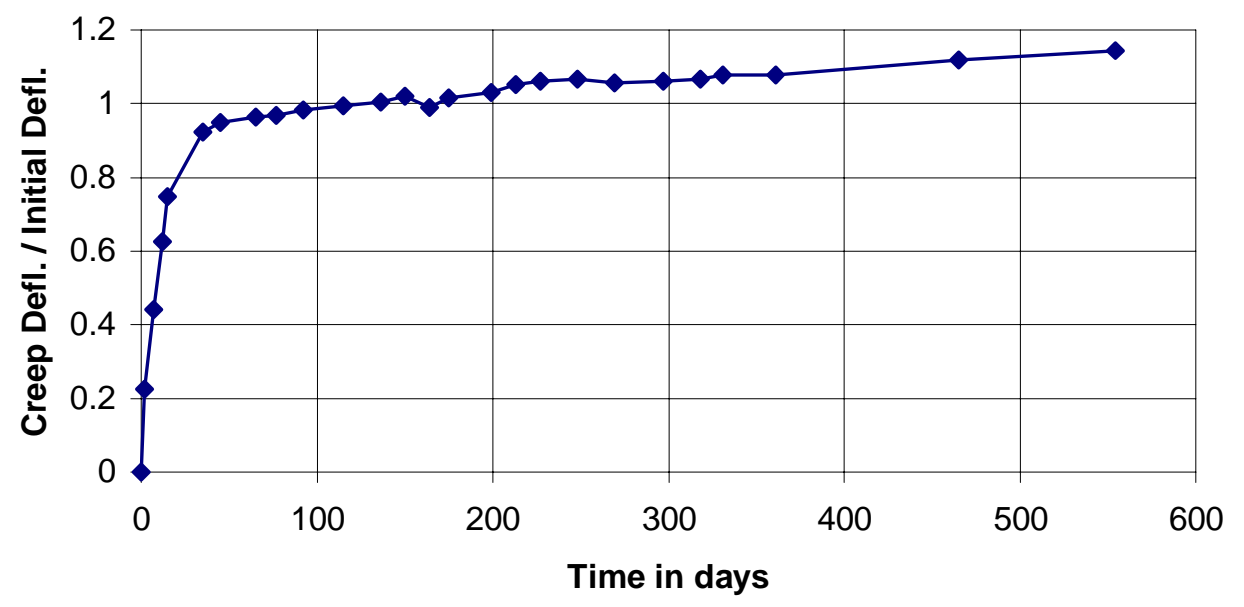

Fig. 10.4 Creep Deflections in Beam(C1CR) Reinforced with GFRP Bars

\subsubsection{GFRP Strains}

Increase in GFRP bar strains can be expected mainly due to changes in strain configurations of a given concrete section under sustained loading. Sustained loading results in an increase in concrete strain, reduction in concrete stress and an increase in FRP reinforcement stress (RILEM, 1993). As reported by several authors, it is to be noted that GFRP bars themselves do not exhibit major creep. Negligible creep strains in glass fiber rods and grids subjected to sustained stresses exceeding $50 \%$ of their ultimate value have been reported by Rahman et al., 1995, and Yamasaki et al., 1993. Among the four beams subjected to creep, GFRP strain increase was found to increase by $25 \%$ to $40 \%$ of the initial strains at loading. Increase in GFRP strains is attributed to:

- Reduction in moment of inertia of the concrete section due to progression of cracks or increase in crack-width.

- Time dependent change in lever arm between tensile and compressive forces.

- Increase in beam curvature. 
- Change in the strength and stiffness of bars embedded in concrete.

\subsubsection{Crack-Widths}

Increase in maximum crack widths was found to be less than or close to their initial values over the duration of sustained stress at the mid-span location. Only a few additional cracks were formed during the sustained load application. The initial rate of increase in crackwidths was more in the case of beams with low sustained load as compared to beams with higher sustained load. This may be due to quicker drop in moment of inertia of concrete beams reinforced with GFRP bars, after first crack.

\subsubsection{Static Testing of Beams under Creep}

Beams under creep were subjected to failure load tests after creep testing was concluded. Loading consisted of a few cycles of loading and unloading followed by final load test to failure (Fig. 10.5). Beam T2CR failed in a near-balanced fashion with compression failure initiation immediately followed by bar rupture (Fig. 10.6). Results of static tests on the beams subjected to sustained loads are provided in Table 10.2. Reduction in deformability factor is found with increasing sustained stress and duration of applied stress.

Table 10.2 Static Testing of Beams under Creep

\begin{tabular}{|c|c|c|c|c|c|c|}
\hline Beam & $\begin{array}{c}\text { No. of Days } \\
\text { under Creep }\end{array}$ & $\begin{array}{c}\text { Load } \\
\text { sustained }\end{array}$ & $\begin{array}{c}\text { Max. } \\
\text { Moment }\end{array}$ & $\begin{array}{c}\text { Ultimate } \\
\text { Load }\end{array}$ & $\begin{array}{c}\text { Test } \\
\text { Span }\end{array}$ & $\begin{array}{c}\text { Deformability } \\
\text { Factor }\end{array}$ \\
\hline & & $\%$ & (kip-inch) & kips & inches & \\
\hline C1CR & 554 & 20 & 301 & 17.705 & 102 & 9.81 \\
\hline C2CR & 560 & 35 & 319 & 18.761 & 102 & 9.27 \\
\hline T2CR & 847 & 50 & 265 & 14.71 & 108 & 8.33 \\
\hline
\end{tabular}




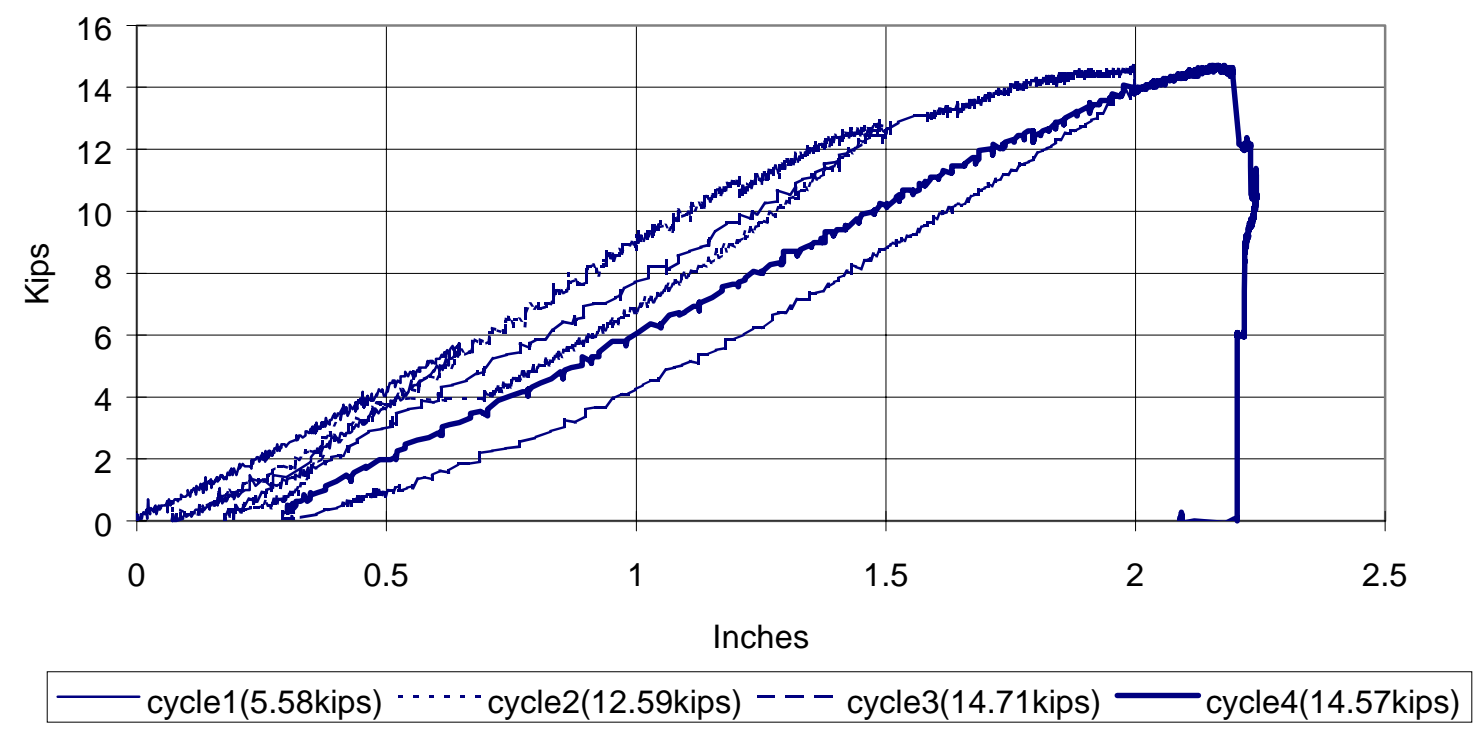

Fig. 10.5 Static Load-Deflection Test of Beam T2CR subjected to 27 months of Creep at $50 \%$ of the Sustained Load
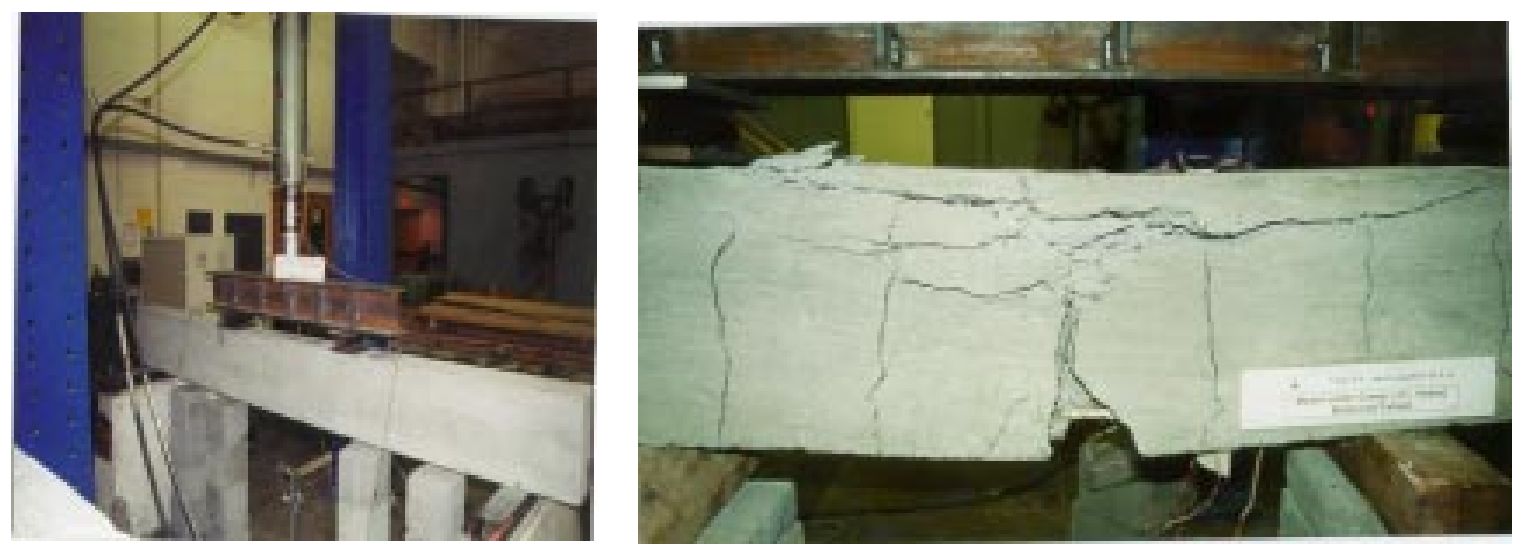

Fig. 10.6 Beam T2CR under Static Test Exhibiting close to Perfect Balanced Failure

\subsubsection{Long Term Deflections}

Based on lower creep deflections, approximate long-term deflections given by ACI 31895 eq. 9-10 can be conservatively estimated by applying reduction factors. A reduction factor of 0.75 is conservatively proposed for the time dependent factor $\xi$. 


$$
\lambda=(0.75) \frac{\xi}{1+50 \rho^{\prime}}
$$

\subsection{CONCLUSIONS ON CREEP STUDY}

Based on test results, the following conclusions are drawn:

- Concrete creep strain curves of GFRP reinforced concrete beams are similar to those of steel reinforced concrete beams.

- Creep coefficient in GFRP reinforced concrete beams is less than those reinforced by steel. This is due to the fact that initial strains and deflections in GFRP reinforced concrete beams are higher as compared to the steel reinforced concrete beams.

- At higher sustained stress level, duration of creep activity was significant up to 175 days, while only 75 days in beams with low sustained stress level.

- Creep coefficient was found to be 1.29 in beams under low sustained loading (20\% of ultimate sustained stress) as compared to 1.54 in beams under high sustained loading (50\% of the ultimate sustained stress). This observation is made from strain values measured on concrete.

- The initial rate of increase in crack-widths was more in beams under low sustained loads as compared than in beams under high sustained loads. This is attributed to the higher rate of decrease in moment of inertia of GFRP reinforced concrete beams soon after the initial crack formation. 
- Conservatively, a reduction factor of 0.75 is proposed for the time dependent factor $\xi$, used by ACI 318-95 (Eq. 9-10) for the purpose of approximately estimating long-term deflections resulting from creep and shrinkage.

\subsection{FATIGUE STUDY}

Concrete beams were subjected to static loading in two cycles and then three-point bending fatigue loads were applied. The dynamic loading consisted of constant amplitude sinusoidal load application at frequencies ranging from 2 to $4.25 \mathrm{~Hz}$. MTS 55 kip closed loop servo-hydraulic 244 series actuator with a MTS 510.10C hydraulic power supply and a MTS-407 controller was used for applying the fatigue loads. Details of the specimens are shown in Table 10.3. Beam T1CR, which was tested under creep through hydraulic loading for 57 days was tested under fatigue. At regular intervals the beams were statically tested and strains, deflections and crack-widths were measured. Maximum strain value and the strain range of both concrete and GFRP had a major impact on the fatigue life of all the beams.

Table 10.3 Beams Tested under 3-Point Bending Fatigue

\begin{tabular}{|l|l|l|l|l|l|}
\hline Beam & Dimension & \multicolumn{2}{l|}{ Reinforcement } & Test Span & No. of Cycles \\
\cline { 3 - 4 } & \multirow{2}{*}{ (in.x in.x in.) } & Tension & Comp. & (in.) & \\
\hline T1CR & $6 \times 12 \times 120$ & $2-\# 4(\mathrm{~S})$ & $1-\# 4(\mathrm{~S})$ & 84 & $0.51 \times 10^{6}$ \\
\hline F1M & $5 \times 6 \times 60$ & $2-\# 4(\mathrm{C})$ & $2-\# 4(\mathrm{~S})$ & 50 & $0.40 \times 10^{6}$ \\
\hline F2M & $5 \times 6 \times 60$ & $2-\# 4(\mathrm{C})$ & $2-\# 4(\mathrm{~S})$ & 50 & $0.40 \times 10^{6}$ \\
\hline F3IG & $5 \times 7 \times 60$ & $2-\# 4(\mathrm{~S})$ & $2-\# 4(\mathrm{~S})$ & 50 & $2.25 \times 10^{6}$ \\
\hline
\end{tabular}

S-Sand Coated (IG); $\quad$ C-C-bar (Marshall) 
10.4.1 Fatigue of Beam T1CR : Beam T1CR was designed for a tension failure. GFRP reinforced beams designed for tension failure in bending has lower area of compression block matching the force generated by tension GFRP bars. Beam T1CR was subjected to a load corresponding to concrete strain of $850 \times 10^{-6} \mathrm{in}$./in. and FRP strain of $3500 \times 10^{-6} \mathrm{in} . / \mathrm{in}$., with a strain range of $550 \times 10^{-6}$ and $2000 \times 10^{-6}$ respectively. After $0.4 \times 10^{6}$ cycles, concrete and FRP strain ranges were increased by $18 \%$ and $68 \%$ respectively as shown in Table 10.4. Only after an additional $0.11 \times 10^{6}$ fatigue cycles, the beam dramatically collapsed with compression failure followed by tension bar rupture as shown in Fig. 10.7. Depth of the compression zone of failed T1CR beam was measured to be less than 2 inches. Hence, fatigue life of beams designed for a tension failure is considerably reduced at concrete strains in excess of $800 \times 10^{-6}$ and a concrete strain range of $500 \times 10^{-6}$.
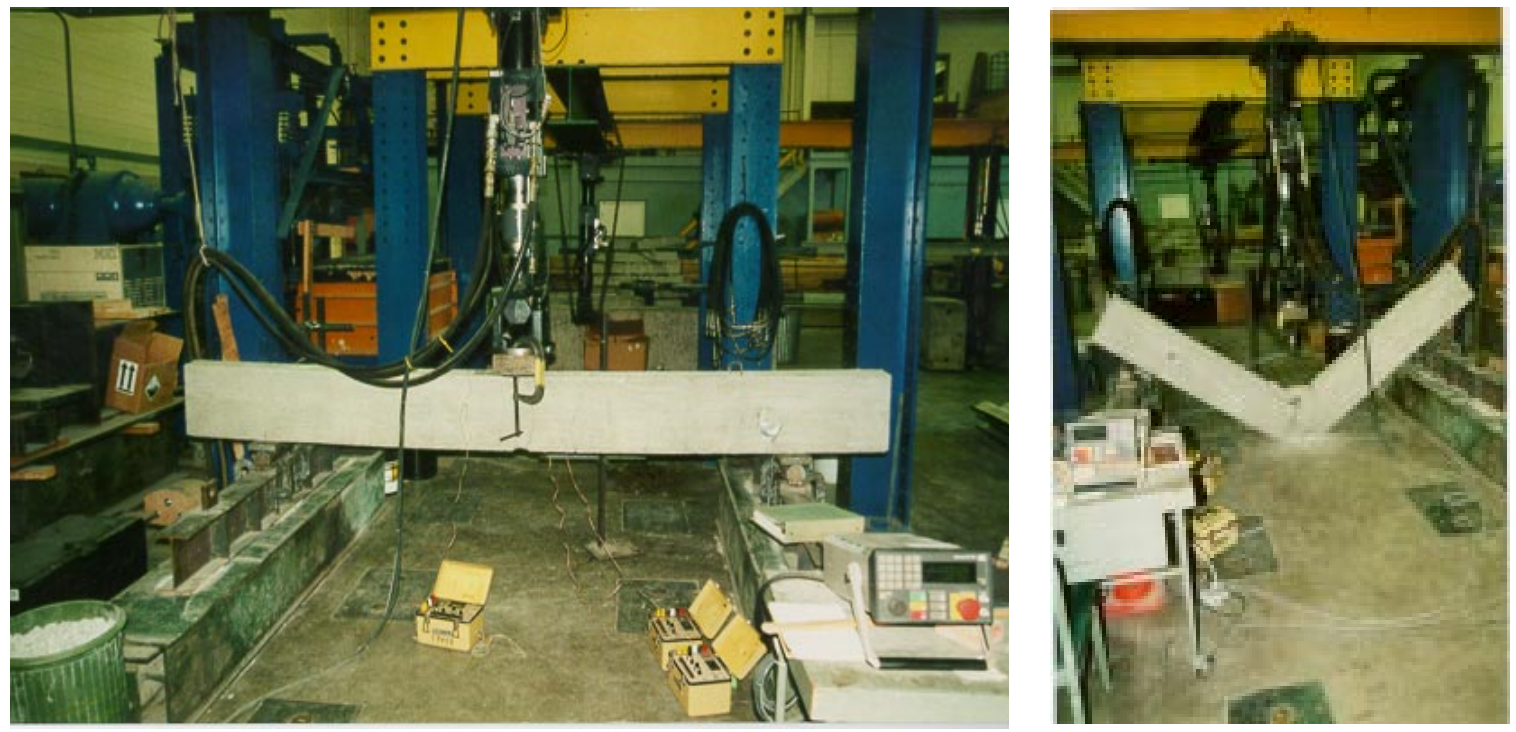

Fig. 10.7 Fatigue of Beam T1CR 
Table 10.4 Details of Fatigue Tests

\begin{tabular}{|l|c|l|l|l|l|l|l|}
\hline Beam & $\begin{array}{c}\text { Increase } \\
\text { in Load }\end{array}$ & \multicolumn{2}{|c|}{$\begin{array}{c}\text { Concrete } \\
\text { Strain } \\
\left(\mathbf{1 0}^{-6} \text { in./in. }\right)\end{array}$} & \multicolumn{2}{|c|}{$\begin{array}{c}\text { FRP Strain } \\
\left(\mathbf{1 0}^{-6} \text { in./in. }\right)\end{array}$} & $\begin{array}{c}\text { Freq. } \\
(\mathbf{H z})\end{array}$ & No. of Cycles \\
\hline & & Max. & Range & Max. & Range & & \\
\hline \multirow{2}{*}{ T1CR } & - & $850^{+}$ & 400 & 3500 & 2000 & 2.0 & $1.0 \times 10^{0}-0.20 \times 10^{6}$ \\
\cline { 2 - 8 } & No & $850^{+}$ & 400 & 3500 & 2000 & 2.0 & $0.2 \times 10^{6}-0.4 \times 10^{6}$ \\
\cline { 2 - 8 } & Yes & $1000+$ & 875 & 4075 & 3350 & 2.0 & $0.4 \times 10^{6}-0.51 \times 10^{6}$ \\
\hline \multirow{2}{*}{ F1M } & - & 750 & 600 & 1800 & 1700 & 1.5 & $1.0 \times 10^{0}-0.20 \times 10^{6}$ \\
\cline { 2 - 8 } & No & $800^{*}$ & $675^{*}$ & $2990^{*}$ & $2255^{*}$ & 2.5 & $0.2 \times 10^{6}-0.40 \times 10^{6}$ \\
\hline F2M & - & 535 & 460 & 1860 & 1760 & 1.5 & $1.0 \times 10^{0}-0.20 \times 10^{6}$ \\
\cline { 2 - 8 } & No & $830^{*}$ & $675^{*}$ & $2870^{*}$ & $2460^{*}$ & 2.5 & $0.2 \times 10^{6}-0.40 \times 10^{6}$ \\
\hline F3IG & - & 750 & 500 & 2000 & 1525 & 4.25 & $1.0 \times 10^{0}-1.50 \times 10^{6}$ \\
\hline & Yes & $1125^{*}$ & $875^{*}$ & $2550^{*}$ & $2075^{*}$ & 4.25 & $1.5 \times 10^{6}-2.00 \times 10^{6}$ \\
\hline & Yes & $1250^{*}$ & $1000^{*}$ & $2725^{*}$ & $2300^{*}$ & 3.50 & $2.0 \times 10^{6}-2.25 \times 10^{6}$ \\
\hline
\end{tabular}

+ Residual concrete and FRP strains were present prior to testing of this beam.

* These values include the residual and creep strains that develop during the continuous fatigue testing or due to an increase in the load application as indicated in the second column.

10.4.2 Fatigue of Beams F1M and F2M: Both beams F1M and F2M were identical in all respects. Therefore, fatigue test was conducted by applying twice the required load through a distribution plate as shown in Fig. 10.8. Static tests were independently conducted on each beam to ascertain the changes in strains, stiffness and crack-widths. Fatigue tests were conducted only 
to $0.4 \times 10^{6}$ cycles. Following the static test after $0.4 \times 10^{6}$ cycles, a controller problem resulted in a load application of about 10 times the anticipated load, resulting in failure of the specimens. Within the range of testing it appeared that the bars of both beams were having high residual strains. This may be due to bond loss between FRP and concrete under fatigue.
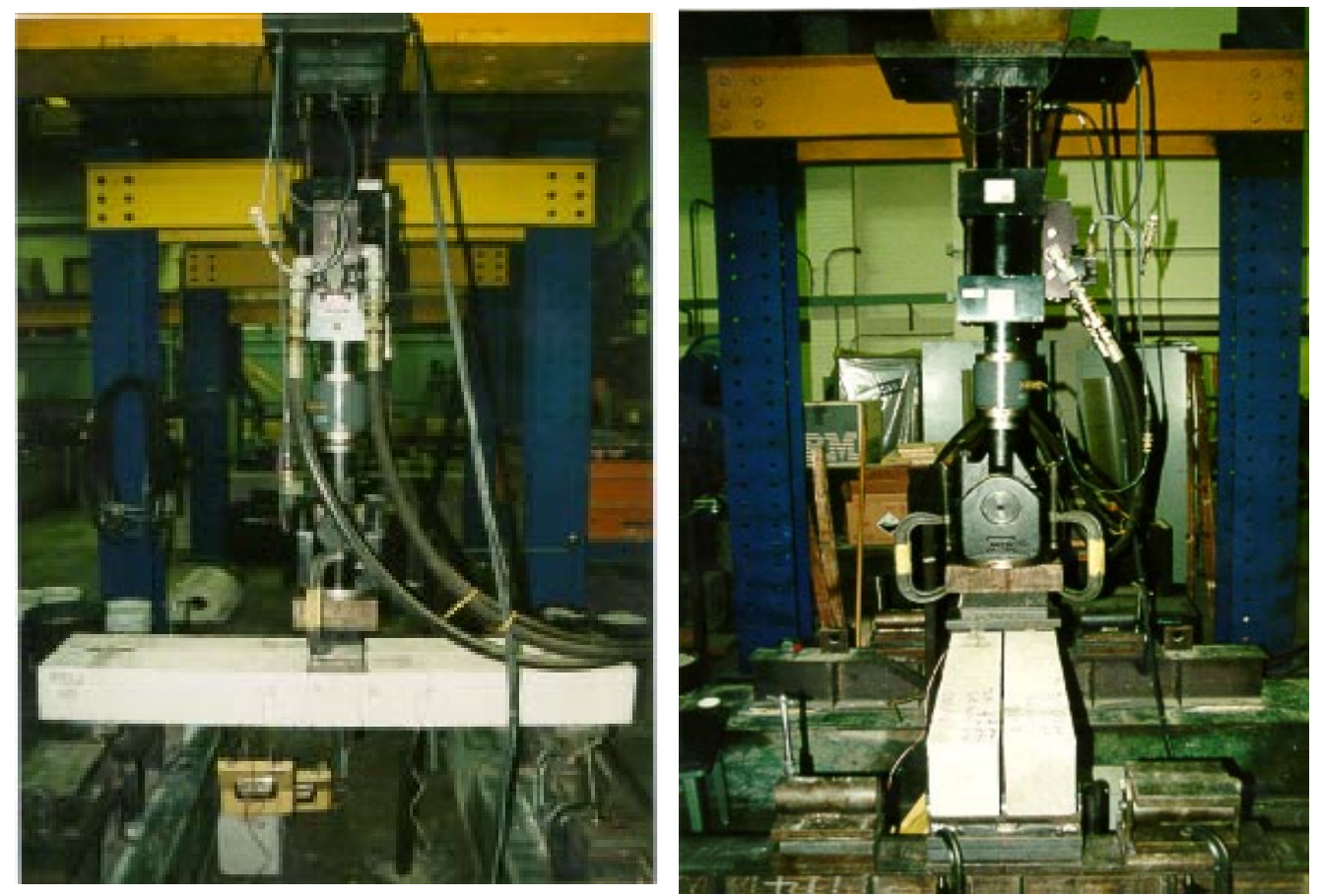

Fig. 10.8. Fatigue of Beams F1M and F2M

10.4.3 Fatigue of Beams F3IG: Beam F3IG was first subjected to $1.5 \times 10^{6}$ cycles with maximum concrete and FRP strain of $750 \times 10^{-6}$ and $2000 \times 10^{-6}$, with a strain range of $500 \times 10^{-6}$ and $1525 \times 10^{-6}$ respectively. Since no significant reduction in stiffness of the beam was noted, it was decided to increase the strain range and the load for an additional $0.5 \times 10^{6}$ cycles as shown in Table 10.4. Residual deflection in the beam after $2 \times 10^{6}$ cycles was less than 0.1 inch (Fig. 10.10) and crack width increase was found to be between $0.002 "$ to $0.003 "$. After $2.0 \times 10^{6}$ cycles, concrete and FRP strains were increased to $1250 \times 10^{-6}$ and $2725 \times 10^{-6}$, and the strain range was increased to $1000 \times 10^{-6}$ and $2300 \times 10^{-6}$ respectively. This resulted in quick deterioration of the 
beam and cracks widened and residual deflections were very high. The beam was again tested to failure and it carried only $40 \%$ of its ultimate load.

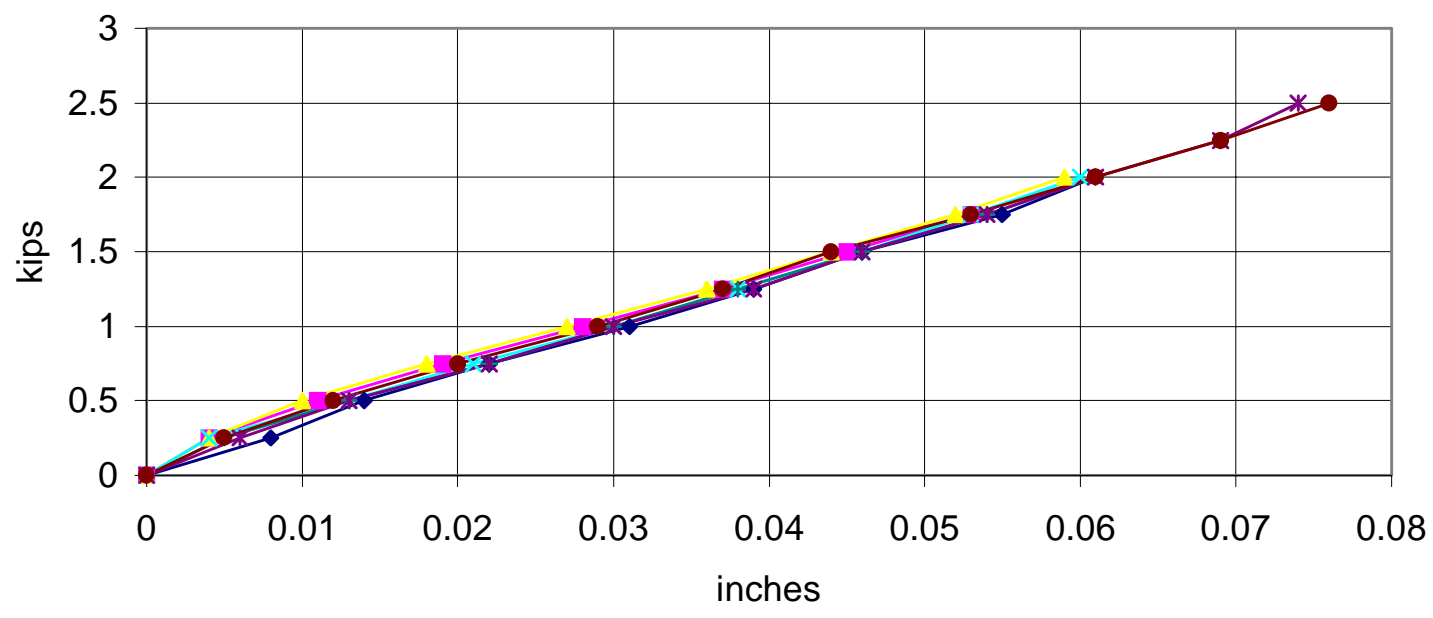

\begin{tabular}{lll|}
$\rightarrow-2$ nd cycle & $\rightarrow-.2$ million cycle & -.6 million cycle \\
$* .8$ million cycle & +1.175 million cycle & $*-1.5$ million cycle \\
$\rightarrow-2$ million cycle & & \\
\hline
\end{tabular}

Note: Residual deflections are not shown after each cycle and maximum residual deflection after $2 \times 10^{6}$ cycles was $<0.01$ inches.

Fig. 10.9 Deflections in the beam F3IG subjected to fatigue loading

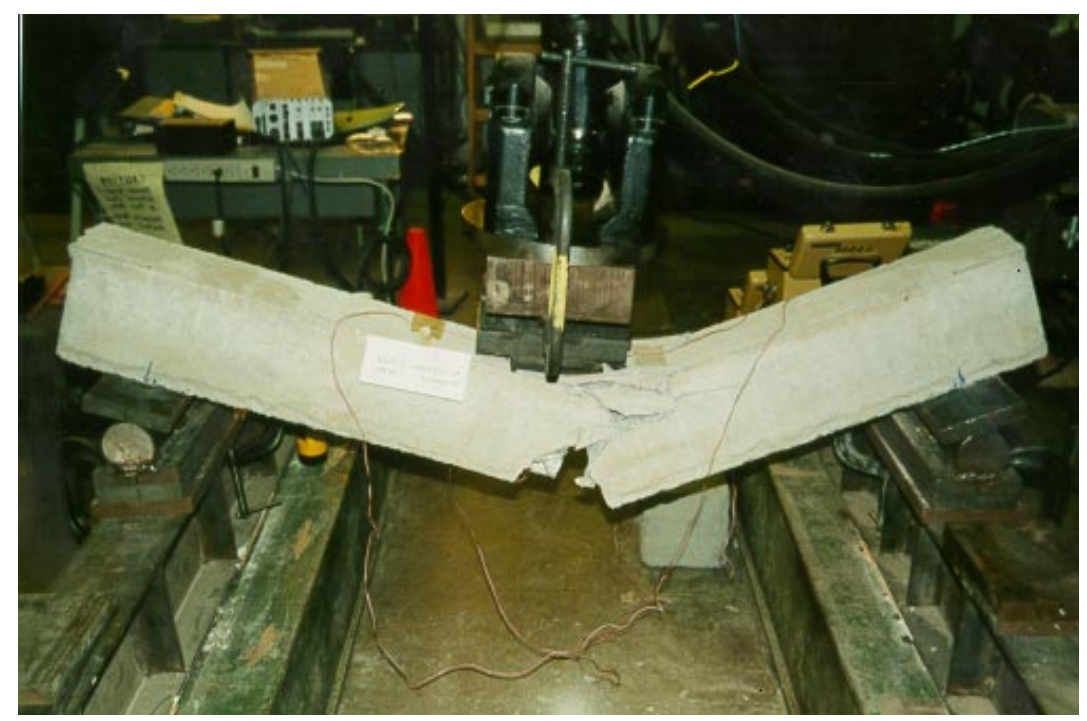

Fig. 10.10 Static Testing of Beam F3IG after 2.25x10 6 Cycles 


\subsection{COMPARISON OF AGING OF GFRP BARS IN BEAMS AND DIRECT GFRP BAR AGING}

Bars were extracted from beams subjected to creep and fatigue after the static tests. Extracted bars were attached with grips and tension tested. Strength losses of the bars are shown in Fig. 10.11. For comparison results of Fig. 9.9 are also included. Maximum tensile strength reduction of $24.0 \%$ was observed in beams under creep and fatigue. These values are less than the strength reductions in the bars directly aged inside the concrete environment and subjected to alkaline immersion and freeze-thaw fluctuations.

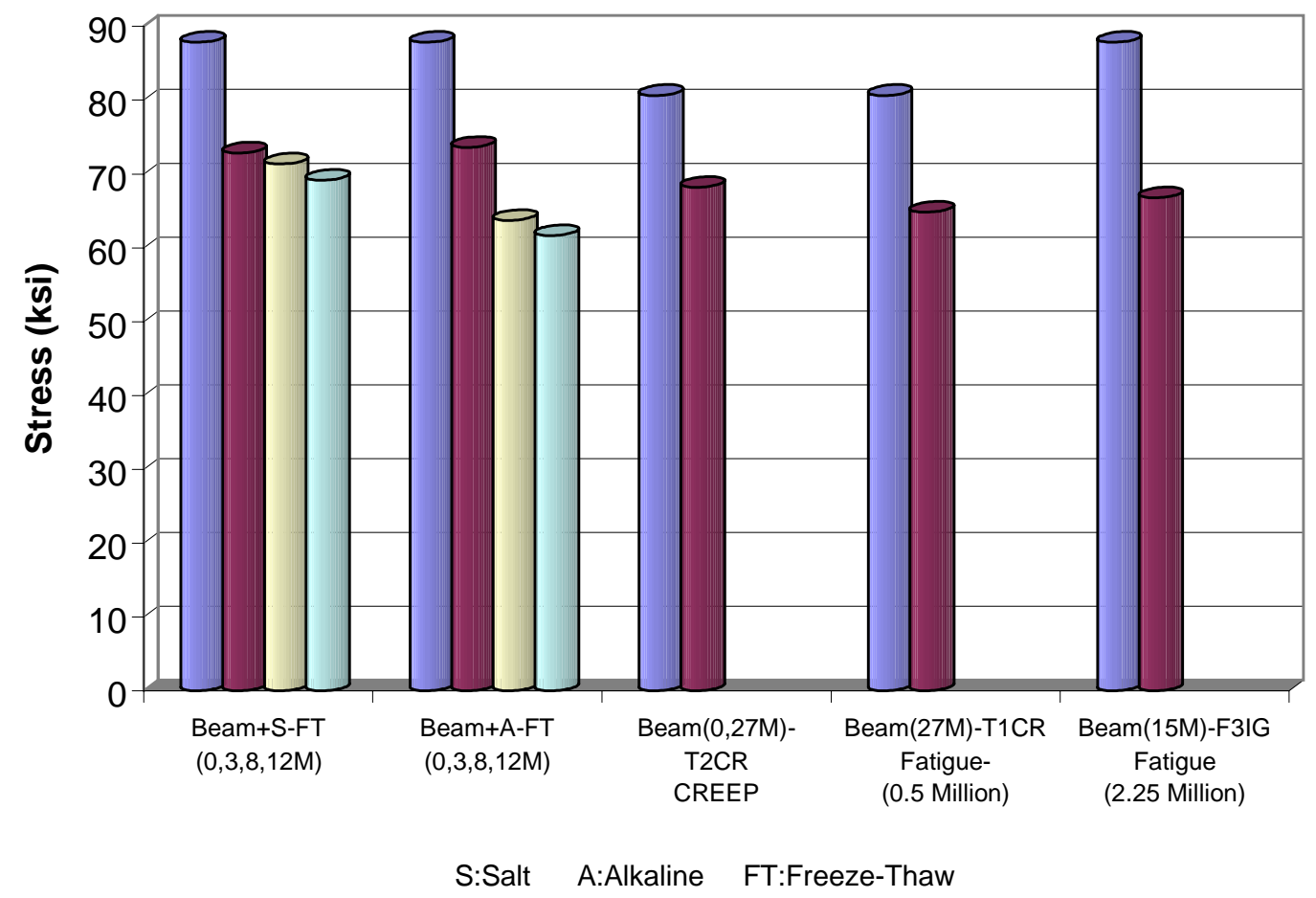

Fig. 10. 11Tensile Strength of Bars Extracted from Concrete Beams Subjected to Creep and Fatigue and Compared with Fig. 9.9. 


\subsection{CONCLUSIONS ON FATIGUE STUDY}

- Beams reinforced with GFRP and designed for compression failure have a better fatigue life as compared to those designed for tension failure. This is due to larger depth of compression block available in the case of beams designed for compression failure.

- Maximum concrete strains at working loads should be preferably well below $750 \times 10^{-6}(25 \%$ of $\varepsilon_{\mathrm{cu}}$ ) for GFRP reinforced concrete beams designed for compression failure due to fatigue considerations. 


\section{CHAPTER 11 \\ SUMMARY AND CONCLUSIONS}

\subsection{SUMMARY}

Strength and stiffness properties of GFRP bars and moisture transport phenomenon into the bars was investigated in this research for various conditioning schemes with and without the application of sustained loads. From this research it is evident that, despite reduction in the properties of GFRP bars over time in the concrete environment, moment capacities of the beams are not affected, provided compression failure philosophy is used. Advantages of compression failure over tension failures was systematically investigated for GFRP reinforced concrete beams under both static and fatigue loads. Reduction in the moment capacity of GFRP reinforced concrete beam designed for tension failure and vulnerability against fatigue loads was clearly demonstrated. Accelerated aging procedure was conservatively calibrated with the natural weathering data to obtain real time weathering. Results of different parameters investigated under this research program are summarized in different sections, and are provided in the following subsections.

\subsubsection{Screening Tests for Selection of Durable Thermoset Resin}

- Bars with urethane modified bisphenol vinylester exhibited the lowest vulnerability to different harsh environments.

- Among unsaturated polyesters, medium reactivity polyesters exhibited least vulnerability to different conditioning schemes. 
- Bars with isocyanurate vinylester resins (IVE) exhibited superior strength and stiffness in unconditioned, salt conditioned and freeze-thaw salt conditioned environments. However, severe strength and stiffness reductions as high as $76.5 \%$ and $31.6 \%$ were observed respectively in alkaline environments.

\subsubsection{Hygrothermal Response of GFRP Bars under Different Conditioning Schemes}

- Moisture absorption of GFRP bars was strongly temperature dependent for tap water, salt water and alkaline conditioning. Increase in moisture content was noted with increasing temperature.

- Alkaline conditioning resulted in maximum moisture absorption as compared to other solutions.

- Maximum moisture content of about $0.6 \%$ by weight or less was observed after 543 days of conditioning under room and freeze-thaw temperatures for tap water, salt water and alkaline solution.

- On an average, alkaline conditioning produced about twice the \%moisture content by weight as compared to tap and salt-water conditioning.

- Higher absorption of alkaline solution in relation to other solutions is an indication of high degradation in tensile strength of GFRP bars under accelerated aging.

\subsubsection{Accelerated and Natural Weathering of GFRP Bars}

\subsubsection{Accelerated Aging Results in Tension}

- For sand-coated bars, maximum strength reductions in salt and alkaline conditioning at room temperature were $18.5 \%$ and $32.2 \%$ respectively, over 15 months duration. Similarly 
maximum strength reductions in salt and alkaline conditioning under freeze-thaw conditioning were $21.9 \%$ and $37.5 \%$ respectively, over 15 months duration.

- For C-bars, maximum strength reductions in salt and alkaline conditioning at room temperature were $24.5 \%$ and $30 \%$ respectively, over 30 months duration. Similarly maximum strength reductions in salt and alkaline conditioning under freeze-thaw conditioning were $51.5 \%$ and $55 \%$ respectively, over 30 months duration.

- For sand-coated bars at room temperature with sustained stress, maximum strength reductions in salt and alkaline conditioning were $22.9 \%$ (8 months of $27 \%$ applied stress) and $49.2 \%$ (6 months of $37 \%$ applied stress) respectively.

- For sand-coated bars under freeze-thaw condition and sustained stress, maximum strength reductions in salt and alkaline conditioning were $25.6 \%$ (12 months of $35 \%$ applied stress) and $82.1 \%$ (12 months of $40 \%$ stress application) respectively. Stress corrosion failures were observed in some bars under this conditioning.

- For C-bars with sustained stress, maximum strength reductions in salt and alkaline conditioning at room temperature were $25.2 \%$ (10 months of $32 \%$ applied stress) and $14.2 \%$ ( 8 months of $25 \%$ stress application) respectively.

- Stress reduction in bars at $150^{\circ} \mathrm{F}$ and immersed in alkaline solution was $84.7 \%$ within 4 months under an applied $40 \%$ sustained stress. One of the bars in this conditioning scheme failed under static fatigue.

- On an average, sand coated International Grating bars showed 5.9\% increase in the tensile stiffness considering different conditioning schemes and duration.

- On an average, tensile stiffness increase was found to be $4.1 \%$ for M1 type and stiffness loss of $4.8 \%$ for $\mathrm{M} 2$ type C-bars under aging. 
- Salt conditioned bars had typical wrap failure followed by vertical splitting and fiber blooming in the mid-zone. Alkaline conditioned bars typically had "necking' failures, where, the outer portion affected by alkalinity would stretch and fail earlier than the core.

- C-bars under salt conditioning generally failed with vertical splitting similar to the unconditioned bars, whereas the alkaline conditioned typically exhibited 'necking' failures.

\subsubsection{Accelerated Aging Results in Compression}

- Length of 2.5D (ASTM D695), where, D is the diameter of the bar, statistically provided least variation in the compression test results and maximum strength.

- Compressive strength of sand coated bars (regular and not conditioned) was about $40 \%$ of the tensile strength.

- Compressive strength of C-bars (regular and not conditioned) was $94 \%$ of the tensile strength.

- Maximum reduction in compressive strength of sand coated bars was found to be $60 \%$ under accelerated aging.

- Maximum compressive strength reduction of C-bars was found to be $39 \%$ for bars immersed in alkaline solution and subjected to freeze-thaw fluctuations. Majority of the bars retained high percent of their original compressive strength under different accelerated conditioning schemes.

- Failure of sand coated bars initiated along the helical wrap used for improving bond strength. Failure plane was found to originate mostly along the helical wrap. Failure modes in sand coated bars also included splitting, crushing and buckling. 
- In C-bars, outer SMC layer separation, fiber splitting and buckling, and vertical splitting were the major modes of failure. Localized crushing was also observed in some cases.

\subsubsection{Calibration of Accelerated and Natural Weathering}

- Calibration charts developed for the non stressed GFRP bars show that one day of chamber conditioning in this study is equivalent to 34 days of natural weathering at Morgantown, West Virginia, or 36 days of U.K. weathering.

- Chamber weathering (freeze-thaw between 12.2 to $120.2^{0} \mathrm{~F}$ or -11 to $49^{0} \mathrm{C}$ ) of 30 months in alkaline conditioning $(\mathrm{pH}=13)$ carried out in these experiments on GFRP bars corresponds to natural weathering of 1020 months (85 years).

- Chamber weathering of 30 months under alkaline conditioning under the selected freezethaw temperature also corresponds to natural weathering of 704 months (58.67 years) of natural weathering with $20 \%$ sustained stress.

\subsubsection{Bond Behavior of GFRP Bars under Accelerated Aging}

- At the end of 15 months of conditioning duration maximum bond strength gains of $10.1 \%$, $14.0 \%, 1.6 \%$ and $5.8 \%$ were observed in tap water at room and freeze-thaw temperature, and salt water at room and freeze-thaw temperature respectively.

- For bundled bars, perimeter of a single bar with an equivalent area can be used for bond strength calculations. Bond strength is proportional to the perimeter of the bundled bars.

- Findings on the bond strength of bundled bars help in arriving at suitable reduction factors on the bond strength equations developed for single GFRP bars with concrete. However, further 
studies are needed to establish accurate reduction factors with respect to bar diameter and concrete cylinder strength.

\subsubsection{Bending Behavior of Concrete Beams Reinforced With GFRP}

- Comparison of failure modes based on experimental results and theoretical computations has indicated better member deformability (analogous to ductility in steel reinforced concrete beams) and gradual member failure in compression as compared to tension failure.

- Deformability factors computed with respect to curvature of $0.005 / \mathrm{d}$ radians/inch gives a unified limit state satisfying deflection, crack-width and energy requirements.

- Deformability factors of about 7 or better were observed for the beams failing in compression.

- Beams under compression failure provide reduction in service load deflections and crackwidths due to higher stiffness and lower FRP bar stress (because of larger area of FRP reinforcement).

- Higher moment of resistance (by involving higher forces in the internal force-equilibrium as compared to a tension failure) was observed in compression failures.

- Deformability factor increases with the addition of compressive reinforcement. For a beam designed for compression failure, moment increase is not proportional to the \% reinforcement increase.

- Experimental results provided excellent theoretical correlation with respect to ultimate moment capacities of about 80 research results of other authors.

- Work conducted in this research on different aspects concrete beam behavior led to ACI specification approval in Oct./Nov. 98 with final approval due by Mid-1999. 


\subsubsection{Shear Behavior of Concrete Beams with GFRP Stirrups}

- Shear failure mechanism in concrete beams reinforced with main FRP bars and FRP stirrups is influenced by the lower modulus of elasticity of FRP bars since shear failure is associated with wider crack widths and delamination of concrete cover.

- Shear resistance from dowel action of longitudinal FRP bars is small and neglected.

- The current ACI equation (11-17), 318-95 for FRP stirrup shear contribution can be modified by suitably limiting stresses in FRP stirrups through average bond strain considerations.

- Average bond strain of 0.006 in./in. for GFRP stirrups provided good theoretical correlation with experimental results from this research as well as those of others.

\subsubsection{Accelerated Aging Behavior of GFRP Reinforced Concrete Beams}

- Under freeze-thaw and salt conditioning, maximum moment capacity loss of $8.7 \%$ and a maximum gain of $11.0 \%$ were observed.

- Under alkaline and freeze-thaw conditioning, maximum moment gain of $17.1 \%$ was observed in all the beams; and no loss in moment capacity was noted.

- Deformability factors showed a reducing trend with increasing duration under salt and alkaline solution immersion under freeze-thaw conditioning.

- Deflections after salt or alkaline immersions and freeze-thaw conditioning did not show any appreciable loss of stiffness.

- Crack-patterns in salt and freeze-thaw conditioned beams were characterized by uniform spacing. Crack-widths of conditioned beams showed small increase (0.001 to $0.002 ")$ in the width. 
- Crack-patterns in alkaline and freeze-thaw conditioned beams were characterized by few cracks and cracking along the longitudinal bar indicated possible bond reduction. However, crack-widths of conditioned beams showed a very small increase in the width (0.001 to $0.002 ")$.

- Strength gain in moment capacity is attributed to an increase in the concrete strength during conditioning and possible statistical variations.

- GFRP bar strength reductions do not necessarily reduce the moment capacity of the beams unless the reductions are such that the failure mode changes from compression to tension.

- Designing for compression failure guards the load factors (which includes safety factors) associated with the design loads, as long as the reduction in strength of GFRP bars do not result in change of failure mode, which can be easily verified through moment equations (7.9) and (7.10).

- Acceleration of aging is higher in GFRP bars directly exposed to alkaline and freeze-thaw conditioning as opposed to the bars embedded in pre-cracked concrete beams and exposed to the same conditioning by a factor of 2 .

- Protection offered by concrete cover may apparently diminish over 100 year service life, when the strength values of GFRP bars asymptotically reach a stabilized value.

\subsubsection{Creep and Fatigue Behavior Of GFRP Reinforced Concrete Beams}

\subsubsection{Creep Behavior of GFRP Reinforced Concrete Beams}

- Concrete creep strain curves of GFRP reinforced concrete beams are similar to those of steel reinforced concrete beams. 
- Creep coefficient is less in the GFRP reinforced concrete beams as compared to those reinforced with steel. This is due to the fact that initial strains and deflections in GFRP reinforced concrete beams are higher as compared to the steel reinforced concrete beams.

- At higher sustained stress level, duration of creep activity was significant up to 175 days, while only 75 days in beams with low sustained stress level.

- Creep coefficient was found to be 1.29 in beams under low sustained loading (20\% of ultimate sustained stress) as compared to 1.54 in beams under high sustained loading (50\% of the ultimate sustained stress). This observation is made from strain values measured on concrete.

- The initial rate of increase in crack-widths was more in beams under low sustained loads as compared than in beams under high sustained loads. This is attributed to the higher rate of decrease in moment of inertia of GFRP reinforced concrete beams soon after the initial crack formation.

- Conservatively, a reduction factor of 0.75 is proposed for the time dependent factor $\xi$, used by ACI Eq. 9-10 for the purpose of approximately estimating long-term deflections resulting from creep and shrinkage.

\subsubsection{Fatigue Study on GFRP Reinforced Concrete Beams}

- Beams reinforced with GFRP and designed for compression failure have a better fatigue life as compared to those designed for tension failure. This is due to larger depth of compression block available in the case of beams designed for compression failure. 
- Maximum concrete strains at working loads should be preferably well below $750 \times 10^{-6}(25 \%$ of $\varepsilon_{\mathrm{cu}}$ ) for GFRP reinforced concrete beams designed for compression failure due to fatigue considerations.

\subsection{CONCLUSIONS}

1) Low viscosity urethane modified vinylester resin (580) is identified as the most suitable resin, from the durability viewpoint, particularly with respect to resistance of glass fibers to alkaline reaction.

2) Moisture uptake at $150^{\circ} \mathrm{F}$ temperature does lead to significant strength reduction and not the stiffness reduction.

3) Based on accelerated test results calibrated with respect to naturally aged results of Litherland et al. (1981), it is safe to conclude that the service life of the FRP bars with 580 is about 60 years as a minimum with $20 \%$ sustained stress on the bar. Concrete cover protection on the GFRP bars does enhance the service life by additional 30 to 60 years.

4) Bond strengths of pull-out specimens did not decrease under salt and tap water immersion, both at room temperature and freeze-thaw variations.

5) Compression failure philosophy has been developed for moment resistance. Serviceability limit states for GFRP reinforced concrete beams were established based on curvature limit of (0.005/d) radians/inch, which unifies limit states such as crack-width and deflection.

6) Average bond strain of 0.006 in./in. for GFRP stirrups provided good theoretical correlation with experimental results from this research as well as those of others. 
7) Deformability factors showed a reducing trend with increasing duration under salt and alkaline solution immersion under freeze-thaw conditioning. However, moment capacities of the beams designed for compression failure were not affected.

8) Conservatively, a reduction factor of 0.75 is proposed for the time dependent factor $\xi$, used by ACI Eq. 9-10 for the purpose of approximately estimating long-term deflections resulting from creep and shrinkage.

9) Maximum concrete strains at working loads should be preferably well below $750 \times 10^{-6}(25 \%$ of $\varepsilon_{\mathrm{cu}}$ ) for GFRP reinforced concrete beams designed for compression failure due to fatigue considerations.

10) Items 5) to 7) lead to the approval of design guidelines for FRP reinforced concrete structures through ACI 440-H.

\subsection{KNOCK-DOWN FACTORS}

Based on the experimental results of this research and also from others $(\mathrm{Wu}, 1990$; Litherland et al., 1981) knock down factors consistent with Eqs. 1.1 and 1.2 from section 1.4 of Chapter 1 are suggested in Table 11.1. The suggested factors reflect an approach to account for strength reduction to the base values of bars for designing GFRP reinforced concrete elements. For example, size effect factor in Table 11.1 can be used to find tensile strength of bigger diameter GFRP bar if no such test data are available. To arrive at physical aging factor, three GFRP bars each, weathered under natural atmospheric exposure for 3, 7 and 10 years by International Grating Inc. were tested in tension as a part of this research. Tensile strength reductions were found to be less than $3 \%$. Hence, physical aging factor for the bar embedded in 
concrete is conservatively taken as 0.9 in Table 11.1 . It is to be noted that the combination of knock-down factors substantially reduce the effectiveness of a GFRP bar. Hence, those factors in Table 11.1 conservatively correspond to about 60 years of service life with $20 \%$ sustained stress (chapter 5) on the GFRP bar (embedded in concrete) and represent stringent knock-down criteria.

Table 11.1 Knock-Down Factors

\begin{tabular}{|c|c|c|c|c|}
\hline Factor & $\begin{array}{l}\text { Notation } \\
\text { (Eqn. 1.1 } \\
\text { and 1.2) } \\
\end{array}$ & Parameter & $\begin{array}{c}\text { Knock-Down } \\
\text { Factor } \\
\text { (Reduction Coeff.) }\end{array}$ & Reference \\
\hline Size Effect Factor & $\mathrm{C}_{\mathrm{f}}$ & Diameter $*$ & $\begin{array}{l}1.00-\# 4 \\
0.85-\# 5 \\
0.70-\# 6 \\
0.65-\# 7 \\
0.60-\# 8\end{array}$ & (Wu, 1990) \\
\hline \multirow{2}{*}{$\begin{array}{l}\text { Moisture Content } \\
\text { Factor }\end{array}$} & \multirow[t]{2}{*}{$\mathrm{C}_{\mathrm{m}}$} & Salt $(\mathrm{pH} \approx 7)$ & $0.9-0.75$ & Chapter 5 \\
\hline & & Alkaline $(\mathrm{pH} \approx 13)$ & $0.8-0.65$ & Chapter 5 \\
\hline $\begin{array}{l}\text { Temperature Factor } \\
\text { (to be used with } C_{m} \\
\text { and } C_{s t} \text { ) }\end{array}$ & $\mathrm{C}_{\mathrm{c}}$ & $\begin{array}{c}\text { Mean Annual } \\
\text { Temperature }\left(\mathrm{T}^{0} \mathrm{~F}\right)^{+} \\
(\text {In combination with } \\
\text { alkalinity and stress) }\end{array}$ & $\begin{array}{c}1\left(\mathrm{~T} \leq 52.5^{0} \mathrm{~F}\right) \\
1-\frac{(T-52.5)}{100} \text { for } \\
\left(52.5 \leq \mathrm{T} \leq 92.5^{0} \mathrm{~F}\right.\end{array}$ & Chapter 5 \\
\hline $\begin{array}{c}\text { Physical Aging } \\
\text { Factor }\end{array}$ & $\mathrm{C}_{\mathrm{a}}$ & & 0.90 & $\begin{array}{c}\text { Sec.11.3, } \\
\text { Chapter } 11\end{array}$ \\
\hline \multirow{2}{*}{$\begin{array}{c}\text { Sustained Load } \\
\text { Factor ( } 20 \% \text { to } \\
\text { 40\%on GFRP bar) }\end{array}$} & \multirow[t]{2}{*}{$\mathrm{C}_{\mathrm{st}}$} & Salt/Water & $0.85-0.70$ & Chapter 5 \\
\hline & & Alkaline & $0.70-0.40$ & Chapter 5 \\
\hline
\end{tabular}

\section{Notes:}

- * size effect factor can be used only for interpolating bigger bar diameter strengths when smaller diameter bar (in this table \#4 is chosen as reference) is tested.

- values in this investigation were correlated for a mean annual temperature of $52.5^{0} \mathrm{~F}$ and hence knock-down factor of 1 is chosen at that temperature.

- + If mean annual temperature is more than $52.5^{\circ} \mathrm{F}$ then a minimum reduction of 0.1 is applied for every $10^{\circ} \mathrm{F}$ increase in the mean annual temperature. This is an empirical approach purely based on strength reductions in GFRP bars under accelerated aging at $69.8^{\circ} \mathrm{F}, 93.68^{\circ} \mathrm{F}$ and $150^{\circ} \mathrm{F}$ in addition to natural weathering results of Litherland et al., 1981, described in chapter 5. Mean annual temperatures above $90^{\circ} \mathrm{F}$ are not expected in any part of the globe. 


\section{REFERENCES}

1. AASHTO LRFD BRIDGE DESIGN SPECIFICATIONS (1998), American Associations of State Highway and Transportation Officials, Second Edition.

2. ACI Special Publication SP-43, Deflection of Concrete Structures

3. ACI Special Publication SP-9, ACI Special Publication SP-9

4. ACI 318-95 (1995), American Concrete Institute Building Code Requirements for Reinforced Concrete, ACI Detroit, MI.

5. ACI Committee Report 209R (1994), ACI Manual of Concrete Practice, Part 1.

6. ACI426R-74, The Shear Strength of Reinforced Concrete Members, pp.11.

7. Canadian Standards Association (1995), Draft Chapter 16: "Fiber Reinforced Structures and Commentary," Canadian Highway Bridge Design, February and October.

8. Composites Institute of the Society of the Plastics Industry Inc. (CISPI) (1992), "Introduction to Composites".

9. Creep and Shrinkage of Concrete (1993), Proceedings of the Fifth International RILEM Symposium, Chapman \& Hill Publication.

10. State-of-Art Report on FRP for Concrete Structures (1998), ACI Committee 440R-98, Manual of Concrete Practice, ACI Farmington Hills, Michigan.

11. Abdalla, H., El-badry, M.M., and Rizkalla, S. (1996), "Deflection of Concrete Slabs Reinforced with Advanced Composite Materials," Edited by Mamdouh El-Badry, ACMBSII, Montreal, Canada pp-201-208, August.

12. Adams, P.B. (1984), "Glass Corrosion, A record of the past? A predictor of the future?," Journal of non-crystalline solids Vol.67, pp.193-205

13. Almusallam, T.H., Alsayed, S.H., and Amjad, M.A. (1996) "Evaluation Of Shear Stresses in Beams Reinforced by GFRP Bars,” Edited by Mamdouh El-Badry, ACMBS-II, Montreal, Canada pp165-172, August. 
14. Almusallam, T.H., Alsayed, S.H., and Amjad, M.A., (1996) "Evaluation Of Service Load Deflection for Beams Reinforced by GFRP Bars," Edited by Mamdouh El-Badry, ACMBS-II, Montreal, Canada pp173-179, August.

15. Al-Zahrani, M.M., Nanni, A., Al-Dulaijan, S.U., and Bakis, C.E. (1996), "Bond of FRP to Concrete in Reinforcement Rods With Axisymmetric Deformations," Edited by Mamdouh El-Badry, ACMBS-II, Montreal, pp. 853-860, August.

16. Arockiasamy, M., Amer, A., Shahawy, M., and Chidambaram, S. (1996), "Long-Term Behaviour of Concrete Beams Reinforced With CFRP Bars Under Sustained Loads," Edited by Mamdouh El-Badry, ACMBS-II, Montreal, pp. 673-680, August.

17. Benmokrane, B., Masmoudi, R. (1996), "FRP C-Bar as Reinforcing Rod for Concrete Structures," Edited by Mamdouh El-Badry, ACMBS-II, Montreal, Canada pp181-188, August.

18. Bentz, D.P., Garboczi, E.J. (1996), "Multi-Scale Models of the Diffusivity of Concrete," Edited by Ken P. Chong, Materials for the New Millenium, Proceedings of the Fourth Materials Engineering Conference, Washington, D.C., pp.574-582, November.

19. Brown and Bartholomew, C.V. (1996), "Long-Term Deflections of GFRP-Reinforced Concrete Beams," ICCI'96, Proc. of First International Conference on Composites in Infrastructure, Tuscon, AZ, pp.389-400, January.

20. Cardon, A.H., Bruggemah, M, Yan, Q., and Harou-Kouka (1996), "Durability Analysis of Polymer Matrix Composites," Edited by Mamdouh El-Badry, ACMBS-II, Montreal, Canada pp 657-664, August.

21. Cheikh Al, A. And Murat, M. (1988), "Kinetics of Non-Congruent Dissolution of E-Glass Fiber in Saturated Calcium Hydroxide Solution," Cement and Concrete Research, Vol. 18, pp.943-950

22. Crasto, R.Y., Kim, and Fowler, C. (1996), "Rehabilitation of Concrete Bridge Beams with Externally-Bonded Composite Plates," Part I, ICCI'96, Proc. of First International Conference on Composites in Infrastructure, Tuscon, AZ, pp.857-869, January. 
23. Doremus, R.H., Mehrotra, Y., Lanford, W.A. and Burman, C. (1983), "Reaction of Water with Glass: Influence of a Transformed Surface Layer," Journal of Material Science, Vol.18, pp.612-622

24. Ehsani, Saadatmeanesh, H., and Tao, S. (1996), "Bond Behavior and Design Recommendations for Fiberglass Reinforcing Bars," ICCI'96, Proc. of First International Conference on Composites in Infrastructure, Tuscon, AZ, pp.466-480, January.

25. Faza S.S. and GangaRao H.V.S. (1992), "Pre and Post cracking Deflection Behavior of Concrete Beams Reinforced with Fiber-reinforced Plastic Rebars," ACMBS-I Conference, pp.151-160.

26. Faza, S.S., and GangaRao, H.V.S. (1991), "Behavior of Fiber Reinforced Plastic Rebar Under Bending," ASCE Structural Congress Abstracts, ASCE, Edited by Iyer, S.L., pp. 262.

27. Fyfe, E.R., Watson, R.J.,and Watson, S.C. (1996), "Long Term Durability of Composites Based on Field Performance and Laboratory Testing," ICCI'96, Proc. of First International Conference on Composites in Infrastructure, Tuscon, AZ, pp.982-995, January,.

28. GangaRao, H.V.S. and Faza, S.S. (1992), "Bending and Bond Behavior and Design of Concrete Beams Reinforced with Fiber Reinforced Plastic Rebars," CFC-92-142, Submitted to WVDOH, Charleston, WV-23505.

29. GangaRao, H.V.S. and P.V. Vijay (1997), "Aging of Structural Composites under Varying Environmental Conditions," Non-Metallic(FRP) Reinforcement for Concrete Structures, Vol.2, Proceedings of the Third International Symposium, Sapporo, Japan, October.

30. GangaRao, H.V.S. and P.V. Vijay (1997), "Design of Concrete Members Reinforced with GFRP Bars," Non-Metallic(FRP) Reinforcement for Concrete Structures, Vol.2, Proceedings of the Third International Symposium, Sapporo, Japan, October.

31. GangaRao, H.V.S. and P.V.Vijay (1998), "Bending Behavior of Concrete Beams Wrapped with Carbon Fabric," Journal of Structural Engineering, vol. 124, No.1, ASCE, pp.3-10, January. 
32. GangaRao, H.V.S., Burdine, E., and Vijay P.V. (1998), "Accelerated Aging Response of Carbon Composites under Tension and Bending," ISOPE-98, Montreal, Canada, , May.

33. GangaRao, H.V.S., Vijay P.V. and Burdine, E. (1988), "Durability of steel beams strengthened with CFRP plates", CDCC '98, Sherbrooke, Canada, August.

34. GangaRao, H.V.S., Vijay P.V. and Dutta, P.K (1995 $\left.{ }^{1}\right)$,, "Durability of Composites in Infrastructure," CORROSION-95, Paper No. 550, The NACE International Annual Conference and Corrosion Show, March.

35. GangaRao, H.V.S., Vijay, P.V. and Derek Altizer. $\left(1995^{2}\right)$, "Durability of Glass Composites Under Alkaline and Prestress Environment", Proc. Of International Conference on Fiber Reinforced Structural Plastics in Civil engg., IIT, Madras, PP.371-378, December.

36. Geankopolis, C.J. (1972), Mass Transport Phenomenon, Ohio State University Book Store Publicaions.

37. Ghali, A. and Favre, R. (1986), Concrete Structures, Chapman and Hall Publication.

38. Gomez, J., and Casto, B. (1996), "Freeze/Thaw Durability of Composite Materials," ICCI'96, Proc. of First International Conference on Composites in Infrastructure, Tuscon, AZ, pp.947955, January.

39. Gurjat, A., Tang, T., Zollinger, D., and Slavick, K. (1996), “Age, Deformation, and Temperature Effects of Viscoelastic Materials Under Large Deformations,” Edited by Ken P. Chong, Materials for the New Millenium, Proceedings of the Fourth Materials Engineering Conference, Washington, D.C., pp.1398-1407, November.

40. Haskins, J.H. (1989), Thermal Aging, SAMPE Journal, Vol. 25, No.2, pp. 29-31, MarchApril.

41. Hosny, O. El-Nawawy, E. I. Mostafa, Khalil, V. (1996), "Behaviour of Concrete Slabs Reinforced with Fiber-Glass Bars," The First Middle East Workshop on Structural Composites, Egypt, pp.267-280, June.

42. Hundley, A., and Dolan, C. (1996), "Non-Accelerated Creep-Rupture of Fiber-ReinforcedPlastics in a Concrete Environment," Edited by Ken P. Chong, Materials for the New 
Millenium, Proceedings of the Fourth Materials Engineering Conference, Washington, D.C., pp.519-526, November.

43. Jaeger, L.G., Tadros, G., and Mufti, A.A. (1995), "Balanced section, ductility and deformability in concrete with FRP reinforcement," Research Report presented in Joint US Canadian Meeting at West Virginia University, June 12.

44. Janas, V.F. and McCullough, R.C. (1987), The Effects of Physical Aging on the Viscoelastic Material of a Thermoset Polyester," Composite Science and Technology, Elsevier Applied Science Applied Science Publishers Ltd., England, pp.99-118.

45. Larralde, J., Mueller-Rochholz, J., Schneider, T., and Willmann, J. (1988), "Bond Strength of Steel, AFRP and GFRP bars in Concrete," ICCI '98, Edited by- Eshani, M.R., Saadatmanesh, pp92-101, January.

46. Litherland, K.L., Oakley, D.R. and Proctor, B.A. (1981), "The Use of Accelerated Ageing Procedures to Predict the Long Term Strength of GRC Composites," Cement and Concrete Research, Vol.11, pp.455-466.

47. Lundy, J.R., and Kachlakev, D.I. (1998),"Bond Strength Study of Hollow Composite Rebars With Different Micro Structure," ICCI 98, Edited by- Eshani, M.R., Saadatmanesh, pp-1-15, January.

48. Lundy, J.R., Kachlakev, D.I (1996), "Evaluation of Bond characteristics of Steel and GlassFiber Reinforcing Bars," Edited by Ken P. Chong, Materials for the New Millenium, Proceedings of the Fourth Materials Engineering Conference, Washington, D.C., pp.638-647, November.

49. Mallick, P.K. (1993), Fiber Reinforced Composite Materials, Manufacturing and Design, Marcel Dekker Inc., NY.

50. Malvar., Warren, G.E., and Inaba, C.M. (1996), "Composite Application in the Navy Waterfront Infrastructure," Edited by Ken P. Chong, Materials for the New Millenium, Proceedings of the Fourth Materials Engineering Conference, Washington, D.C., 1179-1188, November. 
51. Marshall. Jr., O.S., and Busel, J.P. (1996), "Composite Repair/Upgrade of Concrete Structures," Edited by Ken P. Chong, Materials for the New Millenium, Proceedings of the Fourth Materials Engineering Conference, Washington, D.C., pp.932-938, November.

52. Martys, N.S., and Ferraris, C., Nist (1996), "Absorption of Water in Mortar and Concrete," Edited by Ken P. Chong, Materials for the New Millenium, Proceedings of the Fourth Materials Engineering Conference, Washington, D.C., pp.1129-1138, November.

53. Maruyama, K., Zhao, W. (1996), "Size Effect in Shear Behavior of FRP Reinforced Concrete Beams (1996)," Edited by Mamdouh El-Badry, ACMBS-II, Montreal, Canada pp-227-236, August.

54. Masmoudi., Benmokrane, B., and Chaallal, O. (1996), "Cracking Behavior of Concrete Beams Reinforced with FRP Rebars," ICCI'96, Proc. of First International Conference on Composites in Infrastructure, Tuscon, AZ, pp. 374-388, January.

55. Matthys and Taerwe, L. (1996), "Behavior of Concrete Slabs Reinforced with FRP Grids Under Service and Ultimate Loading," ICCI'96, Proc. of First International Conference on Composites in Infrastructure, Tuscon, AZ, pp.359-373, January.

56. Mecklenburg, N.F., Tumosa, C.S. (1996), “The Relationship of Externally Applied Stresses to Environmentally Induced Stresses," ICCI'96, Proc. of First International Conference on Composites in Infrastructure, Tuscon, AZ, pp.956-971, January.

57. Mokuwa, M. (1996), "Molecular Structure and Properties of Thermosetting Resins Used in Advanced Composite Materials," Edited by Mamdouh El-Badry, ACMBS-II, Montreal, Canada pp83-91, August.

58. Mufti, A.A., Newhook, J.P., and Tadros, G. (1996), "Deformability Versus Ductility in Concrete Beams with Frp Reinforcement," Edited by Mamdouh El-Badry, ACMBS-II, Montreal, Canada pp189-200, August.

59. Naaman, A.E., and Jeong, S.M. (1996), "Structural Ductility of Concrete Beams Prestressed with FRP Tendons," Non -metallic (FRP) Reinforcement for Concrete Structures, Proceedings of the Second International RILEM Symposium (FRPRCS-2). 
60. Nawy, E.G. (1990), "Reinforced Concrete: Fundamental Approach," Prentice Hall Publications.

61. Neville, A.M. (1971), Hardened Concrete: Physical and Mechanical Aspects. American Concrete Institute, 143-173.

62. Ortiago, J.A.R. (1996), "FRP Applications in Geotechnical Engineering," Edited by Ken P. Chong, Materials for the New Millenium, Proceedings of the Fourth Materials Engineering Conference, Washington, D.C., pp.535-544, November.

63. Park and Paulay (1975), "Reinforced Concrete Structures," John Wiley and Sons.

64. Porter, M.L., Barnes, B.A. (1998), "Accelerated Durability of FRP Reinforcement for Concrete Structures," CDCC-98, Durability of Fiber Reinforced Polymer (FRP) Composites for Construction, pp.191-201.

65. Proctor B.A. (1985), "The long-term Behavior of Glass Fiber Reinforced Composites," Pilkington Publishers.

66. Proctor, B.A., Oakley, D.R., and Litherland K.L. (1982), "Development in the assessment and performance of GRC over 10 years," Composites, pp.173-179, April.

67. Rahman, A.H., Adimi, M.R., and Benmokrane, B. (1996), "Fatigue Behavior of FRP Reinforcements Encased in Concrete," Edited by Mamdouh El-Badry, ACMBS-II, Montreal, pp. 691-698, August.

68. Rahman, A.H., Kingsley, C.Y. and Crimi, J. (1995), "Behavior of FRP Grid Reinforcement for Concrete Under Sustained Load," RILEM Proceedings 29, pp.90-99.

69. Rao, R.M.G.K. and Balasubramanian, N and Chanda M. (1981), "Factors affecting moisture absorption in polymer composites," Part-II, Influence of External Factors, Environment Effects on Composite Materials, Vol. III, Edited by George Springer, Technomic Publishing Company, pp. 89-95.

70. Razaqpur and Ali, A.M. (1996), "A New Concept for Achieving Ductility in FRP-Reinforced Concrete," ICCI'96, Proc. of First International Conference on Composites in Infrastructure, Tuscon, AZ, pp.401-413, January. 
71. Rostasy, F.S. (1996), "FRP: The European Perspective," ICCI'96, Fiber Composites in Infrastructure, Edited by Saadatmanesh H. and Ehsani M.R., pp. 12-20

72. Roll, R.D. (1991), "Use of GFRP Rebar in Concrete Structures," Advanced Composite Materials in Civil Engineering Structures, Proceedings of the Society of Specialty Conference, Edited by Iyer, S.L., ASCE, NY., January.

73. Schutter, G.De., Taerwe, L., and Matthys, S. (1996), "Influence of Transverse Thermal Expansion of FRP Reinforcement on the critical Concrete Cover," Edited by Mamdouh ElBadry, ACMBS-II, Montreal, Canada pp. 665-672, August.

74. Seible, F. and Karbhari, V. (1996), "Advanced Composites for Civil Engineering Applications in the U.S.," Proceedings of the First International Conference on Composites in Infrastructure, ICCI'96, Tuscon, Arizona, January, pp.21-37.

75. Sheheta, E., Morohy, R., and Rizkalla, S. (1998), "Use of FRP as Shear Reinforcement for Concrete Structures," ICCI 98, Edited by- Eshani, M.R., Saadatmanesh, pp-300-315, January.

76. Shen, C-H and Springer, G.S. (1981), "Moisture Absorption and Desorption of Composite Materials," Environment Effects on Composite Materials, Vol. I, Edited by George Springer, Technomic Publishing Company, pp. 15-33.

77. Sonobe, Y., Fukuyama, H. Okamoto, T,, Kani, N., Kimura, K., Kobayashi, K,. Masuda, Y., Matsuzaki, Y., Nochizuki, S., Nagasaka, T,. Shimizu, A., Tanano, H., Tanigaki, M, Teshigawara, M. (1997), "Design Guidelines of FRP Reinforced Concrete Building Structures," Journal of Composites for Construction, pp.90-115, Aug.

78. Springer (Editor). G.S. (1981), "Environmental Effects on Composite Materials," Vol. I, Vol. II, Vol. III, Technomic Publishing Company Inc.

79. Srtuble, L., and Szecsy, R. (1996), "Rheology of Fresh Concrete," Edited by Ken P. Chong, Materials for the New Millenium, Proceedings of the Fourth Materials Engineering Conference, Washington, D.C., pp.1121-1128, November.

80. Szekeres, A., and Robert A.Heller. (1996), "Heat and Moisture Absorption Effects in Composites," Edited by Ken P. Chong, Materials for the New Millenium, Proceedings of the 
Fourth Materials Engineering Conference, Washington, D.C., Theory and Experiments, pp.63-72, November.

81. Takewaka, K., and Khin, M. (1996), "Deterioration and Stress-Rupture of FRP Rods in Alkaline Solution Simulating as Concrete Environment," Edited by Mamdouh El-Badry, ACMBS-II, Montreal, Canada pp 649 - 656, August.

82. Taylor, H.J.P. (1969), "Investigation of dowel shear forces carried by the tensile steel in R.C. beams," Cement and Concrete Association, London, TRA 431, pp. 24.

83. Tepfers, R., (1998), "Bond Between FRP-Bars and Concrete," Chalmers University of Technology (Building Technology), Publication No 98:3 Work No:22.

84. Themelis, N.J. (1995), Transport and Chemical Phenomenon, Gordon and Beach Publishers.

85. Tighiouart, B., Benmokrane, B., and Gao, D. (1998), "Investigation on the Bond of Fiber Reinforced polymer (FRP) Rebars in Concrete," ICCI 98, Edited by- Eshani, M.R., Saadatmanesh, pp-102-111, January.

86. Umoto, T., and Ohga, H. (1996), "Performance of Fiber Reinforced Plastics for Concrete Reinforcement," pp-125-132, Edited by Mamdouh El-Badry, ACMBS-II, Montreal, Canada, August.

87. Vicki L. B. And Charles L.B. (1996), “Long-term deflections of GFRP-Reinforced Concrete Beams," Proceedings of ICCI, pp. 389-400.

88. Vijay P.V. and GangaRao, H.V.S. (1998), "Accelerated aging and durability of GFRP bars," CDCC '98, Sherbrooke, Canada, August.

89. Vijay P.V. and GangaRao, H.V.S. (1998), "Creep behavior of concrete beams reinforced with GFRP bars," CDCC '98, to be held in August, Sherbrooke, Canada.

90. Vijay P.V., Kumar S.V., and GangaRao, H.V.S. (1996), "Shear and Ductility Behavior of Concrete Beams Reinforced with GFRP Bars", ACMBS-II Conference, Montreal, Canada, August.

91. Vijay, P.V. and GangaRao, H.V.S. (1996), "A Unified Limit State Approach Using Deformability Factors in Concrete Beams Reinforced with GFRP Bars", Materials for the New Millennium, 4th Material Conference, ASCE, Vol.1, Washington D.C., 657-665. 
92. Vijay, P.V. (1995), "Bending Behavior of Concrete Beams Wrapped with Carbon Fabric," MSCE thesis, West Virginia University.

93. Vijay, P.V., Kumar, S.V., GangaRao, H.V.S. (1995), "Design of Carbon Sheet Wrapped Concrete Beam", FORCA TOW SHEET TECHNICAL MANUAL, Tonen Corporation, Japan, pp.4.107-4.126.

94. Wei Yang., Kejin Wang. (1996), and Surendra P. Shah., "Prediction of Concrete Cracking Under Coupled Shrinkage and Creep Conditions," Edited by Ken P. Chong, Materials for the New Millenium, Proceedings of the Fourth Materials Engineering Conference, Washington, D.C., 564-573, November.

95. Wu Wei-Pin (1990), “Thermomechanical Properties of Fiber Reinforced Plastic (FRP) Bars," Ph.D Dissertation, WVU.

96. Yamasaki, Y., Masuda, Y., Tarano, H. and Shimizu, A. (1993), Fundamental Properties of Continuous Fiber Bars, ACI SP 138-43, pp.715-730

97. Zahid S. (1994), Non-Destructive Testing of FRP Bars and Reinforced Concrete using Acoustic Emission and Radar, Problem-Report, Submitted to West Virginia University. 


\section{APPENDIX-A \\ THEORETICAL COMPARISON OF BENDING MOMENT CAPACITIES AND \\ FAILURE MODES}

\section{A. 1 INTRODUCTION}

In this section, theoretical comparison is provided for experimental moment capacities of concrete beams reinforced with GFRP bars. Beam bending test results obtained at WVU and through other research publications have been compared with theoretical values in Table A.1. Computations are carried out for tension and compression failure types. Theoretically, (c/d) < $(\mathrm{c} / \mathrm{d})_{\text {balanced }}$ results in tension failure and $(\mathrm{c} / \mathrm{d})>(\mathrm{c} / \mathrm{d})_{\text {balanced }}$ results in compression failure. (c/d) approach for delineating tension and compression failure modes is discussed in chapter 7 , section 7.8.2.2. Actual failure mode is also shown in Table A.1. To indicate the experimental (actual) failure mode, following notation has been used in Table A.1: T-Tension, C-Compression, SShear, B-Bending, and R-Rupture of Bars (Tension).

\section{A.2 THEORETICAL COMPARISONS}

As seen from Table A.1, good correlation is obtained between theoretical and experimental values. Theoretical comparisons are also shown for beams reinforced with FRP bars made of aramid and carbon fibers, by suitably representing the bar properties as shown in Table A.1 (reference 4). In case of compression failure, most of the experimental to theoretical values exceeded 1.0. In all compression failure computations, concrete strain $\varepsilon_{\mathrm{cu}}=0.003$ is used. Equations A.1 to A.4 have been used for theoretical comparisons. 


\section{$\underline{\text { Tension Failure }}$}

$$
\begin{aligned}
& M_{n}=A_{f} f_{f}\left(d-\frac{a}{2}\right) \\
& a=\left(\frac{A_{f} f_{f}}{0.85 f_{c}^{\prime} b}\right)
\end{aligned}
$$

Compression Failure

$$
\begin{aligned}
& M_{n}=0.85 f_{c}^{\prime} a b\left(d-\frac{a}{2}\right) \\
& \left(\frac{0.85 f_{c}^{\prime} b}{A_{f} E_{f} \varepsilon_{c u}}\right) a^{2}+a-\beta_{1} d=0
\end{aligned}
$$

\section{A.3 NOTES ON TABLE A-1 AND REFERENCES}

Reference 1: Some of the poor comparison is due to the use of smooth bars with low bond strengths or a failure mode other than or in combination with bending.

Reference 2: Poor comparison in some cases is due to the use of bars with low bond strength or the use of smooth bars or failure mode combinations as suggested by the authors.

Reference 3: It is stated that most of these beams failed in compression and actual failure modes have not been individually specified.

Reference 4: GR-Fiber wound Glass bars, AK-Sand braided Aramid bars, CK-Sand braided carbon bars, CR-Fiber wound Carbon bars.

Reference 6: Beam comp-75, has shown high moment because of $75 \%$ compression reinforcement. It is to be noted that compressive reinforcement is not accounted in any of the calculations. 
Table A.1 Theoretical Comparison of Moment Capacities and Failure Modes

\begin{tabular}{|c|c|c|c|c|c|c|c|c|c|c|c|c|c|c|c|c|c|c|c|}
\hline \multirow{2}{*}{\begin{tabular}{|l|} 
Refe- \\
rence \\
\end{tabular}} & \multirow[t]{2}{*}{ Beam } & & \multirow[t]{2}{*}{$f_{c}^{\prime}$} & \multirow[t]{2}{*}{$B_{1}$} & \multirow[t]{2}{*}{ b } & \multirow[t]{2}{*}{ d } & \multirow[t]{2}{*}{$1 / d$} & \multirow[t]{2}{*}{$A_{f}$} & \multirow[t]{2}{*}{$E_{f}$} & \multirow[t]{2}{*}{$f_{f}$} & \multirow[t]{2}{*}{$(\mathbf{c} / \mathbf{d})_{\text {bal }}$} & \multirow{2}{*}{\begin{tabular}{|l|} 
Moment \\
(expt.) \\
\end{tabular}} & \multicolumn{3}{|c|}{ Tension Failure Calc. } & \multicolumn{3}{|c|}{ Comp. Failure Calc. } & \multirow{2}{*}{\begin{tabular}{|l|} 
Actual \\
Failure \\
\end{tabular}} \\
\hline & & & & & & & & & & & & & c/d & $\mathbf{M}_{\text {th }}$ & Mexpt & c/d & $\mathbf{M}_{\text {th }}$ & Mexpt & \\
\hline & & & & & & & & & $\left(x 10^{6}\right.$ & & & & & & $M_{\mathrm{th}}$ & & & $M_{\text {th }}$ & \\
\hline & & & (ksi) & & (in) & (in) & & $\left(\mathrm{in}^{2}\right)$ & psi) & (ksi) & & (k-ft) & & (k-ft) & & & (k-ft) & & \\
\hline & & & & & & & & & & & & & & & & & & & \\
\hline 1 & A2 & & 4.20 & 0.84 & 6.00 & 10.81 & 9.99 & 0.331 & 6.92 & 130.00 & 0.14 & 27.75 & 0.22 & 35.22 & 0.79 & 0.17 & 27.86 & 1.00 & $\mathrm{~T}$ \\
\hline 1 & A3 & & 4.20 & 0.84 & 6.00 & 10.81 & 9.99 & 0.331 & 6.92 & 90.00 & 0.19 & 24.67 & 0.15 & 25.15 & 0.98 & 0.17 & 27.86 & 0.89 & $\mathrm{~T}$ \\
\hline 1 & AVH4 & & 10.00 & 0.65 & 6.00 & 10.75 & 10.05 & 0.295 & 6.92 & 130.00 & 0.14 & 31.50 & 0.11 & 33.11 & 0.95 & 0.12 & 37.61[ & 0.84 & $\mid \mathrm{T}$ \\
\hline 1 & B5 & & 4.20 & 0.84 & 6.00 & 10.75 & 10.05 & 0.393 & 7.00 & 80.00 & 0.21 & 27.75 & 0.16 & 26.23 & 1.06 & 0.19 & $29.75 \mid[$ & 0.93 & $B / S$ \\
\hline 1 & B6 & & 4.20 & 0.84 & 6.00 & 10.75 & 10.05 & 0.393 & 7.00 & 80.00 & 0.21 & 24.67 & 0.16 & 26.23 & 0.94 & 0.19 & 29.75 & 0.83 & $B / S$ \\
\hline 1 & C1 & & 4.20 & 0.84 & 6.00 & 10.56 & 10.22 & 1.203 & 7.35 & 86.00 & 0.20 & 16.50 & 0.54 & 70.25 & 0.23 & 0.31 & 45.14 & 0.37 & C \\
\hline 1 & C4 & & 4.20 & 0.84 & 6.00 & 10.50 & 10.29 & 1.571 & 6.61 & 80.00 & 0.20 & 40.00 & 0.67 & 79.26 & 0.50 & 0.33 & 47.22 & 0.85 & $\mathrm{C} / \mathrm{S}$ \\
\hline 1 & C8 & & 5.00 & 0.80 & 6.00 & 10.56 & 10.22 & 1.203 & 7.35 & 80.00 & 0.22 & 41.63 & 0.45 & 69.58 & 0.60 & 0.29 & 49.30 & 0.84 & C \\
\hline 1 & C-H5 & & 6.50 & 0.73 & 6.00 & 10.50 & 10.29 & 1.571 & 6.61 & 80.00 & 0.20 & 54.75 & 0.50 & 90.14 & 0.61 & 0.30 & 58.18 & 0.94 & $\mathrm{C} / \mathrm{S}$ \\
\hline 1 & CC & & 7.50 & 0.68 & 6.00 & 10.50 & 10.29 & 1.571 & 6.61 & 80.00 & 0.20 & 60.00 & 0.46 & 92.78 & 0.65 & 0.29 & 61.37 & 0.98 & $\mathrm{C} / \mathrm{S}$ \\
\hline 1 & $\mathrm{DH} 1$ & & 6.50 & 0.73 & 6.00 & 10.81 & 9.99 & 0.221 & 6.92 & 130.00 & 0.14 & 18.00 & 0.11 & 24.85 & 0.72 & 0.12 & 27.80 & 0.65 & $\mathrm{~T}$ \\
\hline 1 & DH6 & & 6.50 & 0.73 & 6.00 & 10.81 & 9.99 & 0.221 & 6.92 & 130.00 & 0.14 & 16.50 & 0.11 & 24.85 & 0.66 & 0.12 & 27.80 & 0.59 & $\mathrm{~T}$ \\
\hline 1 & DA & & 7.50 & 0.68 & 6.00 & 10.81 & 9.99 & 0.221 & 6.92 & 130.00 & 0.14 & 27.75 & 0.10 & 24.99 & \begin{tabular}{|c|}
1.11 \\
\end{tabular} & 0.12 & 29.02 & 0.96 & $B / S$ \\
\hline 1 & EH2 & & 6.50 & 0.73 & 6.00 & 10.75 & 10.05 & 0.589 & 7.00 & 107.00 & 0.16 & 31.13 & 0.24 & 51.49 & 0.60 & 0.20 & 42.18| & 0.74 & C \\
\hline 1 & EH4 & & 6.50 & 0.73 & 6.00 & 10.60 & 10.19 & 0.552 & 6.92 & 130.00 & 0.14 & 37.50 & 0.28 & 56.96 & \begin{tabular}{|c|}
0.66 \\
\end{tabular} & 0.19 & 39.98 & |0.94 & $T / C$ \\
\hline 1 & ED & & 7.50 & 0.68 & 6.00 & 10.75 & 10.05 & 0.589 & 7.00 & 107.00 & 0.16 & 40.50 & 0.23 & 52.15 & 0.78 & 0.19 & 44.22 & 0.92 & $\mathrm{~T} / \mathrm{S}$ \\
\hline 1 & EE & & 7.50 & 0.68 & 6.00 & 10.70 & 10.09 & 0.552 & 6.92 & 130.00 & 0.14 & 40.50 & 0.26 & 58.42 & 0.69 & 0.18 & 42.52 & 0.95 & $T / S$ \\
\hline 1 & EF & & 7.50 & 0.68 & 6.00 & 10.75 & 10.05 & 0.589 & 7.00 & 107.00 & 0.16 & 34.50 & 0.23 & 52.15 & 0.66 & 0.19 & 44.22 & 0.78 & $T / S$ \\
\hline 1 & EVH1 & & 10.00 & 0.65 & 6.00 & 10.75 & 10.05 & 0.589 & 7.00 & 107.00 & 0.16 & 40.95 & 0.18 & 53.24 & 0.77 & 0.17 & 51.21 & 0.80 & $\mathrm{~T} / \mathrm{C}$ \\
\hline 1 & EVH2 & & 10.00 & 0.65 & 6.00 & 10.75 & 10.05 & 0.589 & 7.00 & \begin{tabular}{|l|l|}
107.00 \\
\end{tabular} & 0.16 & 43.50 & 0.18 & 53.24 & 0.82 & 0.17 & 51.21 & 0.85 & $T$ \\
\hline & & & & & & & & & & & & & & & & & & & \\
\hline 2 & & 1 & 4.81 & 0.81 & 3.50 & 6.50 & 11.08 & 0.045 & 7.30 & 154.80 & 0.12 & 3.90 & 0.09 & 3.65 & 1.07 & 0.11 & 4.22[ & 0.92 & C \\
\hline 2 & & 2 & 4.10 & 0.85 & 3.50 & 6.50 & 11.08 & 0.045 & 7.30 & 154.80 & 0.12 & 2.95 & 0.10 & 3.63 & 0.81 & 0.11 & $3.95 \mid$ & 0.75 & C \\
\hline 2 & & 5 & 5.03 & 0.80 & 3.50 & 6.30 & 11.43 & 0.057 & 7.30 & 154.80 & 0.12 & 4.20 & 0.12 & 4.38 & 0.96 & 0.12 & 4.53 & 0.93 & C \\
\hline 2 & & 6 & 5.03 & 0.80 & 3.50 & 6.30 & 11.43 & 0.057 & 7.30 & 154.80 & 0.12 & 4.20 & 0.12 & 4.38 & 0.96 & 0.12 & 4.53 & 0.93 & C \\
\hline 2 & & 9 & 4.74 & 0.81 & 3.50 & 6.25 & 11.52 & 0.068 & 7.30 & 154.80 & 0.12 & 5.00 & 0.15 & 5.15 & 0.97 & 0.13 & 4.73 & 1.06 & C \\
\hline 2 & & 10 & 4.53 & 0.82 & 3.50 & 6.25 & 11.52 & 0.068 & 7.30 & 154.80 & 0.12 & 2.90 & 0.15 & 5.13 & 0.57 & 0.14 & 4.64 & 0.62 & C \\
\hline
\end{tabular}


Table A.1 Theoretical Comparison of Moment Capacities and Failure Modes (Contd.)

\begin{tabular}{|c|c|c|c|c|c|c|c|c|c|c|c|c|c|c|c|c|c|c|}
\hline \multirow{2}{*}{\begin{tabular}{|l|} 
Refe- \\
rence
\end{tabular}} & \multirow[t]{2}{*}{ Beam } & \multirow[t]{2}{*}{$f_{c}{ }^{\prime}$} & \multirow[t]{2}{*}{$B_{1}$} & \multirow[t]{2}{*}{ b } & \multirow[t]{2}{*}{ d } & \multirow[t]{2}{*}{ I/d } & \multirow[t]{2}{*}{$A_{f}$} & \multirow[t]{2}{*}{$E_{f}$} & \multirow[t]{2}{*}{$\mathbf{f}_{f}$} & \multirow[t]{2}{*}{$(c / d)_{\text {bal }}$} & \multirow{2}{*}{\begin{tabular}{|l|} 
Moment \\
(expt.) \\
\end{tabular}} & \multicolumn{3}{|c|}{ Tension Failure Calc. } & \multicolumn{3}{|c|}{ Comp. Failure Calc. } & \multirow{2}{*}{\begin{tabular}{|l|} 
Actual \\
Failure \\
\end{tabular}} \\
\hline & & & & & & & & & & & & c/d & $\mathbf{M}_{\text {th }}$ & $\underline{M}_{\text {expt }}$ & c/d & $\mathbf{M}_{\text {th }}$ & $\underline{M}_{\text {expt }}$ & \\
\hline & & & & & & & & $\left(x 10^{6}\right.$ & & & & & & $\mathbf{M}_{\mathrm{th}}$ & & & $M_{\text {th }}$ & \\
\hline & & (ksi) & & (in) & (in) & & $\left(\mathrm{in}^{2}\right)$ & psi) & (ksi) & & (k-ft) & & (k-ft) & & & (k-ft) & & \\
\hline 2 & 13 & 4.49 & 0.83 & 3.50 & 6.29 & 11.45 & 0.079 & 7.30 & 154.80 & 0.12 & 3.60 & 0.18 & 5.96 & 0.60 & 0.15 & 4.99 & 0.72 & C \\
\hline 2 & 14 & 4.97 & 0.80 & 3.50 & 6.29 & 11.45 & 0.079 & 7.30 & 154.80 & 0.12 & 4.40 & 0.16 & 6.00 & 0.73 & 0.14 & 5.21 & 0.84 & C \\
\hline 2 & 17 & 4.97 & 0.80 & 3.50 & 6.25 & 11.52 & 0.091 & 7.30 & 154.80 & 0.12 & 6.40 & 0.19 & 6.74 & 0.95 & 0.15 & 5.46 & 1.17 & C \\
\hline 2 & 18 & 4.49 & 0.83 & 3.50 & 6.25 & 11.52 & 0.091 & 7.30 & 154.80 & 0.12 & 5.10 & 0.20 & 6.69 & 0.76 & 0.16 & 5.23 & 0.97 & C \\
\hline 3 & 1 & 5.60 & 0.77 & 5.00 & 11.25 & 10.67 & 0.392 & 3.80 & 105.00 & 0.10 & 16.14 & 0.20 & 35.62 & 0.45 & 0.14 & 25.05 & 0.64 & \\
\hline 3 & 2 & 5.90 & 0.76 & 5.00 & 11.25 & 10.67 & 0.392 & 3.80 & 105.00 & 0.10 & 14.70 & 0.19 & 35.77 & "0.41 & 0.13 & 25.54 & 0.58 & \\
\hline 3 & 3 & 5.80 & 0.76 & 5.00 & 11.25 & 10.67 & 0.588 & 3.80 & 105.00 & 0.10 & 20.48 & 0.29 & 51.44 & 0.40 & 0.16 & 30.24 & 0.68 & \\
\hline 3 & 4 & 5.60 & 0.77 & 5.00 & 11.25 & 10.67 & 0.588 & 3.80 & 105.00 & 0.10 & 19.60 & 0.30 & 51.21 & 0.38 & 0.16 & 29.83 & 0.66 & \\
\hline 3 & 5 & 5.40 & 0.78 & 5.00 & 11.25 & 10.67 & 0.784 & 3.80 & 105.00 & 0.10 & 22.93 & 0.41 & 64.87 & 0.35 & 0.19 & 33.16 & 0.69 & \\
\hline 3 & 6 & 5.10 & 0.80 & 5.00 & 11.25 & 10.67 & 0.784 & 3.80 & 105.00 & 0.10 & 22.58 & 0.42 & 64.15 & 0.35 & 0.19 & 32.37 & 0.70 & \\
\hline 3 & 7 & 4.70 & 0.82 & 5.00 & 10.85 & 11.06 & 0.980 & 3.80 & 105.00 & 0.10 & 32.03 & 0.58 & 70.95 & 0.45 & 0.22 & 32.23 & 0.99 & \\
\hline 3 & 8 & 4.30 & 0.84 & 5.00 & 10.85 & 11.06 & 0.980 & 3.80 & 105.00 & 0.10 & 28.70 & 0.62 & 68.90 & 0.42 & 0.23 & 30.91 & 0.93 & \\
\hline 3 & 9 & 4.30 & 0.84 & 5.00 & 10.75 & 11.16 & 1.176 & 3.80 & 105.00 & 0.10 & 34.83 & 0.75 & 75.85 & 0.46 & 0.25 & 32.66 & 1.07 & \\
\hline 3 & 10 & 5.10 & 0.80 & 5.00 & 10.75 & 11.16 & 1.176 & 3.80 & 105.00 & 0.10 & 33.95 & 0.67 & 81.31 & 0.42 & 0.24 & 35.39 & 0.96 & \\
\hline 3 & 11 & 5.70 & 0.77 & 5.00 & 10.80 & 11.11 & 1.372 & 3.80 & 105.00 & 0.10 & 37.10 & 0.72 & 93.96 & 0.39 & 0.24 & 39.73 & 0.93 & \\
\hline 3 & 12 & 4.40 & 0.83 & 5.00 & 10.80 & 11.11 & 1.372 & 3.80 & 105.00 & 0.10 & 34.39 & 0.86 & 83.41 & 0.41 & 0.26 & 35.27 & 0.97 & \\
\hline 4 & AK-0.28-300 & 4.27 & 0.84 & 7.87 & 9.65 & 9.79 & 0.213 & 9.40 & 193.64 & 0.13 & 38.71 & 0.18 & 30.64 & 1.26 & 0.15 & 25.87 & 1.50 & CR \\
\hline 4 & AK-0.28-780 & 11.00 & 0.65 & 7.87 & 9.65 & 9.79 & 0.213 & 9.40 & 193.64 & 0.13 & 41.31 & 0.09 & 32.15 & 1.28 & 0.11 & 38.56 & 1.07 & $\mathrm{~T}$ \\
\hline 4 & AK-0.81-300 & 4.27 & 0.84 & 7.87 & 9.65 & 9.79 & 0.615 & 9.40 & 193.64 & 0.13 & 45.54 & 0.52 & 75.09 & 0.61 & 0.24 & 39.92 & 1.14 & C \\
\hline 4 & AK-1.82-300 & 4.27 & 0.84 & 7.87 & 9.65 & 9.79 & 1.382 & 9.40 & 193.64 & 0.13 & 57.25 & 1.16 & 110.74 & 0.52 & 0.34 & 53.44 & 1.07 & C \\
\hline 4 & AK-3.23-300 & 4.27 & 0.84 & 7.87 & 9.65 & 9.79 & 2.453 & 9.40 & 193.64 & 0.13 & 74.82 & 2.06 & 52.86 & 1.42 & 0.42 & 63.94 & 1.17 & C \\
\hline 4 & AK-0.81-780 & 11.00 & 0.65 & 7.87 & 9.65 & 9.79 & 0.615 & 9.40 & 193.64 & 0.13 & 60.83 & 0.26 & 87.76 & 0.69 & 0.18 & 61.58 & 0.99 & CR \\
\hline 4 & CK-0.81-300 & 4.27 & 0.84 & 7.87 & 9.65 & 9.79 & 0.615 & 14.14 & 155.20 & 0.21 & 53.68 & 0.41 & 63.48 & 0.85 & 0.28 & 46.48 & 1.15 & CR \\
\hline 4 & CK-0.81-780 & 11.00 & 0.65 & 7.87 & 9.65 & 9.79 & 0.615 & 14.14 & 155.20 & 0.21 & 63.76 & 0.21 & 71.61 & 0.89 & 0.21 & 73.00 & 0.87 & $\mathrm{~T}$ \\
\hline
\end{tabular}


Table A.1 Theoretical Comparison of Moment Capacities and Failure Modes (Contd.)

\begin{tabular}{|c|c|c|c|c|c|c|c|c|c|c|c|c|c|c|c|c|c|c|}
\hline Refe- & Beam & $f_{c}{ }^{\prime}$ & $B_{1}$ & b & d & I/d & $A_{f}$ & $E_{f}$ & $f_{f}$ & $(c / d)_{\text {bal }}$ & Moment & Tension & Failure C & Calc. & Comp. & Failure C & Calc. & Actual \\
\hline rence & & & & & & & & & & & (expt.) & c/d & $\mathbf{M}_{\text {th }}$ & $\underline{M}_{\text {expt }}$ & c/d & $\mathbf{M}_{\text {th }}$ & $\underline{M}_{\text {expt }}$ & Failure \\
\hline & & & & & & & & $\left(x 10^{6}\right.$ & & & & & & $M_{\text {th }}$ & & & $\mathbf{M}_{\text {th }}$ & \\
\hline & & (ksi) & & (in) & (in) & & $\left(\mathrm{in}^{2}\right)$ & psi) & (ksi) & & (k-ft) & & (k-ft) & & & (k-ft) & & \\
\hline 4 & CR-1.26-780 & 11.00 & 0.65 & 7.87 & 9.65 & 9.79 & 0.957 & 14.14 & 155.20 & 0.21 & 98.89 & 0.32 & 106.94 & 0.92 & 0.26 & 87.05 & 1.14 & Shear \\
\hline 4 & GR-1.26-780 & 11.00 & 0.65 & 7.87 & 9.65 & 9.79 & 0.957 & 4.33 & 78.30 & 0.14 & 58.23 & 0.16 & 57.07 & 1.02 & 0.15 & 53.34 & 1.09 & CR \\
\hline 5 & group 2 & 4.54 & 0.82 & 7.87 & 6.20 & 17.14 & 1.758 & 5.17 & 101.62 & 0.13 & 25.35 & 1.15 & 48.52 & 0.52 & 0.34 & 23.45 & 1.08 & \\
\hline 5 & group 3 & 4.54 & 0.82 & 7.87 & 8.30 & 12.81 & 0.786 & 6.29 & 128.60 & 0.13 & 35.95 & 0.49 & 55.88 & 0.64 & 0.23 & 30.35 & 1.18 & \\
\hline 6 & comp-00 & 5.13 & 0.79 & 7.87 & 7.50 & 13.12 & 0.786 & 6.29 & 128.44 & 0.13 & 30.31 & 0.49 & 50.71 & 0.60 & 0.24 & 27.26 & 1.11 & C \\
\hline 6 & comp-25 & 5.13 & 0.79 & 7.87 & 7.50 & 13.12 & 0.786 & 6.29 & 128.44 & 0.13 & 28.62 & 0.49 & 50.71 & 0.56 & 0.24 & 27.26 & 1.05 & $C$ \\
\hline 6 & comp-50 & 5.29 & 0.79 & 7.87 & 7.50 & 13.12 & 0.786 & 6.29 & 128.44 & 0.13 & 28.83 & 0.48 & 51.08 & 0.56 & 0.23 & 27.63 & 1.04 & C \\
\hline 6 & comp-75 & 5.29 & 0.79 & 7.87 & 7.50 & 13.12 & 0.786 & 6.29 & \begin{tabular}{|l|}
128.44 \\
\end{tabular} & 0.13 & 36.03 & 0.48 & 51.08 & 0.71 & 0.23 & 27.63 & 1.30 & $C$ \\
\hline 7 & GB1 & 4.35 & 0.83 & 6.00 & 8.66 & 10.45 & 0.662 & 6.53 & 145.14 & 0.12 & 27.56 & 0.60 & 52.01 & 0.53 & 0.25 & 25.59 & 1.08 & C \\
\hline 7 & GB5 & 4.53 & 0.82 & 6.00 & 8.66 & 10.45 & 0.662 & 6.53 & 145.14 & 0.12 & 29.72 & 0.58 & 52.70 & 0.56 & 0.24 & 26.10 & 1.14 & C \\
\hline 7 & GB9 & 5.78 & 0.76 & 6.00 & 8.66 & 10.45 & 0.662 & 6.53 & \begin{tabular}{|l|l|}
145.14 \\
\end{tabular} & 0.12 & 29.29 & 0.49 & 56.29 & 0.52 & 0.23 & 29.09 & (1.01 & $C$ \\
\hline 7 & GB10 & 5.78 & 0.76 & 6.00 & 8.66 & 10.45 & 0.662 & 6.53 & \begin{tabular}{|l|l|}
145.14 \\
\end{tabular} & 0.12 & 29.13 & 0.49 & 56.29 & 0.52 & 0.23 & 29.09 & 1.00 & C \\
\hline 8 & D-1 & 5.08 & 0.80 & 4.00 & 4.50 & 14.67 & 0.221 & 6.00 & 80.00 & 0.18 & 4.86 & 0.29 & 5.88 & 0.83 & 0.22 & 4.72 & 1.03 & C \\
\hline 8 & D-2 & 5.08 & 0.80 & 4.00 & 4.00 & 16.50 & 0.221 & 6.00 & 80.00 & 0.18 & 4.33 & 0.32 & 5.14 & 0.84 & 0.24 & 3.91 & 1.11 & $C$ \\
\hline 9 & 1 & 5.20 & 0.79 & 6.00 & 4.81 & 5.39 & 0.110 & 6.50 & 130.00 & 0.13 & 5.19 & 0.14 & 5.43 & 0.96 & 0.14 & 5.20 & 1.00 & C \\
\hline 9 & 2 & 5.20 & 0.79 & 6.00 & 4.81 & 5.39 & 0.110 & 6.50 & 130.00 & 0.13 & 4.90 & 0.14 & 5.43 & 0.90 & 0.14 & 5.20 & 0.94 & C \\
\hline 9 & 4 & 5.20 & 0.79 & 6.00 & 4.81 & 5.39 & 0.110 & 6.50 & 130.00 & 0.13 & 5.33 & 0.14 & 5.43 & 0.98 & 0.14 & 5.20 & 1.03 & C \\
\hline 9 & 5 & 5.20 & 0.79 & 6.00 & 4.81 & 5.39 & 0.110 & 6.50 & 130.00 & 0.13 & 5.42 & 0.14 & 5.43 & 1.00 & 0.14 & 5.20 & 1.04 & C \\
\hline 9 & 6 & 5.20 & 0.79 & 6.00 & 4.81 & 5.39 & 0.110 & 6.50 & 130.00 & 0.13 & 4.98 & 0.14 & 5.43 & 0.92 & 0.14 & 5.20 & 0.96 & C \\
\hline 10 & BC2NA & 7.70 & 0.67 & 5.12 & 6.51 & 9.07 & 0.368 & 5.52 & 112.62 & 0.13 & 16.14 & 0.29 & 20.34 & 0.79 & 0.19 & 13.65 & 1.18 & $S$ \\
\hline 10 & BC2NB & 7.70 & 0.67 & 5.12 & 6.51 & 9.07 & 0.368 & 5.52 & 112.62 & 0.13 & 14.74 & 0.29 & 20.34 & 0.72 & 0.19 & 13.65 & 1.08 & C \\
\hline
\end{tabular}


Table A.1 Theoretical Comparison of Moment Capacities and Failure Modes (Contd.)

\begin{tabular}{|c|c|c|c|c|c|c|c|c|c|c|c|c|c|c|c|c|c|c|}
\hline \multirow{2}{*}{\begin{tabular}{|l|} 
Refe- \\
rence \\
\end{tabular}} & \multirow[t]{2}{*}{ Beam } & \multirow[t]{2}{*}{$f_{c}{ }^{\prime}$} & \multirow[t]{2}{*}{$B_{1}$} & \multirow[t]{2}{*}{ b } & \multirow[t]{2}{*}{ d } & \multirow[t]{2}{*}{ I/d } & \multirow[t]{2}{*}{$A_{f}$} & \multirow[t]{2}{*}{$E_{f}$} & \multirow[t]{2}{*}{$\mathbf{f}_{f}$} & \multirow[t]{2}{*}{$(c / d)_{\text {bal }}$} & \multirow{2}{*}{\begin{tabular}{|l|} 
Moment \\
(expt.) \\
\end{tabular}} & \multicolumn{3}{|c|}{ Tension Failure Calc. } & \multicolumn{3}{|c|}{ Comp. Failure Calc. } & \multirow{2}{*}{\begin{tabular}{|l|} 
Actual \\
Failure \\
\end{tabular}} \\
\hline & & & & & & & & & & & & c/d & $\mathbf{M}_{\text {th }}$ & $\underline{M}_{\text {expt }}$ & c/d & $\mathbf{M}_{\text {th }}$ & $M_{\text {expt }}$ & \\
\hline & & & & & & & & $\left(x 10^{6}\right.$ & & & & & & $M_{\text {th }}$ & & & $M_{\text {th }}$ & \\
\hline & & (ksi) & & (in) & (in) & & $\left(\mathrm{in}^{2}\right)$ & psi) & (ksi) & & (k-ft) & & (k-ft) & & & (k-ft) & & \\
\hline 10 & $\mathrm{BC} 2 \mathrm{HA}$ & 8.29 & 0.65 & 5.12 & 6.51 & 9.07 & 0.368 & 5.52 & 112.62 & 0.13 & 14.52 & 0.27 & 20.50 & 0.71 & 0.18 & 14.08 & 1.03 & C \\
\hline 10 & $\mathrm{BC} 2 \mathrm{HB}$ & 8.29 & 0.65 & 5.12 & 6.51 & 9.07 & 0.368 & 5.52 & 112.62 & 0.13 & 15.18 & 0.27 & 20.50 & 0.74 & 0.18 & 14.08 & 1.08 & C \\
\hline 10 & BC2VA & 14.12 & 0.65 & 5.12 & 6.51 & 9.07 & 0.368 & 5.52 & 112.62 & 0.13 & 16.73 & 0.16 & 21.31 & 0.78 & 0.14 & 19.06 & 0.88 & C \\
\hline 10 & BC2VB & 14.12 & 0.65 & 5.12 & 6.51 & 9.07 & 0.368 & 5.52 & 112.62 & 0.13 & 17.32 & 0.16 & 21.31 & 0.81 & 0.14 & 19.06 & 0.91 & $S$ \\
\hline 10 & BC4NA & 6.70 & 0.72 & 5.12 & 5.32 & 11.10 & 0.736 & 5.52 & 112.62 & 0.13 & 16.50 & 0.75 & 26.93 & 0.61 & 0.28 & 12.42 & 1.33 & $S$ \\
\hline 10 & BC4NB & 6.70 & 0.72 & 5.12 & 5.32 & 11.10 & 0.736 & 5.52 & 112.62 & 0.13 & 15.18 & 0.75 & 26.93 & "0.56 & 0.28 & 12.42 & 1.22 & $C$ \\
\hline 10 & BC4HA & 7.81 & 0.66 & 5.12 & 5.32 & 11.10 & 0.736 & 5.52 & 112.62 & 0.13 & 15.74 & 0.70 & 28.33 & 0.56 & 0.27 & 13.11 & 1.20 & $C$ \\
\hline 10 & BC4HB & 7.81 & 0.66 & 5.12 & 5.32 & 11.10 & 0.736 & 5.52 & 112.62 & 0.13 & 15.77 & 0.70 & 28.33 & 0.56 & 0.27 & 13.11 & 1.20 & $C$ \\
\hline 10 & BC4VA & 13.56 & 0.65 & 5.12 & 5.32 & 11.10 & 0.736 & 5.52 & 112.62 & 0.13 & 20.93 & 0.41 & 31.90 & 0.66 & 0.22 & 18.18 & 1.15 & C \\
\hline 10 & BC4VB & 13.56 & 0.65 & 5.12 & 5.32 & 11.10 & 0.736 & 5.52 & 112.62 & 0.13 & 21.74 & 0.41 & 31.90 & 0.68 & 0.22 & 18.18 & 1.20 & $C$ \\
\hline 11 & Series-1 & 7.55 & 0.67 & 7.87 & 10.33 & & 0.455 & 5.47 & 112.62 & 0.13 & 43.41 & 0.15 & 41.97 & 1.03 & 0.14 & 39.11 & 1.11 & C \\
\hline 11 & Series-2 & 7.55 & 0.67 & 7.87 & 10.33 & & 0.740 & 5.47 & 112.62 & 0.13 & 48.13 & 0.24 & 66.00 & 0.73 & 0.17 & 48.29 & 1.00 & $C$ \\
\hline 11 & Series-3 & 6.53 & 0.72 & 7.87 & 9.45 & & 1.122 & 5.47 & 112.62 & 0.13 & 54.17 & 0.42 & 84.27 & 0.64 & 0.22 & 47.51 & 1.14 & C \\
\hline 11 & Series-4 & 6.53 & 0.72 & 7.87 & 9.45 & & 1.748 & 5.47 & 112.62 & 0.13 & 62.72 & 0.66 & 118.06 & 0.53 & 0.27 & 56.47 & 1.11 & C \\
\hline 12 & T1 & 6.50 & 0.73 & 6.00 & 10.75 & 10.05 & 0.393 & 5.50 & 85.00 & 0.16 & 27.57 & 0.13 & 28.51 & 0.97 & 0.15 & 32.08 & 0.86 & $\mathrm{~T}$ \\
\hline 12 & $\mathrm{C} 2$ & 6.50 & 0.73 & 6.00 & 10.63 & 10.16 & 0.884 & 5.50 & 85.00 & 0.16 & 40.35 & 0.29 & 59.43 & 0.68 & 0.21 & 44.27 & 0.91 & C \\
\hline 12 & T3 & 6.50 & 0.73 & 6.00 & 10.75 & 10.05 & 0.393 & 5.50 & 85.00 & 0.16 & 24.57 & 0.13 & 28.51 & 0.86 & 0.15 & 32.08 & 0.77 & $\mathrm{~T}$ \\
\hline 12 & C4 & 6.50 & 0.73 & 6.00 & 10.38 & 10.41 & 0.884 & 5.50 & 85.00 & 0.16 & 35.64 & 0.30 & 57.86 & 0.62 & 0.21 & 42.62 & 0.84 & $C$ \\
\hline 12 & M1 & 4.50 & 0.83 & 6.00 & 10.69 & 10.10 & 0.614 & 5.50 & 81.00 & 0.17 & 36.74 & 0.25 & 39.80 & 0.92 & 0.20 & 33.10 & 1.11 & C \\
\hline 12 & M2 & 4.50 & 0.83 & 6.00 & 10.38 & 10.41 & 1.228 & 5.50 & 81.00 & 0.17 & 39.10 & 0.51 & 68.02 & 0.57 & 0.27 & 41.23 & 0.95 & C \\
\hline 13 & F-1-GF & 6.09 & 0.75 & 6.06 & 9.00 & 9.19 & 0.823 & 4.93 & 84.95 & 0.15 & 36.90 & 0.33 & 45.96 & 0.80 & 0.21 & 30.99 & 1.19 & $\mathrm{C}$ \\
\hline 14 & - & 4.35 & 0.83 & 19.68 & 5.71 & 23.45 & 1.375 & 6.09 & 128.44 & 0.12 & 42.40 & 0.51 & 66.15 & 0.64 & 0.24 & 34.96 & 1.21 & $C$ \\
\hline
\end{tabular}




\section{A.4 REFERENCES USED IN TABLE A.1}

1. Faza, S.S. (1991), Bending and Bond Behavior and Design of Concrete Beams Reinforced with Fiber Reinforced Plastic Rebars, Dissertation, WVU.

2. Nawy, E.W., Neuwerth, A.M. and Philips, C.J. (1971), Behavior of Fiber Glass Reinforced Concrete Beams, Journal of the Structural Division, ASCE, pp.2203-2215, September.

3. Nawy, E.W. and Neuwerth, A.M. (1977), Fiber Glass Reinforced Concrete Beams and Slabs, Journal of the Structural Division, ASCE, pp.421-440, February.

4. Sonobe, Y., Fukuyama, H., Okamoto, T., Kani, N., Kimura, K., Kobayashi, K., Masuda, Y., Matsuzki, Y., Mochizuki, S., Nagasaka, T., Shimizu, A., Tanano, H., Tanigaki, M,. and Teshigawaka, M. (1997), Design Guidelines of FRP Reinforced Concrete Building Structures, Journal of Composites for Construction, Aug., Vol.1 No.2, pp.90-115, August.

5. Yousef A. Al-Salloum, Saleh H Sayed, Tarek H. Almusallam (1996), Some Design Considerations For Concrete Beams Reinforced By GFRP Bars, First International Conference on Composite Infrastructure, ICCI-96, pp-318-331.

6. Yousef A. Al-Salloum, Saleh H Sayed and Tarek H. Almusallam (1997), Behaviour Of Concrete Beams Doubly Reinforced By GFRP Bars, Non-Metallic (FRP) Reinforcement for Concrete Structures, Proceedings of the Third International Symposium, Vol.2., pp. 471-478, October.

7. Zhao, W., Pilakoutas, K. and Waldron, P. (1997), FRP Reinforced Concrete: Cracking Behavior and Determination, Non-Metallic (FRP) Reinforcement for Concrete Structures, Proceedings of the Third International Symposium, Vol.2., pp. 439-446, October. 
8. Vicki Brown (1996), Long-term Deflections, First International Conference on Composite Infrastructure, ICCI-96, pp.389-400.

9. Vicki Brown, Charles B, ACI material Journal (1993), FRP Reinforcing Bars in Reinforced Concrete Members, pp.34-39, Jan-Feb.

10. Theriault, M. and Benmokrane (1998), Effects of FRP reinforcement Ration and Concrete Strength on Flexural Behavior of Concrete Beams, Journal of Composites for Construction, pp. 7-16, February.

11. Benmokrane and Masmoudi (1996), FRP C-bar as Reinforcing Rod for Concrete Structures, ACMBS-II, Canada, pp181-188, August.

12. Vijay, P.V. and GangaRao, H.V.S. (1996), Unified Limit State Approach Using Deformability Factors in Concrete Beams Reinforced with GFRP Bar, ASCE Structural Congress Proceedings, November.

13. Swamy, N., and Aburawi, M. (1997), Structural Implications of Using GFRP Bars as Concrete Reinforcement, Non-Metallic (FRP) Reinforcement for Concrete Structures, Proceedings of the Third International Symposium, Vol.2., pp. 503-510, October.

14. Cosenza, E., Greco, C., Gaetano, M., and Pecce, M. (1997), Flexural Behavior of Concrete Beams Reinforced with Fiber Reinforced Plastic (FRP) Bars, Non-Metallic (FRP) Reinforcement for Concrete Structures, Proceedings of the Third International Symposium, Vol.2., pp. 463-470, October. 